\title{
La mémoire du roman
}

Sous la direction de Isabelle Daunais

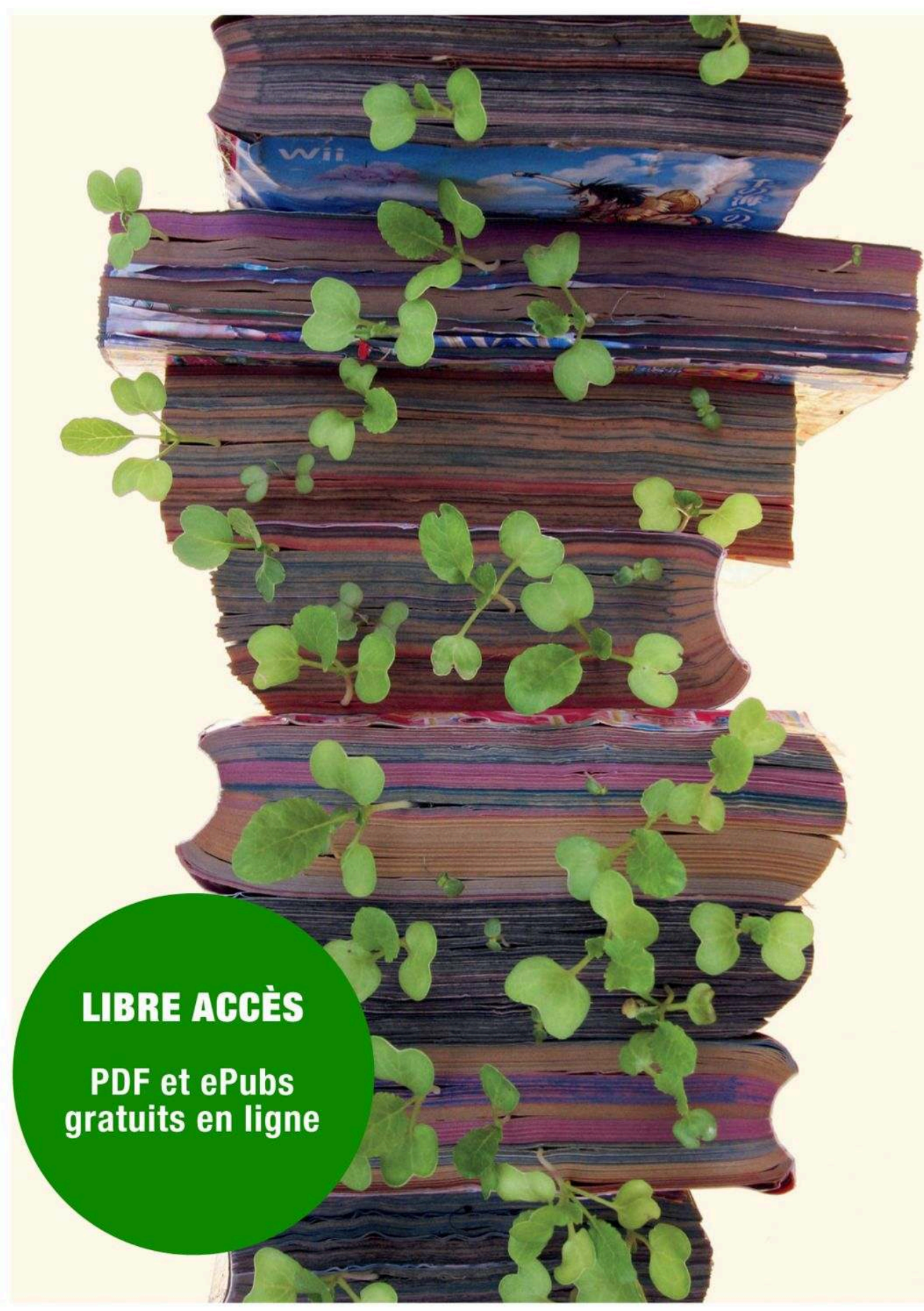

Les Presses de l'Université de Montréal 


\section{La mémoire du roman}

Isabelle Daunais (dir.)

DOI : 10.4000/books.pum.4596

Éditeur : Presses de l'Université de Montréal

Lieu d'édition : Montréal

Année d'édition : 2013

Date de mise en ligne : 23 janvier 2018

Collection : Espace littéraire

EAN électronique : 9782821897700

\section{OpenEdition}

\section{Books}

https://books.openedition.org

\section{Édition imprimée}

EAN (Édition imprimée) : 9782760632547

Nombre de pages : 194

\section{Référence électronique}

DAUNAIS, Isabelle (dir.). La mémoire du roman. Nouvelle édition [en ligne]. Montréal : Presses de I'Université de Montréal, 2013 (généré le 29 janvier 2022). Disponible sur Internet : <http:// books.openedition.org/pum/4596>. ISBN : 9782821897700 . DOI : https://doi.org/10.4000/books.pum. 4596

(C) Presses de l'Université de Montréal, 2013 Conditions d'utilisation :

http://www.openedition.org/6540 


\section{RÉSUMÉS}

Alors que la poésie, le théâtre, la musique ou la peinture se transmettent au premier chef par la continuité de leurs formes, le roman n'a aucune continuité formelle, sinon celle d'être une œuvre en prose d'une certaine longueur, mettant en scène des personnages fictifs.

Par quels repères et quels relais, dès lors, le roman construit-il sa propre histoire ? Ce recueil pose la question de la mémoire non pas diffuse mais précise que l'on garde des romans et des mécanismes qui la sous-tendent : quelles scènes, quelles images, quels personnages, quels « résumés " les lecteurs, mais aussi les romanciers eux-mêmes dans leurs propres œuvres, conservent-ils ou sont-ils amenés à conserver des romans qu'ils ont lus?

Par des exemples qui vont du Moyen-Âge à l'époque contemporaine, c'est à ces questions que répondent les auteurs réunis autour de l'équipe du TSAR (Travaux de recherche sur les arts du roman), qui envisage le roman non pas comme un genre littéraire parmi d'autres mais comme une forme singulière de pensée et d'imagination. 


\section{La mémoire du roman}

Sous la direction de Isabelle Daunais

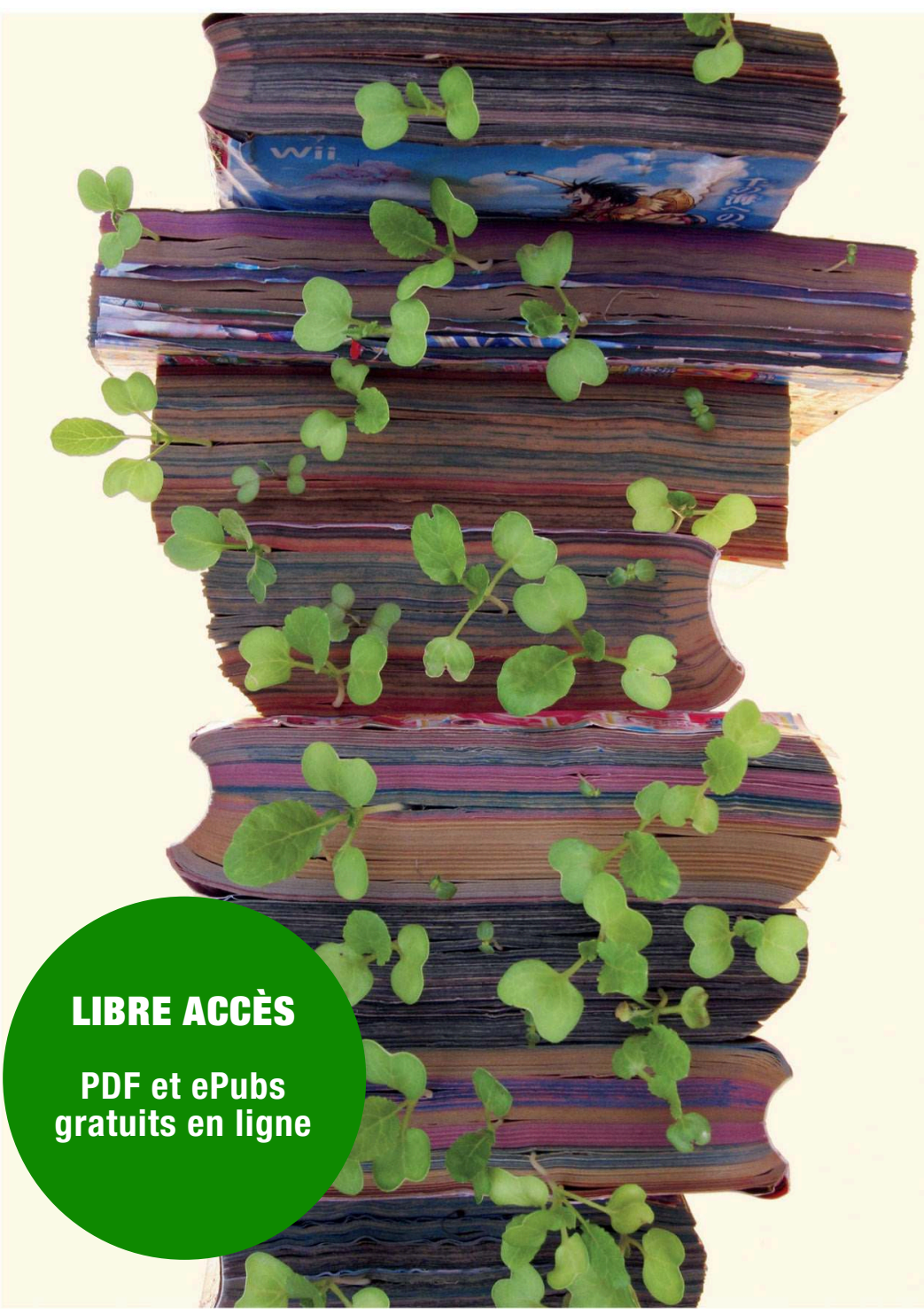

Les Presses de l'Université de Montréal 

LA MÉMOIRE DU ROMAN 
$\left(\begin{array}{l}\text { espace } \\ \text { littéraire }\end{array}\right)$ 


\section{LA MÉMOIRE DU ROMAN}

Sous la direction de

Isabelle Daunais 
Catalogage avant publication de Bibliothèque et Archives nationales du Québec et Bibliothèque et Archives Canada

Vedette principale au titre:

La mémoire du roman

(Espace littéraire)

Textes présentés lors d'un colloque tenu à l'Université McGill les 22 et 23 mars 2012.

Comprend des références bibliographiques.

ISBN $978-2-7606-3253-0$

I. Mémoire dans la littérature - Congrès.

2. Roman - Histoire et critique - Congrès.

I. Daunais, Isabelle, I963- . II. Collection : Espace littéraire.

PN56.M44M452 $2013 \quad$ 809'.93353 C2OI3-940983-I

Dépôt légal: $3^{\mathrm{e}}$ trimestre 2013

Bibliothèque et Archives nationales du Québec

(C) Les Presses de l'Université de Montréal, 2013

ISBN (papier) 978-2-7606-3253-0

ISBN (pdf) 978-2-7606-3254-7

ISBN (epub) 978-2-7606-3255-4

Les Presses de l'Université de Montréal reconnaissent l'aide financière du gouvernement du Canada par l'entremise du Fonds du livre du Canada pour leurs activités d'édition.

Les Presses de l'Université de Montréal remercient de leur soutien financier le Conseil des Arts du Canada et la Société de développement des entreprises culturelles du Québec (SODEC). 


\section{Présentation}

Loin de simplement constituer un genre littéraire parmi d'autres, le roman s'offre depuis ses débuts à notre culture comme une forme singulière de pensée et d'imagination. L'un des éléments centraux de cette pensée issue du roman est la mémoire, que l'équipe de recherche TSAR (Travaux sur les arts du roman) propose ici d'explorer.

L'idée de mémoire du roman peut s'entendre de deux façons, selon qu'on s'intéresse aux personnages et aux récits issus de sa propre imagination à ce qu'il a conservé de l'expérience humaine, dont il est devenu au fil du temps le dépositaire irremplaçable. Ces deux grands axes se déploient en questions multiples, à commencer par celles qui portent sur le contenu de cette mémoire. Au-delà de tous les détails documentaires qu'on peut y puiser et qui servent le savoir historique, de quelle conscience générale le roman est-il le gardien? Quelles questions, quelles découvertes et quelles expériences poursuit-il d'une œuvre à l'autre et qui sans lui risqueraient de se perdre ou de ne plus être comprises de la même façon?

Mais l'enquête peut aussi porter sur le roman comme forme de mémoire et donc sur la façon dont il se transmet. Alors que les autres arts - poésie, théâtre, musique, peinture - se transmettent au premier chef par la continuité de leurs formes, le roman n'a aucune continuité formelle, sinon celle d'être une œuvre en prose d'une certaine longueur, mettant en scène des personnages fictifs. Si ce n'est par sa forme, par quels repères et quels relais le roman construit-il sa propre histoire?

Une autre manière d'aborder la question est de savoir comment nous nous souvenons des romans, dont on ne peut jamais garder qu'une mémoire partielle, même s'il arrive qu'un roman lu une seule fois puisse 
laisser en nous un souvenir qui ne s'effacera pas. De quoi alors nous souvenons-nous? Qu'est-ce qui, dans un roman, résiste à l'oubli et à l'impossibilité de le connaître par cœur?

C'est à ces questions que les textes réunis ici tentent de répondre, à travers des exemples qui vont du Moyen Âge jusqu'à l'époque contemporaine. Ils abordent, dans un premier temps, ce qu'on peut appeler les origines de la mémoire romanesque, c'est-à-dire les conditions qui ont présidé aux commencements de cette mémoire. Ils explorent ensuite la valeur mémorielle des œuvres romanesques, d'abord à partir de ce qui conduit ces œuvres à nous guider et à nous instruire, mais aussi à partir de ce qu'elles lèguent comme souvenirs une fois le livre refermé. Enfin, ils s'intéressent à la mémoire précise que l'on garde des romans et des mécanismes qui la sous-tendent: quelles scènes, quelles images, quels personnages, quels résumés sommes-nous amenés à conserver des romans que nous avons lus?

Ce livre, comme le colloque qui en a été l'origine, ont été rendus possibles grâce à l'aide de plusieurs collaborateurs, que nous remercions vivement: Mathieu Bélisle, Michel Biron, François Ricard, de même que Sonia Théberge-Cockerton et Catherine Côté-Ostiguy, assistantes de recherche au sein de l'équipe TSAR. Nous remercions également, pour leur soutien financier, la Chaire de recherche du Canada sur l'esthétique et l'art du roman, le Fonds de recherche Québec - société et culture, le Conseil de recherches en sciences humaines du Canada, la Chaire James McGill de littérature québécoise et roman moderne ainsi que le Département de langue et littérature françaises de l'Université McGill. 
Aux commencements de la mémoire 



\title{
La mémoire singulière du roman
}

\author{
IsABelle Daunais
}

Si, comme le propose Milan Kundera dans Le Rideau, «l'histoire d'un art», contrairement à l'Histoire tout court, «ne supporte pas les répétitions ${ }^{1}$ ", cette incompatibilité atteint peut-être son point maximal avec l'art du roman. Car pour bien des arts, la répétition n'est pas nécessairement une faiblesse et constitue même un principe central de transmission, si ce n'est d'existence: la poésie a répété pendant des siècles ses formes et ses figures; l'épopée, le théâtre et les contes ont reconduit à travers les temps leurs mythes, leurs récits et leurs héros. Le roman, à l'inverse, est un art de la singularité; il n'a pas de formes fixes et ses personnages ne vivent qu'une fois: Andromaque, Antigone, le Petit Poucet peuvent se réincarner sans cesse, ou plus exactement leur histoire peut se rejouer à l'infini sans jamais s'épuiser, mais Lucien de Rubempré, Anna Karénine, les frères Karamazov ne reviennent pas et ne peuvent pas revenir; pour explorer plus avant la vie d'un provincial montant à Paris, d'une femme malheureuse ou de frères ennemis, le roman crée de nouveaux personnages et imagine de nouvelles situations, mais il ne revient pas sur ce qu'il a déjà créé.

On pourrait minimiser cette différence sinon l'annuler en arguant que, dans tous les cas, c'est le principe plus surplombant de la variation qui agit, et qu'il est secondaire que cette variation porte, dans la poésie, sur des motifs et des figures; au théâtre et dans les contes, sur un même personnage; dans le roman, sur des types (Rastignac, Lucien de

I. Milan Kundera, Le Rideau, dans Euvre, t. II, Paris, Gallimard, coll. «Bibliothèque de la Pléiade», 20II, p. 963. 
Rubempré et Frédéric Moreau sont autant de déclinaisons du même jeune homme conquérant Paris) ou des situations (Emma Bovary confondant comme Don Quichotte la littérature et la vraie vie). Mais on peut aussi proposer que cette distinction - c'est-à-dire l'irréductible singularité du roman - n'est pas secondaire et qu'elle est même fondamentale. Car en ne répétant ni telle ou telle forme ni surtout ses personnages, le roman déploie un principe en quelque sorte supérieur à la variation (qui ne serait, dans l'esthétique générale du roman, qu'un principe «intermédiaire») : celui de la transformation. Si le roman ne se répète pas, s'il se donne la peine, après tout épuisante, de chercher à intervalles réguliers de nouvelles formes et à chaque fois de nouveaux personnages, c'est parce que, contrairement aux contes et aux légendes, et même à la poésie, sa tâche est de dire ce qu'il y a de nouveau dans le monde, ce qui avant n'existait pas et qui maintenant existe, ou inversement, ce qui avant existait et maintenant n'existe plus. La liberté même du roman, l'absence de contraintes qui le caractérise lui viennent précisément de cette tâche qui le distingue: autant le conte, la poésie et le théâtre ont pour fonction de nous raconter ou d'exprimer ce qui, dans l'aventure humaine, est permanent ou inéluctable, autant le roman a celle de montrer ce qui bouge et se transforme; ce qui, sans qu'on sache exactement à quel moment, a cessé d'être une certitude; ce qui se brouille ou se relativise; ce qui aurait pu se produire comme aussi bien ne pas se produire.

Mais alors une question se pose, qui est celle de sa transmission: s'il ne se répète pas, s'il est libre de renouveler ses formes autant qu'il le souhaite, si ses personnages, une fois qu'ils ont vécu, ne peuvent revenir et voir leur histoire se poursuivre, de quelle façon le roman persiste-t-il comme forme que l'on reconnaît? Par quels relais ou par quelle mémoire trace-t-il dans l'histoire des arts une ligne continue?

On peut répondre à cette question en proposant que le roman ne requiert précisément aucune mémoire, ni de technique ni de contenu, comme en témoigne le fait qu'il s'offre d'emblée, comme allant de soi, à quiconque veut raconter une histoire ou témoigner d'une "expérience». Par comparaison, la pratique plus «spécialisée» et moins courante de la poésie, du théâtre et du conte viendrait de ce qu'ils exigent beaucoup de mémoire, non tant parce qu'ils procèdent de formes conçues - ou conçues à l'origine - pour être dites ou récitées, 
mais parce qu'ils gardent de cette conception le fait de reposer sur des procédés - versification, motifs, figures, rhétorique - qu'il faut apprendre à maîtriser et à apprécier. Libre de toute obligation, le roman jouirait, par comparaison, d'une «immédiateté» qui libérerait le lecteur et le romancier de la nécessité de passer par la mémoire, de maîtriser une technique, de recourir à des références.

Cette perception du roman comme un genre qu'on peut pratiquer sans maîtrise particulière des formes n'est pas seulement celle qu'en ont les auteurs de romans populaires ou ceux, innombrables, pour qui l'écriture d'un roman est une forme de thérapie, de passe-temps ou de divertissement. Elle est aussi la perception qu'ont du roman tous ceux qui, à l'inverse de ces auteurs et contre eux, mais néanmoins à partir de la même prémisse, cherchent à introduire dans la forme romanesque ce qu'on peut appeler de la «difficulté» (formalisme, contraintes, travail du langage), c'est-à-dire à compenser son manque apparent d'héritage esthétique par le recours forcé et plus ou moins artificiel à ce que les avant-gardes appellent souvent un «travail du langage». Alors que le premier groupe d'écrivains ne se soucie pas d'écrire en fonction d'un héritage ou non (la forme romanesque leur paraît immédiatement accessible), pour le second groupe, c'est plutôt l'idée qu'il manque au roman un héritage qui leur fait rechercher dans un surcroît de forme une compensation ou une correction : là où les autres arts exigeraient une forme de distance ou de recul, la reconnaissance d'usages ou de codes particuliers (même pour les œuvres dites novatrices et en particulier pour ces œuvres), le roman aurait comme faiblesse ou comme défaut d'être saisissable par tous et à tout instant. Art apparemment sans mémoire ou sans besoin de mémoire, il serait pour cette raison un peu moins qu'un art, ou il n'en serait un qu'à la condition qu'on lui injecte ce que nous avons appris à reconnaître comme de l'art.

Mais une telle réponse, si elle s'accorde avec les apparences ou une sorte de logique intuitive, n'est peut-être pas la plus juste. Car on peut poser l'hypothèse exactement inverse: le roman, pour la raison même qu'il emprunte les formes les plus variées, que sa langue est celle de la prose de tous les jours et que ses sujets sont ceux de la réalité immédiate, exige, pour qu'on le reconnaisse comme forme, beaucoup plus de mémoire que les autres arts, qui se distinguent en quelque sorte d'euxmêmes, par effet de contraste. 
Une telle hypothèse, toutefois, ne vaut que si l'on précise que la mémoire par laquelle on reconnaît le roman n'est pas de la même nature que celle qui a permis à la poésie, à l'épopée, au théâtre, aux légendes et aux contes de traverser les siècles. Ces arts, en effet, reposent sur une mémoire dont ils sont le développement ou le mode de communication: c'est la rime et le rythme qui ont donné naissance à la poésie, ou qui ont contribué à la façonner, comme c'est la conscience intemporelle des grands archétypes de la psyché humaine qui ont assuré aux contes et aux légendes leur constance à travers les époques. Ces arts ne sont évidemment pas nés de la seule mnémotechnie, mais on peut penser qu'ils n'existeraient pas sans l'existence préalable des formes et des objets de la mémoire, qu'ils ont certes affinés et déployés, rendus plus efficaces ou plus frappants, mais qu'ils n'ont pas créés. Il en va autrement pour le roman, dont j'aimerais poser l'hypothèse qu'il ne se serait pas construit à partir des moyens de la mémoire, mais en dehors d'eux, si ce n'est contre eux - en étant long, varié, détaillé, rédigé en prose -, et que pour cette raison il a dû trouver en lui-même une nouvelle manière d'être mémorable. Mieux encore, je dirais que le roman a rendu possible une forme nouvelle de mémoire - plus diffuse, plus subtile et plus complexe que celle, donnée d'avance, à travers laquelle se sont développés contes, légendes et poésie -, une mémoire qui n'existe pas en dehors de lui, c'est-à-dire que nous ne pourrions pas avoir sans lui et qu'il est donc seul à nous faire saisir et expérimenter.

De quoi est faite cette mémoire qu'aurait créée le roman? Pour tenter de répondre à cette question, on peut revenir sur les célèbres "Journées de lecture» de Proust, dans lesquelles l'auteur de $A$ la recherche $d u$ temps perdu rappelle le chagrin qu'il avait enfant à finir un livre livre qu'on devine être essentiellement un roman:

Puis la dernière page était lue, le livre était fini. Il fallait arrêter la course éperdue des yeux et de la voix qui suivait sans bruit, s'arrêtant seulement pour reprendre haleine, dans un soupir profond. [...] Alors, quoi? Ce livre, ce n'était que cela? Ces êtres à qui on avait donné plus de son attention et de sa tendresse qu'aux gens de la vie, n'osant pas toujours avouer à quel point on les aimait [...]; ces gens pour qui on avait haleté et sangloté, on ne les verrait plus jamais, on ne saurait plus rien d'eux. Déjà, depuis quelques pages, l'auteur, dans le cruel «Épilogue», avait eu soin de les «espacer» [...]. L'emploi de chaque heure de leur vie nous avait été narré. Puis subitement: «Vingt ans après ces événements on pouvait rencontrer 
dans les rues de Fougères un vieillard encore droit, etc.» Et le mariage dont deux volumes avaient été employés à faire entrevoir la possibilité délicieuse, nous effrayant puis nous réjouissant de chaque obstacle dressé puis aplani, c'est par une phrase incidente d'un personnage secondaire que nous apprenions qu'il avait été célébré, nous ne savions pas au juste quand $[. . .]^{2}$.

Il s'agit d'un passage souvent cité, presque toujours comme exemple de l'attachement que l'on éprouve pour les personnages de roman. Mais on n'a peut-être pas suffisamment prêté attention à ce que Proust nous dit ici de la spécificité du personnage romanesque et, par là, du rôle capital joué par ce dernier non seulement dans la définition du roman, mais dans les raisons pour lesquelles nous lisons des romans. Ce personnage est celui dont "on ne saur[a] plus rien» lorsque le livre sera terminé, et c'est cette impossibilité de ne jamais en savoir plus qui rend cette fin à la fois si mélancolique et si frappante: "On aurait tant voulu que le livre continuât, et, si c'était impossible, avoir d'autres renseignements sur tous ces personnages, apprendre maintenant quelque chose de leur vie, employer la nôtre à des choses qui ne fussent pas tout à fait étrangères à l'amour qu'ils nous avaient inspiré et dont l'objet nous faisait tout à coup défaut $[\ldots]^{3}$.» Le sentiment décrit par Proust est commun, et Diderot l'avait déjà exprimé dans son Éloge de Richardson (I762):

Je me souviens encore de la première fois que les ouvrages de Richardson tombèrent entre mes mains : j'étais à la campagne. Combien cette lecture m’affecta délicieusement! À chaque instant, je voyais mon bonheur s'abréger d'une page. Bientôt j'éprouvai la même sensation qu'éprouveraient des hommes d'un commerce excellent qui auraient vécu ensemble pendant longtemps et qui seraient sur le point de se séparer. À la fin, il me sembla tout à coup que j'étais resté seul'.

En fait, ce sentiment est si commun - qui n'a jamais voulu que tel ou tel roman se poursuive? - que nous venons à oublier combien il relève d'une expérience singulière. Car à propos d'une personne réelle comme d'un personnage de légende, il est toujours possible d'avoir «d'autres renseignements»: des renseignements réels et cumulables,

2. Marcel Proust, «Journées de lecture», dans Pastiches et Mélanges, Paris, Gallimard, coll. «L'Imaginaire», I992 [I919], p. 250-252.

3. Marcel Proust, "Journées de lecture», p. 252.

4. Denis Diderot, Éloge de Richardson, dans Euvres esthétiques, Paris, Classiques Garnier, 1994, p. 3I. 
qu'ils soient véridiques ou non, vérifiables ou non, dans le cas d'une vraie personne; des renseignements de pure invention mais pour cette raison potentiellement infinis dans le cas des personnages de légende, dont le propre, incidemment, est de toujours venir à nous sous plusieurs versions, d'exister selon différents récits (en cela, ce n'est pas un hasard si le conte et peut-être plus encore le théâtre sont les arts par excellence de la reprise et de l'adaptation, les lieux les plus aptes à proposer, pour une même figure, des incarnations nouvelles).

Le roman, à l'inverse, a ceci de spécifique qu'il n'offre, des vies qu'il raconte, qu'une seule version. Nous ne pouvons rien ajouter à la vie d'Emma Bovary ni à celle de Don Quichotte, sauf à créer de fausses Emma et de faux chevaliers à la triste figure. Et le lecteur le sait bien lorsque, d'aventure, il s'amuse à lire la «reprise» des aventures d'Emma, l'«histoire» de sa fille Berthe ou la «suite» des Misérables. Ces jeux fictionnels peuvent le divertir, mais il ne lui vient pas à l'esprit de confondre les fausses Emma, les fausses Berthe et les faux Javert avec les vrais (au contraire, le fait que plusieurs s'offusquent ou sont déçus par de telles reprises dit bien la difficulté de raccorder ces différentes «incarnations»), alors qu'Antigone, Arlequin et le Petit Poucet peuvent exister autant de fois que possible, leurs différentes versions, loin de s'exclure, s'ajoutant les unes aux autres. Telle est la distinction des arts: le théâtre et les contes contiennent toujours la possibilité de la reprise et de la continuité, mais pas le roman: ce que Flaubert et Cervantès nous ont livré de leurs héros est tout ce que nous en saurons jamais, et c'est pourquoi, lorsque nous refermons les livres qui leur ont donné vie, nous nous trouvons, comme à la fin de chaque roman, sinon attristés du moins un peu étonnés, car nulle part ailleurs, en aucune autre circonstance de l'art ou de la vie ne sommes-nous confrontés à cette situation proprement singulière - et proprement déroutante - de n'avoir, du récit d'une existence, qu'une seule version. Cette situation inhabituelle explique peut-être pourquoi, au moment de lire leurs aventures, nous accordons aux personnages de roman "plus de [notre] attention et de [notre] tendresse qu'aux gens de la vie», mais elle explique peut-être plus encore pourquoi nous nous souvenons d'eux.

Une telle hypothèse, a priori, n'est pas attendue. Pouvoir s'incarner en plusieurs variantes, comme le font les héros des épopées, des tragédies et des légendes, apparaît en toute logique comme un moyen 
beaucoup plus sûr d'échapper au risque de l'oubli - à commencer par l'oubli matériel des textes perdus ou détruits. Mais il existe, si l'on peut dire, une autre stratégie ou, encore une fois, une autre forme de mémoire. Parce que rien d'extérieur ne peut venir l'expliquer ou la compléter, parce que nous devons à jamais nous contenter de la seule "version» que le romancier nous en a livrée, la vie d'un personnage romanesque reste toujours énigmatique. Or c'est de cette énigme que nous nous souvenons, c'est elle qui ne nous abandonne pas et à travers elle que la vie des personnages se poursuit: "C'est là, en effet, écrit Proust, un des grands et merveilleux caractères des beaux livres» - on pourrait dire des beaux romans - «que pour l'auteur ils pourraient s'appeler "Conclusions" et pour le lecteur "Incitations" [...], de sorte que c'est au moment où ils nous ont dit tout ce qu'ils pouvaient nous dire qu'ils font naître en nous le sentiment qu'ils ne nous ont encore rien $\mathrm{dit}^{5}$.»

Nous n'avons pas besoin de transporter avec nous, de garder en nous les grandes figures de l'Histoire, de la tragédie ou des récits immémoriaux; ces figures, en quelque sorte, se transportent sans nous, sans effort ou sans travail de notre part; elles sont des réponses communes ou collectives que nous allons chercher, dans le vaste répertoire des récits qui les reconduisent, aux questions que nous nous posons de tout temps et que nous sommes certains de ne jamais cesser de nous poser. Le personnage de roman, lui, n'existe et ne continue d'exister que parce qu'il s'installe dans notre conscience puis dans notre mémoire comme une énigme. Si nous le "consultons», ce n'est pas pour obtenir de lui une réponse, mais pour qu'il nous rappelle que toute réponse aux questions posées est un leurre ou, à tout le moins, que toute réponse est variable. Nous ne lisons pas Le Château de Kafka pour savoir s'il faut lutter ou non contre l'arbitraire, mais pour découvrir comment, face à l'adversité, la lutte et la résignation sont étrangement réversibles et dès lors impossibles à situer sur une quelconque échelle des valeurs. De même, nous ne lisons pas Don Quichotte pour nous conforter dans l'idée qu'il est bien ou non de poursuivre nos rêves romantiques, mais pour comprendre qu'il est impossible de le savoir. Ou encore: nous ne lisons pas Crime et Châtiment pour avoir une idée de ce que sont le bien 
et le mal, mais pour voir comment une fois qu'on croit détenir la vérité celle-ci se transforme sous nos yeux. Si ces romans n'offrent pas, aux vastes questions de l'existence, de réponses dont nous pouvons ensuite nous souvenir, c'est parce que leurs personnages se trompent et ont raison à la fois, changent d'avis ou pourraient changer d'avis, découvrent que toute réponse est sinon illusoire, du moins temporaire, autrement dit ne représentent pas une valeur en soi mais rien d'autre qu'eux-mêmes. L'unicité, la singularité du personnage romanesque n'entraîne aucune certitude, mais exactement le contraire; et c'est de cela que nous nous souvenons quand nous lisons un roman; c'est ce que le personnage de roman a d'irrésolu que nous gardons dans notre conscience.

Si cette conscience est ce qui assure le relais du roman, c'est-à-dire le fait non seulement que nous le reconnaissons mais aussi que nous ne l'abandonnons pas comme forme, on peut se demander à quel moment celle-ci est apparue comme telle, c'est-à-dire à quel moment elle a commencé à devenir, pour le romancier, un enjeu et un héritage. Il est fort probable que l'expérience décrite par Proust se soit révélée peu à peu et de manière indistincte, la mémoire des personnages de roman se confondant d'abord avec celle des personnages de légende, auxquels ils ont été longtemps attachés. Mais il est également possible de voir, dans les œuvres mêmes, le passage d'une mémoire exemplaire (le héros comme modèle imitable) à une mémoire singulière (le héros comme intrigue). Don Quichotte est sans doute l'un des meilleurs exemples de ce passage, tel qu'il est vécu et perçu par le personnage lui-même. On se rappelle la scène du roman dans laquelle le curé et le barbier passent au peigne fin la bibliothèque d'Alonso Quixano pour l'expurger de tous ces livres de chevalerie qui ont conduit le pauvre gentilhomme à la folie. Les deux compères condamnent au bûcher presque tous les ouvrages qui leur tombent sous la main, mais font exception pour quelques-uns d'entre eux, parmi lesquels Amadis de Gaule, Don Bélianis et l'Histoire du fameux chevalier Tiran le Blanc qu'ils considèrent plus originaux, c'est-à-dire «unique[s] en [leur] espèce ${ }^{6} »$. Nous savons qu'il s'agit égale-

6. Miguel de Cervantès, L'Ingénieux Hidalgo Don Quichotte de la Manche, trad. de César Oudin revue par Jean Cassou, vol. I, Paris, Gallimard, coll. "Folio classique», I988, p. IOI. 
ment des romans préférés de Don Quichotte, qui voit dans leurs héros des personnages particulièrement mémorables. Sauf qu'être mémorable, pour le chevalier à la Triste Figure, c'est encore, à ce moment-là, être digne d'imitation: les personnages qu'il admire n'existent pas pour lui comme des êtres singuliers, mais comme des êtres génériques. Ils lui paraissent supérieurs aux figures auxquelles ils se comparent et parmi lesquelles ils se définissent, mais la comparaison n'empêche pas et même permet qu'aux côtés des exploits d'Amadis de Gaule se trouvent, dans la bibliothèque du chevalier, ceux d'Amadis de Grèce, comme aux côtés des aventures de Palmerin d'Angleterre se trouvent celles de Palmerin d'Olive, dont le barbier nous dit pourtant combien elles ne sauraient être comparées aux premières: "Qu'on fasse tout à cette heure des copeaux de cette olive, et qu'on les brûle, de sorte qu'il n'en demeure pas seulement des cendres. Et cette palme d'Angleterre qu'on la garde et la conserve comme chose unique $[\ldots]^{7}$.»

L'idée de ce qui doit être gardé et de ce qui doit être abandonné, de ce qui mérite mémoire et de ce qui doit être oublié traverse tout le roman de Cervantès. Il ne s'agit pas de dire qu'il marque en cela un tournant, ce qui serait sans doute beaucoup pour un seul livre, fût-il un chef-d'œuvre. Mais Don Quichotte témoigne assurément plus que tout autre livre de la conscience, ou plus exactement de la compréhension de ce tournant. On le sait: c'est parce qu'un imitateur s'est permis de se saisir de son personnage pour en offrir une nouvelle version, ou, comme dirait Proust, pour communiquer sur lui d'«autres renseignements", que Cervantès rédige le second volume des aventures de Don Quichotte, qu'il clôt par la conversion puis la mort de son héros, enlevant par là "toute occasion à des auteurs autres que Cid Hamet Ben Engeli de le ressusciter faussement et d'écrire d'interminables histoires de ses hauts faits ${ }^{8} »$. Les dernières pages du roman suggèrent toutefois que Cervantès ne pensait pas seulement, par cette mort, à s'assurer l'exclusivité de son héros, mais qu'il cherchait aussi à établir les conditions grâce auxquelles ou à travers lesquelles l'Ingénieux Hidalgo, même sans renseignements supplémentaires, resterait unique, c'està-dire n'apparaîtrait pas, aux yeux de la postérité, comme une simple

7. Ibid., p. I03.

8. Ibid., vol. II, p. 600. 
variante excentrique ou une banale déclinaison parodique du personnage séculaire du preux chevalier. Les enjeux techniques, esthétiques et moraux de la fin de Don Quichotte ont été très bien résumés par Thomas Mann dans l'essai qu'il consacre au roman en 1934. En homme de métier, c'est-à-dire en romancier, Mann passe en revue les différents sorts que Cervantès aurait pu réserver à son personnage et les enjeux liés à chacun:

Abattre et faire véritablement périr Don Quichotte dans un de ses combats insensés, il n'y fallait pas songer; c'eût été dépasser les bornes de la plaisanterie et tout gâter. Le laisser en vie après sa conversion au vulgaire bon sens, c'eût été ravaler le personnage au-dessous de lui-même; c'eût été la survie d'un mannequin sans âme de Don Quichotte, sans compter que, pour des raisons de propriété littéraire, il ne lui était plus permis de vivre. J'en conviens également, il n'eût pas été chrétien, il n'eût pas été édifiant de le faire disparaître dans la démence, épargné par la lance du chevalier de la Blanche Lune, mais plongé par sa défaite dans un profond désespoir. Ce désespoir devait faire place, à l'heure de la mort, à la constatation que tout n'avait été que folie. Mais d'autre part mourir en reconnaissant que Dulcinée n'est point une princesse adorable, mais une fille de ferme sentant le fumier, et que toute sa foi, tout son comportement, toutes ses souffrances ont été des extravagances, n'est-ce pas aussi pour Don Quichotte, mourir dans le désespoir ${ }^{9}$ ?

Mann voit tous les pièges qu'a su éviter le romancier en ramenant son héros à la raison, mais il omet de remarquer que Cervantès a aussi tenu compte de la possibilité du second désespoir, soit celui que tout ce qui a été rêvé se trouve perdu. Car si Don Quichotte ne peut plus croire à la beauté cachée de Dulcinée, Sancho, lui, est encore libre de penser que la jeune femme est peut-être, au moment même où son maître n'y croit plus, libérée du sort qui l'empêche de leur apparaître telle une princesse: «Ah! monsieur, dit alors Sancho en pleurant, ne mourez point [...], levez-vous de ce lit et allons aux champs vêtus en bergers, ainsi que nous l'avions résolu. Peut-être trouverons-nous derrière quelque buisson madame Dulcinée désenchantée, de sorte qu'il n'y aura plus rien à imaginer ${ }^{10}$.» Mann aborde les pièges évités par Cervantès

9. Thomas Mann, Traversée avec Don Quichotte, traduction de Fernand Delmas, Paris, Éditions Complexe, coll. «Le regard littéraire», 1986, p. I08-Io9.

Io. L'Ingénieux Hidalgo Don Quichotte de la Manche, op. cit., vol. II, p. 598. 
du point de vue de la dignité du personnage, mais il oublie de dire que cette dignité est beaucoup plus qu'une question de morale ou de charité chrétienne. Il faut se demander à quoi il sert, pour Cervantès, que son personnage ne meure ni dans le désespoir ni dans la folie, ou que la plaisanterie ne soit pas gâtée, ou que Don Quichotte ne se survive pas comme un mannequin. Poser cette question, c'est poser la question de la mémoire que Cervantès voulait qu'on garde de son héros. Or cette mémoire, le personnage en a lui-même conscience ainsi qu'en témoigne le testament qu'il dicte à sa famille et à ses amis au moment de "passe $[\mathrm{r}]$ de cette vie à l'autre ${ }^{11}$ ». Redevenu Alonso Quixano, Don Quichotte stipule que sa nièce ne pourra hériter de ses biens qu'à la condition que l'homme qu'elle épousera ne soit pas un lecteur de romans de chevalerie: «si Antonia Quixana, ma nièce, veut se marier, [que] ce soit à un homme de qui l'on aura premièrement fait enquête qu'il est ignorant des livres de chevalerie, et qu'il n'en a jamais ouï parler. Et advenant le cas qu'il le sache, et qu'avec tout cela ma nièce veuille se marier à lui, ou s'y marie, elle perde tout ce que je lui ai donné ${ }^{12}$.» Cette condition peut paraître anecdotique, et peut-être l'est-elle après tout, mais elle peut aussi se lire comme la formulation d'un enjeu: ou bien les romans de chevalerie seront oubliés, ou bien rien ne sera légué par Don Quichotte; ou bien Amadis de Gaule continuera d'être imité et ses exploits chantés, ou bien c'est du chevalier à la Triste Figure qu'on se souviendra, non pas comme d'un être de légende, mais comme d'un individu relevant des "choses humaines ${ }^{13}$ ». La valeur de Don Quichotte tient à ce qu'on ne peut pas l'imiter. Même si plusieurs de ses qualités - son désir de faire le bien, sa loyauté, son amitié - sont dignes d'admiration, c'est son énigme qui l'emporte: le chevalier ne peut être une réponse ni une explication à quoi que ce soit, et c'est cette énigme qu'il lègue, à rebours du savoir et des réponses que transmettent les héros que l'on peut imiter. C'est essentiellement ce qu'il y a en lui d'inexplicable qui fait que nous nous souvenons de lui.

II. Ibid., p. 599.

I2. Ibid.

13. Ibid., p. 594. "Comme les choses humaines, n'étant point éternelles, vont toujours en déclinant [...] et principalement la vie des hommes, et comme celle de Don Quichotte n'avait pas ce privilège du Ciel de pouvoir arrêter sa course, sa fin arriva lorsqu'il y pensait le moins.» 



\title{
Un enfant tardif de Mnémosyne
}

\author{
Lakis Proguidis
}

D'emblée il faut préciser que, lorsqu'il s'agit de réfléchir sur l'histoire du roman, nous butons sur un obstacle méthodologique majeur. Serat-il jamais possible d'écrire l'histoire de quelque chose qui ne fait pas l'unanimité, loin de là, ni sur son identité ni sur sa date de naissance? Or, la notion de mémoire autour de laquelle doit s'articuler notre pensée nous permet de surmonter cet obstacle. Car elle nous incite à abandonner les efforts pour décrire de l'extérieur l'évolution historique d'un art "indéfinissable» et à nous plonger plutôt à l'intérieur de cet art afin de l'écouter nous raconter lui-même son histoire. Pourvu qu'on admette l'hypothèse, évidemment, qu'il a su en sauvegarder la mémoire. Hypothèse qui me paraît tout à fait légitime, si je m'en remets à ce que dit Bakhtine à propos du roman:

Le genre, par sa nature même, reflète les tendances le plus stables, «éternelles» de l'évolution littéraire. Il conserve toujours des éléments immortels d'archaïsme. Mais cela au prix d'un renouvellement perpétuel, d'une modernisation si l'on peut dire. Le genre est toujours le même et autre, toujours vieux et nouveau en même temps. Il renaît et se renouvelle à chaque étape de l'évolution littéraire et dans chaque œuvre individuelle. C'est la vie même du genre. Par conséquent, l'archaïsme conservé dans le genre n'est pas un archaïsme mort, mais éternellement vivant, c'est-à-dire constamment capable de se renouveler. Le genre vit dans le présent, mais se souvient toujours de son passé, de son origine. Il représente la mémoire artistique à travers le procès de l'évolution littéraire. Aussi est-il en mesure de garantir l'unité et la continuité de cette évolution ${ }^{1}$.

I. Mikhaïl Bakhtine, La Poétique de Dostoievski, Paris, Éditions du Seuil, 1970, p. I5O-I5I. 
Légitime, oui, notre hypothèse peut donc l'être, mais est-elle également vérifiable? Pour y répondre, transformons-la en question: quelle est l'information génétique dont le roman, tout roman, doit se souvenir et qu'il doit reproduire et transmettre afin de ne pas perdre son noyau esthétique dur, sa particularité artistique, sa raison d'être un art à part entière, un art parmi les autres arts?

Commençons par le commencement, à savoir par la mythologie grecque. Au début était Gaïa (la Terre) et Ouranos (le Ciel). Aujourd'hui nous disons: la matière et l'énergie. De leur accouplement naissent douze enfants, six garçons et six filles. Sous l'appellation de Titans et de Titanides, ils règnent sur le monde chaotique. Chacun et chacune est responsable d'une force de la nature sans tenir aucunement compte des droits et des devoirs des autres. C'est la guerre de tous contre tous. Aucune théogonie qui se veut plausible ne peut faire l'économie du chaos.

La guerre ne signifiant pas l'arrêt des accouplements, arrive bientôt la deuxième génération, celle de Zeus (Jupiter), fils du Titan Kronos et de la Titanide Rhéa. Mais, vu que la confrérie des Titans et des Titanides ne respecte aucune loi, allant jusqu'à dévorer ses propres rejetons, Zeus se révolte et, aidé par ses frères et sœurs, ainsi que par deux Titanides qui se rallient à sa cause, Thémis (la Justice) et Mnémosyne (la Mémoire), il se lance dans la plus féroce bataille de tous les temps, la fameuse titanomachie, autrement dit la lutte pour instaurer un certain ordre, établir la paix entre les éléments de la nature, créer un univers harmonieux, un monde ordonné (cosmos) au cœur du chaos. Évidemment, il l'emporte et veille désormais à ce que les nouveaux accouplements divins ne produisent plus d'enfants voués à la destruction. Ce qui confirme notre sentiment le plus profond que nos dieux sont contre la violence délibérée. Encore une fois, la mythologie va de pair avec notre sens de la normalité.

Cependant, il y a une "anomalie» dans cette théogonie à laquelle, me semble-t-il, on n'a pas prêté l'attention qu'elle mérite. Une anomalie pour ainsi dire génétique. En toute logique, Zeus couche avec les filles de sa génération, c'est-à-dire avec les enfants des Titans et des Titanides, en étant lui-même un. Mais, et voilà l'anomalie, il couche aussi avec deux Titanides: Thémis (la Justice) et Mnémosyne (la Mémoire). Et, bien entendu, ils ont des enfants, beaucoup d'enfants. Traduisons: 
parmi les divinités nées pour régner une fois le chaos vaincu (troisième génération), il y a des divinités qui descendent du dieu de l'ordre et des déesses chaotiques, des divinités qui appartiennent par leur naissance autant à l'ordre qu'au chaos.

Laissons à ceux qui s'occupent de la philosophie du droit de réfléchir sur les enfants de Zeus et de Thémis. Occupons-nous de ceux que Zeus a eus avec Mnémosyne. Car ils ne sont autres que les célèbres Muses, toutes des filles, les patronnes des arts ou, pour être plus proche de la réalité puisqu'à ce stade du brouillard cosmique on ne parle pas encore d'arts distincts, les patronnes des œuvres de l'imagination. Ces œuvres sont alors confiées, nous dit le mythe, aux filles de la Mémoire, divinité qui fait partie des forces chaotiques. Mais elles sont aussi, ces Muses, les filles de Zeus, du dieu qui a amené l'ordre dans le monde. Cet accouplement insolite entre le Chaos et le Cosmos, entre deux états du pensable qui s'excluent mutuellement - car là où règne le Chaos il n'y a pas de Cosmos et vice versa -, contient de précieux enseignements concernant l'art en général et chaque art en particulier.

Chaque Muse est censée guider l'imagination pour accomplir correctement les œuvres entreprises. Le résultat ne peut, par conséquent, que refléter et reproduire la double nature de la déesse protectrice. Il doit être de ce monde et hors de ce monde. Pour être du goût de la Muse, pour être à la hauteur de ses attentes, pour satisfaire son sens du beau, l'œuvre doit s'accorder avec son statut originel. Comme elle, l'œuvre doit avoir un pied dans le monde ordonné et l'autre dans le monde chaotique. Comme elle, son cœur doit battre simultanément au rythme de l'a-symphonie primordiale et de l'harmonie cosmique. Comme elle, elle doit prouver qu'elle tient à la fois du chaos et de l'ordre, de l'informe et de la forme. De toutes les créations humaines, dit Cornelius Castoriadis, seule l'œuvre d'art, quand elle en est une, constitue une fenêtre ouverte sur le chaos.

Le mythe évolue suivant les grandes transformations du monde. De l'époque archaïque, où le corpus mythologique prend une forme poétique, à l'époque préclassique, d'Homère à Hésiode, de la fin du $\mathrm{IX}^{\mathrm{e}}$ siècle avant notre ère au début du VII ${ }^{\mathrm{e}}$, nous passons des Muses nombreuses et sans fonction particulière aux neuf Muses éponymes, chacune responsable d'un domaine distinct de la création. Ainsi, pour l'épopée c'est Calliope, pour la danse, Terpsichore, pour l'histoire, 
Clio, etc. Les noms des Muses ne sont pas arbitraires. Leur étymologie s'explique par les travaux que chaque Muse doit surveiller. Par exemple, Calliope vient de calos (bon, bien) et epos (parole, parler); Terpsichore, de terpsis (plaisir) et de choros (danse); Clio, du fait qu'on raconte les clëï (les bravoures des héros), etc. Toutefois, si l'activité (par exemple, faire des vers) spécifiquement liée à telle ou telle création artistique (l'épopée) est à l'origine de l'appellation de la Muse correspondante, cela ne veut pas dire que le principe selon lequel cette même activité aboutira à une chose digne de s'appeler «œuvre d'art» procède de cette seule activité. C'est la Muse qui insufflera la vie (transmuera les vers en épopée). Le nom a beau venir d'en bas, de la vie concrète, des besoins qu'ont les êtres humains de se divertir, de glorifier les bonnes actions et d'honorer leurs dieux, l'inspiration vient d'en haut.

Que signifie le fait d'appeler "œuvre d'art» l'œuvre humaine qui inclut en son sein les forces chaotiques et les forces ordinatrices, formatrices? Selon la grande leçon que nous livre la mythologie, il s'agit d'une œuvre qui prouve que, pour passer du Chaos au Cosmos, il y a aussi un autre moyen que la lutte féroce (la titanomachie). Il y a l'amour, la magie, l'alchimie, la grâce, le mystère, peu importe le nom, qui fait que les divinités du Chaos, les dieux destructeurs, chtoniens, les géants de l'anarchie et de la décomposition, ne sont pas rejetés dans le Tartare, mais appelés à s'unir, à se mettre ensemble pour contribuer à la formation d'une unité qui les transcende. Quand la mythologie s'arrête au combat de Zeus contre les Titans, c'est pour nous confirmer dans l'illusion que le Chaos sera vaincu. Quand elle se souvient de l'accouplement du dieu de l'ordre avec la Titanide Mémoire, c'est pour nous rappeler que la seule chose que nous pouvons espérer est l'apprivoisement momentané du Chaos.

Ce qui nous distingue, nous les humains, des dieux, c'est que, contrairement à eux, nous ne sommes pas confrontés au Chaos en général, mais à une multitude de situations chaotiques qui, de surcroît, ne cessent de changer à travers le temps. Pourtant, nous sommes régis par la même structure chaotico-cosmique, nous efforçant tantôt d'éliminer les éléments incontrôlés et incontrôlables qui nous assaillent de partout, et c'est très bien ainsi, tantôt de les apprivoiser, de les sublimer, de créer à partir d'eux de belles choses. Remarquons que ces choses-là durent beaucoup plus que les œuvres qui résultent de notre lutte contre 
la dégradation. Occupons-nous alors de ce que nous devons faire pour obtenir la clémence et la bienveillance des Muses. De prime abord, cela va de soi, il faut embrasser amicalement, amoureusement le matériau (toujours à l'état chaotique) de la future œuvre artistique. Il faut montrer à notre sévère patronne que nous n'avons pas l'intention d'entrer en conflit avec sa mère Mémoire. Mais cela ne suffit pas. Nous devons en même temps la persuader que nous assumons la bataille de son père Zeus contre le désordre, que nous nous battons pour réaliser des œuvres qui défient la toute-puissance du Chaos.

À titre d'exemple, prenons l'épopée. Epos, nous l'avons dit, c'est la parole. Il s'agit alors de faire œuvre d'art en partant de la matière chaotique que représente la langue parlée. À la place de l'épopée, on dirait aujourd'hui "parolerie» ou quelque chose de similaire. Cependant, puisque tout le monde parle avec tout le monde, pourquoi une «parolerie» supplémentaire serait-elle quelque chose d'exceptionnel? Nous pouvons faire usage des mots, nous pouvons, gratuitement, librement, les disposer selon un certain rythme et une certaine mesure, et alors? D’où viendrait l'épopée, l'art? Quel élément fécondera la faculté que possède l'homme de communiquer au moyen du langage? Je réponds: la puissance formatrice. Une puissance nullement intemporelle, précisons-le, mais inscrite dans le temps historique. Dans le cas précis de l'épopée, c'est la puissance qui transforme l'usage du langage en amour commun ou, ce qui revient au même, qui incarne la volonté d'un ensemble humain de constituer une communauté de langue. Nous considérons, même en l'absence de traces, les formations historiques des différents peuples comme des épopées. Que voulons-nous dire par cette idée? Nous voulons dire que l'élément primordial pour la formation et la vie d'un peuple est l'œuvre de sa langue, c'est le passage de l'usage chaotique des mots à l'intégration de ces mêmes mots dans une construction langagière (épopée, parolerie) aimée et admirée de tous.

D'où vient l'épopée? De la parole. Il est alors tout à fait juste que l'art qui en sort porte le nom du matériau chaotique. Son origine est là, dans l'usage quotidien, anarchique et aléatoire de la langue commune. Le matériau se transforme, s'ordonne, devient forme avec ses lois internes, devient œuvre qui transcende tous les usages de la parole, mais la justice veut que l'appellation générique de cette forme, son signe distinctif parmi les autres arts, sa propre place dans le champ conceptuel, 
soit le reflet de l'état des choses telles qu'elles étaient avant l'intervention de la puissance formatrice. Tout se passe alors comme si on avait voulu souligner que le nom de l'art de la parole doit rester la propriété de tous, de tous ceux qui utilisent les mêmes mots et qui projettent sur la langue leur désir unificateur et identitaire. Notons aussi que cette opération onomastique ne concerne pas seulement l'épopée. Le nom de chaque art provient de son fond chaotique. C'est une règle d'airain. Aucun art ne peut s'y dérober. Sinon, les différents arts seraient de simples caprices humains - car l'homme fait toujours des choses consommables et jetables au moment de leur parution - et non pas des créations embrassées et assimilées par des populations entières à travers les âges. Je me permets toutefois de faire l'économie des autres arts. Un dictionnaire étymologique du grec ancien suffira à chacun pour constater par lui-même que les arts sont nommés d'après une vague expérience collective d'ordre esthétique. Dans le cas de l'épopée, cette expérience n'est autre que le plaisir commun de s'exprimer dans la même langue.

Et du père, pas de trace? En toute logique, l'élément chaotique collectivement partagé sanctionne le nom de l'art (à naître), mais qu'advient-il de la puissance formatrice? L'univers artistique porte-t-il, pour ne pas nous éloigner de la mythologie, seulement les marques de la mère Mémoire? Absolument pas. Le père lui aussi est présent dans chaque art. Il est présent dans l'œuvre fondatrice de chaque art. Si c'était à la mère seule de faire quelque chose avec le matériau chaotique, elle ne reproduirait que le même matériau, en plus grande quantité certes, mais à l'identique. Ainsi, si la mère Mémoire se mettait à fabriquer une œuvre de la parole, elle se contenterait de représenter des gens ordinaires en train de vaquer à leurs affaires, à naître, à faire des enfants, à mourir et à parler sans discontinuer. Or, dans une épopée, nous n'avons pas affaire à des gens ordinaires mais à des héros. La vie ordinaire, quotidienne, la vie tout court est la condition chaotique la plus élémentaire dont l'homme fait l'expérience dès qu'il débarque en ce bas monde. Bien sûr, les êtres humains qui partagent la même langue sentent la nécessité, ne fût-ce que pour des raisons pratiques, de se constituer en groupe plus ou moins autonome. Mais, de là à s'identifier en tant que peuple à une langue, il y a une distance que seule l'imagerie épique peut combler: nous sommes un peuple, nous contribuons à 
la consolidation d'une valeur qui nous transcende tous parce que nos mots, nos phrases sont prononcés par des êtres surnaturels, par des êtres distincts qui ont surpassé la condition humaine banale et triviale, bref, par des héros. Le héros épique incarne la puissance formatrice qui pousse l'homme à ne jamais se contenter de ses données anthropologiques, comme, par exemple, l'usage d'une langue.

Maintenant, après ces observations concernant le nom et la finalité esthétique de l'épopée, revenons à notre sujet: le roman. Mais si je me suis attardé à la question de l'épopée, ce n'était pas par hasard. En m'appuyant sur un fond littéraire commun depuis l'Antiquité et sur des acquis civilisationnels largement répandus (qui ne connaît pas l'Iliade?), c'était, premièrement, pour rappeler que chaque art nous livre à la fois le secret de sa provenance et sa raison d'être. Et, deuxièmement, pour remettre au centre de la discussion l'art qui a souvent été considéré comme l'ancêtre le plus légitime du roman, le plus apte à s'élargir jusqu'à l'inclure dans ses possibilités. Il apparaîtra ainsi plus clairement, me semble-t-il, que le fossé ontologique qui sépare le roman de l'épopée est de la même profondeur et de la même ampleur que celui qui le sépare de la peinture ou de la danse. C'est lui-même qui le précise: roman. Il a son nom. Ce qui veut dire qu'il a son propre passé chaotique et qu'il n'a pas l'intention - comment aurait-il pu avoir une telle intention? Sa mère Mémoire veille - de le partager avec un autre art.

Roman. Au départ ( $\mathrm{xI}^{\mathrm{e}}$ siècle) cela signifie: " "en langue populaire, naturelle" par opposition à "en latin”" (Dictionnaire historique de la langue française). Du "roman», entendu dans ce sens, vient l'idée d'appeler «romanes» toutes les langues européennes sorties du latin. Le processus linguistique et historique pour passer du latin aux langues romanes est bien connu. Il s'agit d'un processus double, unique en son genre (et à ne pas confondre avec la créolisation ou n'importe quelle autre hybridation linguistique). D'un côté, nous assistons à l'effritement du latin, langue dominante, langue qui se veut sacrée et langue d'une grande civilisation, en plusieurs autres langues (transformation « interne» due au contact avec la vie réelle). De l'autre, nous assistons au mûrissement linguistique, au sein du latin, des parlers locaux linguistiquement mineurs, rudimentaires, insignifiants, jusqu'à ce qu'ils deviennent de grandes langues, des langues prêtes à assumer toutes les conquêtes et toutes les fonctions de la langue mère (transformation «externe» due à 
l'aspiration à égaler le grand modèle). Au départ, le mot « roman» avait une connotation légèrement péjorative. Vers le milieu du XII siècle, il est anobli, il est élevé au rang des mots à signification artistique, comme en témoigne l'usage qu'on en fait dans le titre de certains ouvrages littéraires: Le Roman de Thèbes, Le Roman de Troie, Le Roman d'Alexandre, etc. Mais ici, d'après notre sujet, ce n'est pas tant l'aspect linguistico-historique de cette évolution qui doit retenir notre attention que ses retombées existentielles.

Les différents peuples de l'Europe qui ont connu le processus de la «romanisation» (au sens de la naissance des langues romanes) appartenaient tous au grand royaume de la chrétienté et tenaient par conséquent leur unité non plus d'une épopée mais de la Bible. Or, Écriture sainte ou Iliade, le sentiment identificatoire dû à un texte fondateur était le même chez un Grec du viII ${ }^{\mathrm{e}}$ siècle avant J.-C. et chez un Français ou un Catalan du $\mathrm{x}^{\mathrm{e}}$ siècle. Les Français, les Catalans et toutes les autres ethnies de l'Europe latinophone de l'époque formaient le peuple du Christ et les Évangiles leur suffisaient largement pour vivre et transmettre aux générations futures leur identité de foi, leur profonde unité. Cependant, si la question de l'identité semble pour ainsi dire réglée pour eux, ils ne tarderont pas à entrer dans une phase chaotique, liée à la parole, comme chez les Grecs, mais dans un contexte radicalement différent. Car, maintenant, il ne s'agit pas de la parole véhiculée, améliorée et admirée au fil du temps comme un bien homogène (une langue unique), mais de la parole comme bien hétérogène, la parole qui fait désormais écho au rapport entre un bien linguistiquement inférieur (le patois) et un bien supérieur (le latin).

Les linguistes et les historiens des civilisations, lorsqu'ils traitent le phénomène de l'autonomisation des langues romanes, négligent forcément le vécu collectif. Ce n'est pas leur domaine. Ce qui ne signifie pas que ce vécu tout à fait particulier, tout à fait nouveau dans l'histoire de la civilisation occidentale, n'ait pas existé. Au contraire, il a même été si particulier et si nouveau qu'il a été amené à avoir son propre nom: roman. "Roman», c'est l'autonomisation progressive de la langue considérée comme marginale, secondaire, vulgaire, mais qui fait corps avec le cercle restreint des soucis et des occupations quotidiennes des hommes, qui facilite et stimule leurs relations, qui semble surgir du lieu même où prend racine tel ou tel groupe humain, bref, de la langue 
concrètement vécue par rapport à la langue officielle, universelle et quasi éternelle imposée d'en haut. Le mot "roman" n’indique pas seulement un processus linguistique; il indique aussi et avant tout une situation linguistique qui affecte l'imaginaire.

Durant les siècles de romanisation, de vastes populations assistent, acteurs et témoins à la fois, à la valorisation du trivial et de l'incertain au sein du sérieux, de l'immuable, du parfait. Sans arrêt, on expérimente le fait que l'incident langagier provenant de la vie concrète, de l'existence, se détache du tronc langagier commun, à l'instar de l'enfant qui, afin de se réaliser pleinement, doit à un moment ou un autre rompre avec sa famille. Le plus souvent on ne voit dans ce détachement que l'aspect conflictuel, oppositionnel. Cependant, le phénomène de la romanisation, tel qu'il a eu lieu, serait impensable si la tendance vers l'autonomie ne se complétait par un désir mimétique envers le grand modèle que constituait la langue canonique. Ainsi, ici aussi, dans la chrétienté latinophone, comme jadis dans les communautés hellénophones, se forme une expérience esthétique collective autour de la parole. À une différence près: tandis que, pour les Grecs, cette expérience débouchait sur la sublimation de la langue (bannir l'incident), pour les Français du Moyen Âge elle débouchait, qu'on me permette le néologisme, sur l'existentialisation de la langue (embrasser l'incident). Reste à savoir si, dans ce dernier cas, l'expérience chaotique a donné naissance à une grande forme artistique, à un art, comme dans le premier.

Je suis toujours étonné de voir tant d'historiens et de théoriciens de la littérature chercher à identifier l'art du roman dans des époques et des lieux où le nom n'existait pas. C'est comme aller chercher l'épopée grecque dans les siècles qui ont précédé la formation de la langue grecque ou dans les peuplades qui n'ont jamais voulu se constituer en communauté de langue. Mais qu'on se trompe ou non, individuellement, sur le temps historique et le lieu propres de l'émergence du romanesque, cela n'a pas une très grande importance. L'essentiel est que l'art garde la mémoire de son nom. Si l'art perdait la mémoire de son nom, il perdrait du coup son appel à l'être. Car dans son nom se perpétue le chaos qui lui appartient en propre, sa matrice inépuisable, son tissu vital, sa soupe originelle, son terreau particulier, son fond esthétique amplement partagé par une grande partie de l'humanité, son passé en 
somme ou, pour satisfaire aussi les penseurs réfractaires aux enseignements de la mythologie, son subconscient.

Beaucoup d'esprits fins se plaignent de nos jours du fait que les éditeurs collent l'étiquette "roman" sur n'importe quel ouvrage qui mêle un peu de fiction et un peu de récit. Ils pensent, à juste titre d'ailleurs, que cette habitude inflationniste du mot roman disqualifie à la longue un art plutôt rare et difficile. Sans vouloir verser dans le paradoxe, je dirai que cette tendance commerciale est en même temps un bon signe: à une époque où tous les autres arts hérités du passé portent leur nom avec une certaine honte, le peuple croit encore et toujours à l'homme romanesque, cherche son plaisir esthétique dans le "style romanesque» (Alejo Carpentier), s'accroche au seul art qui n'hésite pas à dire son nom. (Évidemment il me faut insérer ici une note parce que le style dont parle Carpentier n'est pas celui dont parle Buffon, mais celui dont ont longuement parlé Hermann Broch et Wladimir Weidlé2.) C'est le style qui résulte moins de l'originalité d'un homme que de la sensibilité artistique de toute une humanité.

Comme il a été dit plus haut à propos de l'épopée, la distance qui, dans l'univers artistique, sépare le nom de la chose est infranchissable sans l'intervention de la puissance formatrice. Est-ce que cette puissance intervient toujours? Rien n'est moins sûr. Certes, la situation chaotique correspondant à chaque art n'est pas une situation de tout repos. Quelque chose y bouillonne toujours. Leffervescence est constante. Une attente se crée et se transmet de génération en génération. N’oublions pas sur ce point que la Titanide Mnémosyne (la Mémoire) a trahi son monde chaotique pour s'allier au dieu de l'ordre, alliance qui, après l'imposition de l'ordre, aboutit au lit nuptial.

2. "Le style est une forme générale qui n’enfreint en rien le jeu du particulier et de l'unique. Il n'est pas la création singulière d'un génie, ni le résultat final d'un grand nombre d'efforts convergents; il n'est que la manifestation extérieure d'une communauté profonde, d'une fraternité constante des âmes; il est une entéléchie collective, ce qui veut dire que ses racines s'enfoncent bien au-delà des moi individuels; on n'y supplée point par le raisonnement, par le désir, par une description méticuleuse des caractères et des procédés, de la grammaire et du lexique d'un style donné. Quand la communauté se dénoue, le style s'éteint, et rien ne saurait le ranimer. On se souvient de lui, sans pouvoir le faire renaître; il est ou il n'est pas; tant pis pour les artistes et les époques qui, ne l'ayant point et ne pouvant s'en passer, cherchent à l'atteindre par de vains artifices" (Wladimir Weidlé, Les Abeilles d'Aristée, Genève, Ad Solem, 2002, p. I68). 
Sera-t-elle fécondée, ne le sera-t-elle pas, qui peut le savoir? Ce qui est sûr et certain, c'est qu'elle en a le désir. Ce qui, en langage moderne, veut dire: le chaos artistique est toujours orienté vers la forme. Lart du roman ne pouvait pas faire défaut à cette loi. À partir du moment (grosso modo au XII ${ }^{\mathrm{e}}$ siècle) où est attesté, à grande échelle, un certain plaisir pour la valorisation de l'incident existentiel au niveau de la langue, les ouvrages littéraires n'ont pas manqué dans lesquels cet incident tentait de s'incarner.

Ainsi, dans toute l'étendue géographique concernée par le processus de la romanisation, nous voyons à partir du XII ${ }^{\mathrm{e}}$ siècle surgir ici ou là des micro-incarnations, des incarnations partielles qui, parfois, comme dans le cas du Décaméron (I350) et de Pantagruel (I532), donnent l'impression que la puissance formatrice a parachevé son œuvre. Néanmoins, pour l'heureux événement il fallait attendre Don Quichotte (1605). Mais, vu que le plus dur des travaux, face auquel même Hercule reste impuissant, est de casser un moule esthétique testé, approuvé et utilisé pendant des siècles et des siècles, le protagoniste de Cervantès n'a pas tardé à être interprété comme un héros à l'ancienne, comme quelqu'un qui échappe à la simple, monotone et prosaïque condition humaine. La seule nouveauté eu égard à la récupération du Don Quichotte par la sensibilité épique réside dans le fait que les scoliastes sont divisés. La moitié d'entre eux y discernent le héros idéaliste qui ne recule pas devant les inconvénients du réel, l'autre moitié, le héros nostalgique qui persiste à ne pas admettre que le monde a changé. Pourtant, il suffisait d'un peu d'attention pour voir que chez le Chevalier des Temps modernes tout tourne autour d'un fait existentiel qui n'a rien d'exceptionnel, rien de sublime, rien qui excède la banalité humaine, rien qui n'est inscrit dans notre expérience de la vie de tous les jours. Don Quichotte n'est pas un personnage hors norme. Il est la norme devenue personnage. Je pense évidemment au fait de croire à ce que nous lisons. N'est-ce pas là quelque chose qui arrive ou qui peut arriver à tout le monde? Or, apparemment, ce qui intéresse justement Cervantès et motive son imagination, c'est l'étude d'un être fictif complètement subjugué par ses lectures. Pour nous autres mortels, croire à nos livres signifie simplement que nous sommes des êtres influençables. Cervantès transforme ce comportement psychique humain, trop humain, en un "code existentiel» (Milan Kundera) autour duquel s'articule la vie d'un homme. Pour le bien? 
Pour le mal ? La question n'est pas là. Ce qui s'offre à nos yeux grâce à l'œuvre artistique, c'est ce déploiement quasi infini des conséquences du motif initial, cette expansion illimitée de sa forme attractive, cette facilité à subordonner à sa logique n'importe quel autre motif, cette adaptabilité à tous les milieux et à toutes les situations sans perdre une once de son charme, cet agrandissement à l'échelle d'une vie entière d'une expérience humaine autrement insignifiante, marginale. Avant le Don Quichotte, il n'y avait pas de Don Quichotte. Don Quichotte naît avec l'exploration romanesque de son motif. (Exploration romanesque: incarnation d'un incident existentiel.) Avant Don Quichotte, il n'y avait rien qui allait dans le sens de cette exploration. Rien, à part la romanisation et l'attente collective du "héros» qui transposerait dans la vie réelle cette nouvelle expérience de la parole (nouvelle par rapport à l'Antiquité). Avant Don Quichotte, il n'y avait rien à part le chaos romanesque. Après, nous pouvons dire: tiens, Don Quichotte est une de nos possibilités existentielles (Milan Kundera).

Nombreux sont ceux qui considèrent l'art du roman comme l'art de l'individu émancipé de la société. C'est qu'ils confondent, me semble$\mathrm{t}$-il, le processus de la romanisation avec celui de l'émancipation. C'est qu'ils se sont détournés du chaos romanesque tel qu'il a été vécu par les peuples européens durant les deux ou trois siècles qui ont précédé l'avènement des Temps modernes. À l'instar du mot "vulgaire», qui n'accéda à sa robustesse sémantique que protégé et enrichi au sein du latin, l'incident existentiel n'aboutira à une vie pleine et autonome (à un roman) qu'une fois immergé dans la vie commune et en dialogue avec elle. Ce que Cervantès n'a jamais oublié, et ce que ses valeureux confrères n'ont pas le droit d'oublier sous peine d'être définitivement dépourvus de tout espoir de voir surgir du for intérieur de l'homme d'autres et encore d'autres variantes de la vie. 


\title{
La mémoire est une faculté qui oublie : la mise en prose du roman de Cligès à la fin du Moyen Âge
}

\author{
IsABELle ArseneAu
}

La mémoire est une faculté qui oublie, dit-on. La chose est particulièrement vraie dans la Bourgogne littéraire de la fin du Moyen Âge où, à partir de la seconde moitié du $\mathrm{Xv}^{\mathrm{e}}$ siècle, la cour des ducs encourage la réfection des romans en vers des $\mathrm{XII}^{\mathrm{e}}$ et XIII ${ }^{\mathrm{e}}$ siècles et confie à des prosateurs la tâche de rajeunir ces œuvres désormais moins goûtées du fait de leur langue (un français ancien) et de leur forme (le vers) surannées. Si ces remanieurs promettent de demeurer fidèles à leurs sources, il n'en reste cependant pas moins que l'on remarque d'importantes variations entre les textes en vers qu'ils relisent et les réécritures en prose qu'ils en fournissent. Bien plus, la lecture parallèle des romans en vers et de leurs réfections permet de parler à propos de ces dernières d'une écriture affadissante qui "déproblématise» le modèle, comme l'écrit Keith Busby à propos des extraits qui paraissent dans la Bibliothèque universelle des romans, qu'il qualifie de "Readers' Digest du XVIII ${ }^{\mathrm{e}}$ siècle $^{1} »$.

Dans le Cligès en prose, qui a été conservé dans un manuscrit unique daté de 1454 et dont le plat de la reliure annonce un Livre de Alixandre empereur de Constentinoble et de Cligés son filz, cet affadissement résulte

I. Keith Busby, «Roman breton et chanson de geste au XVIII siècle», dans David P. Schenck et Mary Jane Schenck (dir.), Echoes of the Epic: Studies in Honor of Gerard J. Brault, Birmingham, Summa Publications, 1998, p. 17-45. 
d'une série d'oublis, qui sont évidemment autant d'omissions, dont l'enjeu touche précisément à la mémoire telle qu'elle s'exerçait dans le modèle, le Cligès de Chrétien de Troyes, composé près de trois siècles auparavant (vers II76). Dans le Livre de Alixandre, la "déproblématisation» passe d'abord par l'élimination des renvois intertextuels assumés par les personnages dans le roman en vers et dont le caractère tantôt partiel, tantôt erroné, témoignait d'une mémoire sinon défaillante du moins sélective qui trahissait un rapport difficile à l'autorité de la tradition. La disparition de ces souvenirs problématiques dans la réécriture est alors lourde de conséquences. À travers eux, c'était aussi une leçon de poétique qui s'articulait et qui se traduisait, dans l'épilogue, par le retour d'un narrateur qui, exerçant à son tour une mémoire hautement sélective, venait frustrer les attentes d'un auditeur-lecteur déjà habitué à des dénouements sinon heureux du moins exemplaires ou contre-exemplaires. Plus sage que son modèle, la réécriture en prose ne s'accommode plus de cette conclusion «antiromanesque» et choisit d'en aplanir les aspérités.

\section{Le dispositif intertextuel: une mémoire des œuvres en action}

Le Cligès de Chrétien de Troyes est un roman bicéphale dont le premier tiers relate les aventures d'Alexandre, fils de l'empereur de Constantinople, qui part "faire ses classes» à la cour d'Arthur où il s'éprend de Soredamor, qu'il épouse et qu'il ramène au pays où son frère, Alix, le croyant mort, s'est emparé du trône. Le conflit qui éclate se résout en faveur d'Alexandre, qui exige que son frère renonce au mariage de façon à ne jamais concevoir d'héritier qui pourrait disputer le trône à son fils, Cligès. Après la mort d'Alexandre, Alix viole sa promesse et épouse la fille de l'empereur d'Allemagne, Fénice, qui, elle, s'éprend de Cligès et reconduit ainsi le modèle triangulaire des amours courtoises. La seconde portion du roman est surtout reconnue pour la réécriture qu'elle propose de la légende de Tristan et Yseut, qui lui sert de repoussoir. Grâce aux talents de nigromance de sa suivante, qui lui prépare deux potions «illusoires", Fénice parvient à échapper à l'oncle pour se donner au neveu. Le premier philtre fournit à l'empereur l'illusion de posséder sa femme alors qu'il n'étreint que du 
«neent» (néant) (v. 3312-3319). Le second permet plutôt à l'impératrice, toujours vierge, de se faire passer pour morte et de s'enfuir au bras de son amant, qui vient l'enlever au tombeau où on l'a fait mettre non sans l'avoir d'abord livrée aux mains de médecins de Salerne qui, se rappelant la ruse de la femme de Salomon, ont flairé l'astuce et tentent de la réveiller de sa "fausse mort", d'abord à force de coups et ensuite en la soumettant au supplice du plomb fondu. Réfugiés dans une tour merveilleuse construite sur mesure par un architecte exceptionnel, Cligès et Fénice sont un jour découverts par un sujet de l'empereur, Bertrand, comme l'étaient jadis Tristan et Yseut dans la forêt du Morrois. Le roman se dénoue rapidement: Alix, devenu fou de n'avoir pu retrouver les amants en fuite, meurt de chagrin et Fénice et Cligès rentrent à Constantinople.

Si l'on a parlé à propos du roman de Chrétien de Troyes d'un "anti» et d'un «néo-Tristan »" le rapport de rivalité avec la tradition dépasse la seule matière tristanienne, comme en font foi les nombreux renvois intertextuels explicites. Ceux-ci prennent le plus souvent la forme de comparaisons hyperboliques ou de formules laudatives qui servent à dire la supériorité des nouveaux protagonistes sur les anciens. Ainsi, le dispositif de guerre d'Arthur est supérieur à ceux de César et d'Alexandre, alors que Cligès est plus beau et plus sage que Narcisse $^{3}$ et plus habile à l'arc et à l'escrime que Tristan (v. 6618-6619). De la même façon, les talents de Thessala en matière de nigromance dépassent ceux de l'antique Médée (v. 2985). Dans tous les exemples cités, les comparaisons se font évidemment en faveur des nouveaux personnages qui l'emportent inlassablement sur ceux du passé, tant ancien - l'Antiquité gréco-latine - que récent - les jeunes traditions narratives françaises que constituent les romans de Tristan et la Chanson de Roland, convoquée par la référence au comte Engrés, qui

2. Sur les liens entre Cligès et les romans de Tristan, voir entre autres: Anton G. Van Hamel, "Cligès et Tristan", Romania, XXXIII, 1904, p. 465-489; Alexandre Micha, "Tristan et Cligès", Neophilologus, XXXVI, I, 1952, p. I-IO (repris dans De la chanson de geste au roman, Genève, Droz, p. 63-72); et Jean Frappier, Chrétien de Troyes. L'homme et l'ouvre, Paris, Hatier, 1957.

3. Chrétien de Troyes, Cligès, Charles Méla et Olivier Collet (éd. et trad.), Paris, Librairie Générale Française, coll. «Le Livre de Poche», 1994, v. 2720-2728. 
atteignent dans l'art de la traîtrise un degré d'excellence supérieur à celui de Ganelon (v. IO7I-IO72).

Ces renvois, qui constituent une «mémoire des œuvres ${ }^{4}$ » en action, ne se cantonnent cependant pas au plan du discours et il arrive qu'on les retrouve dans la bouche même des personnages qui, longtemps avant Don Quichotte et Madame Bovary, semblent vouloir jauger leur monde à l'aune de celui de la «littérature». Si les références assumées par le narrateur témoignent de la volonté de dépasser les traditions narratives concurrentes (les matières de Rome, de France et de Bretagne ${ }^{5}$ ), celles qui circulent sur le plan de la diégèse engagent plutôt avec elles un jeu de contradiction ou de "contrerime", comme le donne à lire une variante du prologue d'Érec et Énide dans le manuscrit BnF fr $375(\mathrm{P})^{6}$. Les défaillances mémorielles de ces personnages qui inversent, charcutent et pervertissent les intertextes qu'ils convoquent, servent alors à réfuter les œuvres passées.

C'est ainsi que l'on peut interpréter le renvoi à l'histoire des fils d'CEdipe, sur laquelle est revenu le Roman de Thèbes une vingtaine d'années avant le deuxième roman de Chrétien de Troyes ( $c a$ II55), qu'il ne convoque que pour mieux la mettre à distance. Le rappel du conflit fratricide n'apparaît plus dans la mise en prose, où l'antagonisme entre les frères se résout à l'écart de toute intertextualité manifeste. Croyant Alexandre mort dans un naufrage, Alix règne sur Constantinople, jusqu'au jour où un messager lui apprend que l'héritier légitime rentre au pays. Inquiets de la guerre qui risque d'éclater, les sujets pressent leur souverain:

4. Nous reprenons la formule de Judith Schlanger (La Mémoire des auvres, Paris, Verdier, coll. "Verdier poche», 2008 [1992]).

5. C'est de cette façon que Jean Bodel, dans sa Chanson des Saxons, distingue les matières narratives (éd. Annette Brasseur, Genève, Droz, "Textes littéraires français», v. 6-II).

6. "Cil qui contrerimoier veulent», fo 28I. Nous retenons les sigles proposés par Wendelin Foerster dans la première édition critique de Cligès (I884): A: BnF fr 794 (la célèbre "copie de Guiot»); S: BnF fr I374; $\mathrm{M}$ : Tours, Bibliothèque municipale, 942; P: BnF fr 375; B: BnF fr I450; C: BnF fr I2560; R: BnF fr I420; T: Turin, Biblioteca Nazionale, L.I.I3. 
Einz li dïent qu'il li soveingne de la guerre Polinicés qu'il prist ancontre Etïoclés qui estoit ses freres germains, s'ocist li uns l'autre a ses mains?

Cligès, mss ASP
Ils l'exhortent au contraire à se souvenir de la guerre que Polynice, entreprit contre Étéocle, qui était son frère de sang. Chacun, de ses mains, tua l'autre ${ }^{8}$.

L'accommodement auquel en arrivent les deux frères - à qui on demande de se souvenir du drame thébain - est presque trop raisonnable: le passif Alix se contentera de jouer les empereurs - il demande à pouvoir en porter le nom et la couronne (v. 2518-2519; 2546-2547) -, alors qu'Alexandre, accueilli en fils prodigue, se chargera des véritables affaires du royaume (v. 2542-2543). Ce « resnable plet» (v. 2506) a beau stipuler un partage bien inéquitable du pouvoir et ressembler davantage à un arrangement boiteux qu'à une solution viable ("une pes ferme est estable» [v. 2513]), il reste néanmoins supérieur à la "novelle lei» (v. 604) établie par les fils d'Edipe, dont le souvenir sert ici d'exemplum négatif.

Si Charles Méla et Olivier Collet supposent, dans leur édition de Cligès, que la version transmise par les manuscrits ASP est «sans doute la plus conforme à l'original ${ }^{9}$ ", il ne s'agit cependant pas de la plus répandue puisque les manuscrits MBCRT donnent à lire la leçon contraire:

Einz li dient qu'il li sovieigne de la gerre qu'Etyoclés

prist encontre Polinicés, qui estoit ses frères germains...
Ils l'exhortent au contraire à se souvenir de la guerre qu'Étéocle entreprit contre Polynice, qui était son frère de sang...

Cligès, v. 2494-2497; mss MBCRT

Cinq des huit manuscrits complets (BCRT) ou fragmentaires (M) qui ont conservé le passage proposent donc un renversement des rôles: on se rappelle que, conformément à la leçon des manuscrits ASP, c'est bien Polynice qui, se heurtant à un frère qui refuse de lui rendre le trône,

7. Cligès, Stewart Gregory et Claude Luttrell (éd.), Cambridge/Rochester, D. S. Brewer, coll. "Arthurian Studies», 1993, v. 2518-2522.

8. Cligès, Charles Méla et Olivier Collet (éd.), p. 193 et 195.

9. Ibid., p. 194 . 
lève contre Thèbes les armées des Argiens et se rend ainsi responsable de la guerre des Sept Chefs. L'enjeu n'est évidemment pas de trancher quant à l'antériorité de l'une ou de l'autre des versions conservées. En revanche, il ne semble pas impossible d'interpréter les vers tels qu'ils se présentent dans les manuscrits MBCRT soit comme une sorte de lectio difficilior qu'on aurait alors cherché à "corriger", soit comme l'intervention d'un scribe sensible à l'esprit de contradiction qui anime le roman qu'il recopie. En effet, on pourrait très bien imaginer qu'en faisant jouer à Étéocle le rôle offensif le copiste se livre au même exercice que le narrateur qui, dans le prologue, déclare être l'auteur d'une œuvre, inventée ou aujourd'hui perdue, dont le titre, Dou roi Marc et d'Iseut la Blonde (v. 5), témoigne d'un important déplacement de la légende puisqu'il recentre l'intérêt sur les amours conjugales d'un roi et de son épouse légitime bien quadultère. Si cette référence possiblement inversée au Roman de Thèbes constituait un exemple isolé, dans le roman de Cligès, d'une mémoire sinon volontairement défaillante du moins franchement problématique, on pourrait s'en remettre, comme on l'a longtemps fait pour ce type de variantes, aux aléas de la transmission manuscrite ou encore accuser l'inculture d'un scribe qui n’aurait rien entendu à la "guerre Polyniciés»" $»^{10}$ Or, l'examen des deux autres renvois intertextuels assumés par les personnages fait vite apparaître que le roman érige en modus operandi ce type de souvenir problématique qui, dans le long entretien entre Fénice et Cligès (v. 5102-5336), peut consister pour un personnage à découper ou à pervertir, au sens chrétien du terme, le discours d'autrui.

$\mathrm{Au}$ cours de cette première véritable entrevue, Cligès tente de convaincre Fénice de fuir Constantinople et de traverser avec lui en Grande-Bretagne. Sa proposition fait suite à une longue tirade où son amie réitère son mépris pour Yseut, qu'elle dit abhorrer. Contrairement à cette dernière, Fénice jure qu'elle n'acceptera jamais de partager son corps entre deux hommes et qu'elle ne se donnera au neveu que lorsqu'il aura trouvé le moyen de la dérober à l'oncle, qui, grâce à un philtre qui procure l'illusion de la jouissance, ne l'a jamais connue «si

Io. Sachant que le narrateur du Roman de Thèbes affiche une nette préférence pour Polynice, on pourrait même avancer qu'en rendant Étéocle responsable de la guerre, Chrétien de Troyes, ou le scribe à qui l'on doit la variante, trahit la lettre du Roman de Thèbes mais en respecte néanmoins l'esprit. 
come Adam conut sa femme» (v. 5175). À cette amante angoissée à l'idée de rejouer les amours illégitimes des amants de Cornouailles, Cligès offrira l'image d'un autre couple, dont on s'explique mal ce qu'elle peut avoir de rassurant:

\begin{abstract}
«Dame, fait il, je pens et cuit que mielz faire ne porrions que s'en Bretaigne en alions la ai pensé que vos en meinne. Or gardez qu'en vos ne remainne, c'onques ne fu a si grant joie Helene receüe a Troie, quant Paris l'i ot amenée, qu'encore ne soit graind $[\mathrm{r}] \mathrm{e}$ menée par tote la terre le roi, mon uncle, de vos et de moi.»
\end{abstract} Cligès, v. 5228-5238
«Madame, dit-il, à mon avis, nous ne pourrions mieux faire que de partir pour la Bretagne. C'est là que j'ai pensé vous emmener. Veillez à ne pas manquer l'occasion, car si grande qu'ait été la joie qui accueillit Hélène à Troie quand Pâris l'y eut amenée, on en montrera une bien plus grande par toute la terre du roi mon oncle, pour vous et pour moi.» Cligès, p. 36I

Cligès est soit très peu versé dans l'art de la psychologie féminine, soit un bien mauvais lecteur de l'histoire et, plus précisément, du Roman de Troie, où malgré les amours plus harmonieuses du Troyen et de la Spartiate, le rapt continue de mener à la destruction de la cité, maintes fois prophétisée par Cassandre, qui n'hésite d'ailleurs jamais à maudire Hélène ${ }^{11}$. À la différence de la citation inversée du Roman de Thèbes, la référence au roman de Benoît de Sainte-Maure n'est cependant pas inexacte, puisqu'il est vrai qu'à l'arrivée de Pâris et d'Hélène, les Troyens vont de réjouissances en réjouissances (Roman de Troie, v. 48674880). En revanche, en ne retenant de leurs amours difficiles que l'épisode susceptible de servir ses desseins égoïstes et en "oubliant» de raconter que c'est une Hélène à qui on demande de sécher ses larmes et de faire bonne figure que l'on promène à travers la cité (v. 4848-4850), Cligès fait preuve d'une mémoire indéniablement sélective et pèche par omission. Les amours malheureuses de la Troyenne sont d'ailleurs fraîches à la mémoire de l'auditeur-lecteur: d'une part, le roman de Benoît de Sainte-Maure ne précède celui de Chrétien de Troyes que

II. Voir par exemple les vers 488I à 4936 (Benoît de Sainte-Maure, Le Roman de Troie, Emmanuèle Baumgartner et Françoise Vielliard [éd. et trad.], Paris, Librairie Générale Française, coll. "Lettres gothiques», 1998). 
d'une petite décennie et, d'autre part, des sept manuscrits plus ou moins complets qui ont conservé le Cligès intégral, quatre incluent aussi le Roman de Troie (APBR), proximité qui devait permettre au lecteur de sentir avec encore plus de force le caractère problématique du renvoi partiel et partial du héros éponyme.

Mais Fénice n'est pas la passive Hélène et la réponse qu'elle fait à Cligès témoigne d'un art oratoire de loin supérieur à celui de son amant. Refusant la proposition du neveu, elle lui explique qu'une fuite chez Arthur reviendrait à s'exposer aux racontars de ceux qui, ignorant qu'elle est toujours vierge, parleraient d'eux dans les mêmes termes que d'Yseut et de Tristan. Fine rhétoricienne, elle recourt à deux types d'autorité, non plus romanesque, mais proverbiale ${ }^{12}$ et biblique:

Mes le commandement saint Pol Mais il est bon d'observer et de retenir fait bon garder et retenir: qui chastes ne se velt tenir, saint Pol a faire li enseigne si sagement que il n'en preigne ne cri ne blasme ne reproiche. bon estoper fait male boiche... Cligès, v. 5258-5264 la recommandation de saint Paul. À qui ne veut rester chaste saint Paul conseille d'agir avec sagesse pour n'encourir ni réprobation, ni blâme ni reproche. Bouche qui médit doit rester bouche close. Cligès, p. 363

Dotée elle aussi d'une mémoire défaillante ou du moins très sélective, elle interprète bien librement les enseignements de la première épître de saint Paul aux Corinthiens où, dans le septième chapitre, l'apôtre formule une série de recommandations sur la chasteté et la continence. Elle détourne cependant à son profit le sens du texte paulinien, notamment en y farcissant un proverbe sur la médisance qui vient servir sa morale élastique («Bon estoper fait male boiche» [v. 5264]). Si elle confère ainsi à la sagesse populaire une autorité supérieure (parce que biblique), elle fait surtout d'un commentaire sur les façons de se garder de l'impudicité une leçon sur les moyens de céder à un désir adultère tout en ménageant les apparences et en échappant à ces «mauvaises langues" prétendument condamnées par l'apôtre. Cet exercice d'exégèse pour le moins hétérodoxe est d'autant plus ironique lorsqu'on sait que,

I2. Voir Élisabeth Schulze-Busacker, «La place du proverbe dans la mentalité médiévale», Paremia, 6, 1997, p. 565-576. 
depuis le soir de ses noces, Fénice contrevient aux prescriptions du saint homme («Ne vous refusez pas l'un à l'autre...» [I Cor, 7, 3-6]) en se soustrayant au devoir conjugal grâce à un artifice magique. Bien ironiquement, cette perversion du texte sacré - pervertere pouvant signifier, en latin chrétien, «fausser le sens, et plus particulièrement, le sens de l'Écriture ${ }^{13}$ " - a pour effet de la rapprocher de celle qu'elle dit tenir en horreur, l'héroïne de Béroul et de Thomas, reconnue tant chez l'un que chez l'autre pour sa facilité à se tirer des situations les plus délicates en faisant un usage pervers du discours.

Ce jeu de perversion acquiert d'ailleurs un sens particulièrement fort dans le manuscrit $\mathrm{BnF}$ fr $375(P)$, tel qu'il a circulé à partir du XIve siècle suite à l'adjonction en tête de codex de cahiers réunissant des textes qui ont pu avoir pour effet d'accentuer, par contraste, la lecture pervertie de Fénice. $\mathrm{Au}$ "premier recueil» qui réunissait bon nombre des intertextes convoqués par le roman de Cligès $^{14}$, un relieur a ajouté, en soignant la soudure des deux ensembles, cinq cahiers ${ }^{15}$ où sont recopiés des exemples positifs d'exégèse biblique et païenne, soit: une Apocalipsis commentée en latin (fos I-I7), une traduction commentée de l'Apocalypse en français (qui s'ouvre elle aussi par une citation de saint Paul ${ }^{16}$ ) (fos I8-26) et enfin, juste avant le Livre des Moralités des philosophes (Livre de Sénèke, fos 28-33), une version des Prophéties de la Sibylle Tiburnica (fo 27) (c'est-à-dire les prophéties de Cassandre). À partir du $\mathrm{XIV}^{\mathrm{e}}$ siècle, ces cahiers rapportés ont dû donner une résonance particulière à la tirade ultérieure de Fénice. Le recueil auquel on les a soudés était de toute façon déjà sensible aux plaisirs de la reprise - on y

13. Francis Gingras, "Thomas et les lecteurs pervers. Le roman de Tristan et la subversion des codes", Esprit de chevalerie et littérature chevaleresque, Taipei, Presses de l'Université Fu-Jen, 2004, p. I2-26. Voir aussi, sur le même roman, Emmanuèle Baumgartner et Robert-Léon Wagner, "As enveisiez e as purvers". Commentaire sur les vers 3125-3129 du Roman de Tristan de Thomas", Romania, LXXXVIII, I967, p. 527-539.

I4. Soit les romans de Troie et de Thèbes ainsi que plusieurs branches d'un roman consacré à un "autre" Alexandre (le Grand), auquel renvoie à une occasion le Cligès (v. 6619) et auquel ne peut pas ne pas faire écho l'Alexandre de Chrétien de Troyes.

I5. Si le manuscrit est composé de deux «recueils» originellement distincts, on a gardé un témoin de la soudure, soit la signature en chiffres romains par celui qui a travaillé à leur raccord et qui a peut-être senti la cohérence du nouvel ensemble ainsi créé.

I6. Il s'agit cette fois d'une citation sur la persécution tirée de la deuxième épître de saint Paul à Timothée: «Sains pols, li aposteles, dist que tout cil ki voelent piuement vivre en Jhesu-Crist soufferront persecutions...» (fo 18 ). 
retrouve non seulement deux Apocalypses, mais aussi, fait plutôt rare, deux copies identiques d'un même texte, le fabliau de La Vieille Truande (fos 295-296 et 344) - et aux jeux d'exégèse ou d'interprétation - comme en témoigne la copie de la Signification de la mort d'Alexandre, qui s'y trouvait déjà et où il s'agit, comme dans l'Apocalypse et les Prophéties, d'interpréter une série de signes avant-coureurs.

Le renvoi aux amours de Pâris et d'Hélène apparaît encore dans la réécriture $\mathrm{du} \mathrm{Xv}^{\mathrm{e}}$ siècle mais pour des raisons qui n'ont probablement rien à voir avec une sensibilité à la valeur du programme intertextuel, mais tout à voir avec le contexte pour lequel œuvre le prosateur du $\mathrm{XV}^{\mathrm{e}}$ siècle. En effet, la matière de Troie connaît à la cour de Bourgogne un succès à ce point retentissant que Philippe le Bon, en plus de commanditer des réfections en prose et une adaptation dramatique de la version en vers du XII ${ }^{e}$ siècle et de sa traduction latine du XIII ${ }^{e}$ (de Guido de Colonna), ira jusqu'à fonder, en I430, l'ordre de la Toison d'or, récupération politique et religieuse du mythe troyen ${ }^{17}$. Quant à l'exercice d'exégèse pour le moins hétérodoxe, il disparaît de la réécriture du $\mathrm{XV}^{\mathrm{e}}$ siècle où la tirade de Fénice ne convoque plus que l'intertexte tristanien et ne sert plus à articuler, aussi directement que dans la source, un rapport problématique à la tradition, qu'elle soit littéraire ou biblique:

$\mathrm{O}$, mon ami, dist Fenice, il nous fault bien aultrement faire la besongne, car se vous m'emmeniés l'en parleroit de nous deux par tout le monde comme l'en fist de Yseult et de Tristran, dont sur ma leaulté je seroie mout desplesante s'ensi advenoit, et ne seroit nul honme qui ne me tenist et reputast trop baude et vous trop fol ${ }^{18}$.

Des références intertextuelles variées qui émaillaient le modèle en vers, le prosateur ne conserve donc, en plus des indispensables renvois aux romans de Tristan, que les moins compromettantes et élimine toutes celles qui, forçant une lecture "à rebours", servaient à rappeler que le roman n'est pas le genre de la reconduction passive des œuvres du passé.

I7. Sur cette récupération du mythe troyen par la cour de Bourgogne, voir notamment Colette Beaune, "L'utilisation politique du mythe des origines troyennes en France à la fin du Moyen Âge", dans Lectures médiévales de Virgile (Actes du colloque de Rome, 25-28 octobre 1982), Rome, Publications de l'École française de Rome, 1985, p. 33I-355.

18. Le Livre de Alixandre empereur de Constentinoble et de Cligès son filz, Maria Colombo-Timelli (éd.), Genève, Droz, 2004, p. I4I, fo 8Ir. 


\section{Ils vécurent heureux... (ou pas)}

Cette mémoire sélective dont souffrent les personnages du roman en vers atteint aussi le narrateur, qui, dans l'épilogue, propose un dénouement nettement moins lisse et exemplaire que le happy end de la version $\mathrm{du} \mathrm{Xv}^{\mathrm{e}}$ siècle. Dans l'un comme dans l'autre, la fin vient en quelque sorte justifier les moyens puisque les amours adultères aboutissent, après la mort providentielle de l'époux, au couronnement et au mariage des amants, à qui la prose attribue d'ailleurs une descendance nombreuse: "Ils fondèrent pluseurs chapellez durant leur vie, et par leur bellez ausmonnez ilz furent tant amés de Dieu qu'ilz eurent de beaux enfants, lesquelz venus en aage, Cligéz et Fenice trespasserent en paix de ceste vie, et leurz enfans, voire l'aisné filz se fist couronner» (Livre de Alixandre, p. 164, fo I05r). Dans la réécriture, la négativité qui caractérisait le dénouement du modèle et qui touchait précisément à l'exercice de la mémoire a cependant été gommée.

En précisant pour l'auditeur-lecteur les conséquences de la double «traïsons» de Fénice (v. 6689), l'épilogue du roman en vers venait briser le rêve d'échapper aux "mauvaises langues» en devenant, contrairement à Yseut, la femme de son amant (v. 6669-6677). Le souvenir de la double déception d'Alix, qu'ont oï ramantevoir ou remembrer (v. 6686 et 6695) les empereurs qui ont succédé à Cligès, a mené l'établissement de la coutume de la réclusion des impératrices dans une sorte de sérail, avec lequel contrastent fortement les chapelles que le couple aurait aidé à fonder dans la mise en prose ("Ils fondèrent pluseurs chapellez durant leur vie...»). Cette «correction» est significative puisqu'elle se fait le témoin de ce qui a gêné le prosateur du $\mathrm{XV}^{\mathrm{e}}$ siècle, qui prend soin d'éliminer la «morale ironique ${ }^{19}$ " du roman en vers où, en se réalisant, le rêve de Fénice tournait au cauchemar. En effet, si les empereurs successifs se sont gardés de parler d'elle dans les mêmes termes que d'Yseut, c'est uniquement parce qu'ils en parlent en de pires termes encore et ne retiennent du récit de ses amours que celui de ses trahisons: 
Qu'ainc puis n'i ot empereor

N'eüst de sa famé peor

Qu'ele nel deüst décevoir,

Se il oï ramentevoir

Comant Fenice Alis deçut...

Cligès, v. 6683-6687
Depuis il n'y eut plus un empereur qui ne redoutât de sa femme qu'elle ne sût bien le tromper, quand il entendait raconter comment Fénice mystifia Alis...

Cligès, p. 45I

En léguant à la postérité un roman "d'Alis et de Fénice» - lui qui dit d'ailleurs avoir écrit un roman "de Marc et d'Yseut» (Cligès, v. 5) -, l'auteur détourne en fait l'horizon des attentes qu'il a lui-même contribué à créer, entre autres par son récit précédent, le "roman conjugal» d'Érec et Énide ${ }^{20}$, qu'il cite au premier vers du Cligès ("Cil qui fist d'Erec et d'Enide...»), et par un commentaire formulé au moment de la naissance du héros éponyme: «Nez est Cligés, en cui memoire / Fu mise en escrit ceste estoire» (v. 234I-2342). Si cette intervention ménage une transition (une jointure, v. 5526) entre les deux grandes parties annoncées dans le prologue (d'Alexandre et de Cligès, v. II-I4), il sert surtout à dire la spécificité mémorielle du roman, dont la particularité semble être - conformément à l'opposition qui orientera plus tard les grands travaux sur le roman et l'épopée - de ne plus chanter les hauts faits de la collectivité, comme le fait alors la chanson de geste, mais de consigner le destin d'individus à ce point exceptionnels qu'ils arrivent à obtenir le privilège de la stabilité de l'escrit. Mais Chrétien de Troyes, trop moderne pour se satisfaire d'une opposition aussi franche, ne la formule que pour mieux la compliquer et, dans son épilogue, fait d'un roman sur les hauts faits de Cligès un roman sur les mauvais coups de Fénice. Cette bifurcation prend à rebours les leçons du Roman de Thèbes, par exemple, où se disait plutôt la nécessité de raconter «chose digne a remembrer ${ }^{21}$ » et œuvres de «bonne memoire» (v. 4365) et où la perpétuation du souvenir des indignités thébaines (l'inceste, le parricide et le fratricide) ne se faisait que sous couvert de progrès moral, comme tend à le suggérer la dernière intervention du narrateur :

20. Gustave Cohen, cité dans Moshé Lazar, Amour courtois et "fin'amors" dans la littérature du XII siècle, Paris, Klincksieck, I964, p. 200.

2I. Le Roman de Thèbes, Francine Mora-Lebrun (éd. et trad.), Paris, Librairie Générale Française, coll. «Lettres gothiques», 1995, p. v. 
Por ce vous die: «Prenez en cure, C'est pourquoi je vous dis: «Prenez-y garde, par dreit errez et par mesure; agissez selon le droit et avec mesure; ne faciez rien countre nature que ne vingiez a fin dure.»

Le Roman de Thèbes, ne faites rien contre la nature, afin de ne pas connaître une fin si dure.» v. I2056-I2059 Le Roman de Thèbes, p. 747

Au contraire du narrateur de Thèbes, qui ne peut clore son récit sans condamner les crimes "countre nature de ses personnages", celui du Cligès suspend son jugement à l'égard des indignités de son héroïne et relate d'une façon assez neutre, voire avec un brin d'humour, le sort qu'elles ont valu aux empereurs d'Orient, qui, depuis, vivent dans la crainte de leurs femmes ("Qu'ainc puis n’i ot empereor / N’eüst de sa fame peor", v. 6683-6684). Il vient ainsi creuser un espace négatif, mais fertile, où pourra venir se loger l'«individu problématique» décrit par Georg Lukàcs ${ }^{22}$.

Le roman en vers n'était donc pas ce genre de la résolution et de la célébration auquel tendent à l'assimiler les réécritures, où apparaît la formule de clôture classique des contes: «ilz furent tant amés de Dieu qu'ilz eurent de beaux enfants» (Livre de Alixandre) et «ils régnèrent long-temps avec gloire et eurent une nombreuse postérité ${ }^{3}$ ». Le dénouement de la mise en prose, où il est précisé qu'à Constantinople «il ne y a nul qui ne soit bien comptend de Fenice» (Livre de Alixandre, p. I64, fo IO5r), vient alors non seulement réhabiliter l'impératrice, mais également aligner le modèle sur de bonnes ouvres dignes de mémoire: les chapelles et les aumônes généreuses d'un couple désormais repentant, comme le suggère la dernière rubrique du Livre de Alixandre où l'on surprend Cligès «confessant à Artus son adventure de Fenice».

22. Georg Lukács, La Théorie du roman, Jean Clairevoye (trad.), Paris, Gallimard, coll. «Tel», I968.

23. "Cligés dans la Bibliothèque universelle des romans", Maria Colombo-Timelli (éd.), Il confronto letterario, vol. 40, 2003, p. 298. 
Le prosateur du $\mathrm{Xv}^{\mathrm{e}}$ siècle s'apparente à un lecteur qui n'aurait retenu de Madame Bovary que l'intrigue à l'eau de rose. En débarrassant l'œuvre initiale de sa dimension non seulement intertextuelle mais négative, il réduit ce que l'on pourrait appeler avec Thomas Pavel un « roman haut de gamme $e^{24}$ » à cette trame narrative convenue qui a valu au roman médiéval d'être défini globalement comme un simple récit "d'armes et d'amour» et de se retrouver ainsi assimilé au genre du conte, terme qui apparaît d'ailleurs, dans une orthographe et un sens un peu différents, dans la mise en prose ${ }^{25}$. Insensible au ludisme qui caractérisait le roman du XII ${ }^{\mathrm{e}}$ siècle, la réécriture force en quelque sorte son modèle à célébrer ce que ce dernier s'amusait jadis à critiquer. En mettant en scène des personnages dont la mémoire sélective réécrit la guerre fratricide du Roman de Thèbes, fausse le sens du Roman de Troie ou pervertit les leçons du Nouveau Testament, Chrétien de Troyes venait pourtant montrer que le romancier médiéval, moderne dans son désir de rupture, peut chercher à dire les choses autrement ou au rebours des autorités anciennes, tant païenne que chrétienne, à l'égard desquelles il exerce une grande liberté interprétative et avec lesquelles il entretient des rapports de filiation difficiles. Il n'est d'ailleurs pas innocent que la mise en prose invente une descendance au couple impérial là où le roman en vers ne se prononçait pas et cherchait plutôt à compliquer les rapports de succession des empires et des empereurs.

En plus de priver le lecteur des intertextes principaux par rapport auxquels lire le récit - ou, du moins, d'en compliquer grandement la reconnaissance à une époque où le lecteur ne peut plus compter sur la proximité temporelle et matérielle avec les intertextes convoqués -, les «oublis» et les ajustements du prosateur atténuent considérablement la force critique qui caractérisait le roman du XII ${ }^{\mathrm{e}}$ siècle. Si les mises en prose connaîtront une fortune toute modeste, les romances qu'elles ont léguées, tout comme celles de la Bibliothèque universelle des romans

24. Thomas Pavel, La Pensée du roman, Paris, Gallimard, coll. "NRF/Essais», 2003, p. I6, où le penseur oppose le "roman haut de gamme» et la "tradition de la lisibilité».

25. Voir éd. cit., p. I89-I90 (annexe I) et l'article de Maria Colombo-Timelli, «Entre histoire et compte: de l'Érec de Chrétien de Troyes à la prose du xve siècle», Les Lettres romanes, numéro hors série, 1997, p. 23-30. 
au XVIII ${ }^{\mathrm{e}}$ siècle, contribueront néanmoins à fixer pour longtemps encore l'image d'un roman médiéval naïf et conventionnel qui lui vaudra le plus souvent d'être rejeté des grands travaux sur le genre romanesque, qui, à quelques exceptions près, auront parfois tendance à oublier que le roman n’aura jamais été aussi «médiéval» qu'à l'aube de ce que l'on appellera bientôt la Renaissance. 



\section{La mémoire exemplaire}





\title{
Désir d'excellence, souci de vérité
}

\author{
Thomas Pavel
}

Dans le chapitre «La mémoire singulière du roman" qu'elle publie ici, Isabelle Daunais défend de manière persuasive la singularité comme principe artistique du roman. Le roman, nous rappelle-t-elle, n'a pas de formes fixes et ses personnages, à la différence de ceux de l'épopée et du théâtre, ne vivent qu'une fois. Une liberté considérable permet au roman d'accomplir sa principale tâche, qui est «de dire ce qu'il y a de nouveau dans le monde, ce qui avant n'existait pas et qui maintenant existe, ou inversement, ce qui avant existait et maintenant n'existe plus ${ }^{1} »$. Ceci ne signifie certes pas que la permanence et la stabilité y soient absentes. Elles se manifestent, de manière paradoxale, dans l'irrésolution même des valeurs que les personnages du roman tour à tour gardent en mémoire et oublient. La mémoire du roman est précisément celle de l'inexplicable conflit entre la survie et la disparition du mémorable.

Je tenterai de rattacher cette belle hypothèse à la réflexion sur l'action humaine dans les œuvres littéraires qui mettent en scène des personnages et racontent une intrigue. Considérée sous cet angle, la question préliminaire, celle qui rend possible des hypothèses plus spécifiques, est de savoir comment on arrive à imaginer des personnages, une intrigue, un décor. Pourquoi et de quelle manière l'action humaine et son sens éveillent-ils l'intérêt du lecteur? Quelle est, en d'autres termes, la raison pour laquelle les œuvres à personnages et à

I. Voir p. II du présent ouvrage. 
intrigue - dont les romans - attirent notre attention? Comment identifient-elles ce qui nous semble important, ce dont nous nous soucions? Une première réponse consisterait à dire simplement qu'en lisant ces œuvres nous voulons savoir ce que les personnages font et pourquoi ils le font. À l'instar du commérage, la littérature narrative nous intéresse dans la mesure où elle considère ce qui provoque l'action humaine, ce qui la limite, ce qui l'oriente et ce qui en rend les résultats inévitables ou imprévisibles. Elle nous intéresse surtout parce qu'en racontant ce que les personnages font et les raisons qui les poussent à agir, cette littérature - à l'instar du commérage - évalue la qualité, le niveau d'excellence, des actions représentées, la mesure dans laquelle ces actions se conforment aux idéaux et aux normes qui guident notre vie.

Dans un des dialogues de Platon les plus connus, Socrate converse avec Ménon au sujet de la vertu, de l'excellence. La question qui aurait pu ouvrir le dialogue est de savoir pourquoi l'excellence présente un tel intérêt pour nous. En tenant cet intérêt pour acquis, Socrate se demande simplement si l'excellence (aretè) est une chose que l'on enseigne/ apprend, si on l'acquiert par la pratique (asketon) ou si on la possède par nature.

En faisant écho à cette interrogation, on peut chercher à savoir si l'art d'écrire des œuvres à intrigue et à personnages - des œuvres narratives, et donc des romans -, si l'art de saisir donc l'action humaine et son sens, ainsi que ce qui répond à l'action, ce qui l'informe, la limite et en rend les résultats inévitables ou imprévisibles est un art essentiellement susceptible d'être enseigné et appris. Ou si ses origines se retrouvent plutôt dans la pratique (celle du commérage, par exemple), ou encore dans la nature, par le biais du talent, du génie.

Mais avant d'en arriver là, il serait utile de réfléchir à l'intérêt permanent, inépuisable, que nous portons à la qualité, au niveau d'excellence des raisons qui nous font agir et de la manière dont nous mettons ces raisons en pratique. Concernant l'action humaine, nous nous soucions certes des buts de l'action et de la stratégie employée pour les atteindre, ainsi que des maximes qui guident l'action, mais ce qui nous préoccupe toujours est le niveau d'excellence (ou d'imperfection) auquel ces maximes et leur application placent l'acteur. C'est le souci permanent de saisir et d'évaluer ce niveau qui motive notre intérêt pour la représentation de l'action - pour l'art de raconter. 
Ceci veut-il dire que la manière de saisir l'action humaine et son niveau d'excellence est cohérente, stable, toujours la même? La réponse qui vient immédiatement à l'esprit consiste à dire "probablement non". L'art d'Homère n'est pas celui de Balzac, tout comme, à l'intérieur de la galaxie romanesque, l'art d'un auteur d'avant-garde se distingue de celui d'un écrivain réaliste ou populaire. Pour concevoir et pour écrire Nadja d'André Breton, Tropismes de Nathalie Sarraute et Le Voyeur d'Alain Robbe-Grillet, il faut bien entendu suivre d'autres préceptes que ceux qui conduisent à la création du Père Goriot de Balzac, des Mystères de Paris d'Eugène Sue ou, plus récemment et dans une tout autre catégorie si bien mise en valeur par les travaux de François Ricard, de La Valse aux adieux de Milan Kundera. Cet art semble bien changer selon les genres et les sous-genres narratifs, et plus fortement encore selon la période historique.

L'histoire n'est-elle pas d'ailleurs le paradigme même du changement? D'un changement profond, viscéral et dont le résultat est la succession de pratiques hétérogènes? C'est du moins ce que nous expliquent à la fois les fondateurs de l'histoire spéculative, téléologique, voire sotériologique, un Hegel, un Karl Marx, un Auguste Comte, ainsi que les créateurs de l'histoire positive, Leopold Ranke, Hippolyte Taine, Fustel de Coulanges. Ils sont tous d'accord pour dire que, relativement à l'activité humaine, l'art et la littérature compris, l'histoire et ses métamorphoses ont le dernier mot. Voulez-vous savoir ce à quoi s'intéressent Mme de La Fayette, Balzac et Proust? Placez-les dans leur temps, étudiez-en l'économie, la société, la politique et les lois, et vous trouverez la seule réponse possible: celle de la convergence entre l'art d'évoquer l'action humaine et le siècle qui l'engendre.

Concernant le théâtre, Sur Racine de Roland Barthes semble pourtant affirmer le contraire. Le grand critique se dispense de toute référence à l'enracinement historique de l'œuvre de Racine: l'homme racinien, dans cet ouvrage, est une figure anthropologique qui transcende le siècle où elle a été conçue et demeure non seulement compréhensible, mais aussi étonnamment pertinente en dépit du passage du temps. La scène racinienne, observe Barthes, n'est pas le lieu où les personnages agissent, mais l'antichambre dans laquelle ils attendent leur sort, toujours décidé ailleurs. Ceci est vrai aussi bien dans Britannicus que dans Bérénice, Bajazet et Phèdre. On peut sans nul doute 
interpréter ce trait en le rattachant au régime politique de l'époque - la monarchie absolue, dont les mesures étaient prises loin du regard des sujets. Il reste que l'accent mis sur l'antichambre et sur le mystère de ce qui se passe derrière la porte qui donne accès au site du pouvoir, loin de se retrouver uniquement chez Racine, organise également l'espace des romans de Franz Kafka, en particulier celui du Château, et fournit le sujet de l'inoubliable récit "Devant la loi» inséré dans Le Procès, ouvrages écrits beaucoup plus tard et dans des conditions historiques profondément différentes.

Le passage d'une époque historique à une autre ne change donc pas toujours et nécessairement la manière dont la littérature saisit l'action humaine et son milieu. Souvent elle répond aux soucis des lecteurs en reprenant délibérément ou sans le savoir des solutions anciennes. Dans son Ulysse, James Joyce fait intentionnellement usage du sujet de l'Odyssée d'Homère, mais le symbole de la porte fermée - tout aussi angoissant au début de Britannicus de Racine que dans Le Château ou, surtout, «Devant la loi» de Kafka - apparaît sans nul doute chez ce dernier pour des raisons qui n'ont rien à voir avec le désir d'imiter Racine. Au contraire même, tout porte à croire que Barthes a pu noter chez Racine la présence de cette forme d'organisation symbolique de l'espace précisément parce qu'il avait lu Kafka.

Accorder trop de poids au critère historique risque donc de détourner notre attention non seulement des sujets et des symboles récurrents, mais aussi des aspects visibles, saisissables, ceux qui s'offrent à nous, dans l'art de représenter l'action humaine. Ces aspects, considérés dans leur plus grande généralité me semblent former la substance, voire, si j'ose employer ce terme, l'essence même, de cet art. Et je suis persuadé que l'irrésolution des valeurs notée par Isabelle Daunais dans le roman n'est pas de l'ordre de la particularité historique, mais saisit quelque chose d'essentiel dans ce genre narratif.

Pour comprendre donc ce qui, dans le roman, rend visible, rend saisissable l'action humaine, il s'agit de chercher non pas seulement tel ou tel trait des sous-genres romanesques, ni la spécificité historique du roman d'une certaine époque (recherches certes utiles), mais de considérer ce qui perdure, ce qui reste présent en dépit de l'histoire, ou mieux, tout le long de l'histoire: l'identique dirait Socrate, ce qui est plus ou moins permanent, plus ou moins stable. 
Or cette stabilité, cette permanence au niveau de la saisie de l'action et des êtres humains qui s'y impliquent, ce caractère perdurable, doivent-ils être attribués à l'apprentissage, à la pratique, à l'entraînement, ou à la nature même de l'invention littéraire? Sont-ils peut-être un effet de mémoire?

Comme Socrate le fait voir dans Ménon, le terme «mémoire», qui signifie d'ordinaire le souvenir d'actions ou d'événements précédents, peut également faire référence à la remémoration, à l'anamnèse de ce qui se trouve en nous à un niveau plus profond que celui de l'expérience. L'anamnèse témoignerait, pour Socrate, de l'immortalité de l'âme, du souvenir de ses pérégrinations avant la naissance.

Il serait tentant de dire: les œuvres qui ne ressemblent guère au monde qui nous entoure, Le Seigneur des anneaux de J. R. R. Tolkien, par exemple, Narnia de C. S. Lewis, ainsi que, à un niveau plus modeste, Rocambole de Ponson du Terrail et à un niveau spectaculaire Les Misérables de Victor Hugo, n'ont été créées que, parce que longtemps avant leur naissance, il y a eu Les Éthiopiques d'Héliodore, Yvain de Chrétien de Troyes ou Parzival de Wolfram von Eschenbach. Quant à ces dernières, notre âme ayant dans ses pérégrinations connu jadis un monde idéal et les personnages invraisemblables qui l'habitent, l'origine de toutes ces ouvres résiderait dans ce mystérieux domaine accessible grâce à l'anamnèse.

Étant donné cependant que ni Hugo, ni Ponson du Terrail, ni Tolkien, ni C. S. Lewis n'ont lu Les Éthiopiques, l'héritage qui semble lier entre elles leurs œuvres est en réalité fort discontinu. Il reste que, si une continuité, si fragile qu’elle soit, a néanmoins pu subsister, quelque chose en nous a dû la rendre possible. Et que peut-être la mémoire nous permet-elle d'entendre des échos qui ressemblent à la remémoration. Nous nous rappelons des choses qui nous ont frappés précisément parce qu'il y avait déjà en nous quelque chose qui nous invitait à nous soucier de ces choses, à en reconnaître l'importance, que nous en soyons conscients ou non au moment même où nous les avons rencontrées. Ainsi, le protagoniste de $\grave{A}$ la recherche du temps perdu de Proust découvre-t-il la beauté et la profondeur du monde grâce à la résonance involontaire d'une sensation qui depuis longtemps avait été accueillie en lui sans qu'il le sache. 
Dans le cas de la madeleine de Proust, le souvenir ravive le sentiment diffus d'appartenir au monde avant et indépendamment de toute action, de tout choix, de tout mouvement de la volonté. Le bonheur que la madeleine évoque est loin des soucis concernant l'excellence ou l'infériorité, soucis toujours présents lorsqu'il s'agit d'action, de choix et de mouvement de la volonté - et que La Recherche du temps perdu décrit en détail sur des centaines de pages. Ce n'est pourtant pas un hasard si Socrate, en s'interrogeant sur l'excellence - entendue comme vertu engagée dans l'action -, a été conduit à réfléchir sur la remémoration. Car ce dont on se soucie le plus souvent à propos de la capacité humaine d'agir, ou encore ce que nous trouvons en nous à propos de cet agir est précisément la manière dont l'excellence s'y manifeste ou s'y dérobe, une excellence qui rayonne au-delà des sources biologiques, des contraintes sociales et des difficultés du monde dans lequel nous sommes plongés, une excellence dont la perte est la source de nos inquiétudes les plus durables. La littérature à sujet et personnages se nourrit à cette source, qui est notre besoin de chercher et d'évaluer l'excellence, et qui nous invite parfois à l'imaginer et à la sentir comme étant nôtre en dépit de sa rareté et de son invraisemblance. Jean Valjean chez Hugo, par exemple, personnage peu plausible, est, pourtant, absolument proche de nous. D'autres fois, la littérature nous invite à considérer et à juger le manque d'excellence, pour en faire l'objet du sarcasme (Rabelais, Cervantès), de la déploration (Mme de La Fayette, Benjamin Constant), du mépris (Flaubert, Zola) ou de la résignation sereine (Adalbert Stifter, Theodor Fontane).

Je ne saurais dire quelle est l'origine de ce souci ni d'où vient notre capacité de regarder le monde par le biais des idéaux. Plutôt que de souscrire à des explications compliquées, qu'elles soient d'ordre scientifique ou métaphysique, je préfère accepter que nous ignorons cette source, tout comme nous ne savons pas d'où vient notre capacité de penser les mathématiques, ni pourquoi le jeune esclave, dans Ménon, n'a aucune difficulté à redécouvrir lui-même, guidé par Socrate, une version du théorème de Pythagore. Il me semble néanmoins hors de doute que nous possédons cette capacité - que sa présence est une donnée primitive - et que donc raconter des histoires vraies ou inventées sur les êtres humains et sur leurs actions est une manière de manifester ce souci et d'exercer cette capacité. 
Le roman a une mémoire parce qu'il répond à cet intérêt primitif, originaire, concernant les idéaux et l'excellence morale, intérêt qui tient, pour parler un langage socratique, de la remémoration, de l'anamnèse, ou encore, dans un langage plus proche de nous, de notre place au monde et de la dotation initiale qui nous permet de la garder. D'où les deux propositions suivantes:

Le roman, d'abord, a pour objet l'action humaine dans ses rapports avec les idéaux qui la guident. En racontant ce qui se passe dans Illusions perdues de Balzac, il ne suffit pas de dire que le jeune poète Lucien de Rubempré né à Angoulême déménage à Paris en compagnie de Mme de Bargeton dans l'espoir, finalement déçu, de devenir un grand écrivain. Cette œuvre n'est compréhensible qu'à la lumière des idéaux qu'elle met en scène: celui du succès artistique - infléchi par le modèle napoléonien de la réussite du génie malgré et en dépit de tout -; celui de l'amour parfait que certains personnages, dont Mme Bargeton, opposent au mariage, alors que d'autres, dont Ève et David Séchard, le cherchent précisément dans l'union conjugale; celui du milieu qui favorise le bonheur - que ce soit Paris pour Lucien ou la province pour sa sœur et son beau-frère - et l'on pourrait continuer encore. Il est clair que tous les personnages ne se placent pas au niveau de l'idéal - car le désir de parvenir finit par corrompre Lucien - et que l'excellence, même lorsqu'elle est présente, comme dans le cas de David Séchard, n’assure pas le succès dans la société. C'est cette tension entre, d'une part, l'idéal de perfection et, d'autre part, la conduite des personnages et l'attitude de la société qui dans ce roman attire l'attention du lecteur, la garde et assure le caractère mémorable des personnages et de l'intrigue. Le roman réveille en nous le souci inné pour cette tension, il l'active ou, pour parler comme Socrate, il en rend possible la remémoration.

Trois grands types de personnages, ensuite, peuplent les romans. Les âmes fortes, dont les protagonistes des romans grecs et des grands romans hérö̈ques du XvII ${ }^{e}$ siècle sont les meilleurs exemples: Chariclée et Théagène dans Les Éthiopiques d'Héliodore, Artamène et Mandane dans Le Grand Cyrus de Mlle de Scudéry rayonnent d'excellence et incarnent spontanément et sans aucun effort les idéaux les plus hauts. Les cœurs sensibles dont parlent les romans pastoraux, les romans du XVIII ${ }^{\mathrm{e}}$ siècle et bien d'autres encore - Céladon dans L'Astrée de d'Urfé, 
Pamela chez Richardson, Julie, nouvelle Héloïse, chez Rousseau -, discernent dans leur cœur un désir d'excellence qui les guide souvent, mais pas toujours, sur le chemin du bonheur. La psyché hésitante, peu apte à saisir les rapports entre le désir et l'idéal fait l'objet, au $\mathrm{XVII}^{\mathrm{e}}$ siècle, de nouvelles de Cervantès et de Mme de La Fayette et finit par fournir, au $\mathrm{Xx}^{\mathrm{e}}$ siècle, le genre le plus fréquent de personnage romanesque.

À côté des incarnations parfaites que je viens de mentionner, chacun de ces types est susceptible d'apparaître sous une forme moins accomplie - l'âme forte pouvant avoir parfois un défaut, l'inattention de Perceval le Gallois, le cœur sensible étant parfois faible, comme chez Werther dans le roman de Goethe. Chaque type peut enfin prendre une forme décidément négative: les âmes scélérates, tel le protagoniste du Roman de Renard, les cœurs froids, dont Mme de Merteuil dans Les Liaisons dangereuses de Laclos est le meilleur exemple, les psychés inconnaissables, souvent décrites dans les romans modernes.

La mémoire du roman consiste à ne pas oublier ces choses, soit qu'elles aient été bien rendues dans le passé, soit qu'elles soient inscrites dans notre manière de voir, de comprendre et de peser l'action humaine. Et c'est dans ce contexte que le principe de la singularité artistique du roman dont parle Isabelle Daunais prend tout son relief. La tâche «de dire ce qu'il y a de nouveau dans le monde, ce qui avant n'existait pas et qui maintenant existe, ou inversement, ce qui avant existait et maintenant n'existe plus" répond, elle aussi, à notre souci de chercher et d'évaluer l'excellence et l'imperfection humaines sous toutes leurs formes. 


\title{
LiAstrée et les intermittences de la mémoire
}

\author{
Julia Chamard-Bergeron
}

O cruel souvenir de mon bon-heur passé, Sortez de ma mémoire,

Helas! puis que le bien d'une si grande gloire, Est ores effacé;

Effacez vous de mesme, il n'est pas raisonnable,

Que vous soyez en moy qui suis si misérable.

Honoré d'Urfé, L'Astrée, I, Io

Le roman français, au tournant des années i66o, semble choisir l'amnésie afin de perdre dans un bienfaisant Léthé son passé «romanesque». C'est à ce moment qu'on cesse d'écrire les romans dits pastoraux, héroïques ou précieux (ceux des d'Urfé, Gomberville, La Calprenède, Scudéry), ces trois sous-genres ayant en commun l'ampleur de leur composition et de leur matière. La vogue est désormais aux récits brefs, centrés autour d'un seul épisode: nouvelles historiques et histoires galantes, inspirées non plus de personnages tirés d'une Antiquité rêvée mais de situations contemporaines. Un peu comme si nous avions réalisé le souhait des réformateurs du genre, nous avons aujourd'hui en grande partie oublié les romans de la première moitié du XVII ${ }^{\mathrm{e}}$ siècle pour leur préférer la seule Princesse de Clèves. Il faut dire que la nouvelle de Mme de La Fayette correspond davantage à ce qui se publie depuis le siècle dernier sous l'appellation de "roman", soit des récits dont le nombre de péripéties est sagement limité. 
L'œuvre d'Honoré d'Urfé, sur laquelle nous nous pencherons ici, répond à d'autres habitudes narratives, et peut-être à un régime de mémoire différent du nôtre. L'intrigue de L'Astrée (I607-I628) serait relativement simple si elle n'était sans cesse interrompue par l'arrivée inopinée de bergers désireux de faire connaître leur histoire à des bergers désireux de l'entendre. Elle concerne les amours contrariées de Céladon et d'Astrée, séparés dès l'entrée du récit à cause d'un commandement irréfléchi de la jeune fille demandant à son amant de ne plus reparaître devant elle. Autour de ces personnages principaux gravitent d'autres couples de bergers, nymphes et chevaliers, eux aussi sujets à la jalousie ou à l'ingratitude. Espoirs et désespoirs amoureux se succèdent, tandis que plane sur le royaume de la grande nymphe Galathée la menace d'une invasion militaire instiguée par un prétendant éconduit: le chevalier Polémas, personnage repoussoir, déterminé à obtenir par la force ce que tous les autres chérissent et célèbrent en un patient art d'aimer. La narration de ces aventures est entrecoupée pour donner la parole à des amants malheureux venus présenter leur cas aux êtres les plus excellents qui vivent au bord de la rivière Lignon.

Nous verrons d'abord quel usage est fait de la mémoire dans ce roman, autant au sein de la psychologie des personnages que de l'articulation des histoires secondaires à l'intrigue principale. Puis nous considérerons, en regard de la réception du roman, les habitudes mémorielles qui furent celles des premiers lecteurs de L'Astrée. Dans les deux cas - mémoire du personnage et mémoire du lecteur -, nous aurons affaire à une mémoire vive, dotée d'une forte dimension morale, mais sujette à des intermittences.

\section{La mémoire du personnage}

L'Astrée reconduit le schéma traditionnel des puissances intellectuelles, lequel appartient à la tradition depuis sa formulation par saint Augustin. Ces puissances sont au nombre de trois: volonté, mémoire, entendement. Elles semblent former chez d'Urfé le tout de l'âme. Son roman envisage ainsi la communion des amants à titre de phénomène psychologique: ceux-ci se confondent avec leur moitié dès lors que l'exercice de leurs facultés intellectuelles est uniquement dirigé vers elle. C’est d'ailleurs le terrain de la mise en récit de l'activité de ces facultés que le 
roman, lorsqu'il se renouvelle dans le courant de la première modernité, investit tout particulièrement. Aux aventures hérö̈ques à proprement parler s'ajoutent de longues pauses narratives pendant lesquelles les personnages se souviennent, délibèrent ou annoncent leurs intentions. Laction romanesque se prolonge dans la description des états psychologiques qui la préparent ou de ceux qu'elle suscite.

L'Astrée est ainsi pleine de scènes de remémoration dans lesquelles, par exemple, un amant éconduit ou condamné au secret se perd dans la contemplation de l'être aimé. Le berger Silvandre - le personnage de L'Astrée qui théorise le plus volontiers - explique à la nymphe Léonide que la mémoire est ce qui permet à l'amour de perdurer en l'absence de l'être aimé:

la cognoissance de la bonté [...] est produite ou des actions ou des paroles, qui toutes deux ont bien besoin de presence pour estre cogneues, mais apres nullement; car cette cognoissance se conserve dans les secrets cabinets de la memoire, sur laquelle nostre ame se repliant apperçoit ce qu'elle y a mis en reserve ${ }^{1}$.

C'est la mémoire qui préserve fidèlement l'impression faite dans l'âme du sujet par un autre et qui permet ainsi de donner une direction unique et stable à sa volonté.

Ce rôle amoureux conféré à la mémoire appelle d'autres métaphores que celles utilisées par saint Augustin dans ses Confessions, ou alors un changement de l'échelle de ces métaphores. Alors qu'Augustin est pris d'enthousiasme en parcourant l'«immense palais» de la mémoire ${ }^{2}$, Silvandre en évoque les «secrets cabinets». On assiste ici à une réduction de portée: la faculté dont l'image du palais - lieu qui exprime la magnificence du pouvoir royal - rappelait la vastitude en même temps que la puissance quasi illimitée se fait tout intime, toute privée l'image du cabinet, lieu où l'on se retire et où l'on préserve ses collections. L'espace occupé par la mémoire se resserre. Il est désormais à la mesure des facultés intellectuelles du sujet, lesquelles s'exercent dans un

I. Honoré d'Urfé, L’Astrée, éd. H. Vaganay, Lyon, Pierre Masson, I925, vol. II, chap. I, p. I5. Toutes les références à L'Astrée renvoient à cette édition. Nous donnons, entre parenthèses, le numéro du volume en chiffres romains, puis le numéro du chapitre et de la page en chiffres arabes.

2. Saint Augustin, Les Confessions, trad. J. Trabucco, Paris, Garnier-Flammarion, 1964, livre X, ch. 8, p. 2 II. 
cadre restreint. Comme l'explique Silvandre, c'est en «se repliant» sur elle-même, dans un mouvement réflexif caractéristique de la psychologie prémoderne, que l'âme "aperçoit ce qu'elle y a mis en réserve".

Aussi la mémoire de l'individu est-elle avant tout dépositaire des expériences passées de celui-ci. Voilà qui est propre à nourrir la méditation mélancolique du roman pastoral, dans laquelle la réalité présente contraste cruellement avec la réalité passée. Amadis de Gaule a donné le modèle de l'ermitage d'amour: l'amant séparé de sa maîtresse se terre en un lieu sauvage, désert ou montagne, pour donner libre cours à sa fureur amoureuse. Céladon s'y adonne à son tour, et dans sa caverne ressasse les souvenirs amers du bannissement que lui a fait subir Astrée. Ressurgit alors une lettre que sa maîtresse lui a écrite avant de le congédier :

Ah! cher papier, [s'écrit Céladon,] autrefois cause de mon contentement, et maintenant occasion de rengreger mes douleurs, comme est-il possible que vous conserviez en vous les propos de celle qui vous a escrit, sans les avoir changez? Puis que la volonté où elle estoit alors est tellement changée qu'elle ny moy ne sommes plus ceux que nous soulions estre? Ô quelle faute! Une chose sans esprit est constante, et le plus beau des esprits ne l'est pas! (I, I2, 484)

Aux désordres de la volonté, à ses caprices, s'oppose la constance de la mémoire, faculté qui, à l'image du papier sur lequel on écrit, garde intact tout ce qui y a une fois été porté. La leçon donnée par le roman pastoral, annonçant ainsi quantité d'œuvres canoniques du roman moderne, prend la forme d'une désillusion: même «le plus beau des esprits» n'a pas été capable de constance; même la volonté de la plus parfaite des bergères, de la divine Astrée, est susceptible de changer.

Si on ne peut se fier à la volonté humaine, c'est donc à la mémoire qu'il faut s'en remettre. C'est ce que fait le récit même de L'Astrée, lequel est tenu par la persistance de la mémoire. Cette faculté est en effet au principe de l'identité du personnage romanesque. Le personnage est lui-même dès lors qu'il se souvient de ce qu'il a été, de ses promesses et de ses volontés passées. Voilà, en substance, ce que rappelle Astrée à Phillis, laquelle se plaint de la jalousie de son amant Lycidas, même après que celui-ci a reconnu sa faute: «ressouvenez-vous que c'est ce Lycidas à qui vous avez bien rendu de plus grandes preuves d'amitié que 
ne sera pas le pardon que son silence et sa soubmission vous demandent; et que, si vous le luy refusez, vous ne ferez une petite offence à vostre vie passée» (II, II, 463). Avoir aimé Lycidas, lui avoir accordé ses faveurs, engage des actions futures: Phillis doit continuer à lui témoigner de la bienveillance sous peine de laisser entendre que sa volonté passée a erré et qu'elle a eu tort d'aimer ce berger. Les mots d'Astrée engagent une définition de la vertu comme fidélité du sujet à ce qu'il a été; comme mémoire de sa "vie passée». La fidélité envers l'être aimé découle de cette première fidélité à soi-même ${ }^{3}$.

«Ressouvenez-vous», dit Astrée: l'appel résonne mainte et mainte fois dans le roman d'Honoré d'Urfé et dans nombre d'œuvres classiques $^{4}$. Or à certaines occasions il n'engage pas seulement le souvenir que l'individu doit avoir de sa vie passée, mais aussi celui des principes éternels qui président au devenir de toutes choses. Ces principes occupent en effet une place centrale dans L'Astrée, et ce malgré le tournant psychologique pris par le roman de la première modernité. Le genre se fait le relais d'une science de l'âme - laquelle n'est pas étrangère à celle que développe saint Augustin - qui permet d'entrevoir le fondement immuable sur lequel repose l'exercice des facultés intellectuelles. Il existe un ordre de vérité supérieur auquel les individus ont mystérieusement accès par le biais de leur mémoire. De même que la mémoire individuelle assure la consistance du personnage romanesque, cette autre mémoire assure la cohérence de la trajectoire du personnage dans le monde: celui-ci agit en vertu de certains principes qui existent pour ainsi dire hors du temps, dans la mesure où ils semblent avoir été connus de tout temps. Dans le Forez des bergers de L'Astrée, les actions des uns et des autres sont jugées en regard des lois édictées par le dieu Amour, dont aucun berger ne pense à se demander quand elles ont été

3. Jacques Ehrmann parle de la fidélité comme de «la grande épreuve amoureuse» visant à assurer «la stabilité, la fixité, la permanence - but ultime de la vie pastorale», et montre que la mémoire se trouve au fondement de celle-ci (Un Paradis désespéré: l'amour et l'illusion dans "L'Astrée», New Haven, Yale University Press, 1963, p. 46-47).

4. Benedetta Papasogli décrit, par opposition à la mémoire intellectuelle, une «mémoire du cœur" qui constitue la "sphère d'une autre affectivité, celle qui vibre dans le cœur de l'homme en réponse à la certitude d'une vérité, à la fascination d'un idéal, ou au pressentiment du sacré" (La Mémoire du cour au XVII siècle, Paris, Champion, 2008, p. 22). Cette autre mémoire «n'est point la faculté du passé; elle s'exerce dans le domaine de ce qui dure» (ibid., p. I29). 
révélées aux hommes 5 . De ces deux points de vue, donc, celui de l'identité individuelle et celui de l'orientation de l'action, le roman s'avère dépendant d'une certaine constance mémorielle.

Or le paradoxe veut que le roman ait aussi besoin d'un dysfonctionnement de la mémoire afin de lancer son récit. Nous avons dit que L'Astrée s'ouvrait sur le bannissement de Céladon par sa maîtresse. Ce bannissement découle non pas d'une faute qu'aurait pu commettre Céladon, amant parfaitement dévoué, mais plutôt d'un oubli momentané de la part d'Astrée. La bergère décrit en termes de défaut de mémoire le fait qu'elle ait pu être abusée par Sémire, lequel a voulu l'éloigner de son amant en lui faisant croire à une trahison de sa part: Sémire, explique-t-elle, «me sceut si bien persuader que Celadon aimoit Aminthe [...] que la jalousie [...] commença de me persuader que cela pouvoit estre vray, et ce fut bien un mal-heur extreme, qu'alors je ne me ressouvins point du commandement, que je luy avois fait de feindre d'aimer les autres bergeres» (I, 4, I49). C'est en effet Astrée elle-même qui avait demandé à un Céladon récalcitrant de courtiser d'autres bergères, afin de donner le change à leurs familles opposées à leur union. Ceux qui seront célébrés à la fin du récit comme de parfaits amants sont d'abord séparés par une banale manifestation d'inconstance.

L'écart de conduite d'Astrée, qui relève du mystère de sa vie intérieure, projette Céladon dans une quête initiatique qui l'amènera à se jeter dans les eaux du Lignon, être rescapé par trois nymphes, s'échapper d'un palais pour se faire ermite, construire un temple sous les ordres d'un grand druide, se travestir en femme pour avoir le privilège de vivre dans l'intimité d'Astrée sans être reconnu d'elle; bref, à mener une vie pour le moins romanesque. Tout cela n'aurait pu advenir sans l'étrange oubli d'Astrée, sans lequel les parfaits amants auraient continué à mener leur vie de parfaits amants. Il faut que de temps en temps la mémoire flanche et laisse place à l'inconstante volonté humaine pour mettre en branle le récit romanesque, surtout lorsque celui-ci

5. Dans un article intitulé «La mesure de la pastorale» (Études françaises, vol. $45, \mathrm{n}^{\circ} 2$, 2009, p. 13-24), Thomas Pavel relie l'alternance entre poésie et prose, propre au roman pastoral, à la tension assumée par celui-ci entre aspiration à l'idéal et fragilité humaine. C'est donc au sein des nombreux poèmes intégrés à L'Astrée que sont énoncées avec le plus de force les vérités qui orientent les aspirations amoureuses des bergers. 
repose davantage sur les aléas de la vie morale que sur les aventures et le merveilleux.

Aux intermittences de la mémoire d'Astrée s'ajoute, au sein du roman d'Honoré d'Urfé, une autre part d'oubli: celle des personnages de peu de mémoire, nécessaires à un autre type de relance romanesque. Le personnage d'Hylas l'inconstant ne souffre pas d'un oubli passager, telle Astrée, mais plutôt d'un défaut radical de mémoire. Ceux qui sont dans sa situation appartiennent au personnel comique du roman, par ailleurs assez peu nombreux. L'inconstant est, par définition, fort oublieux de chacune de ses maîtresses, ce qui lui permet d'en séduire à chaque fois une nouvelle comme si elle était la première. Hylas observe ce qui se passe en lui sans préjuger de la constance de son amour. Il peut ainsi décrire l'état d'âme dans lequel il se trouve alors qu'il courtise deux bergères à la fois: "quand j'estois pres de Floriante, je ne me ressouvenois en sorte du monde d'Aymée, et quand j'estois pres d'Aymée, Floriante n'avoit point de lieu en ma memoire» (I, 8, 309). Hylas, dépositaire d'une sagesse comique, nous révèle que les «secrets cabinets de la mémoire» ont une superficie limitée, qui ne saurait accueillir le souvenir de plus d'une maîtresse. Son extrême inconstance n'en est donc pas moins assujettie aux règles de la psychologie pastorale, lesquelles font dépendre l'amour de la mémoire.

Un second personnage de L'Astrée - celui-là d'une bien moins grande importance qu'Hylas, qui peut à bon droit être considéré comme l'un des personnages principaux du roman - entre dans la catégorie des oublieux. Il s'agit de Fleurial, jardinier qui sert de messager aux nymphes et à leurs amants, mais qui s'avère incapable de rapporter fidèlement leurs paroles ${ }^{6}$. Celui-ci fait ainsi apparaître a contrario un trait des personnages de L'Astrée qui risquerait sans lui de rester inaperçu tant il fait partie du code pastoral: il est tout à fait normal, pour une nymphe ou un berger, d'être en mesure de rapporter non seulement les moindres agissements des autres, mais aussi les mots exacts de leurs discours ou de leurs écrits. Comme le fait remarquer Thomas Pavel, les nombreux narrateurs du roman d'Honoré d'Urfé ont la mémoire phénoménale de personnes appartenant à ces «milieux dans lesquels l'histoire 
de chaque individu appartient de droit à tous les autres ${ }^{7}$ ». Les habitants du Forez se réunissent pour le plaisir d'entendre des histoires d'amours contrariées dont les détails sont minutieusement narrés. Une telle pratique a pour conséquence de rendre l'expérience d'autrui présente à la mémoire des personnages lorsque vient le temps de délibérer sur les actions à accomplir.

Tandis qu'Augustin a révélé au monde chrétien la portée transcendante de la mémoire, Thomas d'Aquin a insisté sur son rôle dans l'acquisition de la prudence: la connaissance du passé constitue la première étape du processus de délibération qui s'achève dans l'acte. Le roman pastoral, alors qu'il représente l'exercice des facultés intellectuelles, souligne ce rôle de la mémoire en ce qui a trait à la vertu de prudence. Cette faculté permet en effet au personnage de mobiliser l'expérience d'autrui afin de mieux juger, au moment de prendre une décision, de la bonne action à accomplir. Plus les cas d'espèce qui forment la jurisprudence amoureuse arrivent nombreux aux oreilles de l'individu, plus la prudence de celui-ci est entraînée, plus sa vie morale est réglée.

Ce principe est illustré dans L'Astrée par l'exemple de Damon. Le chevalier, séparé de la femme qu'il aime, tente plusieurs fois d'attenter à sa vie, jusqu'à ce qu'il entende l'histoire de couples encore plus maltraités par la fortune que le sien. Voici comment Damon raconte avoir pris la résolution de se résigner à son sort:

étant parmi [les] Vandales, j'appris les fortunes d'Ursace et d'Olimbre, et celles de Placidie la jeune et de sa mère Eudoxe, femme de Valentinian, lesquelles, par leurs exemples, ne me divertirent pas d'aimer, mais m'apprirent bien que qui veut aimer, se doit préparer et au bien et au mal, et les recevoir tous deux avec un même visage. (III, 6, 332)

Les personnages de L'Astrée croient au rôle joué par l'exemple d'autrui dans la mise en ordre de la vie morale. Ils entraînent leur mémoire en conséquence.

Or les histoires d'Ursace, Olimbre, Placidie et Eudoxe grâce auxquelles Damon a trouvé la sérénité ont aussi été racontées en Forez, et sont donc connues des lecteurs de L'Astrée. Lue au deuxième degré, la remarque de Damon éclaire le rôle des histoires secondaires dans le

7. Thomas Pavel, L'Art de l'éloignement. Essais sur l'imagination classique, Paris, Gallimard, coll. «Folio Essais», 1996, p. 254. 
roman: tout comme les personnages peuvent tirer des aventures d'autrui des leçons qui leur permettent d'orienter leurs actions, les lecteurs sont invités à faire réflexion sur les renversements de fortune qui affectent les Céladon, Damon et Ursace de manière à fortifier leur propre vertu.

\section{La mémoire du lecteur}

À la mémoire sans faille de personnages appartenant à un univers d'oralité, dans lequel les histoires circulent de bouche à oreille, s'oppose la nature oublieuse de lecteurs qui ont besoin du support de l'écrit pour recueillir les récits susceptibles de leur apprendre à aimer. Il est peutêtre vrai, comme le suggère le Socrate du Phèdre de Platon, que la capacité à mémoriser s'affaiblit en même temps que recule le besoin de mémoriser ${ }^{8}$, et donc qu'elle s'est bel et bien affaiblie à mesure que se sont propagés l'écriture puis l'imprimé. On pourrait ainsi supposer que le rôle moral joué par le souvenir des vies d'autrui est devenu moins crucial dès lors qu'il a été confié au papier plutôt qu'à la mémoire.

Oublieux, les lecteurs de romans? La réception du roman au $\mathrm{XVII}^{\mathrm{e}}$ siècle révèle que l'imprimé ne remplace pas forcément la mémorisation. Nous jugerions désormais l'ensemble formé par la trame principale de L'Astrée et ses histoires enchâssées - une cinquantaine de récits - inassimilables par la mémoire. Certains témoignages révèlent pourtant qu'il n'était pas inhabituel, à l'époque de sa parution, de connaître de larges pans de L'Astrée par cœur'. De même, on rapporte que de nombreux jeux de société supposaient une excellente connaissance des détails de l'intrigue et de sa géographie ${ }^{10}$. Les contemporains d'Urfé fréquentaient les œuvres romanesques avec une assiduité, un amour inouïs, poussant la familiarité jusqu'à la mémorisation. Une telle appropriation du roman découle du rôle conféré à la mémoire par

8. Phèdre, 274-275.

9. Patru rapporte son séjour chez Honoré d’Urfé: «je ne lui parlois que de son Astrée. Il n'y en avoit alors que trois volumes d'imprimés et je les savois presque par cœur parce que je les lisois même au collège» (Norbert Bonafous, Études sur "L'Astrée» et sur Honoré d'Urfé, Paris, Didot, I846, p. 76).

Io. Voir à ce sujet l'article de Delphine Denis et Françoise Lavocat intitulé "L'Astrée, livre des jeux", dans Delphine Denis (dir.), Lire "L'Astrée», Paris, Presses de l'Université Paris-Sorbonne, 2008, p. 269-28I. 
une civilisation nourrie à la patristique et aux humanités; une civilisation ayant contracté ses habitudes dans les collèges des Jésuites.

Cependant, dans le cas de L'Astrée, les concours d'érudition et les travestissements pastoraux sont de l'ordre du jeu, et les vertus qu'on cherche à actualiser par les mises en scène galantes sont beaucoup plus légères que celles des héros de la République romaine célébrés dans les collèges. On rappellera que l'évocation de l'univers des bergers dans le présent des hommes et des femmes du XVII ${ }^{\mathrm{e}}$ siècle suppose l'éloignement par rapport aux exigences de la vie quotidienne. C'est en raison de sa différence que le monde de L'Astrée est si séduisant, et c'est le plaisir de l'exotisme pastoral que les mondains convoquent à leurs fêtes et dans leurs assemblées.

Cette altérité ne saurait cependant être radicale, car si c'était le cas, comment les lecteurs pourraient-ils entretenir un commerce aussi étroit avec la matière romanesque? Pourquoi iraient-ils jusqu'à l'intégrer par la mémorisation? Émettons l'hypothèse, comme plusieurs critiques l'ont fait avant nous, que les hommes de l'âge classique attribuaient aux belles-lettres une fonction existentielle et qu'ils attendaient de la fréquentation des mondes fictifs qu'elle leur apprenne à se conduire dans ce monde- $\mathrm{ci}^{11}$. Au XVII ${ }^{\mathrm{e}}$ siècle, les romanciers français proposent à leurs lecteurs des récits qui, par leur ampleur, semblent vouloir épuiser les possibilités des vies humaines menées par l'amour ou l'ambition. Le roman pastoral et héroïque multiplie péripéties et histoires secondaires au point de constituer un répertoire de cas - une casuistique de la vie morale.

L'un des traits du roman de la première moitié du Xvir ${ }^{\mathrm{e}}$ siècle qui témoigne de son rapport au versant théorique de la vie morale est l'emploi des memorabilia, ou sentences mémorables: des vérités générales qui étaient, dans les premières éditions de L'Astrée, signalées en marge par le double-diplè ${ }^{12}$. Les sentences sont dites mémorables, c'est-

II. Pour comprendre le rôle des belles-lettres - et à travers elles de la mémoire - dans l'éducation morale, on peut se rapporter à l'étude d'Emmanuel Bury, qui décrit comment celles-ci apparaissent à l'âge classique comme "le lieu de mémoire où sont recensés les multiples cas d'espèces, les infinies variations de l'expérience dont ne parvient à rendre compte aucune loi "scientifique" (Littérature et politesse. L'invention de l'honnête homme (I580-I750), Paris, PUF, coll. "Perspectives littéraires», I996, p. 42).

I2. Voir l'article d'Ann Moss, «Entre guillemets: citations à prendre ou à laisser dans L'Astrée», dans Delphine Denis (dir.), Lire "L'Astrée», op. cit., p. I43. 
à-dire dignes de mémoire, et c'est pour cela qu'elles ont été retenues par la tradition et qu'elles circulent d'une œuvre à l'autre.

Or qui dit "digne de mémoire» ne dit pas forcément "mémorisé», et encore moins «mis en pratique dans la vie de tous les jours». C'est dans ces décalages que s'installe le roman classique, avec tous les enseignements dont il est porteur. Ce roman suppose en effet deux choses. D'abord, que le mémorable n'a pas encore été mémorisé, et donc qu'il vaut la peine de le répéter une fois de plus. Ainsi, ce qui doit être indiqué en marge par un symbole typographique pour pouvoir être facilement repéré, ce n'est pas ce dont nous nous souvenons, c'est ce que nous risquons d'oublier et que nous devrions pourtant conserver en mémoire. Le roman classique suppose ensuite que même ce qui a été mémorisé ne fait pas toujours son chemin jusque dans la vie morale du sujet, et donc qu'il est bon, de temps en temps, de rafraîchir la mémoire d'une humanité oublieuse. Car on a beau savoir que la jalousie empoisonne l'amour, il semble pourtant qu'on ne s'en ressouvienne pas toujours au moment opportun, puisqu'on ne cesse pas d'être jaloux. Ainsi que nous le rappellent les memorabilia du livre IV de la première partie de L'Astrée, «il faut peu d'apparence pour [faire naistre la jalousie] dans un cœur qui aime bien" (I, 4, I29). La longueur du roman prémoderne semble ainsi liée à la nécessité de fréquenter pendant de longues heures les vérités générales ayant trait à la vie morale, de les répéter, de les ruminer afin de parvenir, peut-être, à s'en ressouvenir au moment où il sera temps d'agir. Peut-être; car l'horizon moral défini par le roman a comme tout horizon la propriété de s'éloigner à mesure que l'on s'en approche.

Tandis que la réitération des sentences se fait sur fond d'oubli, la multiplication des exempla à travers la juxtaposition des différentes histoires de L'Astrée dépend, elle, de l'efficacité de la mémoire et de son rôle dans la vie morale. C'est parce qu'on suppose qu'il est possible d'entraîner la prudence en donnant à lire des exemples de comportements qui renvoient à des vérités morales qu'on ne se contente pas d'un seul cas de figure, d'un seul couple de bergers. La vertu est dans la quantité aussi bien que dans la qualité. Conséquemment, la poétique du roman de la première modernité repose beaucoup moins sur l'inventio que sur la variatio. Voilà qui explique la grande stabilité des sous-genres romanesques jusqu'au milieu du $\mathrm{XVII}^{\mathrm{e}}$ siècle: romans de chevalerie, 
romans pastoraux et romans héroïques présentent des caractéristiques génériques précises et varient en fonction d'une combinatoire de quelques éléments. Ces romans renvoient à du «déjà connu» et s'appuient, pour avancer, sur des pans existants du savoir (dans le cas de L'Astrée, sur les théories néo-platoniciennes de l'amour, notamment) et sur des lieux communs ${ }^{13}$. Ils font ainsi appel, chez leurs lecteurs, à un autre type de mémoire, s'ajoutant à celle restreinte aux limites - déjà très étendues - de l'œuvre: celle qui permet de mobiliser une culture littéraire qui va se ramifiant à travers le Moyen Âge et l'Antiquité. Honoré d'Urfé et ses contemporains ne se donnent pas pour mandat de révéler aux lecteurs de nouvelles vérités existentielles, mais bien de rappeler des principes connus de tous; et, surtout, de rendre à ces principes toute leur vivacité grâce à des applications inédites qui viendront enrichir la jurisprudence amoureuse.

Les récits de la seconde moitié du siècle (nouvelles galantes et historiques, parmi lesquelles la célébrissime Princesse de Clèves) rompent avec ces usages. Ils ne convoquent pas une aussi vaste mémoire culturelle, mais prétendent faire progresser la science du cœur humain en révélant les causes cachées de l'action humaine. Ils prolongent le travail des moralistes français consistant à démasquer les ruses de l'amour-propre et s'approprient les thèmes de la nouvelle espagnole - au premier titre, le desengaño amoureux. Plus courts et moins nourris de références externes, ces récits (dont ceux de Mme de Villedieu, par exemple) ne font plus tant appel à la mémoire des lecteurs qu’à leur jugement.

Concluons cet aperçu de l'action combinée de la mémoire et de l'oubli dans L'Astrée. Ce sont les intermittences de la mémoire d'une humanité tantôt fidèle, tantôt oublieuse, qui relancent le récit romanesque. La nouvelle n'a pas besoin d'être cent fois projetée dans d'autres directions, dès lors qu'elle ne vise pas l'entraînement de la prudence comme le font

I3. Yves Hersant montre que le " "déjà connu" est largement représenté dans L'Astrée»" dans la mesure où y figurent des personnages mythiques ("L'Astrée. Mythe, allégorie et roman", L'Atelier du roman, $\mathrm{n}^{\circ}$ 17, mars 1999, p. I48). Il souligne toutefois que l'œuvre elle-même appartient bien au genre romanesque et que l'archétype y cède du terrain à la psychologie morale. 
les romans de la première modernité. Son héritier, le roman «moderne», ne s'adresse pas à la mémoire de la même façon que le roman «romanesque». Celui d'Honoré d'Urfé construit son récit à partir de principes que les lecteurs sont appelés à retrouver au sein même de leur mémoire, soit qu'ils s'y trouvent depuis toujours, soit qu'ils s'y soient intégrés au fil d'une éducation morale faite par la vie ou par les livres: car nul n'est censé ignorer les vérités fondamentales du devenir humain. Le roman des trois derniers siècles, par contraste, a pour mandat de faire vivre au lecteur une expérience par procuration et, ce faisant, de lui donner à voir un coin inexploré de l'existence ou de la psyché humaines. "Découvrir ce que seul un roman peut découvrir", dit ainsi Kundera en reprenant les mots d'Hermann Broch, «c'est la seule raison d'être d'un roman. Le roman qui ne découvre pas une portion jusqu'alors inconnue de l'existence est immoral ${ }^{14}$." Il serait pourtant dommage d'oublier que l'autre roman, le romanesque, s'appuyait, lui, sur du «déjà connu»; sur la mémoire, qu'il mettait au fondement de la vie morale. 



\title{
In memoriam de Homo poeticus La lutte du roman pour sauver la mémoire poétique
}

\author{
Simona Carretta
}

Parmi les fonctions de la psyché, la mémoire est celle qui semble la plus directement connexe à la sensibilité esthétique propre de l'homme, la plus romanesque. D'une part, la mémoire représente toujours un phénomène fascinant - surtout aux yeux des romanciers -, pour la raison que les mécanismes à la base de la conservation ou de l'effacement des souvenirs n'ont pas été encore tous éclaircis; même la science n'est pas encore en mesure de les prévoir exactement. Et cela pourrait être l'une des raisons pour lesquelles le phénomène de la mémoire - et le corollaire des motifs qui lui sont liés, tels que la nostalgie de l'oubli - représente encore aujourd'hui l'un des thèmes préférés du roman, art qui est voué à s'intéresser à ces aspects de l'existence qui n'ont pas été encore «colonisés» par la science.

Toutefois, la raison la plus évidente qui justifie la possibilité de trouver une connexion entre l'effet de la mémoire et l'art du roman tient au fait que les mécanismes qui sont à la base de la réminiscence ou de l'oubli ne semblent pas répondre à des paramètres logiques, mais plutôt à un autre genre de critères, aux effets variables selon les cas, et qui sont donc tout à fait subjectifs, des critères que l'on pourrait définir comme "poétiques", en tant qu'ils répondent directement au désir de l'homme - un désir plus ou moins inconscient - d'imaginer son propre vécu dans la forme d'un dessein cohérent. 


\section{La mémoire comme effet, forme et objet du roman}

Sous cette impulsion, la mémoire organise une composition qui accueille les souvenirs des événements qui semblent confirmer la signification particulière qui a été individuée comme la clef d'interprétation de l'existence, alors qu'elle exclut les autres, qui sont alors destinés à tomber dans l'oubli. Quel que soit le dessin qui, de cette façon, a été formé, l'individu trouve dans sa contemplation sa gratification principale, et cela parce que ce dessin, peu importe les objets exacts qu'il présente, paraît, en tout cas, beau, à savoir, harmonieux, bien accompli. Le plaisir qu'on en tire correspond principalement à une satisfaction esthétique: il s'agit, plus ou moins, de la satisfaction qu'on pourrait éprouver devant une composition (qu'elle soit figurative, musicale ou littéraire) dans laquelle chaque élément trouve réellement sa place et qui, pour cette raison, peut être considérée comme réussie.

Cette transformation continue, déterminée par le travail de la mémoire, d'événements quotidiens ou purement accidentels en un récit intérieur à la structure cohérente répond à une profonde tension de l'humain, dans laquelle on peut aussi saisir - je crois - son élan éthique le plus important. Cet élan correspond à l'espoir de pouvoir saisir, à travers le tourbillon des événements, la raison d'être d'une existence; désir qui semble recueillir le seul résidu qui soit encore resté (mais pour combien de temps encore? Jusqu'à quand la foi en l'être résistera devant un monde qui paraît de plus en plus dépourvu de sens?) de ce qu'autrefois on appelait la confiance dans le destin.

Ainsi l'individu, peut-être sans même le savoir complètement, établit à chaque instant sa propre hiérarchie des souvenirs selon des lois de type esthétique. Alors que l'art de la composition qui caractérise le roman - sa possibilité d'organiser les histoires qu'il présente selon des symétries et d'autres types de correspondances - semble refléter le processus poétique de la mémoire, la façon qu'a l'individu d'élaborer ses souvenirs est réciproquement influencée par l'acte de lire des romans: la capacité de se souvenir semble être elle-même inspirée par les romans. Par certains en particulier.

«C'est proustien!»- dit-on ainsi en général pour décrire un souvenir qui nous surprend tout à coup, en nous rendant un morceau de vie lointain et, avec lui, ce que nous étions autrefois et que nous avions cru 
perdu pour toujours. Par le va-et-vient continu de la mémoire de son personnage principal (ces sauts temporels, dans le passé ou dans le futur, que les critiques ont baptisé "flashbacks» ou "flashforwards»), Proust - plus que la philosophie de Bergson - a conditionné la manière de se souvenir propre de l'individu moderne. Il l'a habitué à organiser sa mémoire par des «séries de variations sur un thème» (pour reprendre une expression aimée par Deleuze, lecteur de la Recherche ${ }^{1}$ ), à comparer les événements nouveaux avec les épisodes précédents du même type; et ce, afin de chercher, dans le passé, des «signes» qui prouvent leur valeur de nécessité. Comme l'écrit Isabelle Daunais dans Les Grandes Disparitions. Essai sur la mémoire du roman, on peut reconnaître dans cette aptitude à la comparaison la chiffre artistique de l'univers proustien, où chaque événement prend un sens seulement s'il est possible de le comparer à des événements qui le précèdent ${ }^{2}$.

Par exemple, pour le narrateur de la Recherche, la joie de pouvoir donner un baiser sur la joue d'Albertine est intense parce qu'elle vient de la possibilité de découvrir, enfin, le goût, la saveur d'une couleur qui a été contemplée à l'infini; cette satisfaction ne serait pas la même si ce moment n'était pas vécu à la lumière du souvenir du désespoir, éprouvé plusieurs fois dans le passé, de ne jamais pouvoir y parvenir un jour. L'expérience de l'amour semble elle-même indissociable de la possibilité de relier, par le fil d'Ariane de la mémoire, les différentes images et sensations que, avec le temps, nous avons recueillies de la même personne. Nous pouvons en conclure que, plutôt que d'inventer une nouvelle manière de se souvenir, Proust a découvert une nouvelle possibilité de la mémoire: celle de servir de détonateur pour la reconnaissance d'expériences chargées de sens (c'est-à-dire d'une valeur de nécessité) par la remarque des coïncidences significatives qu'on peut observer entre des événements éparpillés dans le temps.

Donc, la mémoire se présente dans le roman comme un effet. Toutefois, elle s'y présente aussi comme une forme, c'est-à-dire comme

I. Voir Gilles Deleuze, Proust et les signes, Paris, PUF, 1964.

2. "La comparaison, chez Proust, est ce par quoi le monde existe, ce par quoi il est habitable. Lorsqu'un objet ou une personne ne peuvent plus être comparés à quoi ou à qui que ce soit, lorsque aucun relief n'est plus perceptible, cet objet ou cette personne entre dans ce qu'on pourrait appeler le territoire de la non-existence» (Saint-Denis, Presses Universitaires de Vincennes, 2008, p. 57). 
une composante formelle nécessaire à la réalisation de l'objectif cognitif du roman qu'est le développement d'une vision de l'existence qui reste toujours problématique et relative (une vision alternative à celle, plus systématique, de la science ou à celle de la vision plate et superficielle de la vie présentée par les médias). En cela, l'élément de la mémoire peut remplir une fonction importante. L'évocation, dans le temps du roman, d'un temps passé - qui peut comporter la véritable introduction de dimensions temporelles différentes de celle dans laquelle se déroule l'histoire principale, à la manière de $\grave{A}$ la recherche du temps perdu fournit une prise de vue ultérieure par laquelle considérer les événements racontés et, de cette façon, contribue à les problématiser.

La découverte de la relativité temporelle elle-même - comme le disait Bakhtine - représente la conquête principale du roman et en est un aspect fondamental dès sa naissance, en déterminant sa distance de l'epos, genre qui, en décrivant les hauts faits des héros du passé, présente leur époque comme un temps idéal et «absolu».

Non seulement la mémoire fonctionne alors comme un effet ou une forme du roman - selon les cas -, mais elle concerne aussi toujours, en quelque sorte, l'objet de l'exploration romanesque, car la compréhension de la relativité du temps constitue elle-même une condition indispensable au roman pour saisir et examiner (dans sa manière ironique) des aspects toujours nouveaux de l'existence. Ces aspects sont toujours conditionnés, ou mieux : provoqués par le contexte historique dans lequel ils se développent, et chacune de leurs transformations est susceptible de provoquer des bouleversements existentiels. En cela, le roman réalise sa mission cognitive surtout dans la mesure où il est capable de se présenter comme l'observatoire de ce genre de dialogue qui intéresse les différentes époques et qui est à la base des révolutions existentielles.

Il y a différents moyens auxquels le roman peut avoir recours pour mettre en place ce genre de comparaison. Une de ces possibilités correspond au roman fanta-historique, auquel ont eu souvent recours des romanciers tels que Vladimir Nabokov, Danilo Kiš ou W. G. Sebald et qui prévoit l'élaboration d'événements du passé qui ont réellement eu lieu, par une perspective plus récente et imaginaire. Mais, abstraction faite de ces cas, où la mémoire devient directement le sujet de la narration, l'histoire du roman elle-même, comme le rappelle encore 
Daunais, est caractérisée par cette propension à saisir le nouveau à travers le souvenir du passé: «[...] pour le roman, tout moderne soit-il lui-même, le présent n'est jamais un absolu. Il n'existe, et sa nouveauté n'est saisissable, que dans le souvenir de ce qui a disparu, souvenir dont la fonction première n'est pas de s'offrir comme un idéal, mais comme une source d'étonnement et de perplexité. Le roman est fondamentalement l'espace de la comparaison ${ }^{3}$ ». Dans Don Quichotte ou Madame Bovary, par exemple, le moteur de l'action correspond au dépaysement qui provient de l'impossibilité de voir une correspondance entre le monde moderne tel qu'il se présente aux yeux des personnages et leurs attentes personnelles, formées à partir des modèles hérités du passé, qu'il s'agisse des codes en vigueur dans les romans chevaleresques, aimés de Don Quichotte, ou de l'étiquette qui relève des romans d'amour typiques du XIX ${ }^{e}$ siècle, préférés par Emma.

\section{Garder la mémoire poétique}

Le roman du $\mathrm{xx}^{\mathrm{e}}$ siècle est encore peuplé par les fils putatifs de Don Quichotte ou de Madame Bovary, c'est-à-dire par des personnages, à leur tour lecteurs de romans, qui expérimentent une distance, de plus en plus importante, entre le monde dont ces romans parlent et la réalité qui les entoure. Ainsi en est-il du tableau dans lequel prend forme l'histoire de David Kepesh, le personnage principal du roman de Philip Roth Professeur de désir (1977). Le problème de Kepesh est essentiellement le suivant: comment peut-on résister, quel sens peut-on trouver à la vie, si on découvre qu'on habite dans un monde - le monde occidental post-soixante-huitard - dont la logique de consommation, à laquelle même les rapports humains semblent être soumis, rend de plus en plus difficile non seulement la possibilité de construire des relations d'amour durables, mais aussi celle de se laisser aller à la passion? Ce tourment accompagne le personnage de Roth tout au long de sa vie érotique, depuis sa première formation universitaire en Europe - où il se consacre à une tournée d'amours libertins, dont il a vite assez - jusqu'à l'échec de son mariage avec Helen, une belle et riche héritière, et l'amère constatation de la nature despotique qui semble marquer - 
aussi bien que les sentiments - le désir et l'attraction physique, dont l'inconstance risque de mettre en danger la tenue de relations apparemment destinées à durer, comme celle que Kepesh, à la suite de ses aventures sentimentales, noue avec la jeune Claire.

En contrepoint au désordre amoureux que vit Kepesh, se trouve l'exemple de ses parents, souvent mentionnés dans le roman: un couple classique, qu’on dirait de la "vieille école» et qui incarne les idéaux de l'amour éternel et de la fidélité réciproque. Toutefois, dans la deuxième moitié du livre, les parents sont décrits comme faibles, fragiles (vers la fin, la mère meurt) ; ils symbolisent la précarité qui, désormais, caractérise leurs idéaux. Cette situation conflictuelle fait émerger un nouveau dilemme: lorsque s'effritent les codes qui, seulement quelques décennies auparavant, réglementaient encore les rapports entre homme et femme, aussi bien la dynamique de l'amour sentimental que celle du désir, et lorsque ces rapports se manifestent dans leur nudité monstrueuse, en tant que forces abstraites et ingouvernables, échappant aux tentatives de l'individu de les gérer, alors sur quelles bases - si ce n'est ni l'amour, ni la passion - l'individu peut-il espérer fonder son identité?

Le personnage créé par Roth expérimente ce dépaysement très intensément, non seulement parce qu’il est né précisément au début de ce changement historique, mais aussi parce qu'il est un homme de lettres. Kepesh est un professeur de littérature comparée qui, par hasard, au moment où sa vie amoureuse semble prendre la tournure la plus dramatique, prépare un séminaire universitaire sur le thème du roman amoureux et érotique. Sa lecture intensive des romans de ce genre le conduit à comparer ses expériences décevantes avec les grandes passions décrites dans Anna Karénine ou Madame Bovary, ou avec les aventures, plus licencieuses, de Colette ou de Henry Miller, et à trouver ainsi ses défaites encore plus difficiles à accepter. Toutefois, c'est justement le recours à la littérature qui représentera la planche de salut de Kepesh face au dépaysement qu’il éprouve.

Anna Karénine est souvent mentionnée dans un autre roman contemporain: L'Insoutenable Légèreté de l'être (1984) de Milan Kundera, où il figure comme le livre aimé par Tereza, l'un des personnages principaux. Obligée par sa famille d'abandonner ses études, pratiquant le métier de serveuse, Tereza retrouve dans les romans la beauté dont le monde où elle grandit paraît tout à fait dépourvu. Non seulement le 
roman de Tolstoï est cité directement à plusieurs reprises au cours du roman (Tereza le considère comme une sorte de talisman personnel, au point que même son chien s'appelle Karénine), mais il en inspire même des explications structurelles et fournit l'occasion d'exposer quelques réflexions à propos de la mémoire poétique, un concept qui revient souvent dans le roman et qui participe au développement du thème principal, articulé autour de l'opposition légèreté-lourdeur. Ainsi que le fait comprendre le narrateur de L'Insoutenable Légèreté de l'être, l'existence de la mémoire poétique montrerait la valeur positive qui peut caractériser même le pôle de la lourdeur, ici considéré comme nécessaire.

Dans une partie du roman qu'on pourrait définir comme méditative ou essayistique, le narrateur réfléchit à la structure du chef-d'œuvre de Tolstoï, qui semble être basée sur la logique des coïncidences. Les premières rencontres entre Anna et Vronski, par exemple - d'abord à la gare de Moscou, ensuite à la maison d'Oblonski et, quelques jours plus tard, au bal -, semblent souvent provoquées par le destin, comme si une force mystérieuse les poussait dans les bras l'un de l'autre. Cet esprit de fatalité ne gouverne pas seulement Anna et Vronski, il concerne tous les personnages. Dans la troisième partie du roman, le fermier Levine se promène sur les routes désertes de sa campagne; à l'aube, à la suite d'un long raisonnement, il décide de tourner le dos au passé, c'est-à-dire d'oublier Kitty, la jeune aristocrate qui l'a fait souffrir, et éventuellement d'épouser une paysanne. Mais, tout à coup, de façon très inattendue pour ces sentiers et pour cette heure matinale, Levine voit filer une voiture à cheval, en distinguant juste à temps, dans l'obscurité, la passagère: c'est elle, Kitty, qui à son tour le reconnaît et s'illumine. La voiture poursuit son chemin, mais sa vision fuyante suffit à Levine pour comprendre que Kitty est et restera la seule femme pour lui. Cette rencontre inattendue a donc été provoquée par le destin? Malgré ce qu'un lecteur superficiel pourrait penser - explique le narrateur de L'Insoutenable Légèreté de l'être -, la présence de ce grand nombre de coïncidences dans le roman de Tolstoï ne serait pas la preuve d'une structure trop "romanesque», à savoir, fausse, artificielle, trop construite. Au contraire, Anna Karénine serait un roman réaliste dans la mesure où, en décrivant la réaction des personnages face aux nombreuses coïncidences sur lesquelles ils tombent, il saisit cette impulsion, propre aux hommes, à cultiver une mémoire poétique, c'est-à-dire à 
imaginer, au-delà du déroulement d'événements apparemment occasionnels, la présence de connexions significatives, à rechercher, dans leur vie, la cohérence typique d'un roman. Dans ses essais, Danilo Kiš nomme «Homo poeticus» celui qui est capable de saisir des correspondances poétiques dans son existence. Cette fonction - la fonction poétique - serait apparue à l'homme dès les origines et serait à la base de la construction des premiers récits mythiques, qui correspondent aux premières formes d'hypothèses ontologiques.

La propension à concevoir une vision du monde qui n'en réduit pas le mystère et la complexité, cette pensée poétique qui répond à un besoin primaire de l'humain est toutefois aujourd'hui en voie d'extinction, obscurcie par la pensée scientifique, caractérisée par la tendance contraire vers la systématisation et la relative fragmentation de la connaissance.

Du moment que l'une des fonctions principales de l'art du roman consiste à rendre plus nette la perception des changements subis par l'homme, le rôle joué dans cette exploration par les « romans dans les romans» - les œuvres romanesques qui, à leur tour, parlent de romans - est de nous mettre en garde contre la disparition de l'Homo poeticus et contre le péril qui peut dériver - pour la réalisation personnelle - de la perte de la capacité de cultiver une mémoire poétique.

Les personnages de Tereza et de David Kepesh trouvent respectivement dans leurs lectures romanesques une voie de salut. Dans le premier cas, c'est l'habitude d'entrevoir des signes dans des circonstances apparemment fortuites - comme la soudaine apparition de Tomás dans le bar où Tereza travaille, au moment où la radio diffuse la musique de Beethoven, dont l'amour les rapproche -, habitude apprise en lisant des romans, qui conduit Tereza à cultiver sa relation avec Tomás, l'homme dans lequel elle peut croire reconnaître «l'homme du destin».

Dans Professeur de désir, l'évocation des lectures de Kepesh - qui semble occuper une fonction de contrepoint face au monde réel, dont les habitants ont perdu la capacité de cultiver une mémoire poétique indispensable pour nourrir des sentiments comme celui de l'amour ne doit pas non plus être interprétée comme une simple digression de nature essayistique ou comme la preuve de la fermeture autoréférentielle du roman. Au contraire, le sens de l'aventure existentielle de Kepesh s'éclaircit seulement lorsque les deux niveaux sur lesquels est 
articulé Professeur de désir, celui qui organise l'intrigue et le niveau essayistique, se rencontrent. Cela se produit vers la fin, lorsque Kepesh, en s'inspirant du récit «Rapport pour une académie» de Kafka, voit comment organiser son séminaire: il présentera à ses élèves une sorte de confession de sa vie sentimentale et érotique. Si, d'un côté, cette tentative répond au désir de présenter l'univers amoureux et érotique comme quelque chose de concret et qui peut être proche de tous, cette entreprise donne aussi à Kepesh la possibilité de devenir, à son tour, Homo poeticus, c'est-à-dire de lire sa vie comme un roman et de trouver ainsi une consolation. 



\section{III}

Prendre en charge le souvenir 



\title{
"Ce qu'il y a de plus ancien, de plus qu'oublié, d'inconnu à nous-mêmes" : la mémoire du Grand Meaulnes
}

\author{
Mathieu Bélisle
}

Il n'est guère de roman français qui fasse aujourd'hui l'objet d'une vénération aussi marquée que Le Grand Meaulnes d'Alain-Fournier. L'un des livres français les plus lus dans le monde, qui a fait la fortune des éditeurs du Livre de Poche, inscrit au programme de la plupart des classes de français, Le Grand Meaulnes est par excellence le roman "mémorable», d'autant plus mémorable qu'il a généralement été lu au cours de la jeunesse, à un moment où les lectures ont une grande résonance affective, et que le temps passé a permis au jeu mystérieux de l'oubli et du souvenir de ne conserver que les aspects les plus propres à maintenir vivante la conviction d'être en face d'une œuvre magique, enchantée. Il suffit de demander autour de soi - ou alors d'aller lire des blogues tout entiers voués à Alain-Fournier - pour trouver des lecteurs, même «sérieux» ou "experts", pour qui la rencontre avec Meaulnes fut déterminante. Il en va ainsi de l'écrivain Pierre Michon pour qui la lecture du Grand Meaulnes a constitué une véritable révélation, «de l'ordre de la découverte existentielle, de la première nomination des choses». Dans une entrevue accordée à la romancière et critique Tiphaine Samoyault, Michon affirme:

Je me souviens de la première fois où, bien plus tôt, ma mère me montra et nomma le givre, sur un bouleau pleureur qui a disparu, au carrefour d'un chemin qui n'a pas disparu. J'ai compris en un éclair ce qu'était le 
givre, et j'ai su son nom: lire Le Grand Meaulnes est une expérience du même ordre. Je lisais Jules Verne ou James Oliver Curwood. Je ne lisais pas Le Grand Meaulnes, il m'était révélé, divulgué, c'était une vérité naturelle et indubitable qui m'avait été cachée jusqu'à ce jour. Et je me répétais les titres fatals des chapitres de la même façon qu'à trois ou quatre ans je m’étais répété le mot givre, le jour de la découverte du givre ${ }^{1}$.

Mais comment, pourquoi Le Grand Meaulnes est-il si mémorable? De quelle manière, par quels moyens le roman parvient-il à laisser une marque aussi durable? Évidemment, la matière du roman, à savoir les souvenirs d'une jeunesse heureuse, remplie d'aventures, de passions fulgurantes et de mystère, y est pour beaucoup dans l'engouement suscité. Pourtant, cette matière à haut potentiel de nostalgie n'est pas seule en cause. Car si le roman d'Alain-Fournier est si marquant, si mémorable, c'est aussi parce que cette matière, dans une forme de redoublement ou de renforcement, est perçue comme nostalgique dans le roman lui-même. Les personnages passent le plus clair de leur temps à se souvenir de ce qu'ils ont vécu, à mesurer ce qu'ils vivent ou racontent à l'aune d'une mémoire toujours active, voire à privilégier la mémoire d'une chose ou d'un être à la chose ou à l'être lui-même. Ainsi de cette phrase révélatrice que Valentine Blondeau adresse à Meaulnes: "Ce qui me plaît en vous, avait-elle dit à Meaulnes en [le] regardant longuement, ce qui me plaît en vous, je ne puis savoir pourquoi, ce sont mes souvenirs..." (GM, p. 260). Si Le Grand Meaulnes est si mémorable, c'est d'abord parce que l'enjeu de l'œuvre consiste moins à narrer des événements envisagés pour eux-mêmes qu'à mettre en scène des personnages en train de se rappeler ces événements. En somme, ce n'est pas tant l'aventure que la remémoration de l'aventure qui constitue l'enjeu du roman.

Pour s'en convaincre, il suffit de penser au personnage de François Seurel, narrateur-témoin et protagoniste, dont la plupart des interventions au fil du récit portent les marques d'une mémoire en action : "Je me rappelle encore cet être singulier et tous les trésors étranges...» $(G M$, p. II3) ; «Je ne saurais plus reconstituer aujourd'hui [...]. Je me

I. Tiphaine Samoyault, «Entrevue avec Pierre Michon», dans Alain-Fournier, Le Grand Meaulnes, Paris, Flammarion, Garnier-Flammarion, 2009, p. ii-iii. Toutes les citations du roman (désigné dans le texte par « $G M »)$ sont tirées de cette édition. 
rappelle seulement que...» (GM, p. I35); «Je me souviens que...» (GM, p. I40); «Amers souvenirs!» (GM, p. I40); «Et c'est tout ce que je me rappelle de cette morne fin d'un grand jour de défaite» (GM, p. I49); "Je me souvins du triste dîner..."; "Et je me souvenais aussi de mes terreurs...» (GM, p. I86). Remarquons au passage que Pierre Michon emploie les mêmes mots que Seurel ( Je me souviens de la première fois...") et qu'on trouve dans son témoignage une même propension à la rumination ( Et je me répétais les titres fatals des chapitres...») et au ressassement, lui qui affirme encore: «Je l'ouvre au moins tous les étés, quand je vais à la campagne, où ce vieux livre magique, ce talisman rouge et or m'attend ${ }^{2}$.» Si ces similitudes tiennent pour une bonne part aux règles implicites qui président à la narration du souvenir, nous aurions pourtant tort de ne pas voir là le résultat d'une ouvre de persuasion entreprise par le roman lui-même. Car le pouvoir de séduction du Grand Meaulnes est tel que le lecteur semble insensiblement amené à adopter le langage de l'œuvre et la posture du narrateur. La rumination de Seurel s'aggrave au point où le lecteur, sans bien s'en rendre compte, ne peut faire autrement que de ruminer avec lui en "révisant", suivant des angles et des points de vue divers, des événements plusieurs fois racontés. Nous nous trouvons donc en face d'une véritable "programmation " du mémorable, que le lecteur est non seulement appelé à entériner, mais aussi à reproduire et à relayer en suivant l'exemple du relayeur et «relateur» modèle, François Seurel.

François Seurel est un personnage à la fois étrange et fascinant, figure de la transmission qui ne peut se consacrer pleinement à préserver la mémoire des autres que dans la mesure où il s'oublie lui-même - et parvient à se faire oublier. Car si le lecteur conserve dans sa mémoire une image vive d'Augustin Meaulnes, grand survenant romantique, d'Yvonne de Galais, la plus belle et la plus pure de toutes les femmes, de Frantz de Galais, fiancé esseulé ou bohémien dont la tête est couverte d'un bandage depuis qu'il a vainement tenté de se suicider, en revanche, il n'a pas de François Seurel une image claire, sauf peut-être

2. Ibid., p. iii. 
celle, justement, d'une faiblesse - il a un genou qui boite -, et plus encore celle d'un défaut d'être, d'une absence.

Seurel n'est jamais qu'un intermédiaire permettant au lecteur d'accéder au récit, à l'aventure d'un autre. Avec lui, le lecteur se trouve presque toujours dans le domaine du "comme si vous y étiez", dans l'espace de la procuration. Seurel joue auprès d'Yvonne et de sa fille à peine née le rôle de substitut de Meaulnes et le dénouement du récit, loin d'attester sa valeur, l'arrache à la vie qu'il croyait pouvoir mener. Car s'il croira pendant un temps qu'après la mort d'Yvonne et le départ de Meaulnes, la petite fille de ses deux amis puisse devenir sienne, qu'il puisse entrer dans sa propre histoire en assurant enfin sa propre continuation, François Seurel voit Augustin Meaulnes tout lui ravir in extremis - la petite fille, sa vie, son aventure possibles - et le condamner à n'être jamais autre chose que celui qui rêve et raconte: "La seule joie que m'eût laissée le grand Meaulnes, je sentais bien qu'il était revenu me la prendre. Et déjà je l'imaginais, la nuit, enveloppant sa fille dans un manteau, et partant avec elle pour de nouvelles aventures » (GM, p. 233).

L'aventure rêvée ou vécue par procuration n'est pas étrangère au travail de la remémoration. Car la découverte du domaine mystérieux et de la fête étrange, l'événement phare du roman - et dont les lecteurs gardent le plus souvent un souvenir idyllique -, cette découverte, plutôt que de faire l'objet d'une présentation directe, nous est racontée par un double relais: Seurel se souvient de Meaulnes se rappelant à son tour des événements et des personnages qui ont marqué son séjour enchanté. Le jeu du double relais est fréquent dans le roman et implique presque toujours Meaulnes et Seurel. Dans la troisième partie, un troisième relais s'ajoute ou plutôt se confirme: celui de la fiction. Car pour raconter les aventures que Meaulnes a vécues à Paris, Seurel ne peut plus compter sur un témoignage direct, celui que Meaulnes lui aurait offert de vive voix ou qu'il lui aurait transmis, comme à la fin de la seconde partie, par une série de lettres. Dans cette troisième partie, Seurel se donne la tâche de reconstituer les événements vécus par Meaulnes à partir de notes griffonnées par Meaulnes lui-même dans un cahier de devoirs mensuels, sorte de journal intime qu'il a tenu durant son séjour à Paris et dont Seurel affirme qu'il «était rédigé de façon si hachée, si informe, griffonné si hâtivement aussi, [qu'il a] dû reprendre [lui]-même 
et reconstituer toute cette partie de son histoire» $(G M$, p. 220). Loin d'être anecdotique, un tel défi de reconstitution contribue à mettre en évidence l'exigence à laquelle est confronté Seurel et qui traverse tout le roman, à savoir que la mémoire ne peut rien sans l'imagination, que le travail de remémoration est toujours, d'une certaine manière, un travail de recréation ${ }^{3}$. Dès les premières lignes du roman, alors qu'il décrit l'installation de sa famille dans le village de Sainte-Agathe, qu'à l'instar du narrateur d'un roman réaliste, il plante le décor, situe les personnages et définit leur rôle, Seurel ne peut s'empêcher de mettre en évidence la nature partielle et partiale de son récit, en laissant voir la part que ce dernier doit à l'imagination:

C'est ainsi, du moins, que j'imagine aujourd'hui notre arrivée. Car aussitôt que je veux retrouver le lointain souvenir de cette première soirée d'attente dans notre cour de Sainte-Agathe, déjà ce sont d'autres attentes que je me rappelle; déjà, les deux mains appuyées aux barreaux du portail, je me vois épiant avec anxiété quelqu'un qui va descendre la grand'rue. Et si j'essaie d'imaginer la première nuit que je dus passer dans ma mansarde, au milieu des greniers du premier étage, déjà ce sont d'autres nuits que je me rappelle; je ne suis plus seul dans cette chambre; une grande ombre inquiète et amie passe le long des murs et se promène. Tout ce paysage paisible - l'école, le champ du père Martin, avec ses trois noyers, le jardin dès quatre heures envahi chaque jour par des femmes en visite - est à jamais, dans ma mémoire, agité, transformé par la présence de celui qui bouleversa toute notre adolescence et dont la fuite même ne nous a pas laissé de repos. (GM, p. II)

Ce passage montre que l'oubli est inséparable du souvenir, que, pour se rappeler un événement, un lieu ou un être, il faut d'abord que le temps en ait effacé dans notre pensée les traits et les contours; bref, qu'on ne saurait se rappeler une chose sans l'avoir d'abord oubliée. Mais surtout, un tel passage marque l'écart fondamental qui se dessine entre une mémoire idéale, réminiscence parfaite, telle que la concevait par exemple saint Augustin à travers sa célèbre métaphore du palais de la mémoire ${ }^{4}$, et telle que nous continuons spontanément de la définir pour nous-mêmes, c'est-à-dire une mémoire telle qu'il serait possible

3. Voir la synthèse réalisée par Patrick J. Geary dans La Mémoire et l'oubli à la fin du premier millénaire, Paris, Aubier, traduit de l'anglais par Jean-Pierre Ricard, 1996.

4. Voir Les Confessions de saint Augustin, livre X. 
de la recouvrer intégralement, et la mémoire proprement humaine, incomplète et faillible, qui ne peut trouver secours qu'en l'imagination. La mémoire et l'imagination se trouvent liées par le jeu de l'analogie et de l'association: le souvenir, plus précisément la représentation mentale du souvenir, est formé par le rapprochement entre des situations et des objets analogues. Ainsi, Seurel admet que s'il songe à la "première nuit " passée dans sa mansarde, "déjà ce sont d'autres nuits» dont il se souvient, que s'il songe à cette première soirée d'attente, ce sont d'autres soirées qui surgissent. Meaulnes met en branle un processus analogue. Tout se passe comme si, afin de reconstituer l'image d'un souvenir précis, il lui fallait consulter une sorte de répertoire imaginaire:

Souvent, plus tard, lorsqu'il s'endormait après avoir désespérément essayé de se rappeler le beau visage effacé, il voyait en rêve passer des rangées de jeunes femmes qui ressemblaient à celle-ci. L'une avait un chapeau comme elle et l'autre son air un peu penché; l'autre son regard si pur; l'autre encore sa taille fine, et l'autre avait aussi ses yeux bleus; mais aucune de ces femmes n'était jamais la grande jeune fille. (GM, p. 72)

Ce passage pose une question fondamentale: que faire quand la mémoire fait défaut au point que même l'imagination ne parvient pas à pallier ses manquements? La réponse d'Augustin Meaulnes tient de la démesure: il faut retrouver, il faut recouvrer, littéralement s'entend, l'objet de sa mémoire. C'est en grande partie parce que Meaulnes n'arrive pas à reconstituer une image satisfaisante d'Yvonne de Galais qu'il part à sa recherche, non pas tant à la recherche d'Yvonne considérée en elle-même ou pour elle-même, c'est-à-dire comme un être de chair, qu'à la recherche d'Yvonne telle que sa mémoire et son désir la lui dépeignent. Nul hasard d'ailleurs si, dès qu'il la retrouve et l'épouse - c'est-à-dire aussi dès qu'elle quitte le domaine de sa mémoire pour devenir un être de chair, qu'elle a été «salie» par une chute éminemment symbolique ${ }^{5}$-, il sent la nécessité de la quitter. C'est que, déjà, l'image d'Yvonne, de la "vraie», a été ternie par la consommation de l'amour et qu'il faut à Meaulnes réinstaurer entre elle et lui une dis-

5. Immédiatement après la consommation de l'amour, Yvonne de Galais rejoint Augustin Meaulnes et François Seurel qui découvre "une figure échevelée, hagarde»: «Elle avait dû tomber et se blesser, car elle avait le front écorché au-dessus de l'œil droit et du sang figé dans les cheveux» (GM, p. 192). 
tance propre à faire triompher le souvenir sur l'objet lui-même. Cette situation n'est pas sans rappeler la confidence d'Alain-Fournier faite à son ami Jacques Rivière au sujet d'un rendez-vous manqué avec une jeune femme aimée. On trouve dans les mots du romancier au moins autant de déception que de soulagement, lui qui semble savoir que la vraie jeune fille ne saurait rivaliser avec la puissance du souvenir qui lui est rattaché: «fût-elle revenue qu’elle n’aurait pas été la même. - Et quand elle reviendra elle ne sera pas la même ${ }^{6}$.»

Des contemporains d'Alain-Fournier lui reprocheront le trop grand contraste entre la première partie du roman, enchanteresse et haletante, et les deux autres parties, en apparence plus décousues et statiques. Même s'il dit comprendre leur importance dans l'économie de l'œuvre, Gide déplore un roman qui avance péniblement vers sa fin et dont l'intrigue repose tout entière sur le ressassement nostalgique d'événements passés ${ }^{7}$. Thibaudet, dans une étude sur le roman de l'aventure parue en 1919, est plus direct. Il reproche à Alain-Fournier d'avoir prolongé inutilement le roman, au point où le roman d'aventures, fait de péripéties et de rebondissements, est remplacé par ce qu'il appelle le roman «romanesque», c'est-à-dire un roman qui fait toute la place à l'imagination d'un héros passif et pensif:

Le Grand Meaulnes a peut-être cent pages de trop, celles où le romanesque prolonge l'aventure quand l'aventure a donné tout son effet: le romanesque est jeté sur les marcs de l'aventure pour en faire une seconde cuvée. Et la dernière phrase qui nous montre Meaulnes engagé dans le romanesque

6. "Lettre d'Alain-Fournier à Jacques Rivière», 27 mai 1906, dans Jacques Rivière et Alain-Fournier, Une amitié d'autrefois. Lettres choisies, édition préparée par Alain Rivière, Paris, Gallimard, coll. «Folio », 2003, p. 289.

7. Dans une entrée de journal datée de 1933, André Gide note: "Le Grand Meaulnes dont l'intérêt se dilue; qui s'étale sur un trop grand nombre de pages et un trop long espace de temps; de dessin quelque peu incertain et dont le plus exquis s'épuise dans les cent premières pages. Le reste du livre court après cette première impression virginale, cherche en vain à s'en ressaisir... Je sais bien que c'est le sujet même du livre; mais c'en est aussi le défaut, de sorte qu'il n'était peut-être pas possible de le "réussir" davantage.» Cité par Alain Buisine, Les Mauvaises Pensées du Grand Meaulnes, Paris, PUF, 1992, p. 17. 
pour sa vie entière diminue par un choc en retour l'intérêt de la première et pure aventure d'enfant, qui devrait demeurer l'unique ${ }^{8}$.

Si belle soit-elle, la lecture de Thibaudet semble davantage préoccupée par les nécessités de sa propre démonstration que par les données internes de l'œuvre. C'est que l'enjeu fondamental du roman consiste, dans ces deuxième et troisième parties jugées trop longues ou trop lentes, à maintenir vivante la mémoire de ce qui a été vécu dans la première. Il s'agit de retrouver ce qui a été perdu: d'abord, le chemin menant au domaine mystérieux, que Meaulnes et François recherchent activement, notamment dans un chapitre dont l'intitulé n'est pas sans rappeler Proust lui-même: "À la recherche du sentier perdu», et dont Meaulnes s'affaire à dessiner le plan, toujours incomplet, en tentant de situer les lieux entourant le domaine mystérieux. Il est vrai que la première partie se distingue des autres dans la mesure où les événements qui y sont décrits sont de nature enchanteresse, proches de ce que la critique a depuis lors appelé le réalisme magique. À dessein, AlainFournier brouille les repères temporels et spatiaux et maintient les scènes de la fête étrange dans le flou, de sorte que le lecteur se demande si les événements dont Meaulnes témoigne et auxquels ils participent relèvent de la réalité ou du rêve. Comment expliquer, en effet, l'existence de cette fête où il n'y a que des enfants et des vieillards, vêtus de beaux habits des siècles anciens, une fête où les enfants font la loi et où des pierrots jouent la pantomime et, surtout, une fête qui doit permettre à un garçon de quinze ans d'épouser sa fiancée? On peut mesurer l'ampleur du contraste entre la vie morne et ennuyeuse de petits écoliers de province et la découverte aussi inespérée qu'inexplicable d'un pays de contes de fées. Mais cet écart, cette distance infranchissable entre l'idylle et la désolation, entre l'enchantement et la désillusion, entre la plénitude et la dévastation, tels qu'ils se déploient et s'aggravent au fil des deux dernières parties du roman, sont absolument capitaux. Car il ne s'agit pas simplement pour les personnages, et pour François Seurel au premier chef, d'éviter de perdre la mémoire de ces expériences merveilleuses, mais aussi, et peut-être surtout, d'apprendre à vivre avec la mémoire de ce qui a été perdu.

8. Albert Thibaudet, "Le roman de l'aventure» [1919], dans Réflexions sur le roman, Paris, Gallimard, 1938, p. 78. 
Seurel, nous l'avons vu, porte une mémoire qui dépasse les bornes de sa propre vie: il porte la mémoire de ses proches, c'est-à-dire de Meaulnes, de Valentine, de Frantz, d'Yvonne, de Monsieur de Galais, bref de tous les personnages qu'il côtoie et dont il recueille et relate l'expérience. Mais à force de rumination et de ressassement, à force de traverser les lieux, de revoir les êtres et les choses qu'il a déjà traversés et revus, la «vieille âme» de Seurel semble être attirée par quelque chose de plus grand, ou alors pointer vers quelque chose qui transcende les bornes de sa propre vie et de sa mémoire finie, quelque chose comme la mémoire d'un monde ancien, appelé à disparaître ou alors peut-être même déjà disparu, une mémoire qui serait, pour emprunter les mots qu'Alain-Fournier avait lui-même empruntés à Jacques Rivière, la "mémoire de ce qu'il y a de plus ancien, de plus qu'oublié, d'inconnu à nous-mêmes». "C'est de cela que j'avais voulu faire mon livre et c'était fou ", écrira-t-il à Rivière en I9IO: "C’était la folie du Symbolisme. Aujourd'hui cela tient dans mon livre la même place que dans ma vie: c'est une émotion défaillante, à un tournant de route, à un bout de paragraphe, un souvenir si lointain que je ne puis le replacer nulle part dans mon passé9.» Qu'est-ce que cette «mémoire de ce qu'il y a de plus ancien, de plus qu'oublié, d'inconnu à nous-mêmes »? Difficile de répondre, puisque nous nous situons dans le domaine de l'in-mémorable, de l'informulable, dans cela même qui ne peut être nommé mais qui se situe au cœur de toute entreprise artistique. Mais ce qui frappe dans les mots employés par Alain-Fournier, c'est la reconnaissance par le romancier de ses propres limites à comprendre de quoi le roman est chargé de garder la mémoire. Bien sûr, il garde la mémoire d'une enfance perdue, d'un passé édénique qui renvoie à la fois à une expérience individuelle et à l'expérience humaine. Il garde la mémoire de cet « esprit» du temps, du Zeitgeist, d'un monde en cours de disparition. Mais ce dont parle Alain-Fournier tient sans doute aussi à quelque chose qui transcende la mémoire consciente, à la part du souvenir conservé dans une œuvre qui résiste ou échappe à l'intention du romancier, quelque chose à quoi le romancier demeurerait aveugle. Plutôt que de

9. Alain-Fournier, "Lettre à Jacques Rivière», dans Jacques Rivière et Alain-Fournier, Une amitié d'autrefois, op. cit., p. 277. 
fixer son attention sur cette mémoire inconnue et inconsciente, sur ce qui la transcende et ce vers quoi son ouvre doit tendre tout entière, Alain-Fournier choisit, selon sa propre formule, de faire comme dans la vie, c'est-à-dire de ne pas y penser d'abord et de la faire voir et sentir "à un tournant de route, à un bout de paragraphe», autant pour en préserver le mystère que pour montrer le caractère inutile ou hasardeux d'une élucidation.

Avant de terminer, un mot sur 1913, année de publication dans la $N R F$ du Grand Meaulnes mais aussi, quelques mois plus tôt, du premier tome de la Recherche proustienne. Dans les Poésies d'A. O. Barnabooth, parues la même année, Valery Larbaud, pour qui le genre romanesque est périmé ${ }^{10}$, appelle l'art à se livrer tout entier au présent, à en épouser le mouvement et la vitesse. Dans une étude sur le cubisme, Apollinaire écrit: «On ne peut pas transporter partout avec soi le cadavre de son père. On l'abandonne en compagnie des autres morts ${ }^{11}$.» Les nombreux manifestes futuristes, italiens comme russes, en appellent à la suppression de l'histoire, à la liquidation des « arts du monde ancien ${ }^{12}$ ». Â côté de cela, le moins qu'on puisse dire est que les œuvres de Proust et plus encore d'Alain-Fournier, qui avait pensé pour son célèbre roman à des titres tels que $U n$ roman de province et $U n$ roman d'autrefois, indiquent un décalage, montrent l'écart qui est en train de se creuser entre le roman et les autres grandes formes artistiques. Voilà un autre exemple à verser au dossier de ce qu'Isabelle Daunais appelle très justement la "vieillesse du roman », vieillesse qui semble s'affirmer ou se révéler tout particulièrement au cours des premières décennies $\mathrm{du} \mathrm{xx}^{\mathrm{e}}$ siècle. Selon elle, la valeur du roman ne repose pas tant sur son "avance sur ce qui se transforme partout autour de nous», mais au contraire, sur «tout ce qui le retient dans la

Io. Suite à la lecture des Lauriers sont coupés d'Édouard Dujardin, Larbaud se demande en effet si ce livre d'un nouveau genre serait en mesure de se «substituer complètement" au roman tel qu'il se pratique. Valery Larbaud, "Édouard Dujardin ", Ce vice impuni, la lecture. Domaine français, Paris, Gallimard, 194I [1924]. Texte repris aussi en préface des Lauriers sont coupés, Paris, Messein, 1925, p. 249.

II. Guillaume Apollinaire, Les Peintres cubistes. Méditations esthétiques, Paris, Hermann, 1965 [1913], p. 46.

I2. Kazimir Malevitch, cité dans Jean Weisgerber (dir.), Les Avant-gardes littéraires au XXe siècle, vol. 2, Amsterdam-Philadelphie, John Benjamins, 1986, p. 640. 
durée et dans l'histoire [...], la lenteur qu'impose sa forme pour la description des êtres et des choses, autrement dit le "retard" qui est le sien face à tout ce que nous inventons, tout ce que nous bouleversons, tout ce que nous révolutionnons (ou croyons révolutionner), bref à tout ce que nous oublions ou abandonnons parce que nous croyons ainsi être plus libres et plus légers ${ }^{13}$ ".

I3. Isabelle Daunais, "Vieillesse du roman", L'Inconvénient (Montréal), n 37, mai 2009, p. II. 



\title{
Le lecteur comme survivant
}

\author{
Christophe Pradeau
}

«Toute limite est un commencement aussi bien qu'une fin. Qui peut laisser de jeunes vies après une longue fréquentation sans souhaiter connaître leur sort ${ }^{1}$ ?» se demande George Eliot, aux premières lignes de l'épilogue de Middlemarch. Le roman, parce qu'il dispose librement du temps - qu'il ait l'ambition de représenter le présent en marche ou d'épouser le mouvement même de la vie -, est malhabile à faire de sa fin un dénouement. Cette conception d'un temps romanesque desserré, parce qu'elle induit que toute clôture n'est jamais que de convention, corrode l'idée de fin, en l'associant à des formes plus ou moins aiguës de l'insatisfaction : regret, remords, nostalgie, chagrin... Des écrivains aussi différents que James ou Giono ont évoqué ces personnages rémanents qui reviennent hanter le romancier, exigeant de lui qu'il leur donne la chance d'une seconde vie, au nom de possibles inexploités. Symétriquement, l'idée doloriste s'impose peu à peu que le lecteur s'éprouve, au moment de quitter son livre, comme un survivant. Une lettre adressée par Henri Legrand à son ami Jules Romains, lecture faite du vingt-septième et dernier volume des Hommes de bonne volonté, peut servir ici d'emblème:

En refermant un roman, j'ai toujours eu l'impression que les héros du livre étaient au bout de leur vie, que leur fiction s'évanouissait et que moi je restais le vivant, le survivant. [...] Mais cette fois-ci, je n'ai pas ressenti une pareille assurance... À cette dernière étape du Banquet, j’ai éprouvé

I. George Eliot, Middlemarch, trad. A. Loisy, Paris, Omnibus, 1995, p. 666. 
que c'était moi qui partais, qui quittais un monde peuplé de beaucoup de vivants, bien vivants, que j'avais accompagnés pendant bien des années. Soudainement, ils m'ont tous quitté, pour continuer leur vie sans moi, sans que je puisse encore les regarder et marcher avec eux. Celui qui meurt, à la fin des H.B.V., c'est le lecteur ${ }^{2}$.

La lettre d'Henri Legrand cherche à cerner l'effet esthétique des romans de vastes dimensions, cycles romanesques ou romans-fleuves, qu'il invite à considérer comme une inversion de la relation hiérarchique entre réalité et fiction, un roman comme Les Hommes de bonne volonté réussissant à entretenir le lecteur dans l'illusion qu'il excède son corps textuel. Je n'ai pas l'intention d'examiner ici le cas spécifique des romans au long cours. Ce qui m’importe, c'est qu'un lecteur avisé du milieu du $\mathrm{Xx}^{\mathrm{e}}$ siècle ne puisse envisager la fin de la lecture autrement qu'en termes de disparition et de survivance. Une telle conception n'est en rien isolée ou excentrique; elle est même largement partagée, à dater des premières années du siècle dernier, et, à ce titre, peut être considérée comme un signe de l'accession du roman, au sortir de la Première Guerre mondiale, à la fonction structurante de genre cardinal. Penser le moment où se referme le livre comme une cérémonie des adieux, est, en effet, une conception de lecteur de romans, comme j'essaierai de le montrer, en proposant une lecture en parallèle des "Journées de lecture», la préface que Proust publie en 1906, en tête de sa traduction de Sésame et les $L y s^{3}$, et de ce qu'il est convenu d'appeler «le roman d'Albertine», cet entre-deux qui démesure de l'intérieur $A$ la recherche du temps perdú.

La lecture romanesque, telle que Proust en décrit la dynamique, le pouvoir de fascination, chez l'enfant générique des "Journées de lecture», enfant formé de ses souvenirs de vacances à Illiers mais présenté comme le dépositaire de l'expérience commune, est une lecture menacée, toujours près d'être interrompue. Proust y insiste, la lecture,

2. Henri Legrand, "Lettre à Jules Romains", dans Cahiers Jules Romains 6, Paris, Flammarion, 1985, p. 350.

3. Marcel Proust, "Journées de lecture» [désormais $J L$ ], dans Contre Sainte-Beuve, éd. P. Clarac et Y. Sandre, Paris, Gallimard, coll. "Bibliothèque de la Pléiade», I97I, p. I60-194.

4. Marcel Proust, $\grave{A}$ la recherche du temps perdu [désormais RTP], Paris, Gallimard, coll. «Bibliothèque de la Pléiade», dir. J.-Y. Tadié, 1987-1989, 4 vol. 
avant de finir pour de bon, s'impose d'abord comme une succession de fins provisoires. Si elle vous enveloppe dans une intimité qui a ceci de paradoxal qu'elle est aussi un monde, cet éloignement intérieur est fragile et demande à être défendu. Le rythme de la lecture ne s'accorde pas avec les rituels et obligations du quotidien. Lespace réservé de l'enfant-lecteur n'est jamais suffisamment défendu; aussi celui-ci recherche-t-il les recoins, les lieux reculés, chambres closes, cabinets, charmilles. Proust suggère que la lecture doit précisément une partie de sa puissance d'entraînement à ces empêchements, à cette succession d'abandons et de reprises, à la nature segmentée d'un processus qui demande pour s'accomplir un constant travail de ravaudage, mais qui, de ce fait, s'incorpore la suite des jours. Il revient à la mémoire de réunir, de constituer en un corps unifié, ce que le temps quotidien, en s'infiltrant, a donné à éprouver comme une succession mal ajointée, trouée d'interruptions favorisant l'oubli. Le pluriel du titre "Journées de lecture" fait signe vers cette nature cloisonnée, posée d'emblée comme définitoire. Il suggère, en premier lieu, l'enchaînement des lectures, la curiosité insatiable qui conduit le lecteur à sauter d'un livre à l'autre. Mais un examen attentif du texte invite surtout à y voir une façon de prendre en considération une donnée essentielle de la lecture romanesque, ce fait très simple mais lourd de conséquences que plus d'une journée est nécessaire à la lecture d'un roman. Un roman veut pour se réaliser dans la conscience d'un lecteur plus de temps que la tradition aristotélicienne n'en concède au drame pour courir de l'exposition au dénouement. Je rapproche à dessein temps effectif de la lecture et temps conventionnel de la représentation, qui ne participent certes pas d'un même niveau de réalité, mais dont on sait que l'un est à la mesure de l'autre puisqu'aussi bien on s'accorde à reconnaître que ce sont les contraintes pratiques de la représentation qui ont conduit à endiguer le temps de l'intrigue dramatique dans l'étroitesse de vingtquatre heures.

Si une journée, c'est un laps de temps, celui qui s'écoule du lever au coucher du soleil, c'est aussi, en emploi absolu, le travail effectué pendant une journée, celui de la cuisinière qui, mettant la table, interrompt la lecture de l'enfant, ou encore, acception vieillie du terme, mais active dans la langue proustienne, le chemin effectué ou qu'il est possible d'effectuer du lever au coucher du soleil, le mot étant alors compris 
comme un synonyme d'étape. On voyageait, quand cela impliquait encore d'aller au rythme de la marche ou du trot d'un cheval, à petites ou à grandes journées, expression devenue désuète au fur et à mesure que le train, l'automobile et l'avion raccourcissaient les distances, notion toute relative puisque les distances ne sont jamais, selon la définition qu'en donne Proust, que «le rapport de l'espace au temps et varient avec lui ${ }^{5} "$.

«Journées de lecture» se donne, sur le mode itératif, pour le récit synthétique d'une journée de vacances, envisagée du point de vue d'un jeune lecteur captivé. Le texte pour donner à éprouver ce point de vue joue d'un effet d'œillères. La vie quotidienne, les préparatifs du déjeuner, du dîner, le rituel des promenades, des visites de politesse, est entr'aperçu du coin de l'œil, repoussé dans les marges, dans cet entredeux entre le visible et l'invisible que l'on appelle la vision périphérique. Les «journées de lecture» se nichent, comme en fraude, dans les interstices des journées de travail, comme un négatif de celles-ci: le temps océanique du lecteur a pour contrepartie celui, tendu, ritualisé, de la cuisinière, qui met la table, accomplit les tâches successives que l'on attend d'elle, à heure dite. Si les journées de travail participent d'un temps mesuré, le long loisir de la lecture ne demande qu'à déborder, démesurant les heures, prolongeant la journée jusqu'au cœur de la nuit, entassant les années d'une vie dans l'espace de quelques heures.

De fin provisoire en fin provisoire, l'enfant finit pourtant par buter contre le blanc qui prétend mettre un terme à l'aventure: "Puis la dernière page était lue, le livre était fini. Il fallait arrêter la course éperdue des yeux et de la voix qui suivait sans bruit ${ }^{6}$.» Le lecteur semble menacé de perdre l'équilibre, victime de la vitesse acquise, du conflit entre le mouvement en lui des yeux, de l'imagination, et tout autour de lui, de l'immobilité des choses. De fait, la fin de la lecture est chez Proust le moment du plus haut péril, moment d'incertitude, coincé entre vitesse et immobilité, fiction et réalité:

Alors, quoi? ce livre, ce n'était que cela? Ces êtres à qui on avait donné plus de son attention et de sa tendresse qu'aux gens de la vie [...] on ne les verrait plus jamais, on ne saurait plus rien d'eux. Déjà, depuis quelques

5. RTP, t. III, p. 385 .

6. JL, p. 169 . 
pages, l'auteur, dans le cruel «Épilogue», avait eu soin de les "espacer» avec une indifférence incroyable pour qui savait l'intérêt avec lequel il les avait suivis jusque-là pas à pas. [...] On aurait tant voulu que le livre continuât, et, si c'était impossible, avoir d'autres renseignements sur tous ces personnages [...] employer [notre vie] à des choses qui ne fussent pas tout à fait étrangères à l'amour qu'ils nous avaient inspiré $[. . .]^{7}$.

La lecture romanesque, en dépit de l'âge du sujet de l'expérience, est vécue ou demande à se dire à la façon d'une liaison amoureuse. Le roman s'est déposé dans la conscience sous la forme de personnages qui, le roman se refermant, s'éloignent dans un hors champ qui s'impose à l'imagination comme une pâle survivance, à l'image de celle des ombres infernales dans l'Odyssée. La fin de la lecture est dès lors perçue comme une trahison, un exil, mais aussi comme une mise en péril de la fiction menacée d'être ramenée, du fait même qu'elle finit, à une illusion, une contrefaçon de la vie. De la même façon que, selon l'argument cartésien, la discontinuité de la vie onirique trahit le caractère illusoire du rêve au regard de la vie éveillée, la fiction romanesque est trahie par le fait même qu'elle se heurte à la nécessité de finir, donnant ainsi prise au désamour et à l'oubli. Reposer le livre dans la bibliothèque, c'est, pour le lecteur proustien, assumer la mauvaise conscience du survivant, voir ses affections sombrer dans l'irréalité de l'impermanence. Comme le rappelait, à l'ouverture de mon propos, la question rhétorique de George Eliot, ce désir du lecteur de voir le livre continuer, d'inféoder les personnages à son existence, l'épilogue a pour fonction de faire mine de le satisfaire. Le livre, anticipant sa fin, demande au lecteur de faire comme s'il l'avait déjà quitté, comme s'il le considérait à distance, en l'absence des personnages, depuis le deuil d'une présence. Le lecteur, désolidarisé des existences qu'il a épousées, doit se contenter, près d'être congédié, des quelques nouvelles qu'on veut bien encore lui en donner, à la condition qu'il se résigne ensuite à les perdre de vue. Il reviendrait ainsi à l'épilogue d'amender l'un des défauts du roman, le sentiment qu'il donne de vouloir continuer sur son erre, de déborder la fin de tout son poids d'avenir, suscitant ainsi chez ses lecteurs regrets et frustrations. En éloignant le lecteur des personnages - le recours à l'ellipse et au récit sommaire ayant pour conséquence de les débrayer 
en les encapsulant dans deux temporalités inconciliables -, l'épilogue prétend dilapider le capital d'avenir dont est faite la vitesse acquise du récit et neutraliser ainsi l'amertume de la fin. On comprend la révolte du jeune lecteur proustien. La prétention de l'épilogue peut sembler à bon droit exorbitante qui demande au lecteur de chausser des bottes de sept lieues et, sautant d'un bond par-dessus les jours, les semaines, de s'épargner le séjour du chagrin, en anticipant sur l'oubli et l'indifférence. Il s'agit de faire comme si des années de sa vie s'étaient enfuies dans le temps où l'on tournait la page, de faire comme si l'on était détaché, depuis longtemps déjà, des personnages, dans la position de se souvenir d'eux avec la sérénité de celui pour qui tout cela n'est plus qu'histoire ancienne, alors même que l'on éprouve encore en soi la chaleur empathique de la fréquentation. On s'accorde à voir dans ce forçage de la durée une façon de ménager un sas entre le monde de la fiction et le monde réel, dans la pensée d'atténuer ainsi la violence inhérente à la sortie de l'état d'«immersion fictionnelle ${ }^{8}$ ». Si l'épilogue est bien l'entre-deux qu'on y voit généralement, il le doit à ce qu'il met le lecteur en position d'éprouver la fin du roman comme une séparation, autrement dit de glisser, par anticipation, d'un régime de fréquentation textuelle à un régime de survivance mémorielle. L'épilogue modélise ainsi le processus qui met en mémoire le roman, la façon dont il survit dans la mémoire de ses lecteurs, détaché de son corps textuel. Ce processus, j'en ferai du moins l'hypothèse, est l'un des principaux ressorts du «roman d'Albertine». Si l'effet esthétique de l'épilogue, la façon qui est la sienne d'«espacer» les personnages, révolte l'enfant des "Journées de lecture», Proust, dont on connaît par ailleurs l'admiration professée pour "l'énorme "blanc" " qui constitue comme tel l'épilogue de L'Éducation sentimentale, mobilise cet effet esthétique, jusqu'au vertige, dans La Prisonnière et Albertine disparue, constituant ainsi le diptyque albertinien en un lieu réflexif où se disent les enjeux du passage du roman en régime mémoriel.

8. Voir Jean-Marie Schaeffer, Pourquoi la fiction?, Paris, Éditions du Seuil, coll. «Poétique», 1999, p. I79-198.

9. "À propos du "style" de Flaubert" (NRF, I ${ }^{\text {er }}$ janvier 1920), dans Contre SainteBeuve, op. cit., p. 595. 
La situation décrite dans La Prisonnière, cette cohabitation indécente, contrevenant à tous les usages bourgeois, entre un jeune homme et une jeune fille, installe les protagonistes dans une temporalité désocialisante. Cette réclusion volontaire se donne très explicitement, et ce à plusieurs reprises, comme une image de la lecture, de la temporalité aquatique dont chacun fait l'expérience en se plongeant dans un livre. Rien ne contribue autant à l'allégorisation de La Prisonnière que sa composition atypique, qui en fait une suite de sept "journées», autant que de sections dans la Recherche. Ces journées, bien entendu, sont des unités narratives complexes, qu'on ne peut rapporter à la mesure du temps quotidien. Leurs frontières sont néanmoins très nettement marquées. À sept reprises, le Narrateur décrit l'heure de son réveil, son attention encore ensommeillée aux jeux de la lumière sur le mur ou le sol de sa chambre, aux bruits de la rue, aux cris de Paris, qui lui évoquent la déclamation, "à peine colorée par des variations insensibles", de Boris Godounov et de Pelléas et Mélisande ${ }^{10}$. Mais l'heure de ce réveil est incertaine, et sans doute varie-t-elle d'une journée à l'autre, en raison du mode de vie excentrique du Narrateur, qui semble sur le point de recommencer, selon des modalités tout autres cependant, la vie cloîtrée de sa tante Léonie. De fait, si elle suggère une «léonisation» du Narrateur, la dramaturgie de La Prisonnière évoque avant tout celle de la légende proustienne, dont nous connaissons comme de l'intérieur la "mécanique " grâce aux mémoires de Céleste Albaret ${ }^{11}$, dramaturgie de la claustration dans la chambre de liège, où nul n'est censé entrer de sa propre initiative. Tout se passe comme si le Narrateur et Proust avec lui n'avaient eu de cesse d'édifier autour d'eux l'espace utopique dont l'enfant des "Journées de lecture" avait pu rêver, un espace protégé des intrusions, des sollicitations extérieures, qui permette le plein déploiement de la vie imaginative. Entre réveil et coucher, une journée s'écoule mais démesurée par les souvenirs, les rêves, les hypothèses, les comparaisons, les digressions, les épaississements de durée du mode itératif.

IO. RTP, t. III, p. 623 .

II. Céleste Albaret, Monsieur Proust. Souvenirs recueillis par Georges Belmont, Paris, Robert Laffont, 1973. 
Les pensées du Narrateur, à son réveil, vont soit vers Albertine, soit vers les journaux que lui présente Françoise, dans l'attente où il est de la parution prochaine, toujours remise au lendemain, de son premier texte. Les deux préoccupations du Narrateur, son amour jaloux pour Albertine et son entrée en littérature, encore largement hypothétique, se rencontrent en ceci qu'elles questionnent l'une et l'autre, selon des modalités distinctes mais analogues, largement superposables, la réalité de l'art et de la vie.

Au terme de ce long voyage immobile de sept journées, Albertine se transforme, du personnage dramatique ${ }^{12}$ qu'elle fut - toujours en mouvement, penchée sur sa bicyclette, courant sur la plage - en un personnage de roman, entendez un personnage moins fait d'actions que de souvenirs, "être de fuite" toujours, mais, plus radicalement, plus douloureusement, depuis que, et parce que disparue, la jeune fille est perçue comme coextensive au labyrinthe labile de la mémoire. Sa mort achève de faire d'Albertine le personnage que le Narrateur n'aura eu de cesse de voir en elle, en s'acharnant à l'envelopper dans les hypothèses contradictoires d'un roman de la jalousie. Cette métamorphose s'accomplit dans le chagrin que le Narrateur éprouve, dont il fait son séjour, dans lequel il s'installe une année durant, tout entière consacrée au souvenir de la jeune fille, chagrin qu'il déchiffre en lui, qu'il lit à grandes journées, à la façon dont on lit un roman:

Depuis le moment où j'étais éveillé et où je reprenais mon chagrin à l'endroit où j'en étais resté avant de m'endormir, comme un livre un instant fermé et qui ne me quitterait plus jusqu'au soir, ce ne pouvait jamais être qu'à une pensée concernant Albertine que venait se raccorder pour moi toute sensation, qu'elle me vînt du dehors ou du dedans ${ }^{13}$.

Ce que le Narrateur appelle avec insistance son «chagrin» - le mot figure dans le titre du premier chapitre d'Albertine disparue: «Le chagrin et l'oubli» et revient de façon obsessionnelle tout au long du volume -, c'est avant tout la mauvaise conscience de survivre à la jeune

I2. "Comme elle accourait vite me voir à Balbec quand je la faisais chercher, se retardant seulement à verser de l'odeur dans ses cheveux pour me plaire! [...] Tout cela qui n'était pour moi que souvenir avait été pour elle action, action précipitée, comme celle d'une tragédie, vers une mort rapide» (RTP, t. IV, p. 8I).

13. Ibid., p. 33. 
femme: «Et j'avais [...], avec une grande pitié d'elle, la honte de lui survivre $^{14}$.» Sentiment de honte qui se prolonge, s'approfondit en une réflexion métaphysique sur la réalité du monde et de l'art:

L'idée qu'on mourra est plus cruelle que mourir, mais moins que l'idée qu'un autre est mort, que, redevenue plane après avoir englouti un être, s'étend, sans même un remous à cette place-là, une réalité d'où cet être est exclu, où n'existe plus aucun vouloir, aucune connaissance et de laquelle il est aussi difficile de remonter à l'idée que cet être a vécu, qu'il est difficile, du souvenir encore tout récent de sa vie, de penser qu'il est assimilable aux images sans consistance, aux souvenirs laissés par les personnages d'un roman qu'on a lu $\mathbf{u}^{15}$.

Le Narrateur fait face à la mort de la jeune femme en faisant fond sur son expérience de lecteur. La femme aimée est assimilée, par sa mort, à un personnage de roman. Comme eux, elle n'a d'autre réalité désormais que mémorielle. La faiblesse du roman devient dès lors une force. C'est parce que sa présence dans nos mémoires n'est pas textuelle, qu'elle n'est faite que de traces, «souvenirs laissés», que le roman modélise nos existences.

La disparition d'Albertine - la phrase de Françoise qui en informe le Narrateur: «Mademoiselle Albertine est partie ${ }^{16}$ !» - est l'emblème de cet instant où l'on relève le nez de sur son livre, sommé de reprendre pied dans la réalité, instant où se dissipe le charme enveloppant de $l^{\prime}$ «immersion fictionnelle ${ }^{17}$ ». Le doute qui étreint le lecteur, au moment où, tout à la fois, il fait retour sur sa lecture et s'en éloigne, incertain de la réalité d'une expérience qui l'a tenu à l'écart de la vie, c'est celui qu'éprouve le Narrateur, incertain de la façon dont il convient de lire les mois passés avec Albertine:

J'essayais un jour de prendre un livre, un roman de Bergotte que j'avais particulièrement aimé. Les personnages sympathiques m'y plaisaient beaucoup, et, bien vite, repris par le charme du livre, je me mis à souhaiter comme un plaisir personnel que la femme méchante fût punie; mes yeux se mouillèrent quand le bonheur des fiancés fut assuré. «Mais alors, m'écriai-je avec désespoir, de ce que j'attache tant d'importance à ce qu'a

\author{
I4. Ibid., p. 78. \\ 15. Ibid., p. 90. \\ I6. Ibid., p. 3. \\ I7. Voir la note 9.
}


pu faire Albertine je ne peux pas conclure que sa personnalité est quelque chose de réel qui ne peut être aboli, que je la retrouverai un jour pareille au ciel, si j'appelle de tant de vœux, attends avec tant d'impatience, accueille avec des larmes le succès d'une personne qui n'a jamais existé que dans l'imagination de Bergotte, que je n'ai jamais vue, dont je suis libre de me figurer à mon gré le visage ${ }^{18}$ !"

Albertine disparue n'a de cesse de représenter, en variant les formulations, l'instant où le lecteur vacille entre deux mondes. Ainsi de ce moment où, en raison des aléas de l'acheminement postal, le Narrateur reçoit, à quelques minutes d'intervalle, l'annonce de la mort d'Albertine et, coup sur coup, deux lettres d'elle lui annonçant son intention de retourner près de lui. C'est l'un des moments les plus troublants de la Recherche: "J'étais comme quelqu'un qui voit la même place de sa chambre occupée par un canapé et par une grotte. Rien ne lui paraissant plus réel, il tombe par terre ${ }^{19}$." Mais Albertine disparue ne fait qu'amorcer une fin qui ne trouve à se réaliser qu'au terme du Temps retrouvé. Cette fin en deux temps, cette lente décélération, finalement préférée par Proust à la rupture brutale de l'épilogue, modélise - telle est du moins l'hypothèse sur laquelle repose ma proposition de lecture allégorique - les deux phases de la sortie de lecture. Albertine disparue représente le moment de la séparation, avec les doutes, les regrets, les incertitudes que cela implique. Le Temps retrouvé représente l'entrée en mémoire de l'œuvre qui a traversé victorieusement l'épreuve du temps et qui vous accompagne désormais, mêlée à votre vie et pour ainsi dire naturalisée, ce qui se traduit, dans la dramaturgie de la Recherche, par l'entrée en écriture du Narrateur.

Le Narrateur ne saurait, en effet, s'accomplir dans la lecture. Sa vocation, qui donne au roman sa dynamique, est celle d'un écrivain. Aussi bien est-ce à d'autres que lui qu'il revient d'incarner le liseur de romans, à Charles Swann ou au baron de Charlus. Palamède est un "balzacien", au sens que le mot a pris dans les années I880, c'est-à-dire au sens de 
connaisseur mais aussi de dévot, un liseur dont l'admiration se résout en fétichisme. La Comédie humaine ne cesse de faire retour dans sa conversation et contribue à configurer la façon dont il mène et plus encore dont il rêve sa vie. Or, très significativement, si Charlus ramène constamment le réel à $L a$ Comédie humaine, il ne cite jamais Balzac: ainsi, à propos d'un raffinement de toilette d'Albertine, peut-il évoquer la robe que portait la princesse de Cadignan lors de sa deuxième rencontre avec D'Arthez, allusion dont on voit assez qu'elle témoigne d'une connaissance précise de l'œuvre mais une connaissance qui n'a nul besoin de s'appuyer sur la lettre du texte ${ }^{20}$. Si les mots d'un poème ont vocation à demeurer dans la mémoire, il n'en est pas de même du roman, dont le corps mémoriel est presque entièrement émancipé du corps textuel. Un roman ne demande pas à être cité. Il se dit autrement, troué d'oublis, réalisé en personnages, en situations, en anecdotes exemplaires, ou même ramené à une qualité d'atmosphère, présence évanescente mais qui peut suffire. L'absence quasi complète de citations romanesques dans la Recherche est d'autant plus significative que les personnages proustiens ne cessent d'émailler leurs conversations de vers de Racine, de La Fontaine, de Baudelaire mais aussi de citations de Mme de Sévigné ou de Saint-Simon. On le voit, la prose peut donc parfaitement nourrir la connivence citationnelle. Lorsque Mme de Guermantes évoque devant «Marcel» le portrait du marquis d'Allemans par Saint-Simon, il est capable de citer fidèlement, en familier distingué des Mémoires, les premières phrases dudit portrait ${ }^{21}$. Ce sont les mots mêmes de Saint-Simon qui font irruption dans la conversation, comme à livre ouvert. À l'inverse, les discussions balzaciennes entre Charlus et le Narrateur ont lieu in absentia, à distance de l'œuvre. Elles ne portent pas à proprement parler sur elle mais sur le souvenir que l'on en garde.

Une page de Balzac revient sans cesse chez Proust, invariablement présentée comme le haut lieu de La Comédie humaine: il s'agit de la rencontre de Lucien de Rubempré et de l'abbé Carlos Herrera, alias Vautrin, aux dernières pages d'Illusions perdues. Dans Contre SainteBeuve, Proust la baptise, par allusion à un poème célèbre de $\mathrm{Hugo}^{22}$,

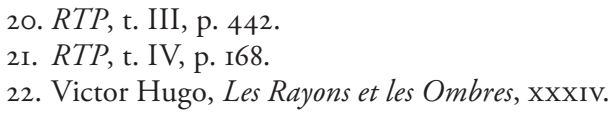


«la Tristesse d'Olympio de l'Homosexualité». Lantonomase revient, légèrement variantée, dans Sodome et Gomorrhe - il est désormais question de «la Tristesse d'Olympio de la pédérastie ${ }^{23} »-$, Charlus reprenant à son compte une formule attribuée à Swann. Il est frappant de constater que les mots qui viennent à l'auteur de Contre Sainte-Beuve pour évoquer cette page et plus précisément la rêverie de Vautrin devant le vieux manoir des Rastignac, ne sont pas empruntés à Balzac mais au poème de Hugo: "Il voulut tout revoir, l'étang près de la source.»C'est sans doute que celui-ci bénéficie d'une plus grande popularité, au tournant des $\mathrm{XIX}^{\mathrm{e}}$ et $\mathrm{XX}^{\mathrm{e}}$ siècles, que le roman de Balzac; mais c'est, plus décisivement, qu'il constitue une ressource textuelle disponible, instantanément mobilisable, ce à quoi ne peut prétendre Illusions perdues. Le même fragment de Contre Sainte-Beuve convoque le souvenir d'une rencontre nocturne entre Rastignac et Vautrin. L'analyse tourne court, faute de pouvoir faire fond sur un texte. Une note de régie vient dès lors trouer le lissé de l'analyse critique: "Citer le passage ${ }^{24}$ ».

«La Tristesse d'Olympio de l'homosexualité» emblématise ce que Charlus appelle "le côté hors nature» de Balzac; autrement dit, elle fait signe vers tout ce qui dans La Comédie humaine peut entretenir Charlus dans son identité sexuellement déviante; elle représente le Balzac de Charlus, la façon qui est la sienne de mêler Balzac à sa vie. Mais Proust invite également à y voir, par-delà le personnage de Charlus, un lieu stratégique où se dit quelque chose du propre du roman. La scène emblématise la technique du retour des personnages, l'«idée de génie de Balzac», cruellement méconnue par Sainte-Beuve, qui n’a pas su voir qu'elle faisait une beauté du défaut constitutif du roman, l'impossibilité où il est tenu de finir. Le poème, qui est convoqué pour dire l'effet esthétique du retour des personnages, "Tristesse d'Olympio", est une méditation lyrique sur le sentiment de finitude:

D’autres vont maintenant passer où nous passâmes.

Nous y sommes venus, d'autres vont y venir;

Et le songe qu'avaient ébauché nos deux âmes,

Ils le continueront sans pouvoir le finir!

23. RTP, t. III, p. 437.

24. "Sainte-Beuve et Balzac», dans Contre Sainte-Beuve, op. cit., p. 273. 
Car personne ici-bas ne termine et n'achève;

Les pires des humains sont comme les meilleurs;

Nous nous réveillons tous au même endroit du rêve.

Tout commence en ce monde et tout finit ailleurs.

Si la poésie d'un Hugo, d'un Baudelaire, n'a eu de cesse de dire et de donner à éprouver le sentiment de finitude ou le remords de la survivance, le roman possède en propre d'avoir su en faire le ressort de l'expérience de lecture.

Dans l'un de ses récits de voyage, Ernst Jünger rapporte une anecdote, qu'il présente comme un souvenir de pension de l'une de ses amies:

Les lectures nocturnes étaient strictement interdites, et pourtant possibles dans la mesure où la lumière d'un phare éclairait la chambre si on tirait le rideau. Mais comme le phare avait un feu tournant, la lecture subissait une interruption rythmée, et aussi une tension accrue puisqu'elle n'était possible que pendant les secondes où le rayon traversait la fenêtre. L’obscurité retombait, et il fallait ensuite se précipiter de nouveau sur le texte comme sur une proie ${ }^{25}$.

La situation évoquée par l'écrivain allemand n'est pas aussi singulière, aussi «hors nature» qu'on pourrait le croire de prime abord. Elle dramatise l'expérience commune. Le lecteur se vit moins, dès lors que les mots disparaissent à tout instant dans l'obscurité, comme un survivant qu'à la façon d'un prédateur. Mais le dispositif quasi expérimental décrit par Jünger s'accorde avec les scénarios proustiens pour faire de la nature segmentée du processus de lecture, et du sentiment de frustration, du chagrin qui en résulte, un enjeu. Le survivant, tel que le roman en a construit la figure, c'est celui qui s'installe dans la longue durée cernée d'oubli du chagrin. Survivre, c'est faire l'expérience de l'in absentia, se découvrir dans l'impossibilité de se reposer sur la lettre d'un texte, vivre dans la labilité de la mémoire, éprouver en soi la fugacité des présences, la fragilité du souvenir ; c'est l'expérience la plus proprement romanesque qui soit. Cette expérience n'est pas tout entière tournée vers le passé mais paradoxalement lourde d'avenir.

25. Ernst Jünger, Serpentara, dans San Pietro suivi de Serpentara, trad. P. Morel, Paris, La Délirante, 1998, p. 60. 



\title{
Réflexions sur la mémoire romanesque en partant du Neveu de Rameau
}

\author{
Olivier Maillart
}

De quoi le roman garde-t-il la mémoire? C'est là l'une des questions auxquelles nous invite la proposition sur la mémoire propre au roman. Or, dans l'invitation qui nous est faite, cette question est aussitôt suivie d'une distinction: "Au-delà de tous les détails documentaires qu'on peut y puiser et qui servent le savoir historique, de quelle conscience générale le roman est-il le gardien?» Cette précision est un premier renseignement, puisqu'elle oppose l'histoire au roman, le grand récit qui aide à se souvenir d'un côté, de l'autre le récit qui, s'il se souvient lui aussi, se souvient autrement.

On partira de cette opposition en proposant le pari suivant: en s'appuyant sur des textes volontairement choisis à la marge du roman (Diderot, Saint-Simon, mais cela aurait pu être Chateaubriand ou d'autres encore), il s'agira d'interroger les moyens esthétiques qui font que le roman (ou le romanesque) semble pouvoir surgir, même brièvement, alors même que se trouvent fixés, et donc possiblement remémorés, des traits, des personnes, des comportements réels. Autrement dit, comment, dans des textes de mémorialistes qui semblent partager avec le discours historique une même matière, celle du "réel passé», on arrive par l'écriture à une sorte de romanesque de la mémoire, de mémoire construite par une écriture, et partagée par un lecteur.

Compte tenu des textes choisis (au premier rang desquels Le Neveu de Rameau de Denis Diderot), notre approche ne sera pas sans lien avec 
l'art du portrait, cet art qui traverse aussi bien l'histoire que le roman, l'écriture mémorialiste que l'écriture de fiction et, même, aussi bien l'image que le texte. Tâchons à présent d'identifier quelques-unes de ces stratégies d'écriture qui font mémoire.

\section{Une expérience de lecture}

Ce que nous cherchons à développer ici est parti d'une réflexion incidente, irréfléchie, en relisant Le Neveu de Rameau de Diderot (texte au curieux cheminement, d'abord paru en allemand, après la mort de son auteur, dans une traduction de Goethe, le manuscrit original étant finalement retrouvé et publié en I89I) : les disputes dont il est question dans ce livre ne nous disent plus rien, les êtres que mentionne Diderot, avec qui il entend polémiquer (parce qu'ils appartiennent au camp des anti-philosophes), ont été oubliés de tous, sinon des spécialistes de l'histoire littéraire, qui ne les retiennent d'ailleurs qu'à cause de la lumière que Diderot jette passagèrement sur eux. Pourtant, grâce au Neveu de Rameau, indéniablement, ces êtres existent encore, pour le lecteur du moins, le temps de sa lecture.

Posons, dès lors, la question: "De quoi le roman garde-t-il la mémoire?» Dans ce texte hybride, au croisement de la satire (Satire seconde était son premier titre), de la polémique d'actualité et du romanesque, on trouve peut-être un début de réponse: le roman se souvient d'une "qualité essentielle de présent ${ }^{1}$ " non pas consignée comme archive, mais revécue comme présent. Peu nous importe, pourrait-on croire, les ridicules de Jean-François Rameau, ou la préférence de Diderot pour l'opéra italien (Pergolèse) plutôt que pour les œuvres de l'oncle illustre de ce dernier. C'est pourtant l'inverse qui se produit: dans les jardins du Palais-Royal où ils se promènent (situation délicieusement concrète), cela compte à nouveau. Revivre le superflu, ou plus exactement: revivre le passé comme présent, telle est peut-être l'expérience romanesque de la mémoire; le romanesque serait alors ce qui rend sensible à nouveau ce qui n'était qu'une pique, une polémique pour son temps présent.

I. Pour parler comme Charles Baudelaire dans Le Peintre de la vie moderne (texte paru en 1863 , repris dans les Écrits sur l'art, Paris, Classique de poche, 1999, p. 504). 
En nous tournant vers des textes non spécifiquement romanesques (si l'on en croit une catégorisation trop rigide) qui pourtant, dans ces instants, nous apparaissent comme plus romanesques que tant de romans, nous pouvons nous interroger sur cette capacité de l'écriture qui consiste à recueillir une certaine qualité de présent, une beauté de circonstance que le romanesque aura saisie, gardée en mémoire, et su restituer. Autrement dit: un passé, véridique mais inconnu, et même indifférent, remémoré comme vivant, revécu comme présent, par la grâce du récit qui en est fait: est-ce cela la «mémoire du roman»?

\section{La mémoire comme roman}

Première remarque: la mémoire (en elle-même) est un roman. Quand saint Augustin l'évoque, il la narrativise: c'est la métaphore fondatrice des «vastes palais de la mémoire», dans Les Confessions (livre X, chapitre VIII, «De la mémoire»)². Saint Augustin matérialise en un mouvement physique ce qui était un phénomène purement intellectuel. Par la métaphore, il transforme la mémoire en petit roman de poche. On retrouve la même approche chez Borges, dans des contes comme «Funes ou la mémoire» ou «La Bibliothèque de Babel» (tous deux repris dans Fictions) : la mémoire y est systématiquement récit, parfois lieu où se déplacer. Ce qui n'en fait peut-être pas automatiquement un roman, mais nous en rapproche déjà.

Étape suivante: si la mémoire est récit, elle peut aussi, par l'écriture, devenir roman (tout en restant mémoire). C'est ainsi que Philippe Sollers se propose de lire l'un des grands mémorialistes de la littérature française, le duc de Saint-Simon. Dans La Guerre du goût, il écrit: «Notre romancier est là (le plus grand, avec Sade, Chateaubriand, Proust et Céline). La mémoire est le seul roman. Plus elle est grande, aiguë, immédiate, complexe, plus elle rend les autres écrits inutiles, partiels, étriqués.» Et, plus loin, il nous dirige implicitement vers la question du portrait:

Qui ne se souvient de cette attaque: "Mme de Castries était un quart de femme, une espèce de biscuit manqué...» Mais prenons la marquise de

2. Pour une analyse de cette image, voir Paul Ricœur, La Mémoire, l'Histoire, l'Oubli, Paris, Éditions du Seuil, 2000, p. II5-I22. 
Prie, la "jument de prix», maîtresse de M. Le Duc (c'est son nom, rien à voir avec Saint-Simon). Journal de Mathieu Marais: "C'était une femme aimable de sa figure, spirituelle, intrigante, avare et très libertine.» Mémoires secrets de Duclos: "Elle cachait, sous un voile de naïveté, la fausseté la plus dangereuse: sans la moindre idée de vertu, qui était à son égard un mot vide de sens, elle était simple dans le vice, violente sous main de douceur, libertine par tempérament. " Pas mal, n'est-ce pas? (Et voilà pour la nécessité des notes en fin de volume). Scène enchantée: les personnages sont ce qu'on peut dire d'eux. Comment ne pas rêver trente secondes sur ce "violente sous-main de douceur", ce "simple dans le vice»? Les expressions sont venues d'elles-mêmes, le style se donne ses corps ${ }^{3}$.

La formule "les personnages sont ce qu'on peut dire d'eux» donne la clef de l'opération qui a cours ici. C'est le récit qui fait la mémoire, c'est l'écriture qui transforme les êtres en personnages. Ce type de récit qui va puiser dans la réalité passée sa matière (la mémoire, meilleur roman) postule que la question, si souvent pesante, du réalisme est déjà réglée, et n'en fait donc pas un problème. Cette question disparaît de fait, puisque le "réel» n'est plus un effet à produire, il est compté comme allant de soi. On peut donc se concentrer sur le récit (romanesque) qui va construire la fable de la mémoire. Car c'est parce qu'il raconte que l'écrivain (Saint-Simon, Diderot) constitue tel détail, tel être comme personnage ou tel événement comme fait. Et donc que la mémoire peut se mettre en branle, puisque se trouvent devenus mémorables, pour le lecteur, des êtres et des événements qu'il n'a pas connus.

\section{La mémoire, un récit entre fiction et histoire}

Derrière le rapprochement entre mémoire et roman, on voit poindre ici un rapprochement entre fiction et histoire. Quelques éléments de mise au point s'imposent: l'histoire se définit comme écriture et comme récit. Elle partage un certain nombre de procédés rhétoriques avec la fiction, tout en conservant une orientation différente, qui réside dans sa prétention à tenir un discours de vérité sur le réel qu'elle raconte. C'est ce que Paul Ricœur nomme sa visée à la représentance, visée fra-

3. Philippe Sollers, La Guerre du goût, Paris, Gallimard, coll. «Folio», 1996, p. 278 et $28 \mathrm{I}$. 
gile qui cependant maintient la distinction entre récit historique et récit de fiction:

Le mot «représentance» condense en lui-même toutes les attentes, toutes les exigences et toutes les apories liées à ce qu'on appelle par ailleurs l'intention ou l'intentionnalité historienne: elle désigne l'attente attachée à la connaissance historique des constructions constituant des reconstructions du cours passé des événements. [...] À la différence du pacte entre un auteur et un lecteur de fiction qui repose sur la double convention de suspendre l'attente de toute description d'un réel extralinguistique et, en contrepartie, de retenir l'intérêt du lecteur, l'auteur et le lecteur d'un texte historique conviennent qu'il sera traité de situations, d'événements, d'enchaînements, de personnages qui ont réellement existé auparavant, c'est-à-dire avant que récit en soit fait, l'intérêt ou le plaisir de lecture venant comme par surcroît ${ }^{4}$.

C'est ce plaisir "par surcroît » qui nous intéresse, au sens où c'est lui qui, par endroits, fabrique de la mémoire, une mémoire "du roman", romanesque, qui n'est pas de même nature que le savoir historique et documentaire. Pourquoi cela? Dans les textes ici évoqués (Le Neveu de Rameau, les Mémoires du duc de Saint-Simon), il ne s'agit que de "personnes ayant réellement existé», mais qui n’en sont pas moins retournées à l'oubli pour la plupart, précisément parce que leur vie échappe aux récits des historiens. Or ce qui les réintroduit dans nos pensées, ce qui confère à leurs propos comme à leurs actions la densité et l'énergie de la vie, c'est une écriture. Et cette écriture, c'est leur mémoire. Il ne s'agit pas de conserver une mémoire (qui n'existe pas), mais de la créer, de la fabriquer de toutes pièces par la conjonction d'un style et de sa lecture.

\section{Le Neveu de Rameau: satire ou roman, mémoire ou fiction?}

Reste à définir cet ouvrage si curieux qu'est Le Neveu de Rameau. On voit bien qu'il ne relève pas de ce que l'on entend habituellement par roman (ni à l'époque de Diderot ni à la nôtre). Dès lors, qu'est-ce donc? Une satire? C'est son premier titre (Satire seconde), mais en soi c'est un texte plus complexe, dialogique. Là réside son principe même: non 
seulement parce qu'il repose sur le dialogue entre Moi et Lui, entre Denis Diderot et Jean-François Rameau, neveu de Jean-Philippe, le grand musicien; mais parce que les points de vue n'y sont pas figés, et régulièrement le Neveu, personnage amoral et cynique, tient des propos dont on sait que Diderot les a lui-même tenus ailleurs, même s'il pose en sage (parfois un peu trop d'ailleurs) dans cet échange. Or, si l'on se souvient de la définition hégélienne de la satire (qui évoque dans son Esthétique une conscience vertueuse, pleine d'esprit noble, qui s'indigne contre l'état du monde qui l'entoure), celle-ci doit être quelque chose de sérieux, de moral, de figé quant aux valeurs. En ce qui concerne Le Neveu de Rameau, une telle définition n'est juste que jusqu'à un certain point. Il entre dans cette œuvre trop de «jeu» entre les points de vue et les personnages, l'ensemble s'avère par trop instable, ce qui, introduisant une sorte de relativité dans le monde ainsi créé (il n'y pas une seule vérité morale d'où ce monde serait contemplé), rapprocherait le texte du roman.

Par contre, on peut relever un point qui contribue à éloigner le texte de l'univers romanesque: les personnages qui y évoluent sont des personnages ayant réellement existé, tous. Tout n'y est pas inventé, mais ce n'est pas non plus un roman à clef, puisque les noms des protagonistes sont les vrais, de même que ceux de leurs cibles, les lieux où ils évoluent, les noms des ouvres qu'ils commentent, etc. Ce détail explique d'ailleurs sans doute l'histoire légèrement rocambolesque du texte évoquée plus haut (sa publication posthume, le détour par l'Allemagne). Quoi qu'il en soit, cette nature documentaire, mémorialiste, nous ramène au problème suivant: quelle est la part de fiction dans $L e$ Neveu de Rameau? Et, question subsidiaire, peut-on envisager un roman sans fiction? Un roman qui tiendrait à sa seule mise en récit? N'est-ce pas le cas, plus près de nous, de Louis-Ferdinand Céline et de ses romans d'après-guerre (Féerie pour une autre fois, D'un château l'autre) ? Rapprochement nullement fortuit, si l'on songe à tout ce qu'un ouvrage comme les Entretiens avec le professeur $Y$ a en commun avec Le Neveu de Rameau (la situation dialogique, la promenade dans Paris, les règlements de comptes, l'art poétique déguisé en conversation comique avec un «fou», une sorte de bouffon de théâtre).

Dès lors, il est peut-être permis de parler de "roman non fictionnel». Comme on l'a dit plus haut, dans ce genre de texte, le réel est donné, 
mais, et c'est là le point intéressant, cela ne veut pas dire que les personnages (puisqu'ils le deviennent, de fait, dans la fable de Diderot) soient vivants. Ni que l'intérêt pour le lecteur réside dans l'exactitude factuelle de ce qui nous en est raconté (puisqu'on ne sait rien de ces êtres, sinon ce que ce seul texte nous en dit, ou à peu près, en partant du principe que l'on n'est pas historien, c'est-à-dire un lecteur spécialisé). C'est ici que l'écriture entre en jeu. On peut par exemple comparer la description des jardins du Palais-Royal qui ouvre le texte à celle donnée du même lieu par Balzac dans Illusions perdues (I836-I843). Plus d'un demi-siècle sépare les deux instantanés. Les prostituées sont toujours là, mais les libraires et les éditeurs ont remplacé les joueurs d'échecs. Surtout: d'un côté Diderot prétend décrire ce qui est, de l'autre Balzac invente pour faire plus vrai. D'où cette question: cela produit-il la moindre différence pour le lecteur du Xxi siècle? On peut tenter de répondre à cette question en partant d'un extrait de l'incipit du Neveu de Rameau:

Si le temps est trop froid ou trop pluvieux, je me réfugie au café de la Régence. Là, je m’amuse à voir jouer aux échecs. Paris est l'endroit du monde, et le café de la Régence est l'endroit de Paris où l'on joue le mieux à ce jeu; c'est chez Rey que font assaut Légal le profond, Philidor le subtil, le solide Mayot; qu'on voit les coups les plus surprenants et qu'on entend les plus mauvais propos; car si l'on peut être homme d'esprit et grand joueur d'échecs comme Légal, on peut être aussi un grand joueur d'échecs et un sot comme Foubert et Mayot [... $]^{5}$.

Ces joueurs d'échecs (Légal, Philidor, Mayot, Foubert), qui les connait aujourd'hui? Et quelle trace en reste-t-il, sinon ce qu'en a dit Diderot? Pour autant, malgré la parcimonie de nos informations, qui peut nier qu'ils s'animent sous nos yeux? Et l'on pourrait multiplier les exemples, avec les «ennemis» de Diderot, membres du clan des antiphilosophes (Palissot, Poinsinet, Fréron, La Porte); avec les musiciens qui prirent part à la querelle des Bouffons; avec Bertin, ses invités (dont le Neveu) et ses maîtresses enfin. Quelle différence avec Lucien de Rubempré, les auteurs et les éditeurs que l'on découvre dans la deuxième partie d'Illusions perdues ("Un grand homme de province à Paris»), lors de l'épisode du Palais-Royal? Les uns et les autres se sont éloignés dans 
le temps, pour le lecteur actuel, au point que le degré d'authenticité (ou de "fictionnalité») ne joue pratiquement plus. Rubempré a eu ses modèles, Bertin a réellement existé. Mais ce qui fait vivre l'un et l'autre, et qui fabrique donc un passé remémorable, c'est dans un cas comme dans l'autre l'écriture. Finalement, le propre du procédé du Neveu de Rameau est, non de revendiquer un quelconque caractère documentaire, mais plutôt de dissoudre celui-ci, au point que cette dimension semble à peine intervenir dans la réception de l'œuvre, et la découverte de ses personnages. On peut pour autant se demander si cette dimension disparaît entièrement pour le lecteur.

\section{Une écriture qui rend à la vie}

Reprenons donc, de manière plus développée, la belle formule employée par Baudelaire dans son essai sur le dessinateur Constantin Guys:

c'est à la peinture des mœurs du présent que je veux m'attacher aujourd'hui. Le passé est intéressant non seulement par la beauté qu'ont su en extraire les artistes pour qui il était le présent, mais aussi comme passé, pour sa valeur historique. Il en est de même du présent. Le plaisir que nous retirons de la représentation du présent tient non seulement à la beauté dont il peut être revêtu, mais aussi à sa qualité essentielle de présent ${ }^{6}$.

Car la beauté, explique Baudelaire dans Le Peintre de la vie moderne, a deux aspects: l'un éternel, l'autre transitoire, appelé à se démoder, et pourtant aussi essentiel que le premier. Et sans doute est-ce cette dimension de vie transitoire, que saisit si bien M. G. (Constantin Guys), qui justifie l'admiration de Baudelaire pour ses images. Encore s'agit-il là d'images. Pour ce qui est de l'écriture, de l'art du récit comme du portrait littéraire, on tient peut-être dans la «mémoire romanesque» telle qu'il nous semble que la pratiquent notamment Diderot ou SaintSimon un miracle du même ordre. À savoir: rendre au présent enfui (au présent devenu passé) sa "qualité essentielle de présent».

Cette manière de «ramener à la vie» par l'écriture, de proposer par le romanesque une mémoire en actions qui fasse revivre les êtres, elle est une possibilité que tous n'empruntent pas, qui n'est pas le tout de la

6. Charles Baudelaire, Le Peintre de la vie moderne, op. cit., p. 504. 
littérature. On peut songer au célèbre chapitre qui ouvre Mimésis d'Erich Auerbach, «La cicatrice d'Ulysse»: l'opposition que dresse le grand critique entre les personnages homériques et les personnages bibliques (selon son optique qui est, rappelons-le, la «représentation de la réalité dans la littérature occidentale») repose sur l'idée que, chez Homère, il n'y a qu'un premier plan, un présent sans profondeur de passé. À l'inverse, ce qui donne aux personnages bibliques une plus grande densité, c'est que ceux-ci vieillissent, possèdent une individualité liée à la décrépitude, au fait qu'ils sont habités par leurs souvenirs, par le temps qui les a marqués:

Les actes d'Abraham ne s'expliquent pas uniquement par ce qui lui arrive sur le moment, ni non plus par son caractère (comme les actes d'Achille découlent de sa bravoure et de son orgueil, ceux d'Ulysse de son habileté et de sa prudence), mais par son histoire antérieure; il se souvient, il est toujours conscient de ce que Dieu lui a promis et a déjà accompli en sa faveur - son âme est profondément divisée entre une révolte qui doute et une attente qui espère ${ }^{8}$.

La force de réalité des personnages bibliques est qu'ils sont liés au passé, à la mémoire: à la différence des héros épiques, il s'agit d'êtres présents travaillés par un passé qui vit encore. Or il faut ajouter qu'ils ont longtemps conservé (et qu'ils conservent encore pour une partie de leurs lecteurs) le statut de personnages historiques, de ceux que les mémorialistes décrivent, puisque le croyant est supposé les voir comme des personnages ayant réellement existé. Mémoire et roman, il ne s'agit donc pas seulement de deux façons d'écrire, mais également de deux manières de lire. De deux façons de fabriquer de la mémoire par le présent, de penser le présent comme un passé en devenir, de le vivre ainsi. C'est ce que font les personnages du Jardin des Finzi-Contini (1962), ce beau roman de Giorgio Bassani sur la mémoire. Si ce romancier réussit à insuffler de la nostalgie dans une histoire qui est aussi celle de la destruction des Juifs de Ferrare, c'est que ses personnages vivent à égalité la tragédie politique et la tragédie de l'existence. Et que le personnage de Micòl comme le narrateur font de la nostalgie leur mode d'être privilégié, le propre de leur rapport au monde:

7. Erich Auerbach, Mimésis, Paris, Gallimard, coll. «Tel», I977, p. I6.

8. Ibid., p. 2I. 
[...] pour moi, non moins que pour elle, ce qui comptait c'était, plus que la possession des choses, le souvenir qu'on avait d'elles, le souvenir en face duquel toute possession ne peut, en soi, apparaître que décevante, banale, insuffisante. Comme elle me comprenait! Mon désir que le présent devînt " tout de suite» du passé, pour pouvoir l'aimer et le contempler à mon aise, était aussi le sien, exactement pareil. C'était là "notre» vice: d'avancer avec, toujours, la tête tournée en arrière. N'en était-il pas ainsi ${ }^{9}$ ?

La posture ainsi décrite, qui rappelle les mélancoliques héros baroques, le célèbre Hamlet comme le Page disgracié, et moins connu, de Tristan L'Hermite, est celle du spectateur du monde qui a renoncé à l'action, n'envisageant nullement d'avoir la moindre prise sur le cours des choses. Encore s'agit-il là de personnages fictifs. Pris dans le tourbillon de l'Histoire réelle (le fascisme, les lois raciales, la destruction des Juifs d'Europe), mais au moyen de figures inventées. Face à des phénomènes aussi dramatiques (tellement plus dramatiques que ceux racontés dans Le Neveu de Rameau!), y a-t-il une différence, pour le lecteur, de savoir si le modèle de l'être construit par la narration a existé ou non, si ce qu'on raconte de lui est vrai ou pas? On aimerait répondre: oui et non.

Non, pourrait-on penser, si l'éloignement dans le temps et l'espace, la méconnaissance qui va toujours croissant, l'oubli qui est la destinée de toute existence, font que des personnages autrefois vivants ne nous touchent plus que comme des personnages de fiction. Surtout si nous les découvrons par le biais de récits littéraires, de textes d'écrivains, mémoires, histoires, Neveu de Rameau: textes ambigus, au carrefour de formes diverses.

Oui, répond la fillette de l'ouverture du Jardin des Finzi-Contini: dans ce préambule (qui précède la fiction, que Bassani présente comme relevant de la sphère "réelle»), la visite d'une tombe étrusque éveille un sentiment de compassion, de mélancolie chez une enfant qui, contre l'avis de ses parents (qui lui expliquent qu'elle n'a pas à être triste, puisqu'il s'agit de gens, certes morts, mais qu'elle n'a pas connus, et qui de plus ont disparu il y a fort longtemps), choisit de prendre en charge le souvenir de ces morts réels, quand bien même ils ne seraient rien

9. Giorgio Bassani, Le Jardin des Finzi-Contini, trad. de Michel Arnaud, 1964 [1962], repris dans Le Roman de Ferrare, Paris, Gallimard, coll. "Quarto», 2006, p. 389. 
pour elle. Quand bien même, ajoutera-t-on, ils n'ont pour elle que l'immatérialité, l'évanescence de personnages de fiction.

Bien sûr, le contexte des romans de Bassani dramatise plus que ne le faisait jusqu'à présent notre propos, mais l'idée est là: que les personnages aient existé ou non, cela change quelque chose pour le lecteur. Ils peuvent y gagner une densité. Même chose pour les portraits, en peinture: il est toujours émouvant de se dire que ces gens ont existé. Si l'on pense par exemple à la peinture flamande, à celle de Hans Memling (prenons volontairement l'exemple de cet art qui complète si heureusement la peinture italienne, parce qu'il cherche à témoigner de l'humanité des êtres, non de leur beauté, et que ce sont deux manières égales de louer la Création chez ces artistes également chrétiens), par exemple le Diptyque de Maarten van Nieuwenhove (réalisé en 1487), on a un portrait extraordinaire. Peinture de dévotion, dont on imagine la ressemblance, alors même que l'on ne pourra jamais la vérifier, que l'on n'a aucun indice sur le modèle (à nouveau, fondons-nous ici sur l'expérience d'un non-spécialiste). Pourtant, ce jeune homme a vécu, respiré, aimé, prié. Et cela se voit. L'art fabrique donc de la mémoire.

Des êtres disparus dans le temps renaissent, même d'une manière problématique, romanesque, pour un instant qui est celui de notre présent. Comme si la "mémoire romanesque" était capable, à michemin du document et de l'invention, de la remémoration et de la fiction, de fabriquer du souvenir à partir de l'inconnu. C'est en tout cas ce que l'on aura cru ressentir, au détour d'une relecture du Neveu de Rameau de Diderot. 



\section{IV}

Les œuvres remémorées 



\title{
Mémoire du roman : dialogue de quelques livres fantômes
}

\author{
Aude Leblond
}

Paradoxalement, alors qu'il paraît le genre le plus apte à fixer l'imaginaire d'une époque, ou, comme le montre Isabelle Daunais dans Les Grandes Disparitions, à préserver un passé en train de sombrer, le roman semble programmer son propre oubli par le lecteur. Là où l'épopée, le poème ou le théâtre ménagent des éléments de mémorisation textuelle (motif, rimes, passages détachables), le roman se présente comme une unité impossible à envisager de manière synoptique ou à mémoriser intégralement. Dans nos mémoires se produisent les mêmes naufrages que dans l'épopée de la conservation matérielle des livres: les livres brûlent, les manuscrits se perdent au fond des cartons et des rayonnages des bibliothèques, et leur souvenir s'efface et se déforme avec le temps. Dans Comment parler des livres quion n'a pas lus, Pierre Bayard définit ainsi notre relation aux livres comme « un espace obscur hanté de bribes de souvenirs, et dont la valeur, y compris créatrice, tient aux fantômes imprécis qui y circulent ${ }^{1}$ ». De même, Judith Schlanger rappelle que, dans la mémoire collective, l'immense majorité des œuvres se mue en «fantômes d'œuvres, fantômes bâillonnés qui trầnent encore un peu dans les déchirures du présent comme des objets indésirables dont l'usage premier et l'intention échappent ${ }^{2} »$. Le choix récurrent de cette image permet d'insister à la fois sur le flou des images

I. Pierre Bayard, Comment parler des livres quion n'a pas lus?, Paris, Éditions de Minuit, coll. "Paradoxe», 2007, p. 18.

2. Judith Schlanger, Présence des æeuvres perdues, Paris, Hermann, 20II, p. I55-I56. 
mémorielles, leur précarité et leur subsistance un peu envahissante. Mais on voudrait ici s'intéresser, non plus à l'identification de ces fantômes (quels romans subsistent dans la mémoire collective?), mais à leur forme (à quoi ressemblent-ils?).

En fait de fantôme, je propose d'envisager le souvenir que nous conservons d'un roman comme un univers de lecture, que je définirais comme la représentation mentale disponible pour le lecteur d'un roman lu auparavant. L'univers de lecture comprendrait l'ensemble de ce que nous pouvons convoquer lorsque nous essayons de nous remémorer un roman. Il s'agit de parcourir les éléments et les supports de cette représentation, qu'ils soient visuels, sonores, langagiers, qu'ils concernent les personnages, ou, selon l'opinion de Proust, qu'ils concernent plutôt le support matériel ou l'environnement dans lequel on a lu le livre ${ }^{3}$. La question, dès lors, est de voir à quel point ces univers de lecture se recoupent. Y a-t-il des constantes dans les univers de lecture projetés sur la conscience du lecteur? Sont-ils «programmés» par le roman lui-même, ou plutôt par ses conditions de réception (appartenance ou non à un canon, place dans l'institution scolaire, déterminismes sociaux, etc.)?

J'ai recueilli pour tenter de répondre à ces questions des témoignages de lecture, où les participants se sont prêtés au jeu de l'évocation et de la rédaction, de mémoire, d'un univers de lecture. Quinze participants ont mis par écrit leur souvenir d'un roman canonique (au choix, Madame Bovary, Le Père Goriot ou Les Liaisons dangereuses), puis celui d'un roman de leur choix. Un participant a été recruté de façon posthume, puisque Julien Gracq avait non seulement envisagé mon expérience et prédit ses résultats - on va voir avec quel succès -, mais qu'il avait eu en outre l'obligeance de s'y soumettre par anticipation ${ }^{4}$ :

3. Voir les "Journées de lecture», Marcel Proust, Contre Sainte-Beuve, Paris, Gallimard, coll. "Bibliothèque de la Pléiade», I97I, p. I60-I94.

4. Par la suite, Sophie Calle l'a conduite sur L’Assassin menacé, de Magritte (voir Robert Storr, Dislocations, MoMA, 1992). L'expérience de Sophie Calle pouvait amener à différencier la mémoire visuelle selon la place qu'occupait le tableau dans la vie de chacun (historien de l'art, gardien du musée, visiteur occasionnel, habitué, etc.). Les descriptions "à l'aveugle» recueillies ont surpris par leur diversité et leur inexactitude, ce que souligne Daniel Schacter, neurologue et spécialiste de la mémoire: "The most striking outcome was the sheer variety of recollections that her inquiry elicited. Some people recalled only an isolated color or object; others remembered at length subtle 
Il faudrait comparer entre eux les souvenirs que gardent à distance d'une même œuvre des lecteurs exercés et de bonne foi, leur faire raconter de mémoire à leur idée le livre - ou plutôt ce qu'il en reste, toute référence au reste omise - noter la récurrence plus ou moins régulière du naufrage de pans entiers qui ont sombré dans le souvenir, de points d'ignition au contraire qui continuent à l'irradier, et à la lumière desquels l'ouvrage se recompose tout autrement. Un autre livre apparaîtrait sous le premier comme un autre tableau apparaît sous le tableau radiographié - qui serait un peu ce qu'est à la carte économique d'un pays celle de ses seules ressources d'énergie. Et, au bout de cette réduction aux seuls matériaux radioactifs ainsi opérée par le tri de la mémoire, on obtiendrait des écarts surprenants. Certains chefs-d'œuvre, la mémoire les restituerait à peu près conformes à leur squelette, avec la gradation de leurs épisodes, leur courbe d'ensemble, l'équilibre de leurs proportions, ce qui a lieu pour moi, par exemple, pour Le Rouge et le Noir (mais non pour la Chartreuse) comme pour Madame Bovary. Dans d'autres cas, toute la carcasse consumée, il ne subsisterait qu'une espèce de phosphorescence incorporelle: de Dominique, rien qu'une certaine tonalité frileuse et automnale, des Liaisons dangereuses, rien que leur frénésie abstraite et sèche comme l'amadou. Et ce qui demeure dans mon souvenir de la relecture que j'ai faite naguère de la Chartreuse, c'est autre chose encore: ce sont les épaves pêle-mêle sur la grève d'un galion porte-trésors. La descente de l'armée sur Milan. Waterloo. La page divine sur les rives du lac de Côme. La tour Farnèse. Les oiseaux de Clélia. L'évasion. Le prince de Parme (avec l'aide du film). L'orangerie du palais Crescenzi. Le tout aussi désinvoltement battu qu'un jeu de cartes, mais uniformément baigné dans l'ozone allègre, hilarant, de la haute montagne 5 .

Notons que, dans son esquisse stendhalienne, les souvenirs sont liés à différentes composantes, sensorielles ou intellectuelles, de l'activité de lecture: scènes, morceaux choisis, détail, personnage, sensation ressentie à la lecture, lieux. On voit déjà à quel point l'activité de lecture est irréductible à un type singulier de perception - ce que confirme la divergence des souvenirs livrés pour l'expérience. Les textes que j’ai recueillis ressemblent tous, dans la forme, à cette évocation de La Chartreuse de Parme: ce sont des entassements jubilatoires d'"épaves

nuances of form, space, people and things» (Daniel Schacter, Searching for Memory: The Brain, the Mind and the Past, New York, Basic Books, 1996, p. 40).

5. Julien Gracq, En lisant en écrivant, Euvres complètes, t. 2, Paris, Gallimard, coll. "Bibliothèque de la Pléiade», I989, p. 646-647. J'avais évidemment oublié ce passage et je remercie Daphné Leblond de s'en être souvenue pour moi. 
pêle-mêle». Gracq présuppose pourtant que différents lecteurs restitueraient de manière similaire le «squelette» de certains romans particulièrement structurés, tandis que d'autres œuvres donneraient lieu à un souvenir plus impressionniste. Différents types de remémoration seraient ainsi programmés par les romans, plutôt que par l'histoire personnelle des lecteurs. Or, si j'ai pu constater les «écarts surprenants» prédits par Gracq, ces écarts se produisent également pour le même roman, d'un lecteur à l'autre.

Si bien que le dialogue envisagé entre ces fantômes de roman est peut-être avant tout un dialogue de sourds. La première constatation qui s'impose, en effet, est celle de la variété. J'avais envisagé un certain nombre de "types de souvenir", dont j'ai donné quelques exemples en classant les souvenirs évoqués par Gracq; mais pour rassembler tous ceux qui m'étaient proposés, j'ai dû élargir le classement à dix-sept catégories de souvenirs. Les fantômes de roman ont donc en premier lieu la forme de chimères, et là où Gracq avait l'impression de rassembler des épaves comparables, il n'est pas évident de mettre sur le même plan la structure globale d'une intrigue, un détail visuel comme des gants beurre frais, les voyages en train dans Anna Karénine ou l'image d'Isabelle Huppert sur une couverture de Garnier-Flammarion.

Je me suis donc demandé pour commencer quel type de souvenir revenait le plus souvent. Trois types dominaient assez nettement: intrigue (la conquête programmée de Tourvel), détails (le dégoût de Solal pour les disques de Mozart que lui fait écouter Ariane), sentiments éprouvés lors de la lecture (la peur de "finir comme Emma»). Ces trois catégories rassemblaient chacune autour de $20 \%$ des souvenirs exprimés. Puis, autour de $15 \%$, morceaux choisis (la scène des comices agricoles), personnages (Mme de Rosemonde) et circonstances de lecture (lire La Princesse de Clèves pendant le mouvement universitaire de 2009, après la lecture publique qui en avait été faite au Panthéon). Puis, entre 5 et Io \% des souvenirs cités, on pouvait compter les lieux, les impressions visuelles, les faits de style et les citations. Enfin, plus marginaux, on notait des souvenirs liés au contenu idéologique, à une adaptation, à un cours portant sur le roman, à la tonalité, au livre matériel, à une critique ou à une autre œuvre.

Ce que nous savons du fonctionnement de la mémoire laissait prévoir cette diversité: dès 1932, Frederic Bartlett, dans un ouvrage intitulé 
Remembering, avait montré que les gens se souvenaient très différemment d'une même légende qui leur avait été racontée, et en concluait que les souvenirs étaient des reconstructions imaginaires ${ }^{6}$. Imagination et affectivité jouent ainsi un rôle essentiel dans la remémoration. De fait, j’ai été surprise par l'importance accordée à des éléments liés à l'histoire personnelle du lecteur (sentiments éprouvés et circonstances de lecture). Mais les neurosciences apportent un élément d'explication à cela: un engramme mémoriel a une longévité supérieure s'il a fait l'objet d'un encodage particulier, lié à une émotion vive ou à un élément de notre histoire personnelle. Ce qu'a confirmé le test suivant: en ramenant chaque texte à son élément de remémoration le plus valorisé par le lecteur, j'ai trouvé un classement différent. Les sentiments éprouvés arrivaient en première position (neuf textes), suivi à égalité des personnages et du style (sept textes) ${ }^{7}$. On pourrait argumenter que les souvenirs des personnages et du style sont particulièrement connectés à l'expérience subjective de la lecture, si l'on considère le personnage comme un support de projection et le style comme l'incarnation d'une voix s'adressant au lecteur. Fallait-il donc concevoir les univers de lecture comme essentiellement solipsistes?

C'est là le point de vue de Pierre Bayard, qui insiste sur le choc de non-reconnaissance qui se produit en général à la relecture:

Pour se convaincre que tout livre dont nous parlons est un livre-écran [...] il suffit de faire l'expérience simple consistant à confronter les souvenirs d'un livre aimé de notre enfance avec le livre «réel», pour saisir à quel point notre mémoire des livres, et surtout de ceux qui ont compté au point de devenir des parties de nous-même, est sans cesse réorganisée par notre situation présente et ses enjeux inconscients ${ }^{8}$.

6. Voir notamment Daniel Schacter, Searching for Memory, op. cit., p. Iог: «He [Bartlett] argued that the experience of remembering is shaped as much by the rememberer's "attitude" - expectations and general knowledge regarding what should have happened and what could have happened - as by the content of specific past events." Bien plus tard, dans Le Sens de la mémoire, Jean-Yves Tadié et Marc Tadié confirmaient, en rapprochant histoire des idées, textes littéraires et observations cliniques, que la mémoire est reconstruction et non reconnaissance: voir Jean-Yves Tadié et Marc Tadié, Le Sens de la mémoire, Paris, Gallimard, coll. «Folio», 2004, p. 9.

7. Le reste du classement est le suivant: 5 textes accordent la priorité à un contenu, 4 à un morceau choisi, et 2 à des lieux.

8. Pierre Bayard, Comment parler des livres qu'on n'a pas lus, op. cit., p. 53. 
Pourtant, à la relecture, c'est le sentiment de reconnaissance qui l'emporte. Et de fait, les fantômes décrits pour l'expérience ressemblent à leur modèle: les erreurs factuelles sont très rares ${ }^{9}$, malgré des doutes avoués $^{10}$. On ne peut donc éliminer d'office l'hypothèse formulée plus haut par Gracq, selon laquelle le roman lui-même programme sa remémoration. Il fallait donc isoler les textes écrits sur chaque roman «imposé », pour voir si différents types de souvenirs étaient "programmés" par Madame Bovary, Le Père Goriot ou Les Liaisons dangereuses. En n'envisageant que les souvenirs du Père Goriot, on constate une attention accrue accordée aux impressions visuelles (qui remontent à la $3^{\mathrm{e}}$ position, avec $15 \%$ des souvenirs recensés) et aux lieux ( $5^{\mathrm{e}}$ position, I2 \%). Pour Les Liaisons dangereuses, l'ordre ne change pas par rapport au classement global, mais la place accordée à l'intrigue est accentuée (près du tiers des souvenirs exprimés). Pour Madame Bovary, ce sont les morceaux choisis qui passent en tête (25\%), suivis des personnages $(22 \%)$. En comptant les souvenirs communs, enfin, on peut effectuer un dernier test. Le point commun le plus cité, avec cinq occurrences, est l'ennui d'Emma, sa vie intérieure; puis, à égalité, le "À nous deux, Paris» du Père Goriot et la mort d'Emma, la pension Vauquer et le personnage d'Homais. Pour autant, il n'est pas évident de conclure que ces tendances sont le fait des romans eux-mêmes. Dans la mesure où l'expérience concernait des lecteurs avertis, il faut se garder de sousestimer l'influence de l'approche scolaire et universitaire de ces romans. Si les points communs sont assez nombreux, on peut être tenté de les ramener au développement de livres-écrans, favorisés par l'enseignement de ces ouvrages canoniques ${ }^{11}$.

9. À propos des Liaisons dangereuses, une confusion entre la lettre de rupture recopiée par Valmont (lettre I4I) et la lettre à double sens écrite sur le dos d'une prostituée (lettre 48), établissait un rapprochement pertinent entre deux épisodes.

Io. J'avais demandé aux lecteurs de préciser s'ils considéraient se souvenir plutôt bien ou plutôt mal du roman en question. Ce qui donnait deux types de fantômes, selon que le roman était globalement bien connu ou globalement effacé. La proportion était comparable: II sur 27 effacés, soit $40 \%$, et I 6 sur 27 bien connus, soit $60 \%$. La proportion ne changeait pas lorsqu'on n'envisageait que les livres étudiés.

II. Au total, $25 \%$ des souvenirs évoqués sur Le Père Goriot étaient communs et $40 \%$ sur Madame Bovary - mais seulement I3\% sur Les Liaisons dangereuses. Le nombre de points communs semble proportionnel à la fréquence de l'inscription de ces romans aux programmes de cours, du collège à l'université. 
En tant que lecteurs professionnels, nous faisons l'expérience du fait que les souvenirs de lecture constituent un espace de dialogue pour les lecteurs. De fait, si on n'envisage que les œuvres étudiées, ce sont les morceaux choisis qui passent en tête (autour de $20 \%$ ), suivis par les éléments d'intrigue et les sentiments personnels. Ce qui provient sans doute de l'approche anthologique et formaliste des exercices comme l'explication de texte. Les témoignages expriment d'ailleurs une distinction entre lecture professionnelle et lecture personnelle: certains souvenirs sont explicitement liés à un cours, certains souvenirs manquent dans l'expérience subjective alors qu'on sait intellectuellement qu'on devrait avoir retenu ce détail ( La casquette de Charles, évidemment. M'en souviens pas, mais faudrait»).

Certes, les fantômes de roman se ressemblent, à la manière des membres d'une famille; mais cela ne suffit pas pour conclure que le roman lui-même façonne la manière dont on s'en souvient: le discours qui se déploie autour du livre à l'école et dans la société forme peut-être un livre-écran plus influent que l'expérience personnelle de la lecture. L'horizon d'attente, et son influence après la lecture, interfère avec le caractère à la fois subjectif et déformant de la remémoration. Cet horizon d'attente, dans l'échantillon de lecteurs que j'ai étudié, se construit de façon collective: ces lecteurs forment une «communauté interprétative» (pour reprendre l'expression proposée par Stanley Fish), qui a tendance à mettre en relief les mêmes éléments ${ }^{12}$. C'est à cause de Barthes que nous savons qu'il y a un baromètre chez la vieille Félicité, ou à cause de Michel Charles que je sais qu'Illiers est mentionné chez Rabelais. Inversement, ce sont aussi les critiques qui tendent à faire oublier toute la deuxième partie, pourtant somptueuse, d'Anna Karénine.

Les fantômes de roman sont donc, comme tout souvenir, malléables et divers. Mais leur incomplétude a peut-être son utilité. Si le roman ne parvient pas à programmer une réminiscence parfaite, peut-être faudrait-il envisager au contraire que le roman a intérêt à se faire oublier. Y aurait-il donc une vertu de l'oubli des romans? Mon hypothèse, ici, est que le roman se dérobe à la mémorisation pour mieux nous pousser à y revenir. La nécessité devant laquelle nous nous trouvons de retourner

I2. Ce qui rend nécessaire, pour la poursuite de cette recherche, une comparaison avec des lecteurs non avertis. 
au livre ou de compléter les vides de notre souvenir peut avoir deux fonctions essentielles.

On peut d'abord supposer que l'oubli des romans a une fonction addictive. Plus un livre est long, plus il favorise l'oubli et la désorientation, car il est impossible à première lecture d'en construire une vue synthétique; mais les formes romanesques longues sont aussi celles qui offrent le plus de repères à la mémoire du lecteur. Dans les romans longs ou les cycles romanesques, les repères tels que chapitrage, sommaires ou retour des personnages apparaissent d'autant plus souvent qu'ils sont suffisamment vastes pour que le lecteur s'y perde. La fonction informative de ces repères ne me semble pas aussi déterminante que leur fonction addictive: ils peuvent en effet contribuer à fidéliser le lecteur en orchestrant reconnaissances et réminiscences - à la manière, dans les séries policières, de ces rappels qui permettent d'introduire un nouveau titre en note et de faire la publicité de l'ensemble. L'effacement progressif du roman développerait ainsi le désir de revenir à un univers de lecture aimé. Ceci peut expliquer la persistance, du $\mathrm{XIX}^{\mathrm{e}}$ au $\mathrm{Xx}^{\mathrm{e}}$ siècle, de formes longues telles que cycles romanesques ou roman-fleuve, du réalisme à la science-fiction. $\grave{A}$ la recherche du temps perdu, ainsi, assume cet appel à la relecture, renvoyant le lecteur à son commencement, tout en ménageant à celui qui relira les premières pages à la lumière de l'ensemble le plaisir de reconnaissances, voire de réminiscences multiples. Il s'y trouvera en terrain familier, saturé de signes de connivence (la chambre de Balbec, Gilberte à Tansonville, etc.). Le plaisir de recouvrer des souvenirs oubliés et que l'on croit reconnaître ne peut jouer que grâce à l'effacement inexorable des romans: c'est là ce qui explique que certains puissent être relus inlassablement. Le livre est reparcouru de chapitre en chapitre, à la recherche de nouveaux éléments ou d'un détail caché. L'idée d'univers de lecture prend ici un sens plus spatial: on peut se représenter les romans comme des mondes ou des pièces, des lieux où l'on peut retourner, à la manière des pièces qu'on parcourt dans la description antique des arts de la mémoire ${ }^{13}$. Gracq décrit ainsi la Stendhalie comme un pays de vacances unique:

I3. Voir à ce propos l'ouvrage classique de Frances Yates, The Art of Memory, Londres, Routledge, 1966. 
Mais si je pousse la porte d'un livre de Beyle, j'entre en Stendhalie, comme je rejoindrais une maison de vacances: le souci tombe des épaules, la nécessité se met en congé, le poids du monde s'allège; tout est différent: la saveur de l'air, les lignes du paysage, l'appétit, la légèreté de vivre, le salut même, l'abord des gens. Chacun le sait (et peut-être le répète-t-on un peu complaisamment, car c'est tout de même beaucoup dire), tout grand romancier crée un «monde» - Stendhal, lui, fait à la fois plus et moins: il fonde à l'écart pour ses vrais lecteurs une seconde patrie habitable, un ermitage suspendu hors du temps, non vraiment situé, non vraiment daté, un refuge fait pour les dimanches de la vie ${ }^{14}$.

Il semble significatif que, parmi les témoignages recueillis, j’aie compté seulement un tiers de romans lus une seule fois. Mais cette fonction addictive a eu une autre conséquence plus spectaculaire. Elle explique deux "aberrations", deux récits de lecture concernant un roman "connu par cœur", d'après ses transcripteurs, grâce à de multiples lectures et un fort investissement émotionnel - il s'agissait en l'occurrence du Maître et Marguerite et du Tour du monde en 80 jours. Les textes se focalisent sur des détails oubliés et retrouvés au fil des relectures, des citations multiples, et même l'évocation d'une note de bas de page. Le plaisir de l'évocation est ici un plaisir de collectionneur, un plaisir d'appropriation.

Envisageons à présent la fonction inverse, une fonction créative: l'enjeu de l'effacement des romans ne serait plus de nous attacher à eux, mais de nous libérer de l'encombrement d'une bibliothèque intérieure trop imposante. Informée par l'oubli, la lecture entraîne dans notre esprit une reconfiguration constante des œuvres, à mesure qu'elles s'effacent de notre mémoire. Cet effacement, de Montaigne ${ }^{15}$ à Proust, a été envisagé comme ce qui permet au lecteur de se muer en auteur. L'oubli permet de ne pas étouffer notre propre vision du livre. L'imperfection de notre remémoration des romans nous incite à nous faire à

I4. Julien Gracq, En lisant en écrivant, Euvres complètes, t. 2, op. cit., p. 574-575.

I5. "Je feuillette les livres, je ne les estudie pas: ce qui m'en demeure, c'est chose que je ne reconnois plus être d'autruy; c'est cela seulement dequoy mon jugement a faict son profict, les discours et les imaginations dequoy il s'est imbu; l'autheur, le lieu, les mots et autres circonstances, je les oublie incontinent" (Montaigne, Essais, Paris, PUF, coll. "Quadrige», 2004, t. 2, p. 65I). 
notre tour auteur des livres à mesure que nous les oublions ${ }^{16}$. En s'effaçant, le roman permet ainsi un acheminement à l'écriture.

Les souvenirs de lecture de Proust entrent ainsi en résonance avec sa stratégie d'auteur. Proust insiste sur la place du lecteur, les circonstances de sa lecture et les phénomènes de reconnaissance permis par l'objet matériel livre; ce qui fait écho à la nécessité de pratiquer le pastiche, pour se libérer d'écrivains qui nous imposeraient leur langue; à la nécessité de se libérer de l'idolâtrie, de l'admiration paralysante des œuvres d'art. Le Temps retrouvé s'ouvre sur la reconnaissance de François le Champi et se termine par l'appel au lecteur à utiliser à son tour $\grave{A}$ la recherche $d u$ temps perdu pour déchiffrer son livre intérieur et devenir à son tour auteur.

L'oubli du roman serait ainsi une condition de l'apprentissage de l'écriture: c'est une idée qui est prolongée par Martin du Gard, qui affirme ne pouvoir écrire sans le processus d'oubli et de remémoration. Pour faire une scène, raconte-t-il, il lui faut élaborer un brouillon, puis l'enfermer dans un tiroir pour six mois au minimum. Il ne peut revenir à la scène et véritablement l'écrire que lorsque les événements imaginés ont pris la patine du souvenir ${ }^{17}$. La mémoire joue le rôle d'un filtre unificateur où les souvenirs de toutes sortes prennent la même substance, et c'est le flou, l'imperfection de la mémoire qui permettent l'écriture. De sorte que Martin du Gard ne distingue pas vraiment entre souvenir réel et souvenir de fiction: pour lui, la confusion est au contraire créatrice. Il évoque ainsi Natacha Rostov: «Je vous assure que je ne puis faire de différence entre Natacha et telle ou telle enfant que j'ai vu devenir jeune fille et femme: un même halo les enveloppe dans mon souvenir ${ }^{18}$.» C'est précisément cette transhumance des personnages de roman dans sa mémoire qui permet à Martin du Gard d'écrire.

Cette confusion entre souvenirs de fiction et souvenirs réels ne doit pas déconcerter, dans la mesure où le lien entre mémorisation, oubli et

I6. Voir Pierre Bayard, Comment parler des livres qu'on n'a pas lus?, op. cit., p. I33: "Cette mobilité du texte ne doit pas être comprise comme un inconvénient. Bien au contraire, pour celui qui sait en tirer profit, elle offre une remarquable opportunité à devenir soi-même le créateur des livres que l'on n'a pas lus."

17. Voir Roger Martin du Gard, Correspondance générale, Paris, Gallimard, I980, t. 8, p. $800-80$ I.

I8. Roger Martin du Gard, Correspondance générale, ibid., t. 2, p. I52. 
narration est essentiel - et je m'appuierai ici sur les apports des neurosciences sur le fonctionnement de la mémoire, pour donner un éclairage supplémentaire sur ce lien. La construction d'une histoire ou l'établissement d'un lien avec un souvenir plus ancien, explique Daniel Schacter, sont les meilleures façons d'encoder un souvenir que l'on veut préserver de la «fugacité ${ }^{19}$ ». De là, explique-t-il, notre tendance à la narration de notre propre vie:

Les êtres humains sont d'abord des conteurs qui adorent raconter des histoires, que ces récits aient une teneur autobiographique ou non; or, en réfléchissant à nos expériences et/ou en les verbalisant, non seulement nous donnons un sens au passé, mais nous influons de surcroît sur la probabilité de nos remémorations ultérieures ${ }^{20}$.

Le lien entre remémoration et narration est donc une composante essentielle de notre expérience et de notre capacité à maintenir et à définir notre identité.

Ce lien est d'autant plus crucial que la fragilité de la mémoire nous impose de plus en plus, avec les années, ce besoin de reconstruction narrative. Avec l'âge diminue ce qu'on appelle la mémoire "épisodique », c'est-à-dire la capacité à retenir ce qui nous arrive. Les personnes âgées ont aussi des souvenirs moins "connectés" à des émotions, d'où peut-être leur attachement à des souvenirs plus anciens. En effet, ce sont les souvenirs engrammés vers la fin de l'adolescence et le début de l'âge adulte qui sont les plus persistants, dans la mesure où ce sont les plus chargés émotionnellement. Mais ce sont aussi ceux qui peuvent donner lieu aux narrations les plus évoluées. De sorte que la perte de la mémoire épisodique qui survient avec l'âge s'accompagne souvent d'une pratique accrue et approfondie de la narration de souvenirs plus anciens: les personnes âgées élaborent pour évoquer leur jeunesse des récits complexes, marqués par un fort intérêt dramatique, voire une part faite au romanesque. Le récit prend ici le relais d'une mémoire défaillante, se focalisant sur la reprise d'épisodes essentiels pour le

19. Daniel Schacter, Science de la mémoire: oublier et se souvenir, trad. Christian Cler, Paris, Odile Jacob, 2003, p. 39: «D’autres expériences ont encore confirmé que la mémorisation est meilleure chaque fois qu'une information destinée à être apprise est liée à des données et/ou des idées familières via la production de phrases ou d'histoires."

20. Ibid., p. 45. 
conteur. D'où la valorisation, dans la plupart des cultures, du récit de l'expérience des aînés: ces récits sont reconnus comme de précieuses résurgences du passé, et comme fondateurs d'une identité collective ${ }^{21}$.

On pourrait objecter qu'il s'agit là de narration orale et non plus de roman. Mais peut-être ce fonctionnement différencié de la mémoire pourrait-il justement expliquer la grande fréquence du schéma d'apprentissage dans les romans: peut-être tient-elle à l'importance que nous attachons, lecteurs comme auteurs, à cette période de la vie qui concentre le mieux la réserve de la mémoire épisodique. Plus généralement, pour le lecteur, le roman peut remplir la même fonction que le conteur: les effets de voix, de transmission, d'adresse subsistent dans la lecture - et les premiers livres que nous rencontrons nous sont lus, ce qui favorise sans doute cette mise en voix. Alors que Benjamin affirmait que le roman, voix désincarnée s'adressant au lecteur dans la solitude, mettait fin à l'activité du conteur (c'est-à-dire à la fois à la narration épique, à la possibilité de transmettre des contenus éthiques, et plus généralement à la transmission de l'expérience ${ }^{22}$, il est tentant de proposer une logique inverse, non de rupture, mais de collaboration ou de continuité entre roman et récit mémoriel. Je voudrais, à l'inverse de la thèse développée dans "Le conteur", proposer de voir la lecture des romans comme une propédeutique à la pratique du récit. Lire des romans pourrait préparer le passage, à mesure qu'échappe la mémoire épisodique, à la narration de nos souvenirs les plus précieux. L'oubli du roman, sa redécouverte à la relecture peuvent fournir au lecteur le paradigme d'une préservation du souvenir par le récit.

Nous oublions allègrement les romans, mais nous y sommes profondément attachés: peut-être parce qu'ils fournissent le modèle d'une remémoration sans faille (il suffit de relire le roman), mais peut-être aussi parce qu'ils nous donnent petit à petit le pouvoir de narration. Dès lors, notre oubli assez général des romans ne doit pas effrayer, tant il est lié à une appropriation - que celle-ci nous pousse à la relecture ou

2I. Daniel Schacter, Searching for Memory, p. 308: «Memory is a central part of the brain's attempt to make sense of experience, and to tell coherent stories about it. These tales are all we have of our pasts, and so they are potent determinants of how we view ourselves and what we do."

22. Walter Benjamin, «Le conteur», Euvres, trad. Maurice de Gandillac revue par Pierre Rusch, Paris, Gallimard, coll. «Folio Essais», 2000, t. III, p. II6 sq. 
à l'écriture. Il semble que cette appropriation n'enferme pas pour autant le lecteur de roman dans le solipsisme prédit par Benjamin: le bon accueil que les participants ont réservé à l'expérience suggérait qu'ils tenaient non seulement à ces fantômes de roman, mais aussi à la possibilité de les comparer - et de partager leurs univers de lecture. Qu'ils en soient ici remerciés. 



\title{
Le roman au risque de l'amnésie. Stratégies mémorielles du récit différé (Leblanc, Sue, Mouhy)
}

\author{
Ugo Dionne
}

Quand paraît la troisième partie de L'Astrée, en I6I9, près de dix ans se sont écoulés depuis la publication de la deuxième, douze ans depuis celle de la première. Lorsque Marivaux fournit au public le neuvième volume de La Vie de Marianne, en mars 1742, plus de quarante-huit mois séparent ce volume du huitième. Quant au dernier feuilleton des Mystères de Paris, il paraît le lendemain du précédent, mais un an et quatre mois après celui du 19 juin 1842 , dans lequel le lecteur, sur les traces du Chourineur, a pénétré pour la première fois dans le dédale interlope de l'île de la Cité.

Malgré leurs différences manifestes, malgré leur appartenance à des régimes historiques et génériques distincts, ces trois ouvrages partagent un mode de publication dilaté, dans lequel le récit est produit par tranches successives, obéissant à une périodicité diversement capricieuse; ils appartiennent à un ensemble transhistorique qu'on propose de regrouper sous l'étiquette générale du roman différé. Ils en illustrent d'ailleurs trois grandes époques, dans le domaine littéraire français. Les douze livres de L'Astrée inaugurent en 1607 une nouvelle pratique de production par tomes, propre à l'âge baroque, et qui prévaudra jusqu'aux années I660, avec le remplacement du roman héroïque par la nouvelle galante et l'histoire secrète - bien que le jeune Marivaux, dans Les Effets surprenants de la sympathie (I7I4-I7I5), s'inscrive encore dans cette tradition. Ce sont les romans de maturité du même Marivaux qui, 
en conjonction avec ceux de Prévost, imposeront une autre formule de publication différée, dans les années i730. Enfin, les fresques socialisantes d'Eugène Sue (Les Mystères de Paris, Le Juif errant) contribueront, avec les œuvres de Dumas, de Soulié, de Balzac et de Féval, à faire émerger le genre du roman-feuilleton, dont le modèle continue à irriguer les paralittératures (et littératures) d'aujourd'hui.

Modelés par le temps, ces romans périodiques présentent donc des caractères structurels, narratifs, thématiques et stylistiques communs, qui se prêtent à une poétique d'ensemble. Ils posent aussi, à leur premier public, des problèmes similaires de réception. Que leurs unités correspondent à quelques colonnes de quotidien (comme dans le roman-feuilleton des origines) ou à quelques volumes (comme dans certains grands romans baroques), que le délai qui les sépare s'étende sur vingt-quatre heures, sur quelques jours ou sur plusieurs années, ils s'exposent à un même défaut de la mémoire. La tension romanesque $a$ le temps de s'y relâcher, le fil narratif de s'y distendre, le lecteur d'y devenir amnésique: retenu ou détourné par d'autres récits, il court le risque d'oublier celui qu'il a délaissé (qui l'a délaissé) entre-temps. Dans un régime périodique marqué par la fongibilité, où son attention fait l'objet d'une sollicitation permanente, ce lecteur peut également confondre les personnages ou les péripéties d'un roman avec ceux, souvent indiscernables, des ouvrages qu'il aura fréquentés depuis l'arrêt temporaire de sa publication. Le problème de rétention, qui se pose à tout long récit (et qui se posera encore à ces romans différés, lorsqu'ils feront l'objet de versions colligées), se trouve donc compliqué par la «différance» temporelle elle-même, qui superpose à la longueur du roman les retards de sa propre production.

Dans ces conditions de diffusion, le romancier est confronté à un double défi. Il doit bien sûr maintenir l'intérêt du public, s'assurer que le lecteur aura encore le désir de se procurer une nouvelle livraison du roman, malgré le délai parfois fort long qui la sépare de la précédente; mais ce maintien de la tension narrative, par-delà les pauses et les hiatus de la narration, ne suffit pas à garantir le bon fonctionnement de l'ouvrage. Le romancier doit aussi prendre les mesures nécessaires pour que le lecteur comprenne toujours ce dont il s'agit, qu'il se remémore les données essentielles de l'histoire interrompue; il doit rendre en quelque sorte le roman présent à lui-même, malgré sa dispersion 
physique et temporelle. Une partie de cette tâche est déjà remplie par le récit, qui favorise la réminiscence en renvoyant à une grammaire narrative familière (topique ou stéréotypée) et en s'articulant autour d'épisodes mémorables; de ce point de vue, les romans d'Ancien Régime et les productions "populaires» ou paralittéraires des $\mathrm{XIX}^{\mathrm{e}}$ et $\mathrm{XX}^{\mathrm{e}}$ siècles s'inscrivent dans une parfaite continuité. Mais les (proto) feuilletonistes sont aussi forcés de renvoyer directement au contenu des épisodes précédents, qui font alors l'objet d'une référence plus ou moins explicite et plus ou moins détaillée.

Ces renvois au passé romanesque peuvent d'abord être distingués en fonction du lieu qu'ils occupent dans le système textuel. Certains apparaissent dans le paratexte - plus exactement dans cette zone propre au roman différé, cet interstice à la fois spatial et temporel qui sépare les différentes livraisons. Par rapport à l'épisode qu'il précède et auquel il est attaché, cet espace est liminaire; le texte qu'il héberge agit d'ailleurs à la manière d'une préface aux XVII ${ }^{\mathrm{e}}$ et XVIII ${ }^{\mathrm{e}}$ siècles, quand la livraison elle-même correspond à un volume entier, voire à une série de volumes. Toutefois, si on envisage le roman dans sa globalité, il s'agit bien d'un lieu limitrophe, d'un entre-deux - position qui correspond très précisément à la fonction du discours de rappel, point de rencontre de ce qui a déjà été dit et de ce qui reste encore à dire. Lors de la stabilisation du roman différé - quand les chapitres du Juif errant ou les parties du Paysan parvenu sont réunis sous une même reliure -, cet espace est (généralement) appelé à disparaître, emportant avec lui le résumé qu'il contenait et qui a désormais perdu toute pertinence: à quoi bon synthétiser le passé du roman pour un lecteur qui vient de le parcourir ou qui peut immédiatement s'y référer? À quoi bon rappeler ou remettre en mémoire un récit toujours présent?

S'il investit parfois ces failles péritextuelles que révèle la publication en segments - constitutives de ce qu'on a ailleurs proposé d'appeler le paradispositif ${ }^{1}$-, le rappel peut aussi se situer dans le texte lui-même, où il s'intègre de façon plus ou moins harmonieuse à l'économie romanesque. Cette intégration des passages récapitulatifs leur assure une certaine permanence; pour procéder à leur retranchement, on devrait

I. Ugo Dionne, La Voie aux chapitres, Paris, Éditions du Seuil, coll. "Poétique», 2008, p. 85-93. 
s'astreindre à un travail d'adaptation plus laborieux que celui consistant à élider, sans autre forme de procès, un résumé marginal devenu caduc. On est d'autant moins porté à intervenir sur ces récapitulations qu'elles sont assumées par les acteurs textuels eux-mêmes - narrateur ou personnages -, quand les résumés sont attribués à ce responsable réel, individuel ou corporatif (éditeur, revue, journal, réseau) de qui origine l'ensemble du paratexte et dont l'autorité, à tort ou à raison, est considérée comme secondaire et rectifiable.

L'autre variable qui permet de classer les possibles du discours récapitulatif est la taille - qu'on pourrait exprimer en termes de longueur, de pure masse textuelle, mais qu'il est sans doute plus exact d'envisager en tant que quantité ou densité d'information ${ }^{2}$. Le rappel peut en effet ébaucher un mouvement vers les livraisons antérieures; il peut faire allusion à certains événements passés - et à certains événements seulement, dont la connaissance est nécessaire à la compréhension de l'épisode courant. À l'inverse, la récapitulation peut être globale et revenir sur l'ensemble des développements précédents. Dans le premier cas, le rappel s'adresse à ceux qui connaissent déjà le roman ou l'ont à tout le moins déjà connu; il s'agit de réveiller, chez ces (pré)lecteurs fidèles mais distraits, le souvenir de ce qu'ils ont provisoirement oublié. La récapitulation plus détaillée remplit encore cette fonction d'anamnèse, mais peut aussi permettre à un nouveau lecteur de monter dans le récit en marche; elle atteint un degré de précision suffisant pour assurer un rattrapage adéquat ${ }^{3}$.

2. S'il est besoin de trancher entre ces deux manières de définir le critère de la taille - fondées l'une sur la longueur, l'autre sur la densité informative -, c'est qu'elles peuvent à l'occasion s'opposer l'une à l'autre. Un résumé qui interviendrait après deux ou trois livraisons serait nécessairement plus bref, mais aussi plus complet qu'un rappel intervenant à la fin de la publication du roman, alors que des dizaines, voire des centaines d'épisodes doivent être synthétisés; comment qualifier ce résumé de court ou de long, sans adopter une perspective précise?

3. Du reste, une fois qu'on a renoncé à une mesure purement quantitative - appréciable en nombre de mots, de lignes ou de colonnes -, l'application de ce critère peut poser certaines difficultés. Une récapitulation ne peut jamais être exhaustive - à moins de répéter le texte entier, dans une sorte de fantaisie borgésienne de la redondance; il s'agit toujours d'un concentré, qui peut être diversement précipité. Dès lors, à partir de quel degré d'économie ou de complétude franchit-on la limite qui sépare le court du long? Entre la reprise appliquée de tous les principaux retournements du récit et l'allusion laconique à un passé vidé de son contenu, tous les cas de figure restent possibles, dont le classement dépendra souvent du bon vouloir de l'interprète. 
Le croisement de ces deux variables permet de construire un tableau à quatre entrées, distinguant par le fait même quatre phénomènes, qu'on désignera désormais à l'aide de termes employés jusqu'ici de façon indifférenciée:

\begin{tabular}{|c|c|c|}
\hline $\begin{array}{r}\text { Densité } \\
\text { Taille }\end{array}$ & Court & Long \\
\hline Lieu & Évocation & Résumé \\
\hline Texte & Rappel & Récapitulation \\
\hline
\end{tabular}

On s'intéressera essentiellement ici aux deux catégories paratextuelles de l'évocation et du résumé. Étrangères à l'espace du texte, elles ne sont pas emportées par le jeu de l'interprétation qui caractérise le roman lui-même et que chaque roman renouvelle à sa manière; moins riches d'emplois, de significations, d'investissements, elles se prêtent sans doute mieux à une (courte) présentation synthétique - même si elles présentent aussi leurs bizarreries et leurs difficultés, et peuvent à l'occasion se rapprocher des catégories (textuelles) du rappel et de la récapitulation ${ }^{4}$.

L'évocation consiste à remettre en mémoire, de façon allusive, un ensemble narratif plus ou moins oublié. Le sens magique du terme ${ }^{5}$, qui continue à poindre sous l'acception moderne, est ici tout à fait approprié, dans la mesure où il s'agit bien de rappeler l'esprit d'un texte, de le faire revenir de l'oubli qui l'a englouti, de lui redonner vie - ne fût-ce qu'un bref instant.

Les nouvelles qui composeront Arsène Lupin, gentleman-cambrioleur - le premier recueil consacré par Maurice Leblanc à son personnage fétiche - sont pour la plupart publiées dans le magazine Je sais tout entre juillet 1905 et juillet 1906. Dans la maquette du mensuel illustré

4. Pour un exemple de l'approche monographique à laquelle est tenu tout critique qui entend étudier le système récapitulatif d'un roman, voir mon article «Les bégaiements du cour et de l'esprit. Marianne, la récapitulation et le marivaudage romanesque», dans Catherine Gallouët (dir.), Marivaudages: théorie et pratique d'un discours, coll. «SVEC», à paraitre.

5. "EVOCATION, se dit aussi en parlant des Demons, des spectres, dont on dit que les Magiciens font voir des apparitions au moyen de leurs Charmes» (Antoine Furetière, Dictionnaire universel, t. I, Rotterdam, I690). 
de Pierre Lafitte, elles sont introduites par des chapeaux, que la mise en page désigne clairement comme extérieurs au texte: ils se présentent en caractères gras, sur une seule colonne, dans une justification plus étroite que celle du récit; par la graisse comme par la disposition, ils forment un espace de transition entre la facture du titre et celle de la nouvelle. Cette séparation typographique se double d'une différence de voix. C'est bien la direction de Je sais tout qui s'exprime dans ces manchettes, s'adressant à "Nos Lecteurs ${ }^{6}$ » et formant un système avec le discours éditorial du journal: l'accroche de la livraison du is décembre I905 annonce par exemple le premier "Concours Arsène Lupin», un des innombrables jeux lancés mensuellement par Lafitte, dans lequel le lecteur est appelé à deviner un élément, central ou secondaire, du prochain épisode à paraître? Dans cet appareil énonciatif, Leblanc lui-même occupe une position ambiguë: il est l'auteur «réel» des aventures d'Arsène Lupin (sa signature apparaît à l'orée de chaque nouvelle), mais aussi leur narrateur et un de leurs personnages récurrents, remplissant auprès du cambrioleur des fonctions similaires à celles que remplit aux côtés de Sherlock Holmes le bon docteur Watson (qui ne peut, lui, être confondu avec Conan Doyle). Leblanc consacre même un de ses récits, "Le sept de pique», aux événements qui l'ont amené à jouer ce rôle de chroniqueur officiel; or, s'il relate les circonstances de sa première rencontre avec Lupin, c'est bien à la demande de la rédaction de Je sais tout, qui agit comme truchement entre le romancier et les lecteurs - et dont les chapeaux mettent la médiation en scène ${ }^{8}$. S’il

6. Je sais tout, I5 décembre 1905 , p. 663, I5 janvier 1906, p. 372, et 15 novembre 1906 , p. 373. Le périodique sera dorénavant désigné à l'aide des lettres JST, suivies de la date de publication et du numéro de page.

7. Par exemple: "Comment Arsène Lupin s'évadera-t-il?» (JST, I5/I2/1905, p. 672); "Quelle sera la prochaine victime d'Arsène Lupin?» (JST, I5/or/1906, p. 742); "Quel est le bijou historique déjà célèbre par une affaire retentissante que dérobera Arsène Lupin?» (JST, 15/02/1906, p. II6 - question à laquelle répond d'emblée le titre de la nouvelle de mars 1906, «Le collier de la reine»).

8. «Un grand nombre de lecteurs, qui s'intéressent prodigieusement au célèbre gentleman-cambrioleur, devenu aujourd'hui populaire dans toute la France et dans le monde entier, nous ont en effet posé cette question: Arsène Lupin existe-t-il réellement? Et comment son historiographe le connaît-il? Nous avons transmis à M. Maurice Leblanc cette question, et il se propose d'y répondre lui-même dans "Je sais tout" en nous racontant de quelle façon étrange et mystérieuse il a fait la connaissance de son héros» (JST, I5/04/1907, p. 428). Cette annonce intervient en fin de livraison, mais elle trouve un écho dans le chapeau de l'épisode suivant: «Ainsi que nous l'avons annoncé dans 
adopte plusieurs postures, dans le texte comme dans ses marges, Leblanc n'est donc pas celui qui prend (explicitement) la parole dans les accroches des nouvelles, lesquelles le désignent d'ailleurs à la troisième personne, prenant leurs distances par rapport à une figure équivoque, chevauchant de façon inquiétante la frontière d'espaces textuels autrement étanches?.

Les chapeaux de Je sais tout remplissent trois fonctions complémentaires. Ils agissent d'abord comme réclame pour l'épisode, à coup d'hyperboles et de formules mélioratives, s'appliquant tantôt aux aventures - qualifiées d' "extraordinaires" (JST, i5/07/1905, p. 708), d'«originales» (JST, is/or/1906, p. 732), de "sensationnelles ${ }^{10}$ »-, tantôt à Lupin lui-même - dont on vante l'«extraordinaire maîtrise» (JST, I5/II/I906, p. 373), saluant au passage telle «magistrale leçon de savoirfaire" (JST, I5/06/1906, p. 543) ou tel «nouveau et prodigieux tour de force génial» (JST, I5/07/1906, p. 665). En plus de cette fonction publicitaire, rendue nécessaire par le caractère mercantile et la cacophonie polytextuelle d'un périodique familial comme celui de Lafitte, les préfaces des nouvelles renvoient au fonctionnement sériel du texte. En symbiose avec d'autres éléments du paratexte (surtitre, annonces, mention "À suivre»), elles assurent la présence d'un ensemble qui n'existe pourtant encore qu'à l'état de programme $e^{11}$. L'accroche de la deuxième

notre dernier numéro, Maurice Leblanc montre ici de quelle façon étrange et mystérieuse il fit la connaissance du gentleman cambrioleur Arsène Lupin" (JST, I5/05/1907, p. 489).

9. Le chapeau du I5 octobre 1907 opère une séparation plus nette (et plus rassurante) entre la vérité et la fiction: "Devant le succès considérable obtenu aussi bien dans Je sais tout qu'en librairie par les aventures d'Arsène Lupin, nous avons demandé à Maurice Leblanc de nous faire assister à une nouvelle lutte entre son héros et le grand policier anglais Herlock Sholmès» (p. 22I). La commande faite à l'auteur ne porte plus sur la divulgation de ses relations ("réelles») avec son héros, mais sur la production d'une nouvelle histoire le mettant en scène - bien que le verbe employé ("faire assister») conserve une certaine ambiguïté.

Io. Le terme apparaît au moment d'ouvrir L'Aiguille creuse: "Nous recommençons ou plutôt nous continuons la sensationnelle série des exploits du célèbre gentlemancambrioleur Arsène Lupin qui, nos lecteurs en jugeront, s'est surpassé lui-même dans cette nouvelle suite d'aventures, à force d'ingéniosité mystérieuse et de géniale hardiesse » (JST, I5/II/I908, p. 437).

II. Cette dimension est absente du chapeau apposé au tout premier récit, «L'arrestation d'Arsène Lupin", dont la velléité archidispositive est encore hésitante: pas de surtitre renvoyant la nouvelle à un ensemble plus large (comme le fera, dès la livraison suivante, "La vie extraordinaire d'Arsène Lupin»); pas de "À suivre» ou de mention équivalente; l'accroche désigne même la nouvelle au singulier ( Qui peut se vanter 
nouvelle, le is décembre 1905 , annonce déjà une «suite ininterrompue de prouesses inouïes dont Je sais tout réserve la sensationnelle révélation à ses lecteurs" (p. 663). Celle du mois suivant inscrit l'épisode dans une séquence temporelle, en évoquant le passé et le futur d'un personnage dont ce n'est pourtant que la troisième apparition: Arsène Lupin n'est "qu'au début de ses originales aventures", mais il tient de grandes ressources "en réserve pour l'avenir" (JST, I5/or/1906, p. 732). En novembre 1906, alors qu’on passe d'une sous-série («La vie extraordinaire d'Arsène Lupin ») à une autre ("Les nouvelles aventures d'Arsène Lupin»), la préface se charge de souligner cette modification archidispositive: "Arsène Lupin, l'escroc de génie, était resté quelque temps sans faire parler de lui. Le voici qui reprend le cours de ses exploits» (JST, i5/II/I906, p. 373).

La fonction mémorielle du chapeau - la troisième qu'il est appelé à remplir - s'inscrit encore dans cette perspective sérielle: rappeler le passé du récit est aussi une manière de mettre l'épisode en rapport avec la totalité narrative qui l'informe. Dès la deuxième livraison, alors que le mythe de Lupin n'est pas encore constitué, on peut tabler sur une certaine mémoire du public: "Nos lecteurs connaissent Arsène Lupin, puisqu'ils ont déjà assisté à l'arrestation du génial escroc» (JST, I5/I2/1905, p. 663). Le mois suivant, le répertoire des aventures de Lupin a augmenté, au point où le déjà-lu peut être conjugué au pluriel: «il a déjà montré à nos lecteurs d'incomparables échantillons de son savoir-faire» (JST, I5/or/1906, p. 732). L'évocation peut porter sur l'épisode immédiatement précédent, comme lorsque le chapeau rappelle l'arrestation de Lupin, ou lorsqu'il revient sur l'un des premiers échecs

d'échapper aux criminelles entreprises d'un coquin de l'envergure de celui dont le récit que nous publions expose l'extraordinaire aventure!», JST, i5/07/1905, p. 708), comme si on ne prévoyait pas lui donner suite. Le personnage de Lupin, par contre, est immédiatement sériel. La première mention de son nom (à l'occasion d'un télégramme annonçant sa présence aux passagers du paquebot Provence) entraîne une surprise liée à la reconnaissance: "Arsène Lupin parmi nous! l'insaisissable cambrioleur dont on racontait les prouesses dans les journaux depuis des mois! l'énigmatique personnage avec qui le vieux Ganimard, notre meilleur policier, avait engagé ce duel à mort dont les péripéties se déroulaient de façon si pittoresque! Arsène Lupin, le fantaisiste gentleman qui n'opère que dans les châteaux et les salons [...]" (M. Leblanc, Les Aventures extraordinaires d'Arsène Lupin, présentations de Jacques Derouard, Paris, Omnibus, t. I, 2004 [1905], p. I2). D'emblée connu des passagers, Lupin a déjà à son actif une liste d'exploits susceptibles de donner lieu à des récits futurs et de se prolonger à l'infini. 
du jeune escroc, aux mains de la célèbre Thérèse Humbert (rebaptisée Imbert) : «Nous avons vu Lupin aux prises avec plus fort que lui » (JST, I5/06/1906, p. 459). Mais la référence, plus imprécise, peut aussi porter sur l'ensemble des péripéties antérieures - comme lorsque, le is juillet I906, l'auteur de l'amorce se demande si « [pour] la première fois Arsène Lupin se trouvera [...] dans l'embarras» (p. 665) -, supposant connues les aventures déjà parues, dont Lupin est toujours sorti (à peu près) victorieux.

Toutefois, même lorsqu'il s'agit de rappeler un épisode précis - et à plus forte raison lorsqu'on renvoie à l'ensemble de l'œuvre d'Arsène Lupin -, l'évocation porte moins sur le contenu de la mémoire du lecteur que sur cette mémoire elle-même; ce qui est évoqué, c'est moins la teneur des épisodes antérieurs que le fait que ces épisodes ont bel et bien eu lieu. Par leur caractère constatif, les verbes employés dans les chapeaux mettent les lecteurs devant un fait accompli: ils "ont déjà assisté» à l'arrestation de Lupin, on leur "a déjà montré» certains de ses exploits - ils devraient donc être capables de se rappeler ces épisodes, sans qu'on ait besoin de les expliciter. Où l'on retrouve le sens religieux de l'évocation: par quelques paroles vagues, aussi brèves qu'une formule ou qu'une incantation, on entend rappeler un contenu qui n'est lui-même jamais nommé ou qui n'est suggéré que dans les termes les plus incertains.

Ce caractère (très) allusif de l'évocation est du reste favorisé par la structure narrative des nouvelles qui composent la série de "La vie extraordinaire d'Arsène Lupin ». Malgré les signaux habituels de la narration périodique ("À suivre» final, référence numérique aux épisodes antérieurs - qu'on pourrait d'ailleurs considérer comme une forme particulièrement laconique d'évocation), les nouvelles constituent moins des chapitres que des récits indépendants. Sauf exception, elles ne forment pas une suite orientée appelant une lecture linéaire; au contraire, en évoquant dans le désordre différents moments de la carrière de Lupin, elles refusent la séquence chronologique qui aurait pu en organiser le développement ${ }^{12}$. La connaissance des livraisons précédentes n’est pas

I2. Les trois premiers segments forment une suite plus rigoureusement linéaire; par leurs titres mêmes ("L'arrestation d'Arsène Lupin», "Arsène Lupin en prison », «L'évasion d'Arsène Lupin»), ils se présentent comme les trois étapes d'un même récit, à l'ordre immuable: Arsène Lupin ne saurait évidemment s'évader avant d'avoir été arrêté et mis 
nécessaire à la compréhension d'un nouvel épisode: il suffit de saisir la logique de l'ensemble et le paradigme sériel qui le fonde, à quoi suffisent les chapeaux allusifs fournis par la rédaction de Je sais tout.

Le besoin d'un véritable résumé se fait cependant sentir à partir du moment où les aventures du gentleman-cambrioleur adoptent un modèle plus régulier. Le I5 novembre 1906, Je sais tout publie le premier chapitre de "La dame blonde», l'un des deux petits romans qui, une fois complétés et refondus, composeront Arsène Lupin contre Herlock Sholmès. Contrairement aux huit précédentes, les six livraisons mensuelles de «La dame blonde» correspondent aux segments d'un unique récit, dans lequel Herlock Sholmès s'attache à résoudre une seule énigme - même si les ramifications de cette énigme sont multiples, et même si, dans leur tracé comme dans leurs dimensions, ses chapitres continuent de présenter une opacité rappelant le fonctionnement de la nouvelle. Cette dynamique narrative inédite appelle de nouvelles pratiques de rappel. Dès le premier chapitre de "La dame blonde», le rapport au passé du texte a changé: au chapeau (qui remplit toujours son rôle de réclame et de régie sérielle) s'est ajouté, en bas de page, un «Résumé des précédentes aventures» - ces aventures qui ne formaient pas jusqu'ici une trame ordonnée, mais qu'on traite désormais comme une suite cohérente. Le "Résumé» infrapaginal reprend en effet les différents récits de "La vie extraordinaire d'Arsène Lupin» dans leur ordre de publication, sans tenter de les réorganiser selon un principe biographique (alors que le cinquième, "Le collier de la Reine», et le sixième, "Le coffre-fort de Mme Imbert», se déroulent respectivement dans l'enfance et la jeunesse de Lupin). La (toute récente) vectorialisation du récit entraîne une fixation de la série, considérée comme un système unifié. Il reste parfaitement possible pour un nouveau lecteur de suivre l'enquête de «La dame blonde» sans avoir fréquenté auparavant l'univers d'Arsène Lupin; la focalisation du récit sur Sholmès, le détective anglais calqué sur Sherlock Holmes (et qui porte le même

en prison. Mais justement: les titres des nouvelles fournissent déjà au lecteur toute l'information dont il a (absolument) besoin; pour comprendre "L'évasion d'Arsène Lupin", nul besoin de se rappeler, ou même de connaître, les circonstances précises de son arrestation et de son séjour carcéral, que leur apparente séquentialité n'empêche pas de fonctionner autarciquement, sur le modèle de la série (voir U. Dionne, La Voie aux chapitres, op. cit., p. 58-70). 
nom que lui, avant que des menaces venues d'outre-Manche ne poussent Leblanc à la contrepèterie), assure cette indépendance du nouveau roman par rapport aux exploits antérieurs du cambrioleur, ici relégué (comme plus tard dans L'Aiguille creuse) au rang d'adversaire machiavélique. Et pourtant: le mensuel insiste pour fournir, à cet (éventuel) nouvel arrivant, un abrégé auquel l'« ancien» lecteur n'a jamais eu droit.

Le résumé s’arroge rapidement la fonction de réclame du chapeau (lequel, après avoir été réduit à deux lignes dans le numéro du I5 décembre 1906, disparaît complètement des livraisons suivantes). Sa première phrase adopte le ton hyperbolique des anciennes accroches, tout en conservant leur perspective extérieure sur l'écrivain et sa création $^{13}$. L'attaque des résumés de "La dame blonde», où se concentre cette dimension publicitaire, est d'ailleurs le seul de leurs éléments qui reste à peu près immuable durant six mois; le résidu subit une réorganisation constante, alors que progresse le roman et que les informations nécessaires à sa compréhension prennent le pas sur les exploits antérieurs de Lupin. Ceux-ci, qui occupaient entièrement le premier "Résumé», ne forment plus qu'un tiers environ du deuxième, le reste étant accordé aux événements introduits dans le premier chapitre de «La dame blonde»; et ainsi de suite, la partie consacrée au passé de Lupin s'amenuisant peu à peu, alors que la portion dédiée à l'enquête de Sholmès devient à la fois plus longue et plus synthétique (puisque, si les péripéties s'accumulent, l'espace infrapaginal qu'on peut leur consacrer reste à peu près constant) ${ }^{14}$.

Les résumés de «La dame blonde» se distinguent donc clairement des chapitres du roman, à la fois par leur position (en bas de page), par leur taille (réduite), par leur caractère (italique) et par leur voix (éditoriale,

I3. "Avec un talent d'invention qui fait de lui l'égal du grand romancier anglais Conan Doyle, Maurice Leblanc a narré dans Je sais tout la "Vie extrordinaire d'Arsène Lupin", cet escroc de marque dont les audacieuses aventures ont émerveillé des centaines de milliers de lecteurs" (JST, I5/12/1906, p. 605).

I4. La pratique du résumé est si bien implantée qu'elle persiste après la fin de «La dame blonde», lors de la publication du «Sept de cœur» dans Je sais tout du 15 mai 1907. Ici, le résumé est pourtant inutile: la nouvelle est une sorte d'«épilogue», de supplément, d'autant plus détaché du roman qui précède qu'elle se situe avant, au moment de la «rencontre» de Maurice Leblanc et d'Arsène Lupin - et qu'elle sera recueillie, non pas dans Arsène Lupin contre Herlock Sholmès, mais dans le recueil précédent, Arsène Lupin, gentleman-cambrioleur. 
collective, irréductible en tout cas à celle du narrateur). Symbolisée par un trait traversant la page, la frontière entre les espaces du texte et du paratexte est à peu près étanche. Dans d'autres cas, cependant, le résumé peut trouver place dans un espace plus ambigu, qui participe à la fois, et de diverses manières, des zones textuelles et péritextuelles. On en donnera deux exemples, qui de la première décennie $\mathrm{du} \mathrm{xx}^{\mathrm{e}}$ siècle nous ferons reculer jusqu'à l'âge d'or du roman-feuilleton, puis jusqu'aux années 1730 .

Dans Le Constitutionnel du 30 juillet 1845 parait le $155^{\mathrm{e}}$ feuilleton du Juif errant d'Eugène Sue, qui connaît depuis juin I844 un succès phénoménal ${ }^{15}$. Ce feuilleton n'est toutefois pas identique aux cent cinquante-quatre qui l'ont précédé, ni aux dix-neuf qui le suivront. Avant d'entreprendre la publication de la dixième et dernière partie $\mathrm{du}$ roman, et après une interruption de deux semaines, la direction du Constitutionnel fournit en effet à ses abonnés, au rez-de-chaussée de la une, le «Résumé des neuf premiers volumes du Juif errant». Et il s'agit bien d'un résumé, qui essaie de condenser «le sens et les incidents principaux de cette grande fable [...], pour qu'il y ait moins de lacune dans les souvenirs du lecteur, lorsqu'il va lire le dernier volume de cette belle étude ${ }^{16}{ }^{\prime}$. L’enjeu du roman - l'héritage des membres de la famille Rennepont - y est minutieusement exposé, avec une parfaite exactitude comptable ${ }^{17}$. Les forces en présence sont méthodiquement identifiées, à travers le portrait des sept héritiers Rennepont (du côté du Bien) et la présentation des principaux membres du parti jésuite (du côté du Mal); une place est aussi accordée à quelques-unes des «figures accessoires» (la disgracieuse mais courageuse Mayeux, le poète socialiste Agricol Baudoin) que Sue «a groupées autour des principaux personnages de son roman véridique» $(L C$, p. 2). Les manigances des pères Rodin et d'Aigrigny sont rappelées, comme l'apparition miraculeuse

I5. Sur la genèse et l'histoire éditoriale du roman, voir Maria Adamowicz-Hariasz, "Le Juiferrant" d'Eugène Sue: du roman-feuilleton au roman populaire, Lewiston, Edwin Mellen Press, coll. "Studies in French Literature», 200I, p. I3 sq.

I6. Le Constitutionnel, mercredi 30-jeudi 3I juillet I845, p. I. Dorénavant désigné à l'aide des lettres $L C$, suivies du numéro de page.

17. "Les dépositaires ont placé les 50,000 écus à l'intérêt de $5 \%$, suivant les intentions du testateur. À l'expiration des cent cinquante années, la succession du marquis de Rennepont s'est élevée à 225,950,000 fr dont $13,775,000$ à déduire pour frais de gérance, etc., soit 212,175,000 à remettre aux héritiers» $(L C, \mathrm{p}$. I). 
d'Hérodiade, sœur du Juif errant, qui les empêche in extremis de s'emparer de l'héritage et accorde aux Rennepont un sursis de trois mois. Le feuilleton et le résumé se terminent par une sorte de bilan provisoire, à la veille de la dernière manche ${ }^{18}$ : une fois (re)traversé tout le roman en quelques colonnes, l'abonné du Constitutionnel est revenu au point précis où, le surlendemain, il pourra reprendre sa lecture.

Sa richesse et ses dimensions distinguent ce résumé paratextuel d'une simple évocation. Mais s'il cherche à retracer les «incidents principaux" du Juif errant, le résumé entend aussi en restituer la signification morale. À la synthèse du récit s'ajoute un commentaire critique sur «M. Eugène Sue» et sur sa place dans la littérature de son temps. Mis en rapport avec de brillants ancêtres, tant du point de vue de la «comédie de mours" (Rabelais, Montesquieu) que de la littérature utopique (More, Campanella), Sue reste pourtant incomparable; il a ouvert au roman les «nouveaux horizons» de la critique sociale. Les Mystères de Paris et Le Juif errant - envisagés de concert, comme un vaste ouvrage bicéphale - demandent de ce fait « une attention plus sérieuse que celle qu'on accorde habituellement à des fantaisies littéraires» ( $L C, \mathrm{p}$. I). Le feuilleton du 30 juillet 1845 remplit ainsi la fonction publicitaire qui caractérisait les chapeaux des récits de Maurice Leblanc, mais sur un mode plus solennel, axé sur la valeur historique et philosophique de l'œuvre plutôt que sur sa valeur de divertissement; il retrouve aussi un des rôles traditionnels du feuilleton quotidien, qui avant d'être monopolisé par la fiction romanesque accueillait la chronique littéraire, dramatique ou musicale ${ }^{19}$. Ces deux aspects - publicitaire et critique - fusionnent à plusieurs reprises, alors que sont encensés «la main de maître» d'Eugène Sue ( $L C$, p. I), la simplicité aristotélicienne de sa composition (ibid.) ou la «chaleur» et la «vie» qu'il a su insuffler à son récit. Le feuilleton procède enfin à une défense du roman, adoptant

I8. «En résumé, voici quels sont les progrès de l'œuvre de Rodin, à la fin du neuvième volume. L'un est mort, Couche-tout- $\mathrm{Nu}$; la Société de Jésus s'est substituée à deux autres: à Gabriel et à M. Hardy. Restent les deux filles du maréchal Simon, Mlle de Cardoville et Djalma. Ceux-là luttent encore. Mais déjà le maréchal est presque hors de combat. Djalma et Mlle de Cardoville ont toutes leurs forces; ils sont amoureux et réunis. Puissent-ils sortir sains et saufs des mains de leurs puissans adversaires!» (LC, p. 2)

19. Voir Marie-Ève Thérenty, La Littérature au quotidien: poétiques journalistiques au XIX siècle, Paris, Éditions du Seuil, coll. «Poétique», 2007, p. I26-I29. 
une attitude combative et idéologique. À ceux qui reprochent au Juif errant son irréligion, il fait valoir la religiosité positive de Gabriel de Rennepont, qui montre que Sue «ne confond pas le vrai prêtre et les mauvais ministres» (ibid.); aux critiques que suscite le noir portrait de la Compagnie de Jésus, le résumé répond que Sue a voulu en faire un exemple: «il a mis en lumière les merveilleux ressorts du mécanisme jésuitique, pour nous faire pressentir tout ce que l'esprit du bien pourrait tirer de la combinaison intelligente des forces humaines» (ibid.).

L'objet proposé par Le Constitutionnel est donc un hybride mêlant le rappel, la critique, l'histoire littéraire, l'apologie et le plaidoyer, en plus d'identifier quelques beaux passages offerts à l'attention du relecteur curieux ${ }^{20}$. Il s'intègre par certains aspects au paratexte (temporaire) du Juif errant - comme l'atteste sa disparition des éditions collectives, qui peuvent désormais en faire l'économie. Cependant, par sa propension au commentaire (qui rappelle les habitudes prolixes d'Eugène Sue luimême), par sa manière de pousser à bout la logique analeptique (en l'étendant à la signification de l'œuvre, et non plus à ses seules composantes narratives), par sa façon enfin de clarifier certains aspects de la pensée et de la religion de Sue, le résumé revêt des attributs proprement textuels. Surtout, il se loge dans l'espace même du texte, dans ce feuilleton que le récit, jusqu'ici, a été le seul à investir. Le résumé ne fait pas qu'emprunter le ton et le style d'un (vrai) chapitre du Juif errant: il en occupe aussi le lieu, il en mime la forme, il en reprend la coupe. Il se confond avec une des unités de ce roman dont, simultanément, il fait la synthèse et prend la place.

Le second de ces résumés ambigus, participant à la fois du texte et du paratexte, se situe au centre exact d'un des romans les plus perplexifiants du XVIII ${ }^{\mathrm{e}}$ siècle: ce Lamekis que le chevalier de Mouhy fait

20. «[...] l'auteur aura décrit en passant les prodiges de la nature indienne, les mystères de son antique civilisation; il nous aura conduits, dans le repaire de bêtes féroces; il aura esquissé leur dompteur, plus hideux cent fois que les élèves» ( $L C$, p. 2). «L'un des épisodes les plus touchans et les plus vrais de ce roman est celui où Mlle de Cardoville, enfermée par ruse dans une ignoble maison de fous, livrée aux soins repoussans de femmes sordides et grossières, épouvantée des cris étranges que la folie pousse dans cette horrible maison, sent sa raison se troubler peu à peu et commence à croire qu'elle est réellement folle $[\ldots]$ " (ibid.). "Parmi toutes les scènes véritablement saisissantes que le fléau a inspirées à $M$. Eugène Sue, nous voulons citer seulement celle ou l'abbé d'Aigrigny, poursuivi comme empoisonneur par la populace égarée jusque dans l'église de Notre-Dame, est sauvé grâce à l'intervention de Gabriel» (ibid.). 
paraître, à Paris puis La Haye, entre 1735 et 1738 . Texte "bizarre ${ }^{21}$ ", "monstrueux ${ }^{22}$ ", excessif ${ }^{23}$, dans lequel on a pu deviner un "précurseur» du romantisme, de Michaux ${ }^{24}$ et de la science-fiction ${ }^{25}$, Lamekis suscite depuis quelques années un enthousiasme critique qu'on peut trouver paradoxal, compte tenu de l'indéniable illisibilité d'un texte qui se dérobe obstinément à toute saisie ${ }^{26}$.

Les quatre premières parties paraissent rapidement: la quatrième est approuvée le 17 novembre 1736 , quatorze mois à peine après le début du roman - quatorze mois durant lesquels Mouhy publie seize autres livraisons romanesques. Un délai plus important sépare cependant ce premier bloc des quatre parties suivantes, que la proscription du roman oblige à indiquer un lieu de publication hollandais: elles n'offrent donc,

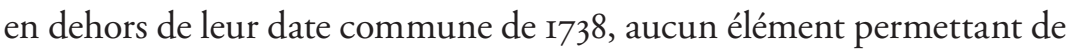
dresser un calendrier plus exact. Mais que ces dernières parties constituent une seule (très) grande livraison, ou que leur production ait été échelonnée sur quelques semaines ou quelques mois, elles paraissent après une pause assez considérable pour que l'«Avertissement» de la cinquième se sente forcé d'en mitiger l'ampleur:

Comme je suis le plus prévenant de tous les hommes \& le plus attentif, j’ai travaillé cette cinquième Partie de sorte que votre mémoire, mon cher Lecteur, ne souffrira point de l'intervalle considérable qu'il y a eu des premières à celle-ci $[\ldots]^{27}$.

2I. Yves Giraud, «Monstres et merveilles au centre de la terre: les fantasmes fantastiques du chevalier de Mouhy", Studi di Letteratura Francese, n ${ }^{\circ} 3$, 1987, 45-60, p. 47.

22. Mathieu Brunet, L'Appel du monstrueux. Pensées et poétiques du désordre en France au XVIII siècle, Louvain, Peeters, coll. "La République des Lettres», 2008, p. II3-I2I.

23. Yves Citton, «Inspiration et renoncement dans Lamekis», dans Jan Herman, Kris Peeters et Paul Pelckmans (études réunies par), Le Chevalier de Mouhy. Bagarre et bigarrure, Amsterdam, Rodopi, coll. "Faux titre», 20I0, p. I53.

24. Jacques Bousquet, Anthologie du dix-huitième siècle romantique, Paris, Pauvert, I972, p. I78-I79.

25. Peter Fitting, "Imagination, Textual Play and the Fantastic in Mouhy's Lamékis», Eighteenth-Century Fiction, vol. 5, nº 4, 1993, 311-329.

26. De façon symptomatique, si le nombre d'articles ou de chapitres consacrés au roman rivalise désormais avec celui des travaux sur La Paysanne parvenue, cette dernière a connu deux éditions critiques dans les dix dernières années, alors que les éditeurs reculent devant la tâche suicidaire de fournir une version scientifique du premier.

27. Charles de Fieux, chevalier de Mouhy, Lamekis, ou les voyages extraordinaires d'un Égytien dans la Terre intérieure, Cinquième partie, La Haye, Néaulme, I738, p. vi. La Quatrième partie est parue à Paris, chez Poilly, en 1737 . Les références au texte se feront dorénavant par la lettre $L$, suivie des numéros de partie et de page. 
Cet avertissement s'intercale dans un des épisodes les plus commentés du roman, une des plus longues et des plus vertigineuses métalepses romanesques de l'âge classique. À la fin du quatrième volume - alors que la narration est déléguée au personnage du philosophe Dehahal, qui relate son initiation aux mystères d'une race de Sylphes aériens -, Mouhy s'interrompt en prétextant un défaut de son manuscrit (défaut d'autant plus étonnant que la fiction éditoriale mise en place par la préface identifiait Lamekis à un récit oral, conté à l'écrivain par un étrange compagnon de voyage arménien):

La quatrième partie finit dans cet endroit, $\&$ dans la cinquième il ne se trouve aucune trace de l'histoire de Déhahal, ce qui m’ayant fait imaginer que ce défaut venoit d'une lacune considérable, ou de la perte de quelques pages du manuscrit, j'ai cru y devoir suppléer en cherchant dans les Auteurs les plus sçavans quelques passages qui pussent maider à finir une histoire si intéressante, deux ans se sont passés à feuilleter dans les Bibliothéques les plus connues tous les Sçavans qui ont écrit dans ce genre, $\&$ sur-tout ceux qui ont commentés les Avantures de Lamekis. (L4, p. I09)

Mouhy «commen[ce] à se rebuter» de ces recherches infructueuses quand intervient une suite de circonstances extraordinaires qui le mettent "en état d'achever son ouvrage» (ibid.). Il serait peu raisonnable de prétendre condenser ici un développement dont la logique semble se dissoudre davantage à chaque relecture. Précisons simplement que Mouhy est visité par plusieurs personnages de son roman, dont l'immense chien bleu Falbao, qui l'entraîne dans des catacombes égyptiennes situées sous le faubourg Saint-Antoine; qu'il s'y entretient avec Dehahal (dont le chien Falbao a pris la forme), qui lui propose de subir lui-même l'initiation aux mystères des Sylphes (laquelle exige, entre autres délicatesses, que l'impétrant soit écorché vif, suspendu par la langue à un crochet et broyé par les mandibules d'une abeille géante); qu'ayant refusé l'épreuve, Mouhy retourne dans ses quartiers, où il est confronté à une série de phénomènes inexplicables (manuscrit vivant, plume douée de vie et de volonté, apparition d'une femme parfaitement belle qui après avoir noirci quelques pages disparaît dans un tiroir de son bureau); et que, pris d'une furie créatrice, le romancier termine son œuvre en un seul marathon d'écriture de plus d'un mois, durant lequel il ne s'arrête ni pour dormir ni pour manger. Le scénario de provenance, si bizarre soit-il, est alors conclu; la cinquième partie 
pourrait commencer - si elle n'avait déjà atteint sa quatre-vingtdeuxième page. Le récit métaleptique, amorcé avant la fin de la quatrième partie, s'est en effet poursuivi dans la suivante; il enjambe non seulement la frontière des deux unités centrales de Lamekis, mais aussi les deux années qui séparent les parties parisiennes de 1735-I737 et le bloc pseudo-hollandais de 1738 . Il se situe dans un espace indécis, cette indécision étant relayée par différents éléments de l'épisode.

Le cadre, moderne et parisien, n'est manifestement plus celui du roman, qui alterne entre l'Égypte ancienne, le royaume souterrain des Hommes-vers et l'île céleste des Sylphides; il ramène le lecteur dans l'univers «réaliste» des préfaces romanesques du XviII siècle, dont la fonction d'authentification se fonde sur un ancrage - souvent bien ténu - dans la réalité contemporaine. Le discours subit une transformation analogue: il n'est plus assumé par Lamekis, Dehahal ou Motacoa - les trois personnages qui se sont jusque-là partagé la narration du roman -, mais par la figure responsable de la «Préface» de la première partie et de l'«Avertissement» de la cinquième, où elle se désigne comme «de Mouhy». L'objet du récit est par ailleurs celui de la plupart des préfaces de l'époque, même s'il fait l'objet d'un renversement: plutôt qu'à la découverte du manuscrit (authentique) contenant le roman, on assiste à son effacement, et aux conséquences de sa disparition sur un texte qui ne peut procéder sans lui. Enfin, le caractère paratextuel de l'épisode est signalé physiquement: en amont (dans la Quatrième partie), par la réduction de la taille des caractères, lorsqu’on passe du récit de Dehahal à celui de Mouhy (L4, p. Io9); en aval (dans la Cinquième partie), par un nouveau faux-titre, intervenant près de quatre-vingts pages après le premier, lorsqu'on quitte l'intermède pour revenir au roman $(L 5$, p. 83$)$.

Certains autres éléments empêchent pourtant de renvoyer résolument cette section du côté du paratexte - à commencer par l'irruption métaleptique des personnages de Lamekis. Émergeant de strates narratives distinctes ${ }^{28}$, ceux-ci remontent une à une les couches romanesques

28. Dehahal apparaît de plain-pied avec le narrateur Lamekis, qui le rencontre sur l'île aérienne des Sylphides (niveau I) - en plus d'être le personnage central de son propre récit d'initiation, sur lequel s'interrompt d'ailleurs la Quatrième partie; Sémiramis est un personnage du récit que Lamekis fait de sa vie à son camarade Sinouïs (niveau 2); quant à l'Hourcaïs et Falbao, ils interviennent à deux différents moments du récit de Motacoa, qui est lui-même inséré dans celui de Lamekis (niveau 3). 
pour s'arrêter à ce niveau associé au réel, où Mouhy lui-même se situe; ils surgissent dans cet espace ambigu qui devrait en toute logique leur être interdit. Les frontières sont en tout cas résolument brouillées, au point où l'on peut se demander si ce sont les créatures du texte qui surgissent dans l'univers paratextuel ou si c'est cet univers qui bascule dans le roman - comme semblerait le suggérer la proposition d'initiation que fait Dehahal à Mouhy, symétrique de celle faite à Lamekis dans le système du texte, et se soldant par un refus analogue. Pour compliquer les choses, non seulement ces personnages apparaissent dans le paratexte, mais ils y racontent des bribes de leur histoire, reproduisant «la structure narrative [en tiroirs] qui avait caractérisé la première moitié du roman, à un moment où on est censé en être sorti ${ }^{29}$ ".

Or, c'est dans cet espace équivoque que Mouhy remplit sa promesse de soulager la «mémoire» du lecteur et de combler l'«intervalle considérable» séparant les parties. Il procède en trois temps, multipliant les occasions et les sources de rappel, complétant progressivement l'information en fonction de différentes perspectives. Il met d'abord à profit la visite nocturne et hallucinatoire des personnages des premières parties, venus hanter "de Mouhy» pour lui reprocher la noirceur des portraits qu'il en a brossés; leurs récits acrimonieux permettent ainsi de revenir, par antiphrase, sur le contenu des livraisons précédentes. C'est en suggérant au romancier terrorisé une interprétation révisionniste de ses actions que la reine Sémiramis, bourreau du père de Lamekis, rappelle indirectement les ignominies déjà relatées à son sujet (L5, p. I6-I8). L'intervention fantomatique du roi Hourcaïs, qui a par jalousie exilé sa femme et son fils Motacoa dans un souterrain inexpugnable, opère plutôt sur le mode de la paralepse: le tyran raconte ce qu'il a vécu au cours des aventures relatées dans les premiers volumes, qui se trouvent de la sorte évoquées (L5, p. 19-29). Dans les deux cas, l'insatisfaction des personnages devant leur avatar public renvoie à l'interactivité liée au fonctionnement périodique, qui donne au roman l'occasion de s'adapter aux réactions (hostiles, perplexes ou bienveillantes) ayant accompagné la publication de ses livraisons initiales. Sémiramis, notamment,

29. Mathieu Brunet, "Lamekis de Mouhy ou la tentation de l'illisible», dans René Démoris et Henri Lafon (textes réunis par), Folies romanesques au siècle des Lumières, Paris, Desjonquères, 1998, p. 3II. 
évoque les dommages à sa réputation causés par le début de Lamekis: "Depuis le tems fatal où ton livre a paru, mes tourmens ont redoublé, les Lecteurs augmentent tous les jours, \& par conséquent l'horreur qu'on a contre moi» ( $L 5$, p. I8). En introduisant un développement plus favorable à la reine d'Égypte (fût-ce en faisant quelques entorses diplomatiques à la vérité), les nouveaux volumes du roman pourraient réparer cette atteinte à sa mémoire.

Dans le souterrain où il est entraîné par le chien Falbao, Mouhy découvre par ailleurs (et entre autres choses) un grand bas-relief, qui résume en douze cartouches le contenu des épisodes déjà parus:

Je ne fus pas peu étonné de ce qu'ils représentoient; ils retracerent à mon esprit toutes les Aventures de Lamekis, décrites dans les quatre premières Parties de cet Ouvrage, avec un tel art, que les ayant lûes, on ne pouvoit s'y méprendre. ( $L 5$, p. 47$)$

Comme dans les résumés précédemment envisagés, il s'agit de « retracer à l'esprit» le contenu des volumes antérieurs. La remémoration ne s'effectue cependant pas ici à travers le discours du narrateur ou les souvenirs d'un personnage, mais par la description commentée des bas-reliefs, qui se suivent justement "dans l'ordre de l'histoire» - c'està-dire (pour corriger Mouhy, qui n'a pas eu la chance de lire Genette), dans l'ordre du récit: les sculptures épousent le tracé sinueux emprunté par les premières parties, en n'omettant aucun détour, aucune digression, aucun emboîtement narratif ( $L 5$, p. 47-58). Chaque circonstance importante fait l'objet d'une note renvoyant au volume et à la page de référence, assurant une correspondance encore plus étroite du roman passé et de son rappel monumental. Enfin, une fois terminée cette ekphrasis de plus de dix pages, une dernière portion de résumé est fournie par le personnage de Dehahal, qui tout en appelant Mouhy à l'initiation lui rappelle les événements sur lesquels s'est interrompue la quatrième partie (L5, p. 63-67).

Dans les commentaires sur l'épisode central de Lamekis, cette dimension temporelle et mémorielle a été généralement ignorée. Il n’est pourtant pas indifférent que cette confusion progressive entre le monde romanesque et le monde réel (filtré par la fiction éditoriale) intervienne alors que le roman est lui-même en arrêt. Le délai entre deux livraisons favorise toujours une certaine circulation entre la réalité et le roman. 
Celle-ci s'effectue le plus souvent du dehors vers le dedans, alors que les circonstances de la publication ou de la réception infléchissent les données du récit (ce dont rendent ici compte, de façon autoréflexive et fantasmatique, les tentatives de révision d'une Sémiramis); mais elle peut aussi s'effectuer du dedans vers le dehors, alors que les couches les plus «profondes» du récit profitent d'une pause (ou d'une panne) pour s'approcher sournoisement de la surface des choses. Le roman périodique permet cette contamination: il ne peut opposer au réel la forme close du livre, ce cadre qui contribue à faire de l'univers romanesque un monde à part, autonome, protégé des invasions du dehors en même temps que le dehors est protégé de son débordement ${ }^{30}$. L'ouvre se pulvérise en livraisons ouvertes, petits cadres à la fois autarciques et dépendants qui empêchent la coalescence de l'univers fictionnel et rendent ses limites poreuses, franchissables.

Il n'est pas non plus indifférent que ce retour graduel vers le passé du roman s'effectue à un moment où son avenir est en crise. Entre la quatrième et la cinquième partie, Lamekis ne parvient plus à avancer. Malgré les recherches érudites entreprises par Mouhy pour trouver la «suite» de l'histoire du jeune Égyptien, malgré les années passées à la table de travail, le roman n'augmente pas d'une ligne. L'épisode est jonché de figures et de signes renvoyant aux différentes facettes de cette impossibilité. Le motif de l'interruption se répète lui-même au moins trois fois. C'est d'abord, on l'a vu, le manuscrit sur lequel se fonde l'écrivain qui s'interrompt, sans qu'il soit possible d'en reprendre le cours. L'histoire de l'Hourcaïs s'arrête ensuite, quand il est «enlevé tout à coup par un homme aîlé qui s'écri[e] : c'est assez» (LS, p. 29). Les circonstances extraordinaires de cette ascension n'empêchent pas Mouhy d'évoquer une continuation possible: "L'Intelligence de [l'auteur] lui a fait espérer qu'elle lui dicteroit incessamment la suite de l'Histoire de l'Hourcaïs, dès qu'elle lui aura fait cette grâce, on aura soin

30. Sur cette notion de cadre, voir Boris Uspenski, A Poetics of Composition. The Structure of the Artistic Text and Typology of a Compositional Form, trad. de V. Zavarin et S. Wittig, Berkeley, University of California Press, I973 [1970], p. 137-I55, et Iouri Lotman, La Structure du texte artistique, trad. sous la dir. d'H. Meschonnic, Paris, Gallimard, coll. "Bibliothèque des sciences humaines", 1973, p. 298-309. Les effets du support (livresque) sur l'énonciation (du roman et de la nouvelle) ont été évoqués par Bruno Monfort dans «Sherlock Holmes et le "plaisir de la non-histoire". Série et discontinuité", Poétique, no IOI, I995, p. 53-54. 
d'en faire part au Public» (ibid., note $a$ ) ; est-ce un trait d'autodérision (ou d'autocritique), de la part d'un écrivain qui use et abuse de ce type de promesse dans sa propre pratique périodique? Enfin, le dialogue de Mouhy et d'une voix invisible, tenu en pleine rue, prend fin lorsqu'une vieille femme compatissante secoue l'écrivain tétanisé. Comme les précédentes, cette suspension entraîne un appel à la patience du lecteur ${ }^{31}$; comme les précédentes, elle singe et creuse la coupure de Lamekis.

Les autres figures de l'écriture impossible prennent souvent un tour fantastique. Effrayé par les personnages qui l'ont assailli dans son sommeil, Mouhy "con[çoit] le dessein de ne jamais continuer Lamekis» et déchire "une cinquième partie [...] commencée» $(L 5$, p. 30-3I) - soit le livre même que le lecteur tient entre ses mains, ou un autre dont celui-ci a pris la place. Sa main droite, puis sa main gauche se figent comme par enchantement au moment de transcrire un "rêve extraordinaire» (L5, p. 60-6I, note $a$ ). Un «rouleau de papier», qui apparaît à la main de Mouhy après son entretien souterrain avec Dehahal et qui contient sans doute «la suite des Aventures de Lamekis», est malheureusement "ecrit dans des caracteres inconnus", qui résistent à "un sçavant dans les Langues Orientales» ( $L 5$, p. 69). On évoque aussi des obstacles plus concrets à la poursuite du roman. Dans une note, Mouhy suggère le rôle joué par la police du livre, qui aurait empêché la publication de l'histoire de Dehahal, «le Censeur rigide s'étant persuadé, parce qu'il ne l'entendoit pas plus que l'Auteur, qu'elle pouvoit donner lieu à des explications sérieuses» (L5, p. 66, note $a$ ). Même l'«ouvrage de piété» que mentionne en passant le romancier peut être considéré comme une piste, sinon une clef: c'est dans cet ouvrage, les Nouveaux motifs de conversion à l'usage des gens du monde (1738), qu'on trouve l'un des principaux témoignages de l'époque sur la proscription du roman ${ }^{32}$, ainsi identifiée, de façon (très) allusive, comme un des obstacles s'opposant à la production de Lamekis. Manuscrit et récit troués, paralysie de

3I. "Le Lecteur seroit sans doute bien aise d'apprendre ce que la voix secrete me dit, $\&$ sur quel chapitre roula la conférence; il viendra un tems où je lui donnerai cette satisfaction: il ne m'est pas permis pour le présent de m'étendre davantage sur cet article: revenons" $(L 5$, p. 40$)$.

32. Georges May, Le Dilemme du roman au XVIII siècle. Étude sur les rapports du roman et de la critique (I7I5-I76I), Paris, PUF, coll. "Institut d'études françaises de Yale University", 1963, p. 80. 
la main écrivante, illisibilité des caractères, destruction d'une suite amorcée, censure ponctuelle ou systématique de la Direction de la Librairie: tout concourt pour empêcher la narration de se poursuivre et pour emprisonner Mouhy dans l'espace incertain de la métalepse.

Incapable d'aller de l'avant, le roman se projette en arrière; mais ce regard lancé vers le passé opère lui-même par subterfuge, en prenant des détours extravagants, comme s'il était impossible de procéder plus directement. Sémiramis, penchée au chevet de Mouhy transi de frayeur, propose de sa propre histoire une version ouvertement paradoxale, où le palimpseste des premières parties ne peut réapparaître qu'à l'issue d'un travail de reconstruction. Les aventures de Motacoa et de sa mère n'apparaissent qu'en filigrane du récit paraleptique de l'Hourcaïs, époux de l'une et père de l'autre. Lors de l'examen des basreliefs, le résumé change de support et de mode: il passe du texte au tableau, du narratif au descriptif. Enfin, dans le complément fourni par Dehahal, le rappel des épisodes antérieurs s'effectue par déplacement: l'initiation subie par le philosophe est évoquée au moment où elle est offerte à un nouveau personnage, en l'occurrence Mouhy lui-même, qui se situe théoriquement à l'extérieur du lieu (textuel) où le rituel trouvait son espace de validité.

L'épisode métaleptique qui occupe le centre exact de Lamekis est donc le lieu d'une coïncidence entre pause, crise et mémoire - entre un présent figé, un futur en panne et un passé (littéralement) envahissant. Le bas-relief récapitulatif est particulièrement symptomatique de cette stagnation temporelle. En remplaçant le récit par la description - en donnant au récit la forme d'une description -, le procédé entraîne aussi une modification des temps verbaux: au passé de la narration romanesque se substitue le présent de l'hypotypose. Toutes les circonstances des quatre premiers volumes sont pétrifiées en un seul point du temps, celui que le narrateur ne peut dépasser ni en aval ni en amont. 


\title{
Les écrivains contemporains lecteurs de Claude Simon : sur la mémoire contemporaine du roman
}

\author{
Katerine Gosselin
}

Plusieurs écrivains désignent aujourd'hui l'œuvre de Claude Simon comme l'une des plus importantes de la deuxième moitié du $\mathrm{Xx}^{\mathrm{e}}$ siècle. Les nombreux hommages rendus à l'auteur au moment de son décès en 2005 ont permis de prendre la mesure de l'admiration qu'elle suscite aujourd'hui ${ }^{1}$. Au-delà de cette admiration, plusieurs écrivains, parmi lesquels Pierre Bergounioux, François Bon, Olivier Rolin, Richard Millet et Pascal Quignard, ont consacré de courts essais à Simon, et y font fréquemment référence dans les entretiens qu'ils accordent. Depuis le début des années 2000, un discours se cristallise autour de la figure et de l'œuvre de Simon, au sein duquel s'énoncent plusieurs enjeux de la littérature contemporaine, à partir duquel, plus spécifiquement, celle-ci peut se situer dans l'histoire récente du roman.

Il est frappant de constater le peu de références au nouveau roman dans le discours que tiennent aujourd'hui les écrivains sur Simon; alors que l'œuvre simonienne compte une vingtaine de romans publiés de I945 à 200I, les écrivains contemporains s'intéressent majoritairement à la dernière période de production de l'auteur, qui va des Géorgiques (198I) au Tramway (200I). Des romans comme La Bataille de Pharsale (1969) ou Triptyque (1973), par exemple, et même la très étudiée Route

I. Voir notamment Cahiers Claude Simon, $\mathrm{n}^{\circ}$ 2: Claude Simon, maintenant, Dominique Viart (dir.), 2006, et les hommages rassemblés sur remue.net: <http://remue.net/spip. php?rubriqueI23>. 
des Flandres (1960) sont pour ainsi dire absents du discours des écrivains, alors qu'ils avaient valu à Simon une grande attention critique dans les années 1970 et jusqu'à la fin des années 1980. Les romans de Simon qui semblent aujourd'hui retenir l'attention des écrivains, ceux qu'ils admirent et commentent longuement, appartiennent à la période dite «contemporaine». En ce sens, les écrivains parlent de l'œuvre de Simon comme d'une œuvre encore proche, mais aussi d'un tournant à partir duquel leur pratique doit se situer.

Selon Pierre Bergounioux, l'œuvre simonienne marque un tournant complet, une révolution, en raison de la position active et impliquée de son narrateur. Bergounioux distingue Simon de ces trois autres grands prédécesseurs qu'ont été Proust, Joyce et Kafka, en raison de sa bonne santé, laquelle l'a mené à faire directement l'expérience de la guerre, de l'histoire en train de se faire:

à la différence des grands valétudinaires qui ont porté la narration classique, homérique, à son terme, [...] dans leur chambre, [Claude Simon] est un être diurne, soucieux des événements terribles, tout extérieurs, qui ont bouleversé le monde ancien. [...] Il n'est sujet ni à l'asthme proustien, ni à la demi-cécité joycienne, donc apte au service armé. C'est à cheval, sous les armes, qu'il découvre ce que l'historien Marc Bloch, juste avant de mourir, fusillé par les Nazis, tient pour le fait inouï, saillant de l'histoire qui se fait: l'intrusion de la vitesse ${ }^{2}$.

Simon accomplit ainsi en France une révolution faulknérienne:

Faulkner s'avise, en 1929, de la relativité de ce qui se donne pour la réalité, selon qu'on l'examine du dehors en toute sérénité, ou qu'on s'y trouve impliqué. [...] Pour qui est accaparé par un intérêt vital, au présent, qui est le seul temps réel, des choses que décrira complaisamment un homme assis à sa table n'existent purement et simplement pas, tandis qu'un détail que [...] celui-ci négligera - parce qu'il ne vit pas, ne sait pas - envahira le champ de la conscience. En cela consiste l'avancée faulknérienne. Un homme jeune d'un pays neuf réintroduit le mouvement de la vie dans les structures du récit ${ }^{3}$.

2. Pierre Bergounioux, dans Cahiers Claude Simon, ${ }^{\circ}{ }_{2}:$ Claude Simon, maintenant, 2006, p. 36.

3. Pierre Bergounioux, Bréviaire de littérature à l'usage des vivants, Rosny-sous-Bois, Bréal, 2004, p. 3IO-3II. 
Bergounioux montre comment Simon inscrit dans son ouvre ce «mouvement de la vie» en le confrontant aux structures narratives existantes, qui le nient, le contrarient:

Claude Simon [...] entre dans l'âge d'or en 1930 quand l'appareil conceptuel de l'Europe occidentale s'effondre. Il devient malaisé de raconter le cataclysme. Le récit n'est plus à la hauteur de son objet. Avec une extraordinaire intelligence, il confronte son expérience avec l'appareil déglingué des catégories narratives dont il a héritét.

Cette confrontation avec l'héritage littéraire, qui n'est pas un pur rejet, ni une négation, met en branle une certaine mémoire de la littérature, dont François Bon souligne pour sa part la profondeur:

Les formes, ils [Claude Simon et ses contemporains] les ont inventées à mesure, dans des directions différentes. Ce n'est pas une voie simple. On peut s'y effondrer: voyez Robbe-Grillet à l'Académie. On peut s'y soumettre jusqu'au plus tendu de l'énigme, ainsi Beckett. On peut en renouer le fil avec la très vieille origine de la littérature, depuis Gilgamesh ou la Bible ou Sophocle, dans l'épopée, opacité et fureur, de l'aventure des hommes. Et c'est l'honneur de Claude Simon que d'être allé là et avoir voulu s'y tenir, sans éclaircissement, mais en convoquant Tolstoï ou Balzac, en acceptant les effets de zoom et cadrage et cinétique du cinéma, ou la bascule du regard et du temps qui naît de la photographie ${ }^{5}$.

Olivier Rolin s'interroge semblablement sur la manière dont la grande modernité formelle de l'œuvre simonienne parvient à faire résonner un fonds littéraire très ancien, originel: «L'œuvre de Claude Simon [...], ce grand poème moderne en quoi résonnent les échos des littératures anciennes (parce que peu d'œuvres où se manifeste avec cette hauteur l'antiquité de la littérature) ${ }^{6}$."

Afin de définir cette mémoire de la littérature que les écrivains contemporains désignent chez Simon, il faut chercher à comprendre comment l'œuvre romanesque simonienne parvient à garder présent un

4. Pierre Bergounioux, "Il est déjà allé si loin”", entretien avec Frédéric Roussel, Libération, II juillet 2005 ; c'est moi qui souligne.

5. François Bon, «D'où vient la rage quand on écrit?", dans Cahiers Claude Simon, $\mathrm{n}^{\circ}$ 2: Claude Simon, maintenant, 2006, p. 46.

6. Olivier Rolin, «Mine de plomb. Les Géorgiques II», dans Cahiers Claude Simon, $\mathrm{n}^{\circ}$ 2: Claude Simon, maintenant, 2006, p. 125-126, repris dans Bric et Broc, Lagrasse, Verdier, 20II, p. 22. 
héritage dont par ailleurs elle ne peut rien faire, parce qu'il est devenu inadéquat. De fait, Simon c'est aussi, pour un écrivain comme Pascal Quignard, «le refus du lien»:

Le moderne comme absence de liaison. Comme refus de la liaison. Comme refus du lien - même social. Ce thème est très puissant chez Claude Simon. C'est peut-être ce que je retiendrai comme le plus puissant. Le plus fondamental.

Le refus du remplissage. Le refus de l'unité. Le refus de la complétude. L'anti couture?.

Comment une œuvre d'une part résolument «moderne» (l'adjectif est employé par Rolin et par Quignard), qui refuse la liaison, qui est l'«anti couture», peut-elle d'autre part «renouer le fil avec la très vieille origine de la littérature», pour reprendre les termes de Bon? Comment une œuvre qui refuse tout lien permet-elle à «l'antiquité de la littérature» de «se manifeste[r] »- et à une hauteur rarement égalée -, selon les termes de Rolin cette fois? En quoi consiste cette «auto-manifestation", cette auto-présentation des œuvres héritées du passé qu'autorise l'œuvre de Simon? En d'autres termes, ceux de Bergounioux cette fois, comment confronte-t-elle l'héritage littéraire sans le reléguer dans l'oubli?

Pour apporter quelque réponse à ces questions, j’aimerais convoquer les propos tenus par Simon dans un entretien avec Bernard Pivot ${ }^{8}$, alors qu'il était l'invité de l'émission Apostrophes, en compagnie du compositeur Pierre Boulez. Cet entretien suit de près la parution des Géorgiques à l'automne 198r. La date est significative: on est au tout début de la période qu'on appellera un peu plus tard «contemporaine», alors que vient de paraître le roman de Simon qui semble avoir été le plus important pour la génération des écrivains nés après la guerre, lesquels commencent alors à publier.

À la fin de son entretien avec Simon et Boulez, Bernard Pivot suggère d'aborder en guise de conclusion la question du "progrès dans la

7. Pascal Quignard, "Ce que vous a apporté Claude Simon», dans Mireille CalleGruber (dir.), Les "Triptyques» de Claude Simon ou l'art du montage, Paris, Presses de la Sorbonne Nouvelle, 2008, p. 207.

8. "Les sentiers de la création", entretien télévisé mené par Bernard Pivot, avec Claude Simon et Pierre Boulez, émission Apostrophes, 22 septembre 198I ; la discussion que je transcris ci-après est comprise entre orhozmi6s et orhosm33s. 
création "; il cite les propos de Boulez dans Points de repère pour lancer la discussion:

B. Pivot - Pierre Boulez, vous dites que, passé un certain moment, "personne ne se serait avisé d'aller à l'encontre de cette idée que la musique s'enrichit sans cesse, qu'il y a progrès indéfini vers une espèce d'eldorado futur. De nos jours il serait malaisé d'adopter un point de vue aussi exclusif.» Enfin, vous ne l'abandonnez pas tout à fait. Je veux dire: est-ce qu'on peut dire, effectivement, que Berlioz marque un progrès par rapport à Mozart, et puis que Boulez marque un progrès par rapport à Berlioz?

P. Boulez - C'est ce qu'on croyait autrefois. [...] Pendant un certain temps, la musique qui était jouée était la musique du jour. Quand Beethoven redécouvre Händel, quand Mendelssohn redécouvre Bach, c'est vraiment tout à fait exceptionnel à l'époque - et c'est probablement le premier signe, justement, de cette conscience de l'histoire dans la musique. Avant, par exemple, du temps de Mozart, il n'y avait absolument pas de conscience historique [...]. Mozart n'était pas du tout intéressé par la musique de ses prédécesseurs, et pendant très longtemps ça a été ça. Au $\mathrm{XIX}^{\mathrm{e}}$ siècle il y a eu une espèce de "balance» entre les choses, c'est-à-dire qu'une certaine période de l'histoire (qui remontait jusqu'à Bach et pas davantage [...]) était mise en parallèle avec les compositeurs de l'époque. Et puis au fur et à mesure qu'on est allé vers une culture de plus grande dimension... disons au point de vue "masse», alors l'histoire a pesé, de plus en plus, d'un poids très lourd, jusqu'au point où, vraiment... S' il y a une chose dans la Révolution, par moments, moi, qui me fait plaisir, c'est qu'ils ont su démolir les statues.

B. Pivot - Non seulement il faut mettre des moustaches à Mona Lisa, mais il faut en plus de ça faire brûler... casser le tableau.

P. Boulez - Quelquefois il faut, vraiment, déménager les musées. Je trouve, moi personnellement, que quand les civilisations deviennent tellement revêtues de tous leurs lainages, elles transpirent tellement, elles deviennent tellement faibles, qu'elles sont à la merci du moindre courant d'air.

Bernard Pivot saisit cette déclaration de Boulez pour relancer Simon, qui était resté en retrait de la conversation; il se tourne vers le romancier, enthousiaste à l'idée d'un accord entre ses deux invités :

B. Pivot (à C. Simon) - Vous êtes de cet avis-là!

C. Simon - Non, pas entièrement... 
La réponse de Simon surprend son interviewer, mais Simon l'énonce clairement à nouveau :

B. Pivot - Ah non? Ah pas entièrement?...

C. Simon - Non, je ne suis pas pour démolir les musées.

Bernard Pivot cherche à clarifier la position de Boulez, qui prend le relais:

C. Simon - Non, je ne suis pas pour démolir les musées.

B. Pivot - Non, mais... c'était une métaphore!

C. Simon - Mais ça correspond quand même à...

P. Boulez - Les démolir en soi.

C. Simon - En soi ? Bien non... non, je pense que nous sommes héritiers de tout ça.

P. Boulez - Je préfère l'ignorer, que ce soit là dans un coin tout simplement.

C. Simon - Comment peut-on l'ignorer? Je ne peux pas ignorer Proust, ce qu'a écrit Proust...

B. Pivot - Mais, alors, est-ce que vous pouvez ignorer Mona Lisa?

C. Simon - Pas plus, non. Là, une chose où je ne serais pas d'accord avec Pierre Boulez, c'est que, il me semble que l'art est quelque chose d'intemporel. Il n'y a pas de mieux. Une tête peinte par Cimabue ou par Picasso, ce n'est pas mieux par Picasso que par Cimabue: c'est différent.

B. Pivot - Donc vous diriez qu'il n'y a pas de progrès de Balzac par rapport à Mme de La Fayette, pas de progrès de Proust par rapport à Balzac...

C. Simon - Non, non il y a changement.

"Je ne suis pas pour démolir les musées", ni au sens propre ni au sens figuré, affirme Simon, qui semble qualifier de leurre une telle entreprise de démolition. Il est vain de démolir les musées, parce que "nous sommes héritiers de tout [ce]» qu'ils recèlent. Boulez revendique le droit pour l'artiste d'«ignorer» cet héritage, de tourner le dos devant sa présence envahissante, qu'il perçoit comme une menace. C'est sur ce point que Simon se dissocie du compositeur'. Cette ignorance volon-

9. Il est clair que la pensée de Boulez ne se résume pas aux propos tenus dans le cadre de cet entretien. Je m'autorise cependant à les considérer ici de manière autonome, dans la mesure où ils constituent un repoussoir à partir duquel Simon explicite sa position propre. Ce que je définis comme «la position de Boulez» se rapporte donc strictement 
taire lui apparaît impossible, parce que vouée à l'échec; quelque envahissant que soit l'héritage, on ne peut pas le répudier. Il ne sert à rien de détruire les musées ni, plus modérément, de feindre l'ignorance sur leur contenu: quoi qu'on fasse, quoi qu'on souhaite, les œuvres du passé demeurent présentes en nous, et cette prégnance rend caduque toute tentative d'anéantissement.

C'est l'exemple d'À la recherche du temps perdu de Proust qui s'impose d'abord à Simon et qui conforte son opposition à Boulez; mais la Recherche emblématise ici toutes les productions culturelles du passé, dans leur infinie diversité, comme Bernard Pivot donne à Simon l'occasion de le préciser. La Recherche, la Joconde, une tête peinte par Cimabue, une autre peinte par Picasso, un roman de Mme de La Fayette, La Comédie humaine, etc., ce sont des œuvres, et on ne peut feindre d'ignorer aucune d'entre elles. Parce que «nous sommes héritiers de tout ça». L'impossibilité d'ignorer cet héritage, doublée de celle, proprement moderne, de le reconduire et de se l'approprier, pourrait être le lot d'une mémoire proprement contemporaine de la littérature.

Boulez relève que la "conscience historique» moderne, dont il voit les premières manifestations au XVIII ${ }^{\mathrm{e}}$ siècle, engage une connaissance du passé démesurément croissante, qui échappe à tout contrôle. Il évoque, pour faire ressortir a contrario le caractère débilitant de cette conscience historique, deux formes de liberté artistique: premièrement, celle des classiques; c'est Mozart qui, affirme-t-il, «n'était pas du tout intéressé par la musique de ces prédécesseurs ${ }^{10}{ }$; deuxièmement, celle des révolutionnaires, qui démolissent les statues, vident les musées. Dans La Mémoire des euvres, Judith Schlanger cherche à définir la liberté des classiques, telle que l'évoque Boulez:

C'est une très bonne chose, assurait Kant (comme bien d'autres), que les modèles du goût soient des monuments écrits dans les langues mortes. Et cette situation a pu paraître longtemps, en effet, une situation idéale. En

aux propos énoncés dans l'entretien cité, en tant qu'ils permettent de saisir a contrario la position de Simon.

Io. Boulez concède que Mozart s'est intéressé à la musique de Bach, mais il juge cet intérêt anecdotique, secondaire: «du temps de Mozart, il n'y avait absolument pas de conscience historique (seulement, [Mozart] a découvert Bach par l'intermédiaire d'un riche baron qui avait une passion absolument furieuse pour Bach); mais, à part ça, Mozart n'était pas du tout intéressé par la musique de ses prédécesseurs». 
étant coupé du monde des modèles par un écart radical de langue et de civilisation - si bien qu'il est manifestement impossible d'ajouter à ces monuments -, on est libre. Le dispositif assure à la fois une source féconde et une liberté dont nous retrouvons mal le principe aujourd'hui ${ }^{11}$.

Dans cette "figure idéale du classicisme ${ }^{12}$ » que décrit J. Schlanger, les monuments à la gloire du passé appartiennent à une époque lointaine. Le classique ne ressent pas le besoin de "démolir les statues», parce que leur poids n'atteint pas son présent tout entier. L'éloignement des temps autorise une liberté que Boulez juge essentielle à la création. Cette liberté perdue, au profit de la conscience historique grandissante, il reste le geste révolutionnaire qui démolit les statues, et rompt catégoriquement avec le passé.

Ce que l'entretien d'Apostrophes me parait révéler essentiellement, c'est la position non avant-gardiste de Simon, que la polémique entourant le nouveau roman a pu longtemps occulter. En I98I, la période néo-romanesque est pour ainsi dire terminée; on est dix ans après le colloque de Cerisy de 197I organisé par Jean Ricardou ${ }^{13}$, et un an avant le colloque de New York ${ }^{14}$ où les écrivains, sans Ricardou cette fois, feront le bilan de ce «mouvement» dans lequel ils se sont retrouvés impliqués plus ou moins malgré eux. Ce qui apparaît, alors, c'est la possibilité d'énoncer une critique de l'avant-garde qui ne soit pas réactionnaire. Devant l'opposition entre la «tradition» et la «nouveauté», entre la continuité et la rupture, qui avait fait la fortune critique du nouveau roman depuis la fin des années I950, devant cette opposition rendue caduque, donc, Simon expose en réaction aux propos de Boulez une autre conception de l'histoire de l'art et de la littérature.

La révolution romantique, en rompant catégoriquement avec la tradition, a paradoxalement maintenu la littérature moderne dans son «régime», en ce sens que renverser la tradition suppose qu'on est toujours déterminé par elle, par opposition diamétrale. En d'autres termes,

II. Judith Schlanger, La Mémoire des æeuvres, Lagrasse, Verdier, 2008 [I992], p. 80-8I.

I2. Ibid., p. 64.

13. Jean Ricardou et Françoise Van Rossum-Guyon (dir.), Nouveau roman: hier, aujourd'hui, actes du colloque de Cerisy tenu en novembre I971, 2 t., Paris, U.G.E, coll. «IO/I8", I972.

I4. Lois Oppenheim (dir.), Three Decades of the French New Novel, traduction de Lois Oppenheim et Evelyne Costa de Beauregard, actes du colloque tenu à la New York University en 1982, Urbana et Chicago, University of Illinois Press, 1986. 
la tradition ou son renversement, c'est toujours le même espace, par le plein ou par le vide, par la reconduction ou par l'évidement. Ce que Simon cherche à construire, et qu'exprime exemplairement son désaccord avec Boulez, c'est précisément un espace autre, qui reconfigure l'espace traditionnel sans l'évider; un espace qui n'instaure pas de continuité avec les œuvres du passé, mais qui «n’ignore pas» leur présence - plus exactement, qui rend compte de l'impossibilité d'ignorer cette présence. Face à Boulez qui revendique le droit de démolir les statues, Simon légitime une certaine mémoire des statues qui ne soit pas étouffante ni purement contraignante.

Dans Les Grandes Disparitions, Isabelle Daunais pose que la nouveauté du roman est "du côté de ce qu'il voit disparaître ${ }^{15}$ ", des mondes qui ne sont plus et dont il garde la mémoire, à partir de laquelle il observe le présent. S'il est une disparition qu'enregistre le roman simonien, ce pourrait bien être celle des avant-gardes, dans leur dimension programmatique; disparition, plus exactement, de leur prétention à faire table rase du passé. Ce qui tend à disparaître, alors, ce n'est pas le geste révolutionnaire qui démolit les statues; c'est plutôt la conviction que la démolition des statues autorisera leur oubli, les évacuera de la mémoire. Le parcours de l'œuvre simonienne, du Tricheur (1945) jusqu'au Tramway (200I), montre précisément l'inverse, une présence irrémédiable et sans cesse renouvelée du passé dans la mémoire.

La difficulté tient à ce que cette présence irrémédiable du passé n'est d'aucun secours pour la compréhension ni la direction du présent. En se dissociant de l'avant-garde, Simon, en effet, ne prône pas une restauration. Il reste résolument moderne: l'histoire du passé n'est pas chez lui, ainsi que l'écrit Jean-François Hamel dans son avant-propos à l'ouvrage collectif intitulé Le Temps contemporain, "dépositaire d'une sagesse fournissant des règles de vie ${ }^{16}$ "; le temps n'est plus, comme sous l'Ancien Régime, un "grand maître», selon la formule de Corneille dans Sertorius (I662). Jean-François Hamel rappelle cette formule, et sa transposition parodique par Balzac dans Illusions perdues: "Le temps

I5. Isabelle Daunais, Les Grandes Disparitions. Essai sur la mémoire du roman, SaintDenis, Presses de l'Université de Vincennes, coll. "L'imaginaire du texte», 2008, p. 6.

16. Jean-François Hamel, "Avant-propos», dans Jean-François Hamel et Virginie Harvey (dir.), Le Temps contemporain, Presses de l'Université du Québec à Montréal, coll. "Figura», 2009, p. I3. 
est un grand maigre. Eh bien! Pour nous aussi le hasard est un grand maigre, il faut le tenter ${ }^{17}$." " Il faut «nourrir [le temps de la modernité] de sa personne», commente J.-F. Hamel, parce qu'il a perdu en luimême toute autorité: «[...] ses leçons sont inaudibles, sa mémoire s'est réduite comme peau de chagrin [...]. Le grand rêve du progrès ne sera pour la modernité que le cache-misère d'une désorientation temporelle $^{18}$.» Au regard tourné vers l'arrière des classiques, qui cherchent dans le passé un enseignement, comme au regard tourné vers l'avant des modernes, qui tentent d'orienter l'avenir devenu imprédictible, Simon oppose un regard sur le présent. Il interroge continuellement le passé, mais à partir d'un "ici et maintenant", un point temporel précis qui est et demeure rigoureusement le présent de l'écriture, et en dehors duquel celle-ci ne prétend pas avoir de portée effective. En cela réside peut-être sa "contemporanéité».

Il s'agit pour Simon de dire cette pure et simple présence du passé, en dehors de tout lien logique - chronologique -, de sorte qu'aucun enseignement ne puisse en être tiré, qu'aucune signification ne s'en dégage définitivement. Le passé n'est pas insignifiant chez Simon; mais la signification qu'il revêt est relative au présent dans lequel il apparaît. L'écriture court-circuite ainsi toute entreprise de rationalisation, d'organisation, d'ordonnance. Le passé apparaît chez Simon comme une somme mobile de fragments, interpellés par le présent, susceptibles d'être combinés et recombinés sans cesse. Le parcours de l'œuvre simonienne est celui, jamais achevé, de ces recombinaisons; s'il opère une déchronologie, il établit une continuité dans le travail scriptural de la remémoration. Le temps simonien, c'est le présent de l'écriture, en tant qu'il représente et reconfigure continuellement le passé.

Cette écriture au présent du passé court-circuite toute entreprise historiographique, y compris dans le domaine de l'art. «[L]'art est quelque chose d'intemporel», répond Simon à Boulez; «[...] il n’y a pas de mieux. Une tête peinte par Cimabue ou par Picasso, ce n'est pas mieux par Picasso que par Cimabue: c'est différent.» D'un changement à l'autre, dans la succession des différences, aucune ligne d'évolution,

17. Honoré de Balzac, Illusions perdues [1843], cité par Jean-François Hamel, ibid., p. I4.

I8. Ibid., p. I4. 
aucun sens ne se dégage. En art, on est toujours dans du différent, autrement dit dans un présent pur, fragmenté, inassimilable: aucune œuvre d'art ne peut être assimilée à un courant et voir sa réalité matérielle subsumée dans une histoire de l'art. Il n'y a que quelque chose comme un «mouvement» des œuvres, qui va de différence en différence.

Cette histoire de l'art, ou plutôt, devrait-on dire, ce «mouvement» des œuvres comme succession de différences coïncide chez Simon avec un retour continuel des mêmes thèmes. Bernard Pivot amène Simon à expliquer ce paradoxe, lorsqu'il s'étonne devant lui que Les Géorgiques se distinguent assez peu, dans leur contenu, des «autres romans»:

B. Pivot - Ce livre, finalement, est très romanesque, parce que, finalement, vous parlez de ce qu'on trouve toujours dans les romans, c'est-à-dire la guerre, la mort, l'amour de la vie, bien entendu, l'amour aussi, mais aussi l'amour de la terre [...]. Finalement... on dit [que] vous faites partie du nouveau roman, mais quand on vous lit... la structure du roman est tout à fait différente, mais on trouve dans votre roman tout ce qu'on trouve dans les autres romans.

C. Simon - Oui, pourquoi pas?! Pourquoi pas?

B. Pivot - Non, mais, est-ce que ça vous choque ou pas?

C. Simon - Non ça ne me choque pas du tout, je pense que...

B. Pivot - Si ça vous choque, dites-le... Vous m'engueulez même, si ça vous choque...

C. Simon - Non je ne vous engueule pas... (rires) je ne vais pas vous engueuler!... Ça ne me choque pas du tout. [...] Oui, c'est toujours l'amour, la mort, la jalousie, etc., ce qui compte c'est la façon dont on le dit, [c'est ça] qui change. Par exemple, si vous prenez la peinture, la crucifixion de Grünewald ou une crucifixion par Tintoret, ça n'a strictement rien à voir, pourtant c'est une crucifixion, toujours ${ }^{19}$.

Simon situe à la base de l'activité artistique une répétition thématique qui n'exclut nullement la différence, garantie par le travail formel, dont le résultat est toujours particulier. En somme, l'art, c'est toujours la même chose, à la base, mais en vertu du travail formel ça devient toujours quelque chose d'autre, de différent.

Ces propos de Simon renvoient dos à dos l'idée d'une tradition et celle d'un progrès en art. Il n'y a ni tradition ni progrès en art: les

19. "Les sentiers de la création", entretien télévisé mené par Bernard Pivot, loc. cit.; la discussion que je transcris ci-après est comprise entre oohızmi2 sec et oohı4mi8s. 
choses évoluent mais sont toujours différentes. Il n'y a ni continuité $n i$ rupture intégrales; aucun des termes de ces oppositions binaires ne fonctionne pleinement chez Simon; il n'y a, toujours, d'ores et déjà, que du différent. Les ouvres s'ajoutent les unes aux autres dans notre mémoire sans entrer en compétition, irréductibles à toute forme de classement. La conception simonienne de la différence détermine une mémoire des œuvres non hiérarchisée, qui prend la forme d'une présentation fragmentée et discontinue de leur particularité sous l'impulsion du présent. Dans cette présentation des œuvres dans la mémoire, certaines œuvres sont mises en relief, d'autres sont laissées dans l'ombre, mais cette configuration demeure toujours relative au présent de l'écriture par et en lequel elle se produit.

Ce qui apparaît certain, chez Simon, c'est que les ouvres nous affectent et ainsi font partie intégrante de notre réalité. Dans une conférence intitulée "Littérature et mémoire», prononcée en 1993 à Queens University, Simon s'est penché sur cette imbrication:

"La nature imite l'art», a dit comme on le sait Oscar Wilde, dans une formulation d'une portée beaucoup plus vaste qu'une simple boutade. [...] [L]'homme (et j'emprunte cette formule à Faulkner)... «l'homme est le seul animal à ne connaître le monde qu'à travers les livres" (ou, aurait-il pu ajouter, à travers les musées et les formules algébriques)... de sorte que, comme l'observe bien Jean Dubuffet, [...] notre esprit ne reçoit du monde qu'une traduction codée [...].

Et pour peu que j'essaie de voir en moi, je peux constater à quel point ma perception (et par conséquent ma mémoire) se trouvent encombrées d'une multitude de ces "traductions" qui, depuis mon enfance sont venues m'habiter: est-il besoin d'énumérer en désordre les souvenirs des Écritures Saintes, de tableaux représentant leurs épisodes, de textes [...] qu'on m’a fait apprendre par cœur au collège, la mythologie antique, des figures ou des raisonnements mathématiques, des images cinématographiques, etc. ${ }^{20}$.

Ainsi, «du "déjà dit" ou du "déjà peint" s'interpose entre les choses et nous ${ }^{21}$ ». Ce que le roman simonien paraît représenter pour certains écrivains contemporains, c'est un espace où les œuvres du passé sont

20. Claude Simon, "Littérature et mémoire» [1993], dans Quatre conférences, éd. Patrick Longuet, Paris, Éditions de Minuit, 2012, p. I07-I08; Simon souligne.

21. Ibid., p. I09. 
purement présentes; où elles s'interposent de toute leur force dans la conscience, mais où cette force est contenue dans le présent au sein duquel elle se manifeste, en dehors de toute chronologie, de tout ordre de valeur. Ce qui perdure, dans ce temps présent toujours différent, ce ne sont plus les œuvres en elles-mêmes, mais cette force avec laquelle elles s'imposent à nous et reconfigurent sans cesse notre présent. Ce présent, qui ne confère pas de signification au passé et qui n'ouvre pas davantage sur un avenir particulier, apparaît pleinement contemporain; s'il autorise une continuité, c'est dans l'activité mémorielle qui le produit et qui préserve, à défaut d'une liberté, une mobilité. 



\title{
La mémoire de Ferron dans La Constellation du lynx de Louis Hamelin
}

\author{
Élisabeth Nardout-Lafarge
}

\begin{abstract}
À Ginette Michaud, qui, de son œil de lynx, m'a orientée dans la constellation vers la planète Ferron, et qui, adolescente, trouvait Robert Lemieux si beau.
\end{abstract}

À partir d'une authentique enquête, sollicitant archives et témoignages, La Constellation du lynx de Louis Hamelin, paru en $20 \mathrm{IO}^{1}$, met en fiction la crise d'Octobre 1970. En exhumant une mémoire des faits, le roman croise aussi une mémoire des discours et des textes. À ce titre, parallèlement au travail de fictionnalisation de la documentation et de manière plus souterraine, il prend doublement le relais de Jacques Ferron, figure fantôme, jamais nommée et pourtant omniprésente du récit, poursuivant à la fois son interprétation politique des événements et plusieurs aspects de son œuvre littéraire. Ce relais, ce passage du témoin, s'inscrit dans un dispositif où sont illustrées certaines des questions que pose la mémoire romanesque: les modalités de sa transmission, son sujet, l'axiologie qui lui est inhérente et la part de refoulement qu'elle comporte.

I. Louis Hamelin, La Constellation du lynx, Montréal, Boréal, 20Io. Désormais abrégé en $C L$, suivi de la page. 


\section{Traces ferroniennes}

Martine-Emmanuelle Lapointe signale dans sa recension du roman ${ }^{2}$ la parenté de Chevalier Branlequeue, l'écrivain de La Constellation du lynx, avec Léon de Portanqueue, le personnage de L'Amélanchier et on ne saurait s'étonner de la présence de Jacques Ferron dans un roman sur la crise d'Octobre. Outre qu'il a participé aux événements en agissant, à la demande des felquistes, comme négociateur lors de leur reddition à la police, en décembre 1970, Ferron a également très tôt soutenu la thèse d'une manipulation visant, selon lui, «une terrorisation sociale de la population québécoise, terrorisation sociale ayant besoin du terrorisme pour se manifester et loin de prévenir celui-ci, le poussant à l'action ${ }^{3}$ ». Dès 197I-I972, il développe ses arguments dans une série d'articles ${ }^{4}$ dont plusieurs deviennent des "historiettes" parues dans Du fond de mon arrière-cuisine en 1973 et Escarmouches en 1975, et il maintient sa version des événements dans les Entretiens qu'il accorde à Pierre L'Hérault en $1982^{5}$. C'est donc d'abord ce Ferron-là que rencontre La Constellation du lynx, qui, en les fictionnalisant, en imaginant les scènes auxquelles elles auraient pu donner lieu, déploie les diverses informations sur lesquelles lui-même s'appuyait: parmi celles-ci, la réunion à Ottawa le 7 mai 1970, donc avant la crise, d'un comité chargé d'examiner un recours possible à la Loi sur les mesures de guerre, l'étonnante liberté de circulation de certains membres connus du FLQ dans une ville en état de siège et le financement du groupe. De nombreux épisodes de La Constellation du lynx, apparemment marginaux, tant antérieurs à la crise d'Octobre (le coup de feu tiré volontairement dans le magasin d'un organisateur politique pour déstabiliser des élections municipales à Jacques-Cartier), que postérieurs (la mort accidentelle, transformée dans le roman en assassinat, de Marcel Vaquet alias Michel

2. Martine-Emmanuelle Lapointe, "Le roman: le sens de l'histoire», Voix et Images, vol. I07, $\mathrm{n}^{\circ} 3$, hiver 2011 , p. I42.

3. Jacques Ferron, "Le comité du 7 mai 1970 ", Le Canada français, $\mathrm{I}^{\mathrm{re}}$ année, $\mathrm{n}^{\mathrm{0}} 7$, Io octobre 1972, p. 5. Cité par P. O’Gormaile, «La représentation de la crise d'Octobre chez Jacques Ferron », dans Brigitte Faivre-Duboz et Patrick Poirier (dir.), Jacques Ferron. Le palimpseste infini, Montréal, Lanctôt éditeur, coll. "Cahiers Jacques-Ferron », n ${ }^{\text {os }} 8$-9, 2002 , p. 74 .

4. Ibid.

5. Jacques Ferron et Pierre L'Hérault, Par la porte d'en arrière. Entretiens, Montréal, Lanctôt éditeur, 1998, p. I54-I68. 
Viger, qui avait caché les felquistes en fuite et ses relations avec un ancien policier, Jean Prieur dont Coco Cardinal est l'avatar romanesque) correspondent à des faits évoqués par Ferron dans les Historiettes, la correspondance avec John Grube ${ }^{6}$ et les Entretiens ${ }^{7}$. La mémoire que le roman d'Hamelin mobilise rejoint alors l'interprétation des événements par le citoyen Ferron, engagé et méfiant, mais aussi, suivant un biais souvent commenté par la critique ferronienne, son point de vue volontairement anecdotique, la propension de l'écrivain à collectionner les petits faits (parentés, relations, rumeurs, commérages même) tissant une vision singulière, presque "villageoise» de la société, commune au péritexte (entretiens, lettres aux journaux, correspondance) et aux textes dont elle contamine l'esthétique (généricité hétérogène passant du conte à la chronique et trouvant l'une de ses formes caractéristiques dans l'historiette, qui réunit la construction allusive des récits, la théâtralisation de la fiction et les interventions d'auteur). C'est dire que $L a$ Constellation du lynx partage avec les textes de Ferron à la fois une matière et une manière mémorielles.

Cette mémoire est aussi celle d'œuvres de fiction. Au premier chef, Le Salut de l'Irlande, d'abord paru en feuilleton dans L'Information médicale et paramédicale que Ferron publie en livre en décembre 1970, en soulignant le lien entre le récit et les événements, notamment par la dédicace sibylline à "Monsieur Peter Dwyer», directeur du Conseil des Arts du Canada mais ancien agent du Foreign Office et donc, aux yeux de Ferron, "espion de Sa Majesté ${ }^{8}$. Aux lecteurs de Ferron, le lynx du roman d'Hamelin, qui apparaît à intervalles réguliers à des personnages qu'il relie entre eux, rappelle le renard des Haffigan dont il amplifie la symbolique animalière en accentuant sa sauvagerie. Comme le note encore Martine-Emmanuelle Lapointe, la topographie de Coteau-

6. Jacques Ferron, Une amitié bien particulière. Lettres de Jacques Ferron à John Grube. Suivi d'"Octobre en question" de Georges Langlois, Montréal, Boréal, I990, p. 86 et p. I30.

7. Ibid., p. 167.

8. Jacques Ferron, Le Salut de l'Irlande, Montréal, Éditions du Jour, 1970; cité par P. O'Gormaile, «La représentation de la crise d'Octobre», op. cit., p. 72-73. Voir également l'analyse de Susan Margaret Murphy, chapitre 4, "Peter Dwyer et l'irlandicité québécoise", dans Le Canada anglais de Jacques Ferron. I960-1970. Formes, fonctions et représentations, préface de Jean Marcel, Québec, Presses de l'Université Laval, 2orI, p. I07-I28. 
Rouge et sa sociographie, cette banlieue "farouest» en un seul mot comme l'écrivait Ferron, à l'expansion rapide propice à la corruption et aux affrontements, où se déroule l'adolescence du felquiste fictif Richard Godefroid, semble calquer le cadre spatial et social du Salut de l'Irlande. On peut enfin voir dans le personnage trouble de Coco Cardinal une version assombrie et complexifiée de la figure de Connie Haffigan.

Par ailleurs, la «constellation» qui inscrit l'idée d'un réseau progressivement découvert d'éléments différents, évoque Le Ciel de Québec paru en 1969. Bien qu'antérieur aux événements, ce texte ne leur est pas étranger puisque, depuis un purgatoire anhistorique, Borduas et Orphée (Saint-Denys Garneau) évoquent l'emprisonnement de Pierre Vallières et l'exil de Gilles Pruneau. Le Ciel de Québec est une machine textuelle complexe, conte fantastique où les animaux parlent, réécriture parodique du mythe orphique, fable de l'identité québécoise à travers la chronique cléricale et politique du diocèse de Québec entre 1937 et I939, roman à clefs où l'on peut reconnaître des hommes de lettres (Saint-Denys Garneau, mais aussi Camille Roy, Gilles Marcotte et Claude Gauvreau), des artistes (Borduas et Paterson Ewen) et des politiciens; son registre allant du règlement de comptes personnel au mythe. Plusieurs similitudes apparaissent entre Le Ciel de Québec et La Constellation du lynx sur le plan formel d'abord, dans le dispositif des récits parallèles, la succession de prolepses et d'analepses, de même que dans la construction paratactique des chapitres. Les deux textes ont recours à des éléments fantastiques naturalisés par le récit, manifestés dans La Constellation du lynx par les apparitions du spectre de Paul Lavoie (alias Pierre Laporte) ou la présence obsédante du lynx, trace d'une mythologie amérindienne très présente aussi chez Ferron. Également commune aux deux textes, une onomastique ambiguë, alternant vrais et faux noms, transparents ou grotesques, suspend le pacte de lecture entre le rétablissement des identités réelles et l'adhésion à des personnages fictifs dans une constante interrogation de la dimension romanesque de la réalité. Sur le plan social ensuite, La Constellation du lynx met en scène, comme Le Ciel de Québec, la corruption, le patronage et leur rhétorique roublarde, ironiquement normalisés dans les deux romans. Enfin, on notera les nombreuses ressemblances dans la représentation du territoire. La géographie du Ciel de Québec découpe, 
depuis Québec, un lieu digne, la paroisse de Saint-Magloire, qui ne l'est qu'à déverser son trop-plein de misère en contrebas, au village des Chiquettes, version rurale et ancienne de Coteau-Rouge. Comme en écho à l'analogie de François-Anacharcis Scot qui, à son arrivée, de nuit, remarque: «Avec un peu d'imagination, j'aurais pu penser que les Chiquettes allaient m'accueillir au milieu des palmiers" ", La Constellation du lynx reporte au Mexique le même rapport d'opposition structurante entre le village des touristes et celui des habitants. Parmi ceux-ci : " [une] vieille paysanne indienne avait sa cabane près du débouché du sentier. Elle vivait là avec ses poules, un énorme dindon et un gros verrat blanc attaché au bout d'une corde» $(C L, 499)$, figure qui rappelle, l'éloquence en moins, la vieille Eulalie, sage-femme et capitainesse du village des Chiquettes. Si, du Ciel de Québec à La Constellation du lynx, il y a trop de différences pour faire du premier un modèle du second, ces aspects communs dévoilent néanmoins une proximité entre deux fresques historiques, plus ou moins ironiquement détournées, qui se saisissent d'une collectivité dans une époque.

\section{Au-delà de Ferron}

Une autre parenté des deux textes réside dans l'intrication serrée qu'ils instaurent entre les événements historiques et la littérature. Le paratexte de La Constellation du lynx comporte une liste des personnages qui reprend la convention du texte de théâtre, donnant ainsi le premier indice d'une mise en scène. L'auteur distingue les «terroristes » des "littéraires" puis des "autres», en une division du travail fictif réparti sur deux générations. À celle de Sam Nihilo, défini comme "tâcheron de la plume», jeune écrivain qui mène dans les années 2000 une enquête sur les événements de 1970, incombe la tâche de se souvenir du passé et de l'interpréter à la suite de celle de Chevalier Branlequeue, désigné comme "éditeur, poète, prof de littérature», qui a vécu ce passé et n'a cessé de l'interroger. Or si Branlequeue joue bien le rôle historique de Ferron, il n'en est pas le double romanesque. Selon Martine-Emmanuelle Lapointe, ce pourrait être aussi bien Miron (pour l'édition, les poèmes toujours en cours et surtout les «funérailles 
quasi nationales») ou Aquin (qui a lui aussi enseigné à cette université et pour Prochain épisode); ajoutons Belleau (pour l'enseignement à I'UQAM, "le groupe des octobierristes", étudiants de Branlequeue voués à la collecte et à l'interprétation d'informations sur la crise d'Octobre pouvant rappeler le cercle Bakhtine). Alors que la plupart des autres personnages incarnent, sous des noms relativement transparents des personnes réelles, force est de constater que Branlequeue est un amalgame construit à partir de nœuds biographiques et sociaux (compromis entre l'enseignement et l'écriture, tension voire contradiction entre les contraintes de la vie personnelle et l'apparente liberté de la vie littéraire, sentiment d'empêchement et de rétrécissement de l'univers social, engagement politique déchirant, crainte de l'échec) qui condensent, dans une sorte de vulgate où elle s'est figée, l'expérience de toute une génération d'écrivains québécois, acteurs et parfois victimes des changements sociaux et culturels de la Révolution tranquille, des soubresauts des années 1960 et 1970 qui culminent dans la crise d'Octobre, de la déflation du projet indépendantiste après 1980, de la transformation de la littérature. C'est bien à cette séquence historique que correspond l'inscription, dans un titre de chapitre, «Branlequeue: 1932-1999" (CL, 46). Ainsi, entre leurre et épouvantail, ce prototype générationnel d'écrivain fictif met à distance la figure de Ferron et l'héritage ferronien de La Constellation du lynx.

La position de Branlequeue évoque pourtant un autre texte de Ferron, explicitement testamentaire, "Les salicaires». Accusant ceux de sa génération d'être des «fossoyeurs sophistiqués» qui «n'ont rien fait pour sauver le monde ${ }^{10}$ ", Ferron conclut à la rupture de la transmission: «Les dieux étant révolus, les cieux vides, le monde incohérent, toute référence d'une génération à l'autre impossible, les ponts coupés, vous deviez vous tenir sur la rive du passé dans l'attitude d'un malheureux coupable; vous ne pouviez pas assurer la suite du monde autrement $^{11}[\ldots]$.» Bien sûr, en fictionnalisant le thème si actuel de la génération, le roman d'Hamelin s'éloigne de la radicalité du Ferron des «Salicaires». Il ne la rejette pas totalement pour autant, comme le

IO. Jacques Ferron, «Les salicaires", dans Du fond de mon arrière-cuisine, Montréal, Éditions du Jour, 1973, p. 28I-282.

II. Ibid., p. 283. 
montre le système complexe par lequel, en creusant la distance entre récit et histoire, en brisant la linéarité et la chronologie, en juxtaposant plusieurs narrateurs, il multiplie les relais et les bifurcations et matérialise, dans la structure du texte, les apories de la mémoire qui ne saurait consister simplement à rebâtir les "ponts coupés» du temps. On en verra un exemple dans le caractère d'emblée second de l'enquête et la trajectoire oblique de la transmission de l'héritage qui passe par une délégation de mandat: à la mort de Branlequeue, son fils demande à Sam de trier les papiers du défunt. Le fils biologique désigne ainsi un autre fils, spirituel celui-là, à qui il confie une tâche vague que le légataire réoriente à sa manière, sans autre légitimité que ses propres souvenirs, non pas des événements eux-mêmes mais des discussions à leur sujet avec son ancien maître. L'héritage et la mémoire en quoi il consiste sont donc indirects et ne se transmettent qu'en creux.

Le roman soulève une autre aporie de la mémoire, celle de son sujet, de qui se souvient. Un nouveau type de relais est alors mis à profit comme dans les monologues de Jean-Claude Marcel (alias René Gagnon), attaché politique de Paul Lavoie. Alors qu'il roule sur la "20", entre Montréal et Québec, Jean-Claude Marcel enregistre sur un magnétophone des souvenirs, voire des confessions ou une déposition, qu'il adresse au lecteur en se projetant dans le temps du récit: "Vous êtes là-bas, quelque part dans le futur et toute cette histoire, à supposer même qu'elle puisse jamais vous intéresser, doit vous paraître épouvantablement compliquée» $(C L, 284)$. Le stratagème permet, sur le plan diégétique, d'éclairer les raisons pour lesquelles l'otage a été «abandonné» à son sort selon la thèse du roman: ancienne rivalité avec le Premier ministre ou fréquentations mafieuses révélées par des écoutes électroniques. En écho aux scènes où Lavoie comprend qu'il est sacrifié, ce personnage secondaire, au pied de la lettre son porte-parole, qui ne cesse de se demander ce qu'il aurait fait "s'il avait été à sa place», incarne la figure du double. Cette figure se manifeste encore dans la recherche obstinée du felquiste Richard Godefroid (le second personnage composite dont le nom évoque celui de Pierre-Paul Geoffroy, mais dont la biographie est en partie celle des frères Rose et qui joue dans les événements le rôle de Francis Simard). Sam ne cesse de le croiser et de le manquer, de la chambre d'hôpital où agonise Branlequeue jusqu'au Mexique où il le rencontre finalement quand «il a cessé de 
chercher» $(C L, 502)$. Liés par leur enfance en Abitibi, le lac Kaganoma, le lynx et l'amitié de Branlequeue, Sam et Godefroid se ressemblent comme des frères au point que la narration passe imperceptiblement du point de vue du premier à celui du second; gémellité qui brouille la succession générationnelle.

Retrouvant Ferron, mais s'en écartant aussi, selon des procédés euxmêmes très ferroniens, le roman d'Hamelin illustre les interférences à l'œuvre dans la transmission de la mémoire. Les dédoublements et redoublements, tant de la figure de l'écrivain que des personnages du récit, donnent à voir une construction indirecte de la mémoire, recomposée à la manière d'une constellation à partir de fragments qui n'appartiennent jamais à personne en propre, le je qui se souvient étant toujours un autre et se souvenir revenant à se demander qui, en soi, se souvient.

\section{Le "grand show tragique ${ }^{12}$ "}

$\mathrm{Si}$, selon un autre modèle littéraire, La Constellation du lynx peut se lire comme un polar politique, ce quautorisent le dispositif du complot et le personnel romanesque typique, aucun des personnages ne réalise vraiment le potentiel tragique dont il est porteur: ni Richard Godefroid le felquiste instrumentalisé, ni Coco Cardinal le traître, ni Paul Lavoie l'otage sacrifié. C'est pourtant la même fictionnalisation de personnes réelles - Lee Harvey Oswald, Jack Ruby et d'autres acteurs potentiellement liés à l'assassinat de John Kennedy - qui produit, dans Libra de Don Dellilo, romancier pour lequel Louis Hamelin a exprimé la plus vive admiration ${ }^{13}$, des personnages non seulement crédibles mais exemplaires, emblématiques, dont les obsessions deviennent des passions et les hissent au rang de héros. Au contraire, La Constellation du lynx interdit ce type de lecture par la trivialité qui affecte l'univers représenté et le grotesque qui s'y attache. Et cela commence évidemment par les noms: comment croire, en effet, quoi qu'il découvre, un Sam Nibilo originaire de Maldoror en Abitibi? Quelles leçons tirer des soubresauts

I2. L'expression est de Pierre Vallières, L'Exécution de Pierre Laporte. Les dessous de l'opération, Montréal, Québec-Amérique, 1977, p. 5; elle est citée dans Pradaig O'Gormaile, «La représentation de la crise d'Octobre», op. cit., p. 74.

I3. Voir «Plus dure sera la chute», Le Devoir, 28 juin 2008. 
d'une époque dont le «grantécrivain» est Chevalier Branlequeue et dont le grand œuvre s'intitule Les Élucubrations? Ici, les spectres eux-mêmes ne sont pas sérieux: quand il apparaît pour la dernière fois à Sam, le fantôme de Paul Lavoie masque sa cicatrice au cou sous un collier de fleurs et, enfin délivré du purgatoire, s'apprête à partir jouer au golf dans le Sud. Certes, le sublime et le grotesque ne s'excluent pas l'un l'autre, la trivialité n'empêche pas le tragique, ils ont même partie liée et, selon Marx, qui n'est pas absent de la crise d'Octobre, «l'histoire se répète d'abord comme tragédie puis comme farce».

Aussi, sans doute est-ce moins le tragique que le roman refuse aux personnages fictionnalisés et aux événements remémorés (mort d'un homme, arrestations de plus de cinq cents personnes, Loi sur les mesures de guerre, atmosphère de coup d'État) que la grandeur. Malgré l'ampleur de la recherche et les 595 pages qu'y consacre le roman, la crise d'Octobre conserve, dans La Constellation du lynx, quelque chose de limité, de petit, de brouillon. Paradoxalement, alors même que le roman corrobore et documente la thèse du complot, avec participation des services secrets internationaux et accorde ainsi aux événements un poids historique accru, il reprend à son compte, par sa tonalité farcesque, la désinvolture atténuante qui caractérise, dans le discours social, de nombreux jugements sur la crise d'Octobre: ridicule de la police et de l'armée (pendant les perquisitions, on aurait confisqué les livres sur le cubisme par association avec Cuba), amateurisme des terroristes qu'on hésite même à désigner ainsi, légèreté des conséquences, poursuite des carrières politiques de dirigeants qui ne sont pas autrement affectés par les décisions qu'ils ont prises, retour dans la société civile, et à l'occasion dans le débat public, des anciens felquistes. Comment comprendre le parti pris du roman, solidaire, à cet égard, d'une certaine mémoire populaire: ni pathos ni martyr? Semblable interprétation s'accorde à nouveau avec celle de Ferron qui remarque: «Pour faire une tragédie, il faut quand même avoir de grands moyens, il faut avoir une espèce d'orgueil insensé $e^{14}$ » et selon qui à des demi-colonisés ${ }^{15}$ ne correspondraient que des demi-révolutionnaires (à quoi on serait tenté de répondre que la répression, elle, n’a pas fait les choses à moitié). À moins que,

I4. Jacques Ferron et Pierre L'Hérault, Par la porte d'en arrière, op. cit., p. I32.

I5. Ibid., p. I25-I26. 
dans La Constellation du lynx, cette défiance goguenarde qui modalise aussi bien les idées et les actes des felquistes que les opérations de la police et de l'armée ne fasse partie du cover-up? Évoquant l'assassinat de Kennedy, un des personnages de felquistes explique: «la preuve est dans le cover-up, tu comprends?» $(C L, 582)$; le roman invitant alors à se demander, dans la perspective paranoïaque que Sam hérite de son maître Branlequeue, à qui profite un récit loufoque où s'agitent des incompétents dépassés par leurs propres actions. Comme Ferron qui écrit en 1972: "C'eût été absolument loufoque s'il n'y avait pas eu la mort de Pierre Laporte ${ }^{16}$ ", La Constellation du lynx maintient cette tension entre loufoque et tragique, dans toute l'ambivalence de l'oxymore, figure récurrente d'une Révolution tranquille.

Tout le récit converge pourtant vers la mort de Paul Lavoie. Le roman en diffère le dévoilement dans le temps et dans l'espace, et il n'est pas innocent que ce qui est désigné, Hubert Aquin à l'appui, comme «un trou de mémoire collectif en forme de mise à mort» $(C L$, 5IO) soit finalement abordé dans le décor exotique d'une plage du Mexique, sous le signe du mezcal partagé. Godefroid évoque d'abord la mort de l'otage par bribes, pressé par les questions de Sam, avant qu'elle soit racontée dans une séquence où la narration, d'abord hétérodiégétique, passe brusquement à la première personne par l'adresse à un énonciataire - «Tu parles d'un hostie de merdier» $(C L, 549)-$, le dispositif ne permettant d'identifier Godefroid comme le narrateur de ce récit qu'au chapitre suivant: "Au bout d'un moment, Gode dit: Je ne peux pas croire que je t’ai vraiment raconté tout ça”" $(C L, 55 \mathrm{I})$. Outre sa brièveté (deux pages), cette scène attendue est marquée par toute une série d'atténuations qui vont de la métaphore sportive (l'otage «fonce [...] la tête basse comme un demi offensif qui se faufile entre les lignes adverses» tandis que le felquiste «bondi $[\mathrm{t}]$ comme un secondeur en maraude» $[C L, 550])$, au gommage du nom puis du corps au profit d'un indéfini animalisé: «ça bougeait encore, mais comme un poisson, un filet de vie à n’en plus finir» $(C L, 550)$. Le mot «mort» est absent, comme il l'est également du très court chapitre intitulé "Terrain",

16. Jacques Ferron, "Le comité du 7 mai 1970 ", Le Canada français, $\mathrm{I}^{\mathrm{re}}$ année, $\mathrm{n}^{\circ} 7$, Io octobre 1972, p. 5. Cité dans Pradaig O’Gormaile, "La représentation de la crise d'Octobre», op. cit., p. 74 . 
consacré à la découverte du corps par deux policiers : «Ils examinèrent le contenu en silence» et plus loin: "Qu'est-ce qu'on fait de ça? demanda Lessard, qui voulait parler du coffre» $(C L, 587)$. Contre la version du blessé qu'on est contraint d'achever, retenue par Pierre Falardeau dans son film Octobre ${ }^{17}$, le roman d'Hamelin opte pour un double accident, dénué de toute intention de tuer: "on s'est dit, il est peut-être juste dans le coma. Et que si quelqu'un le trouvait assez vite, il était peut-être encore temps de le sauver» $(C L, 552)$. Même après ce qui peut être tenu pour un aveu, trente ans plus tard, Godefroid continue de résister à l'idée de meurtre et à Sam qui lui demande s'il est un "tueur», il répond: "C'est ce que le juge a dit que j'étais» (CL, 5I4). Ces atténuations font écho à l'absence de haine entre les protagonistes: le geôlier éprouve des sentiments contradictoires: "L'otage, sous ces yeux, redevenait [je souligne] l'ennemi» $(C L, 549)$ et, à la veille de son propre enlèvement, le ministre dit des ravisseurs de John Travers (alias James Richard Cross): "C'est des petits gars de chez nous. Ils ne tueront pas...» $(C L, 479)$. Ainsi différée et estompée, la mort de l'otage figure ce que la mémoire s'efforce de refouler, peut-être pour ne pas briser l'harmonie bon enfant du «nous» ni faire basculer l'épisode du loufoque dans le tragique. Selon cette logique du refoulement, le roman déplace le récit de la mise à mort qui se trouve préfigurée par un souvenir de Godefroid remontant à son enfance en Abitibi; Bill, un trappeur amérindien à qui son père et lui ont rendu visite, leur propose un lynx qu'il a capturé; comme le père refuse, Bill étrangle la bête sous leurs yeux:

Le lynx est dans l'ombre [...] un collier de chien serré autour d'une patte et relié à la chaîne d'une laisse solidement fixée à une poutre [...]. Sans montrer aucune crainte, l'homme vient lentement s'accroupir devant lui. Un sifflement continu, doublé d'un grondement sourd de matou s'échappe maintenant de la gueule et des entrailles de l'animal [...] l'humain et lui s'observent sans bouger. Puis le premier d'un geste brusque empoigne à deux mains le cou du félin et en serrant le soulève de terre [...] deux tueurs enlacés en une danse quasi immobile. Au cours de l'éternité qui suit, le père et le fils voient, dans le clair-obscur de la cabane, le loup-

17. Pierre Falardeau, Octobre, d'après le livre de Francis Simard, Pour en finir avec octobre [avec la collaboration de Bernard Lortie, Jacques Rose, Paul Rose, Montréal, Éditions Stanké, 1982], Films Lions Gate, 1994, 97 minutes. 
cervier passer de la lutte aux spasmes [...] le trappeur tombé à genoux repose le fauve sur le plancher [...]. On l'entend haleter tandis qu'il retire ses gants, saisit tout doucement, ensuite, une des énormes pattes [...] puis les mains s'égarent un instant dans les longs poils soyeux, en un geste d'une tendresse infinie. (CL, 23-24)

Le récit de la mort de l'otage comporte plusieurs échos de cet épisode: la présence du lynx dans le rêve de Godefroid assoupi, le sifflement envahissant de la bouilloire $(C L, 549)$. Dans cette scène ambiguë où la violence le dispute à la douceur, où la frontière entre l'humanité et l'animalité se brouille, le roman fixe l'image d'une mort sans haine mais non sans cruauté. On notera la résurgence, dans un roman de 20IO, de cette «sauvagerie» (bois, cabane, trappeur amérindien) et le sens de retour du refoulé qui lui échoit. Déplacé, le pôle tragique du récit est maintenu, en contrepoids et en tension avec son pôle grotesque. Le travail de mémoire consiste donc à recueillir ici moins des faits, en l'occurrence impossibles à connaître avec certitude, que les jeux de cadrages, d'angles de vue, de lumière et d'ombre dans lesquels ils ont été fixés, la part variable d'oubli d'où se détache le souvenir.

La comparaison esquissée plus haut avec l'une des nombreuses fictions sur l'assassinat de Kennedy n'est pas fortuite. D’une part, Hamelin fait ce parallèle dans une entrevue où il évoque son projet d'écrire «un grand roman à l'américaine» sur ce qu'il estime être «un traumatisme national jamais élucidé $[. .$.$] notre affaire Kennedy à nous { }^{18}$ ». D'autre part, le lien existe également dans le texte: au cours d'un voyage à Dallas, les membres de la cellule Chevalier (pour cellule Chénier) font le pèlerinage à Dealey Plaza: «là où on disait que le temps s'était arrêté un certain jour de novembre 1963. Ils laissèrent l'auto garée un peu plus loin et posèrent leur cul sur le tertre le plus célèbre de l'univers pour griller une cigarette» $(C L, 582)$. Godefroid et les frères Lafleur (alias les frères Rose) qui sacrifient à ce rite de touristes sont pourtant à Dallas pour obtenir du financement d'une entreprise, en fait, une société écran de la CIA qui les surveille à leur insu ${ }^{19}$. Comme une sorte de vignette, l'épisode de Dealey Plaza fonctionne métonymiquement, à la fois mise

I8. Carole Beaulieu, "La bombe Hamelin ", L'Actualité, I5 octobre 20IO, p. 2I.

19. Si Jacques Ferron n'évoque pas l'affaire Kennedy, il est persuadé lui aussi de la participation de la CIA aux événements d'octobre; voir "L'année mystérieuse», Le Canada français, $\mathrm{I}^{\mathrm{re}}$ année, $\mathrm{n}^{\circ}$ 9, 24 octobre $\mathrm{I} 972$, p. 5. 
en abyme et prémonition, sur le double plan de la diégèse (les felquistes sont manipulés et s'apprêtent à jouer le rôle qu'on attend d'eux, comme Oswald est «le pigeon" que Ruby "a effacé») et sur celui de la lecture (comme pour le fin mot de l'affaire Kennedy, "on ne le saura jamais", $[C L, 582])$.

Outre qu'elle situe le roman d'Hamelin dans une tradition littéraire américaine, l'analogie avec l'assassinat de Kennedy inscrit l'épisode québécois dans la série (la constellation) des conspirations, complots, «affaires» en même temps qu'elle le classe, selon une hiérarchie implicite, dans une position seconde. La crise d'Octobre apparaît en effet, dans La Constellation du lynx, comme une affaire Kennedy modèle réduit, plus modeste tant par ses acteurs que par son retentissement; cette secondarité est d'ailleurs reconduite à la fin du roman, dans une autre comparaison, cette fois avec la marche zapatiste qui, selon Sam, est «en train de réussir ce que vous avez voulu faire à l'époque. Un gros coup de pub» $(C L, 507)$. Les personnages ne s'approchent que fantasmatiquement de l'affaire Kennedy, caressant le projet d'enlever Jackie $(C L, 583)$ ou rêvant sur Dealey Plaza, sans voir, tant ils sont persuadés que ce qui se passe à Montréal ne peut être que périphérique, marginal par rapport aux grands desseins des puissances de ce monde, que la CIA les tient dans sa mire. Que le lecteur, lui, le sache, relève de l'avantage dont dispose le roman: le jugement d'une mémoire qui rapproche les deux événements pour en minimiser l'un au regard de l'autre ne s'en trouve pas renversé, mais il est cependant mis au jour et donc interrogé. $\mathrm{Si}$, à travers sa part de mémoire, «l'histoire juge», le roman peut sinon, suspendre le jugement, du moins le mettre à l'épreuve.

En rouvrant dans un roman le dossier de la crise d'Octobre, $L a$ Constellation du lynx accomplit une démarche complexe. La mémoire romanesque s'adosse à la fiction revendiquée comme moyen d'élucidation du réel, comme herméneutique des événements, en rivalité, plus qu'en contradiction, avec l'histoire. Dans une telle entreprise, la présence de Ferron, attendue, n'était cependant pas indispensable, ni comme personnage, son rôle historique n'ayant pas été capital, ni comme référence pour l'interprétation des événements, sa thèse d'une 
manipulation s'étant désormais, à divers degrés, imposée; cette présence imprègne pourtant le roman à différents niveaux. Les liens intertextuels ainsi tissés invitent à penser que La Constellation du lynx, croisant Ferron sur le terrain de la crise d'Octobre, relaie et poursuit moins une réalisation qu'un projet littéraire, partagé non seulement par l'auteur du Ciel de Québec mais par de nombreux écrivains des années 1960 et 1970, d’André Major à Victor-Lévy Beaulieu, de Jacques Godbout à Hubert Aquin; projet d'un roman où histoire et littérature se rejoindraient et se porteraient l'une l'autre, dans l'«imperfection» identifiée par Gilles Marcotte, pour dire l'identité québécoise dans toutes ses composantes et tous ses paradoxes. C'est, semble-t-il, le sens qu'on peut accorder au barde national composite qui inspire l'enquête romanesque. En s'attaquant au récit de la crise qui a constitué la pointe extrême de ses luttes, le roman d'Hamelin se trouve à recueillir et réinvestir, à juger et réchapper de l'oubli non seulement des faits et des textes qui ont marqué une génération, mais aussi son projet et son rêve, au double niveau du littéraire et du politique. Dans cette perspective, La Constellation du lynx, en imaginant le fil qui relie les "Historiettes", effectue peut-être, à distance de quatre décennies, entre fidélité et trahison, le sauvetage du Ciel de Québec. 


\section{Liste des collaborateurs}

Isabelle Arseneau est professeure au Département de langue et littérature françaises de l'Université McGill. Elle a codirigé, avec Francis Gingras, Cultures courtoises en mouvement (Presses de l'Université de Montréal, 20II).

Mathieu Bélisle enseigne la littérature au Collège Jean-de-Brébeuf de Montréal. Il a publié Le Drôle de roman. L'ouvre du rire chez Marcel Aymé, Albert Cohen et Raymond Queneau (Presses de l'Université de Montréal, 20Io).

Simona Carretta est étudiante de doctorat à l'Université de Trente (Italie) et à l'Université Paris-Sorbonne (Paris IV).

Julia Chamard-Bergeron est étudiante de doctorat au Department of Romance Languages and Literatures de l'Université de Chicago.

Isabelle Daunais est titulaire de la Chaire de recherche du Canada sur l'esthétique et l'art du roman à l'Université McGill. Elle a publié Les Grandes Disparitions. Essai sur la mémoire du roman (Presses universitaires de Vincennes, 2008) et Frontière du roman. Le personnage réaliste et ses fictions (Presses de l'Université de Montréal, 2002).

Ugo Dionne est professeur au Département des littératures de langue française de l'Université de Montréal. Il est l'auteur de La Voie aux chapitres. Poétique de la disposition romanesque (Éditions du Seuil, 2008). 
Katerine Gosselin est professeure adjointe à l'Université du Québec à Rimouski. Elle a soutenu à l'Université McGill, en 2orI, une thèse de doctorat intitulée "Claude Simon et Marcel Proust: lecture d'une recherche du temps perdu simonienne».

Aude Leblond enseigne les lettres au Lycée Louise-Michel de Bobigny (France). Elle a soutenu à l'Université Paris 3 Sorbonne nouvelle, en 20IO, une thèse intitulée "Vestiges du livre-monde: poétique du roman-fleuve, de Jean-Christophe à Maumort».

Olivier Maillart enseigne les lettres au Lycée Louis-Bascan de Rambouillet (France) et est enseignant vacataire à l'Université Paris Ouest Nanterre La Défense. Il est l'auteur d'une thèse de doctorat intitulée "Les fables du fascisme. Fictions et représentations du fascisme dans la littérature et le cinéma italiens (I959-1989) ", soutenue en 2008.

Élisabeth Nardout-Lafarge est professeure au Département des littératures de langue française de l'Université de Montréal. Elle a cosigné, avec Michel Biron et François Dumont, une Histoire de la littérature québécoise (Boréal, 2007) et est l'auteure de Réjean Ducharme. Une poétique du débris (Fides, 200I).

Thomas Pavel est Gordon J. Laing Distinguished Service Professor à l'Université de Chicago, auteur notamment de Comment écouter la littérature (Fayard, 2006), La Pensée du roman (Gallimard, 2003), L'Art de l'éloignement. Essai sur l'imagination classique (Gallimard, 1996) et Univers de la fiction (Éditions du Seuil, 1988).

Christophe Pradeau est maître de conférences à l'Université ParisSorbonne (Paris IV). Il a coédité, avec Antoine Compagnon, Réflexions sur la littérature d'Albert Thibaudet (Gallimard, coll. "Quarto», 2007) et codirigé avec Marielle Macé, Vies possibles, vies romanesques (revue Itinéraires, 20I0).

Lakis Proguidis est directeur de la revue L'Atelier du roman (Paris). Il est l'auteur de De l'autre côté du brouillard. Essai sur le roman français contemporain (Nota bene, 200I) et de La Conquête du roman. De Boccace à Papadiamantis (Les Belles Lettres, 1997). 


\section{TABLE DES MATIÈRES}

Présentation

Aux commencements de la mémoire

La mémoire singulière du roman

Isabelle Daunais

Un enfant tardif de Mnémosyne

Lakis Proguidis

La mémoire est une faculté qui oublie: la mise en prose du roman de Cligès à la fin du Moyen Âge

Isabelle Arseneau

$$
\text { La mémoire exemplaire }
$$

Désir d'excellence, souci de vérité

Thomas Pavel

L'Astrée et les intermittences de la mémoire

Julia Chamard-Bergeron

In memoriam de Homo poeticus

La lutte du roman pour sauver la mémoire poétique

Simona Carretta 
Prendre en charge le souvenir

"Ce qu'il y a de plus ancien, de plus qu'oublié, d'inconnu

à nous-mêmes": la mémoire du Grand Meaulnes

Mathieu Bélisle

Le lecteur comme survivant

Christophe Pradeau

Réflexions sur la mémoire romanesque en partant du Neveu de Rameau

Olivier Maillart

\section{IV}

Les œuvres remémorées

Mémoire du roman: dialogue de quelques livres fantômes

Aude Leblond

Le roman au risque de l'amnésie.

Stratégies mémorielles du récit différé (Leblanc, Sue, Mouhy)

Ugo Dionne

Les écrivains contemporains lecteurs de Claude Simon:

sur la mémoire contemporaine du roman

Katerine Gosselin

La mémoire de Ferron dans La Constellation du lynx

de Louis Hamelin

Elisabeth Nardout-Lafarge

Liste des collaborateurs

I9I 



\section{La mémoire du roman}

Alors que la poésie, le théâtre, la musique ou la peinture se transmettent au premier chef par la continuité de leurs formes, le roman n'a aucune continuité formelle, sinon celle d'être une œuvre en prose d'une certaine longueur, mettant en scène des personnages fictifs.

Par quels repères et quels relais, dès lors, le roman construit-il sa propre histoire? Ce recueil pose la question de la mémoire non pas diffuse mais précise que l'on garde des romans et des mécanismes qui la sous-tendent: quelles scènes, quelles images, quels personnages, quels « résumés » les lecteurs, mais aussi les romanciers eux-mêmes dans leurs propres œuvres, conservent-ils ou sont-ils amenés à conserver des romans qu' ils ont lus?

Par des exemples qui vont du Moyen-Âge à l'époque contemporaine, c'est à ces questions que répondent les auteurs réunis autour de l'équipe du TSAR (Travaux de recherche sur les arts du roman), qui envisage le roman non pas comme un genre littéraire parmi d'autres mais comme une forme singulière de pensée et d'imagination.

Isabelle Daunais est professeure au Département de langue et littérature françaises depuis 2004. Ses travaux et ses recherches portent sur la littérature française $d u x I x^{e}$ siècle et sur le roman moderne, abordé comme forme de pensée et d'exploration du monde.

Avec les textes de

Isabelle Arseneau

Mathieu Bélisle

Simona Carretta

Julia Chamard-Bergeron

Isabelle Daunais

Ugo Dionne

Katerine Gosselin
Aude Leblond

Olivier Maillart

Élisabeth Nardout-Lafarge

Thomas Pavel

Christophe Pradeau

Lakis Proguidis 